\title{
Normas Primárias e Secundárias do Setor de Telecomunicações - 2013
}

\section{Statutes and Regulations of the Telecommunication Sector}

\author{
Márcio lorio Aranha \\ João Lima \\ Renata Tonicelli de Mello Quelho
}




\section{Sumário}

Lista de Abreviaturas e Siglas ................................................ 239

Normas e Atos de 2013 ............................................................ 267

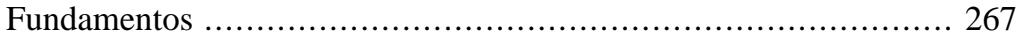

Aspectos Históricos ............................................. 267

Direito à Privacidade ......................................... 267

Infraestrutura e Recursos do Setor de Telecomunicações ............... 267

Infraestrutura de Telecomunicações ................................... 267

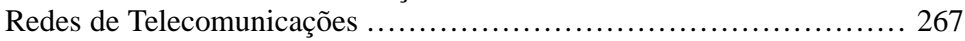

Numeração dos Serviços .......................................... 268

Equipamentos de Telecomunicações .................................. 268

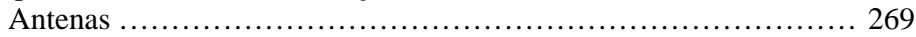

Estações de Telecomunicações ..................................... 269

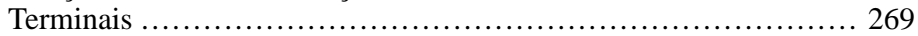

Certificação / Homologação ............................................. 271

Espectro de Radiofrequência ..................................... 271

Atribuição, Destinação e Distribuição de Radiofrequência ........... 271

Condições de Uso de Radiofrequência e Canalização (Distribuição

de Canais) ..................................................... 272

Órbita e Satélite ........................................................ 272

Administração do Setor de Telecomunicações ............................ 272

Fiscalização das Telecomunicações ................................... 272

Tributação no Setor de Telecomunicações .............................. 274

Prestação de Serviços ...................................................... 274

Licitação ......................................................... 274

Espécies de Outorga ........................................ 274

Concessão (regras aplicáveis) ................................... 274

Permissão (regras aplicáveis) ..................................... 275

Autorização (regras aplicáveis) ............................... 275

Preço Público e Preço Privado ...................................... 276

Planos de Serviços ....................................................... 277

Políticas de Telecomunicações .......................................... 278

Política Tarifária .................................................. 278

Política Industrial ............................................... 279

Concorrência no Setor de Telecomunicações ........................... 279

Universalização e Massificação ......................................... 280

Acesso às Telecomunicações ....................................... 280

Portador de Deficiência ..................................... 280

Educação e Pesquisa .............................................. 280

Financiamento da Universalização ................................ 281

Metas de Universalização ........................................ 281

Pesquisa \& Desenvolvimento ...................................... 281

Qualidade do Serviço ............................................... 282

Controle Social, Hierárquico e Interorgânico ......................... 283 
Sigilo em Telecomunicações .................................... 283

Classificações de Serviços no Setor de Telecomunicações ........... 283

Quanto ao Interesse .......................................... 283

Serviço de Interesse Restrito ............................... 283

Quanto ao Gênero ............................................. 284

Serviço Limitado ............................................ 284

Serviço Limitado Privado ................................. 284

Serviço Limitado Especializado .......................... 284

Serviço Especial .......................................... 285

Serviço de Valor Adicionado ................................. 285

Serviço de Radiodifusão ....................................... 285

Serviços no Setor de Telecomunicações ............................ 286

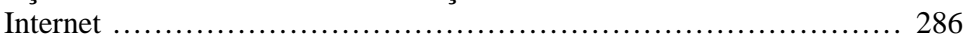

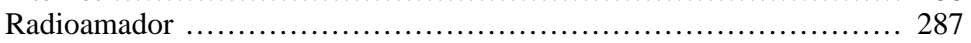

Radiodifusão .................................................. 288

Radiodifusão Comunitária ...................................... 289

Serviço Auxiliar de Radiodifusão e Correlatos (SARC) ............. 289

Televisão Aberta ................................................... 290

TV Digital ........................................... 290

Serviço Avançado de Mensagens (SAM) .............................. 290

Serviço Especial de Radiodeterminação por Satélite (SERDS) ......... 291

Serviço Especial de Boletim Metereológico ........................ 291

Serviço Especial de Frequência Padrão ............................... 291

Serviço Especial de Radioautocine ................................. 291

Serviço Especial de Radiochamada (SER) - ou Serviço Móvel Especial de Radiochamada ................................................ 292

Serviço Especial de Radiorrecado ................................... 292

Serviço Especial de Rádio Acesso .................................... 292

Serviço Especial de Sinais Horários .................................. 292

Serviço Especial de Supervisão e Controle .......................... 293

Serviço Limitado Especializado (SLE) ............................. 293

Serviço de Circuito Especializado ............................... 293

Serviço Limitado Móvel Privado ..................................... 293

Serviço Limitado Privado de Radiochamada (SLPR) .................. 293

Serviço Limitado de Estações com Operação Itinerante ................. 294

Serviço Limitado de Radioestrada .................................. 294

Serviço Móvel Especializado ou Trunking ou Trunk ou Sistema

Troncalizado ................................................. 294

Serviço Móvel Global por Satélite (SMGS) ........................... 294

Serviço Móvel Marítimo ........................................... 295

Serviço Móvel Pessoal (SMP) ....................................... 295

Serviço Rádio do Cidadão ........................................... 297

Serviço Telefônico Fixo Comutado (STFC) ......................... 297

Serviço de Acesso Condicionado (SeAC) ............................ 300

Serviço de Comunicação Multimída (SCM) ........................ 301

Serviço de Radiotáxi ........................................... 302

Serviço de Radiotáxi Especializado ............................ 302 
Serviço de Rede ...................................................... 302

Serviço de Rede Especializado ................................... 302

Serviço de Rede de Transporte de Telecomunicações (SRTT) ........... 302

Serviço de Telecomunicações Aeronáuticas .............................. 303

Serviço Móvel Aeronáutico .................................... 303

Serviço de Radiocomunicação Aeronáutico Público Restrito

(SRA) ...................................................... 303

Serviço de Telestrada ou Serviço Telefônico Público Móvel

Rodoviário ................................................................ 303

Serviços Científicos ............................................... 304

Ramos Jurídicos Afins ......................................................... 304

Direito do Consumidor ................................................. 304

Direito Aeroespacial .................................................. 305

Aplicações de Telecomunicações ........................................ 306

Aplicações Educacionais ......................................... 306

Aplicações de Segurança .......................................... 306

Internet ...................................................... 306

Acesso a Serviços de Interesse Público e Uso de Radiofrequência por tais

Serviços ......................................................... 307

Defesa Civil ......................................................... 307

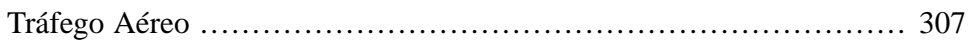

Radiolocalização .................................................... 307

Banda Larga ........................................................... 308

Atores no Setor de Telecomunicações ................................... 309

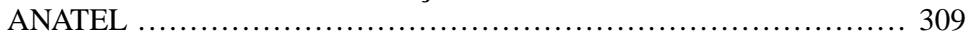

Poder Legislativo ................................................ 310

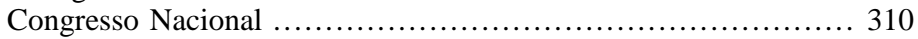

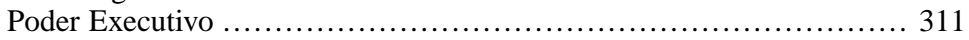

Ministério das Comunicações ................................... 311

Prestadora / Operadora ............................................ 312

Usuário / Consumidor .............................................. 314

Normas Referenciadas .............................................. 315

Lei Ordinária ..................................................... 315

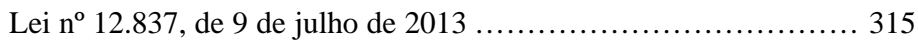

Lei $\mathrm{n}^{\circ} 12.841$, de 9 de julho de 2013 ........................... 316

Lei $n^{\circ} 12.865$, de 9 de outubro de 2013 .......................... 316

Decreto ...................................................... 317

Decreto $\mathrm{n}^{\circ} 7.903$, de 4 de fevereiro de 2013 ...................... 317

Decreto $\mathrm{n}^{\circ} 7.913$, de 7 de fevereiro de 2013 ...................... 317

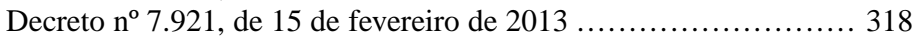

Decreto $\mathrm{n}^{\mathrm{o}}$ 7.932, de 19 de fevereiro de 2013 ..................... 319

Decreto $n^{0}$ 7.962, de 15 de março de 2013 ........................... 319

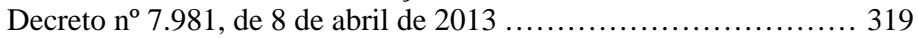

Decreto $\mathrm{n}^{\circ} 8.061$, de 29 de julho de 2013 ....................... 320

Decreto $\mathrm{n}^{\circ} 8.135$, de 4 de novembro de 2013 ...................... 321

Decreto $\mathrm{n}^{\circ} 8.139$, de 7 de novembro de 2013 ........................ 322 
Decreto $\mathrm{n}^{\mathrm{o}} 8.174$, de 26 de dezembro de $2013 \ldots \ldots \ldots \ldots \ldots \ldots \ldots \ldots . \ldots . \ldots . \ldots 322$

Portaria Ministerial ............................................ 322

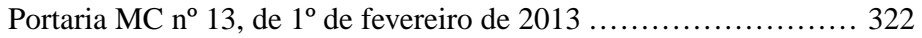

Portaria MC no 14, de 6 de fevereiro de $2013 \ldots \ldots \ldots \ldots \ldots \ldots \ldots . . . \ldots . \ldots 323$

Portaria MC n $\mathrm{n}^{\mathrm{0}}$ 55, de 12 de março de 2013 ....................... 323

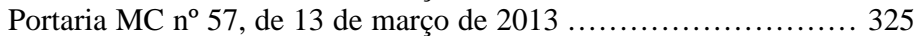

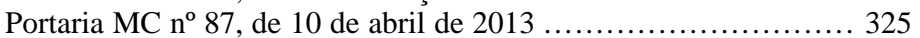

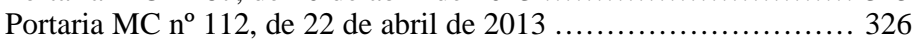

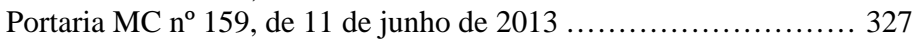

Portaria MC no 197 , de $1^{\circ}$ julho de 2013 ....................... 329

Portaria MC n $\mathrm{n}^{\mathrm{o}} 231$, de 7 de agosto de 2013 ..................... 329

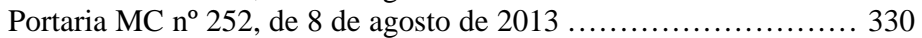

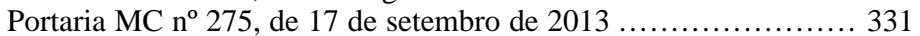

Portaria MC n $\mathrm{n}^{\mathrm{o}} 282$, de 25 de setembro de $2013 \ldots \ldots \ldots \ldots \ldots \ldots . \ldots . \ldots . \ldots 333$

Portaria MC n ${ }^{\circ} 299$, de 7 de outubro de $2013 \ldots \ldots \ldots \ldots \ldots \ldots \ldots \ldots . . . \ldots . \ldots 333$

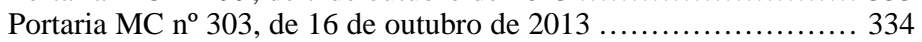

Portaria MC no 305 , de 24 de outubro de 2013 ................... 335

Resolução ..................................................... 335

Resolução da ANATEL n ${ }^{\circ}$ 606, de 4 de fevereiro de 2013 .......... 335

Resolução da ANATEL nº 607, de 13 de março de 2013 ............ 336

Resolução da ANATEL n ${ }^{\circ}$ 608, de 5 de abril de 2013 ............... 337

Resolução da ANATEL n ${ }^{\circ}$ 609, de 18 de abril de 2013 .............. 338

Resolução da ANATEL no 610, de 18 de abril de 2013 .............. 339

Resolução da ANATEL no 611, de 25 de abril de 2013 .............. 340

Resolução da ANATEL no 612, de 29 de abril de 2013 .............. 340

Resolução da ANATEL n ${ }^{\circ}$ 613, de 9 de maio de 2013 ............... 341

Resolução da ANATEL n ${ }^{\circ}$ 614, de 28 de maio de 2013 ............. 342

Resolução da ANATEL n ${ }^{\circ} 615$, de 7 de junho de 2013 .............. 343

Resolução da ANATEL n ${ }^{\circ}$ 616, de 18 de junho de 2013 ............ 344

Resolução da ANATEL nº 617, de 19 de junho de 2013 ............ 345

Resolução da ANATEL n ${ }^{\circ} 618$, de 24 de julho de 2013 ............. 347

Resolução da ANATEL n ${ }^{\circ} 619$, de 8 de agosto de 2013 ............ 348

Resolução da ANATEL n ${ }^{\circ}$ 620, de 9 de agosto de 2013 ............. 349

Resolução da ANATEL n ${ }^{\circ}$ 621, de 14 de agosto de 2013 ........... 350

Resolução da ANATEL n ${ }^{\circ}$ 622, de 23 de agosto de 2013 ........... 350

Resolução da ANATEL n ${ }^{\circ}$ 623, de 18 de outubro de 2013 ........... 351

Resolução da ANATEL n ${ }^{\circ}$ 624, de 30 de outubro de 2013 ........... 353

Resolução da ANATEL no 625, de 11 de novembro de 2013 ........ 354

Resolução da ANATEL n ${ }^{\circ}$ 626, de 20 de novembro de 2013 ........ 355

Resolução da ANATEL no 627, de 28 de novembro de 2013 ........ 356

Resolução da ANATEL n ${ }^{\circ}$ 628, de 6 de dezembro de 2013 ......... 356

Resolução da ANATEL n ${ }^{\circ}$ 629, de 16 de dezembro de 2013 ........ 358

Resolução emitida por outros órgãos ............................... 359

Resolução no 4 do Senado Federal, de 2013 ....................... 359

Atos Referenciados ................................................. 360

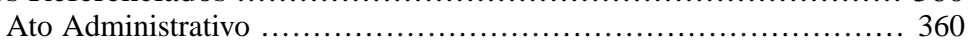

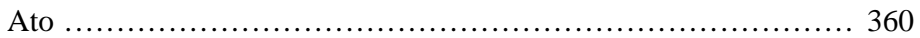


Ato do Conselho Diretor da ANATEL n ${ }^{\circ} 1.724$, de 11 de março de 2013 360 Ato do Conselho Diretor da ANATEL n ${ }^{\circ} 3.833$, de 20 de junho

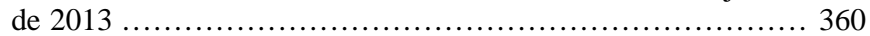

Enunciado ................................................. 361

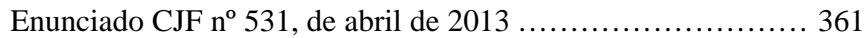

Portaria ................................................. 362

Portaria ANATEL n ${ }^{\circ} 238$, de 9 de abril de $2013 \ldots \ldots \ldots \ldots \ldots . . . . . . .362$

Portaria ANATEL n ${ }^{\circ} 448$, de 4 de junho de 2013 ............. 362

Portaria ANATEL n ${ }^{\circ} 559$, de 3 de julho de 2013 ............. 363

Portaria ANATEL/SOR n ${ }^{\circ}$ 639, de 25 de julho de 2013 ......... 364

Relatório da Ouvidoria da ANATEL ............................. 364

Relatório da Ouvidoria da ANATEL 2013 ..................... 364

Súmula ................................................ 365

Súmula da ANATEL $\mathrm{n}^{\circ} 14$, de 28 de junho de 2013 ............ 365

Índice Alfabético e Remissivo .......................................... 367 


\section{Lista de Abreviaturas e Siglas}

$1 \mathrm{G}$

$2.5 \mathrm{G}$

$2 \mathrm{G}$

$3 \mathrm{G}$

3G HS

3GPP

$4 \mathrm{G}$

$8 \mathrm{~K}$

AACD

ABA

ABAP

ABAR

ABCiber

ABEMTIC

ABEPEC

ABEPEC

ABEPREST

ABERT

ABETS

ABIFUMO

ABINEE

ABJC

ABNT

ABPI-TV

ABPITV

ABPTA

ABR Telecom

ABRA

ABRACOM

ABRADECEL

ABRAFIC
Primeira Geração de Tecnologia de Telefonia Móvel (analógico).

Geração 2.5 de Tecnologia de Telefonia Móvel (GPRS).

Segunda Geração de Tecnologia de Telefonia Móvel (digital para dados, 9.6-14.4Kbps).

Terceira Geração de Tecnologia de Telefonia Móvel (digital para voz e dados, mínimo de 144Kbps).

3G High Speed (Rede celular de Terceira geração de Alto Desempenho).

3rd Generation Partnership Project.

Quarta Geração de Tecnologia de Telefonia Móvel (requisitos da UIT IMT-Advanced).

Tecnologia de Ultra High Definition Television.

Associação de Assistência à Criança Deficiente.

Associação Brasileira de Anunciantes.

Associação Brasileira de Agências de Propaganda.

Associação Brasileira de Agências de Regulação.

Associação Brasileira de Pesquisadores em Cibercultura.

Associação Brasileira de Entidades Municipais de Tecnologia da Informação e Comunicação.

Associação Brasileira das Emissoras Públicas Educativas e Culturais. Associação Brasileira de Ensino e Pesquisa em Comunicação (inativa). Associação Brasileira de Empresas de Soluções de Telecomunicações e Informática.

Associação Brasileira de Emissoras de Rádio e Televisão.

Associação Brasileira das Empresas de Telecomunicações por Satélite. Associação Brasileira da Indústria do Fumo.

Associação Brasileira da Indústria Elétrica e Eletrônica.

Associação Brasileira de Jornalismo Científico.

Associação Brasileira de Normas Técnicas.

Associação Brasileira de Produtores Independentes de Televisão.

Associação Brasileira das Empresas Produtoras Independentes de Televisão.

Associação Brasileira dos Programadores de TV por Assinatura.

Associação Brasileira de Recursos de Telecomunicações (Portabilidade Numérica).

Associação Brasileira de Radiodifusores.

Associação Brasileira de Antenas Comunitárias.

Associação Brasileira de Defesa dos Moradores e Usuários Intraquilos com Equipamentos de Telecomunicações Celular.

Associação Brasileira de Film Commissions (Brazilian Association of Film Commissions). 
ABRAFIX

ABRAMULTI

ABRAPPIT

ABRATEL

ABRATER

ABRINT

ABRISAN

ABTA

ABTU

Acel

ACERP

AD

ADGI

ADI

ADPF

ADSL

AEB

AET

AFTN

AGVSEL

Ah

AI

AI

$\mathrm{AI} / \mathrm{E}$

AICE

AIE

AIRR

ALAIC

ALCA

ALCAR

AM

AM-DSB-SC

AME

AMMB
Associação Brasileira de Concessionárias de Serviço Telefônico Fixo Comutado.

Associação Brasileira dos Operadores de Telecomunicações e Provedores de Internet.

Associação Brasileira de Pequenos Provedores de Internet e Telecomunicações.

Associação Brasileira de Radiodifusão, Tecnologia e Telecomunicações.

Associação Brasileira de Telecomunicações Rurais.

Associação Brasileira de Provedores de Internet e Telecomunicações.

Associação Brasileira de Registro de Obras Audiovisuais.

Associação Brasileira de TV por Assinatura.

Associação Brasileira de TVs Universitárias.

Associação Nacional das Operadoras Celulares.

Associação de Comunicação Educativa Roquette Pinto.

Adicional por Chamada (Serviço Móvel Pessoal).

Gerência Geral de Gestão da Informação (ANATEL).

Ação Direta de Inconstitucionalidade (Jurisdição).

Gerência Geral de Planejamento, Orçamento e Finanças (ANATEL).

Asymmetric Digital Subscriber Line.

Agência Espacial Brasileira.

Associação dos Engenheiros de Telecomunicações.

Aeronautical Fixed Telecommunications Network (Rede Internacional Fixa de Telecomunicações Aeronáuticas).

Agravo em Suspensão de Execução de Liminar.

Ampère-hora.

Acesso Instalado.

Agravo de Instrumento (Jurisdição).

Acesso Instalado da Estação de Comutação.

Acesso Individual Classe Especial.

Acesso Instalado Equivalente.

Agravo de Instrumento em Recurso de Revista (Tribunal Superior do Trabalho).

Asociación Latinoamericana de Investigadores de la Comunicación. Área de Livre Comércio das Américas.

Associação Brasileira dos Pesquisadores de História da Mídia.

Amplitude Modulation (Modulação em Amplitude).

Amplitude Modulation, Double-Sided Band, Suppressed Carrier (Modulação em Amplitude, em Faixa Lateral Dupla, com Portadora Suprimida).

Valor de Ativo Moderno Equivalente (Separação e Alocação de Contas).

Associação de Marketing Móvel do Brasil. 
AMN

AMNT

AMPS

AN

AN

ANACOM

ANATEL

ANCINE

ANEEL

ANER

ANER

ANJ

ANOp

ANP

ANSI

ANTT

APEX-Brasil

APS

Aptel

AR

AR

AR

AR

ARCTEL

ARIB

ARICEA

ARM

ART

ARTAC

ASTM

AT

AT

ATA

ATB

ATB

ATC

ATS
Artificial Mains Network (Rede Fictícia em V).

Assembléia Mundial de Normalização das Telecomunicações.

Advanced Mobile Phone System (Rede celular 1G).

Área de Numeração.

Área de Numeração (Serviço Telefônico Fixo Comutado).

Autoridade Nacional de Comunicações (de Portugal).

Agência Nacional de Telecomunicações.

Agência Nacional do Cinema.

Agência Nacional de Energia Elétrica.

Associação Nacional das Empresas de Revistas.

Associação Nacional dos Servidores Efetivos das Agências Reguladoras.

Associação Nacional de Jornais.

Auditoria de Natureza Operacional (Tribunal de Contas da União).

Agência Nacional do Petróleo.

American National Standards Institute.

Agência Nacional de Transportes Terrestres.

Agência de Promoção de Exportações do Brasil.

Área de Prestação do Serviço ( Serviço de Acesso Condicionado).

Associação de Empresas Proprietárias de Infra-Estrutura e de Sistemas Privados de Telecomunicações.

Área de Registro.

Área de Registro (Serviço Móvel Especializado).

Área de Registro (Serviço Móvel Pessoal).

Área de Registro (Serviço Telefônico Fixo Comutado).

Associação de Reguladores das Comunicações e Telecomunicações da Comunidade de Países de Língua Portuguesa.

Association of Radio Industries and Businesses (Japão).

Association of Regulators of Information and Communications for Eastern and Southern Africa.

Acordo de Reconhecimento Mútuo (Certificação e Homologação).

Anotação de Responsabilidade Técnica.

Association des régulateurs de telecommunications de l'Afrique central - Telecommunication Regulators' Association of Central Africa.

American Society for Testing and Materials.

Área de Tarifação (Serviço Móvel Especializado).

Área de Tarifação (Serviço Móvel Pessoal).

Analog Telephone Adaptor.

Área de Tarifa Básica.

Área de Tarifação Básica (Serviço Telefônico Fixo Comutado).

Ativos de Tecnologia Corrente (Separação e Alocação de Contas).

Ativos de Tecnologia Substituída (Separação e Alocação de Contas). 
ATSC

AVADAN

BACEN

BAL

BB

$\mathrm{BBC}$

$\mathrm{BCB}$

BDO

BDR

BDR

BDT

BDTA

BGAN

BIA

BID

BIRD

BIS

Bn

BNDES

BPL

BR

BRASSCOM

BS

BSR

BT

BWA

C-INI

$\mathrm{C} 0,25$

C10

$\mathrm{C} 120$

CA

CAACI

CADE
Advanced Television Systems Committee (Padrão de TV Digital Estados Unidos da América).

Avaliação de Danos - Formulário (Sistema Nacional de Defesa Civil).

Banco Central do Brasil.

Balanceamento Longitudinal.

Banda-Base.

British Broadcasting Corporation (Reino Unido).

Banco Central do Brasil.

Base de Dados Operacional (Portabilidade).

Base de Dados de Referência (Portabilidade).

Base de Dados Nacional de Referência da Portabilidade.

Bureau de Développement des Télécommunications (Escritório de Desenvolvimento das Telecomunicações da UIT).

Banco de Dados Técnicos e Administrativos (Radiofreqüência).

Broadband Global Area Network (INMARSAT).

Bens e Instalações em Andamento (Separação e Alocação de Contas).

Banco Interamericano de Desenvolvimento.

Banco Internacional para Reconstrução e Desenvolvimento (Banco Mundial).

Bens e Instalações em Serviço (Separação e Alocação de Contas).

Largura da Faixa Necessária (Certificação).

Banco Nacional de Desenvolvimento Econômico e Social.

Broadband over Power Lines (Banda larga por meio de redes de energia elétrica).

Bureau des Radiocommunications (Escritório de Radiocomunicações da UIT).

Associação Brasileira de Empresas de Tecnologia da Informação e Comunicação.

Base Station (Estação Rádio Base).

Bloqueador de Sinais de Radiocomunicações.

Linha de distribuição de Baixa Tensão.

Broadband Wireless Access (4G).

Comitê sobre Infra-estrutura Nacional de Informações.

Capacidade nominal para regime de alta intensidade de descarga (C0,25).

Capacidade nominal para regime de média intensidade de descarga (C10).

Capacidade nominal para regime de baixa intensidade de descarga (C120).

Corrente Alternada.

Conferência de Autoridades Audiovisuais e Cinematográficas IberoAmericana.

Conselho Administrativo de Defesa Econômica. 
CADIN

CAMR

CAPDA

CAPT

CARR

CATIS

$\mathrm{CBC}$

CBC 1

CBC 2

CBC 3

CBC 4

CBC 5

CBC 6

CBC 7

CBC 8

CBC 9

CBC 1

CBC 10

$\mathrm{CBC} 11$

CBC 12

CBC 13

CBC 2

CBC 3

$\mathrm{CBC} 4$

CBC Temp.

CBDT

$\mathrm{CBF}$

CBLC
Cadastro Informativo de Créditos não Quitados do Setor Público Federal.

Conferência Administrativa Mundial de Radiocomunicações.

Comitê das Atividades de Pesquisa e Desenvolvimento na Amazônia.

Controle Automático da Potência Transmitida.

Conferência Administrativa Regional de Radiocomunicações.

Centro de Acesso a Tecnologias para a Inclusão Social.

Comissão Brasileira de Comunicações.

Comissão Brasileira de Comunicações $n^{\circ} 1$ - Redes de Dados e Características de Sistemas Telemáticos (extinta).

Comissão Brasileira de Comunicações $\mathrm{n}^{\circ} 2$ - Transmissão de Áudio e Vídeo e Sistemas Multimídia (extinta).

Comissão Brasileira de Comunicações $n^{\circ} 3$ - Tarifas e Princípios Contábeis (extinta).

Comissão Brasileira de Comunicações no 4 - Definição de Serviços, Planos Estruturais e Gerência de Redes (extinta).

Comissão Brasileira de Comunicações n ${ }^{\circ} 5$ - Sinalização, Comutação, Protocolos, Linguagens e Aspectos Gerais de Redes (extinta).

Comissão Brasileira de Comunicações n ${ }^{\circ} 6$ - Planta Externa e Compatibilidade Eletromagnética (extinta).

Comissão Brasileira de Comunicações $n^{\circ} 7$ - Desenvolvimento das Telecomunicações (extinta).

Comissão Brasileira de Comunicações $n^{\circ} 8$ - Serviços Móveis, de Radiodeterminação e de Radioamador (extinta).

Comissão Brasileira de Comunicações $n^{\circ} 9$ - Serviços Fixos e Científicos (extinta).

Comissão Brasileira de Comunicações n ${ }^{\circ} 1$ - Governança e Regimes Internacionais.

Comissão Brasileira de Comunicações $\mathrm{n}^{\mathrm{o}} 10$ - Administração do Espectro Radioelétrico e Propagação (extinta).

Comissão Brasileira de Comunicações $n^{\circ} 11$ - Radiodifusão (extinta).

Comissão Brasileira de Comunicações $n^{\circ} 12$ - Negociações Internacionais em Telecomunicações (extinta).

Comissão Brasileira de Comunicações $n^{\circ} 13$ - Governança da Internet (extinta).

Comissão Brasileira de Comunicações n 2 - Radiocomunicações.

Comissão Brasileira de Comunicações $\mathrm{n}^{\circ} 3$ - Normalização de Telecomunicações.

Comissão Brasileira de Comunicações $n^{\circ} 4$ - Desenvolvimento das Telecomunicações.

Comissão Brasileira de Telecomunicações Temporária.

Coleção Brasileira de Direito Regulatório das Telecomunicações.

Confederação Brasileira de Futebol.

Comissão Brasileira de Liquidação e Custódia. 


\begin{tabular}{|c|c|}
\hline CBR & Comissão Brasileira de Radiocomunicações. \\
\hline CBT & Código Brasileiro de Telecomunicações (Lei nº 4.117/62). \\
\hline CBTTs & Comissões Brasileiras de Telecomunicações. \\
\hline $\mathrm{CC}$ & Corrente Contínua. \\
\hline $\mathrm{CCC}$ & Central de Comutação e Controle (Serviço Móvel Pessoal). \\
\hline $\mathrm{CCC}$ & $\begin{array}{l}\text { Central de Comutação e Controle (Sistemas de Acesso sem Fio do } \\
\text { STFC). }\end{array}$ \\
\hline $\mathrm{CCC}$ & Central de Controle e Comutação do SMC (Internacional). \\
\hline CCIR & Comitê Consultivo Internacional das Radiocomunicações. \\
\hline CCITT & Comitê Consultivo Internacional de Telegrafia e Telefonia. \\
\hline CCJC & Comissão de Constituição e Justiça e de Cidadania. \\
\hline $\mathrm{CCOM}$ & $\begin{array}{l}\text { Centro de Políticas, Direito, Economia e Tecnologias das } \\
\text { Comunicações da UnB. }\end{array}$ \\
\hline CCOMGEX & Centro de Comunicações e Guerra Eletrônica do Exército. \\
\hline CCP.I & $\begin{array}{l}\text { Comitê Consultivo Permanente } \mathrm{n}^{\circ} 1 \text { da Comissão Interamericana de } \\
\text { Telecomunicações. }\end{array}$ \\
\hline CCP.II & $\begin{array}{l}\text { Comitê Consultivo Permanente } \mathrm{n}^{\circ} 2 \text { da Comissão Interamericana de } \\
\text { Telecomunicações. }\end{array}$ \\
\hline CCP.III & $\begin{array}{l}\text { Comitê Consultivo Permanente } \mathrm{n}^{\circ} 3 \text { da Comissão Interamericana de } \\
\text { Telecomunicações. }\end{array}$ \\
\hline CCPs-CITEL & Comitês Consultivos Permanentes da CITEL. \\
\hline $\mathrm{CCT}$ & Cargo Comissionado Técnico (Agências Reguladoras). \\
\hline $\mathrm{CCT}$ & $\begin{array}{l}\text { Comissão de Ciência, Tecnologia, Inovação, Comunicação e } \\
\text { Informática (Senado Federal). }\end{array}$ \\
\hline $\mathrm{CCT}$ & Conselho Nacional de Ciência e Tecnologia. \\
\hline CCTCI & $\begin{array}{l}\text { Comissão de Ciência e Tecnologia, Comunicação e Informática } \\
\text { (Câmara dos Deputados). }\end{array}$ \\
\hline ccTLD & $\begin{array}{l}\text { country code Top Level Domain (Domínio de Primeiro Nível) } \\
\text { (INTERNET). }\end{array}$ \\
\hline CDA & Certidão de Dívida Ativa. \\
\hline $\mathrm{CDC}$ & Código de Defesa do Consumidor. \\
\hline CDEIC & $\begin{array}{l}\text { Comissão de Desenvolvimento Econômico, Indústria e Comércio } \\
\text { (Câmara dos Deputados). }\end{array}$ \\
\hline CDI & Comutação Digital Integrada. \\
\hline CDMA & $\begin{array}{l}\text { Code Division Multiple Access (Múltiplo Acesso por Divisão em } \\
\text { Código). }\end{array}$ \\
\hline CDMA 1xEV-DO & CDMA Evolution Data-Optimized (Rede celular 3G). \\
\hline CDMA 1xEV-DV & CDMA Evolution, Data and Voice (Rede celular 3G). \\
\hline CDUST & Comitê de Defesa dos Usuários de Serviços de Telecomunicações. \\
\hline CEDEC & $\begin{array}{l}\text { Coordenadoria Estadual de Defesa Civil (Sistema Nacional de Defesa } \\
\text { Civil). }\end{array}$ \\
\hline CEFET & Centro Federal de Educação Tecnológica. \\
\hline CEITEC & Centro Nacional de Tecnologia Eletrônica Avançada S.A. \\
\hline
\end{tabular}




\section{CENAD}

CENELEC

CEPED

CERT.br

CETIC.br

CFM

CFTV

CG-CBC

CG-ProTIC

CGCOB

CGIbr

CGPD

CGPID

CGRBT

CIC

CIDE

CIP

CIPA

CISCOMIS

CITEL

CJF

CMDT

CMGLO

CMI

CMPC

CMR

CMSI

$\mathrm{CN}$

CNAL

$\mathrm{CNC}$

CNDI

CNI
Centro Nacional de Gerenciamento de Riscos e Desastres (Sistema Nacional de Defesa Civil).

European Commitee for Electrotechnical Standardization.

Centro Universitário de Ensino e Pesquisa sobre Desastres (Sistema Nacional de Defesa Civil).

Centro de Estudos, Resposta e Tratamento de Incidentes de Segurança no Brasil (Comitê Gestor da Internet no Brasil).

Centro de Estudos sobre as Tecnologias da Informação e da Comunicação (Comitê Gestor da Internet no Brasil).

Conselho Federal de Medicina.

Serviço Especial de Circuito Fechado de Televisão com Utilização de Radioenlace.

Grupo de Coordenação das Comissões Brasileiras de Comunicações.

Comitê Gestor do Programa de Apoio à Pesquisa, Desenvolvimento e Inovação em Tecnologias Digitais de Informação e Comunicação.

Coordenação-Geral de Cobrança e Recuperação de Créditos.

Comitê Gestor da Internet no Brasil.

Comitê Gestor de Políticas de Inclusão das Pessoas com Deficiência (Presidência da República).

CGPID.

Comitê Gestor de Articulação Institucional da Rede Brasil de Tecnologia.

Central de Intermediação de Comunicação Telefônica.

Contribuição de Intervenção no Domínio Econômico.

Câmara Interbancária de Pagamentos.

Comissão Interna de Prevenção de Acidentes.

Comissão de Desenvolvimento do Projeto e da Implantação do Sistema de Comunicações Militares por Satélite.

Comissão Interamericana de Telecomunicações.

Conselho da Justiça Federal.

Conferência Mundial de Desenvolvimento das Telecomunicações.

Gerência de Engenharia, Planejamento e Controle de Licitações e Outorgas.

Cúpula Mundial da Informação.

Custo Médio Ponderado de Capital.

Conferência Mundial de Radiocomunicações.

Cúpula Mundial sobre a Sociedade da Informação (World Summit on the Information Society - WSIS).

Código Nacional.

Cadastro Nacional de Áreas Locais.

Conselho Nacional de Comunicações.

Conselho Nacional de Desenvolvimento Industrial.

Confederação Nacional da Indústria. 


\begin{tabular}{|c|c|}
\hline $\mathrm{CNPq}$ & Conselho Nacional de Desenvolvimento Científico e Tecnológico. \\
\hline CNPq-MCT & Centro Nacional de Pesquisa do Ministério da Ciência e Tecnologia. \\
\hline $\mathrm{COE}$ & Coeficiente de Onda Estacionária. \\
\hline $\mathrm{COE}$ & Coeficiente de Reflexão. \\
\hline COER & Certificado de Operador de Estação de Radioamador. \\
\hline COFDM & Coded Orthogonal Frequency Division Multiplexing. \\
\hline COFINS & Contribuição para o Financiamento da Seguridade Social. \\
\hline COG & Cabo Óptico Geral. \\
\hline COGEF & $\begin{array}{l}\text { Comissão de Gerência do Espectro de Radiofreqüência de Interesse } \\
\text { do Ministério da Defesa. }\end{array}$ \\
\hline $\mathrm{COL}$ & Copa do Mundo FIFA 2014 - Comitê Organizador Brasileiro Ltda. \\
\hline COMDEC & $\begin{array}{l}\text { Coordenadoria Municipal de Defesa Civil (Sistema Nacional de Defesa } \\
\text { Civil). }\end{array}$ \\
\hline COMESA & Common Market for Eastern and Southern Africa. \\
\hline COMPÓS & Associação Nacional das Pós-Graduações em Comunicação. \\
\hline CONANDA & Conselho Nacional dos Direitos da Criança e do Adolescente. \\
\hline Conapsi & Conselho Nacional dos Provedores de Serviço de Internet. \\
\hline CONAR & Conselho Nacional de Auto-Regulamentação Publicitária. \\
\hline CONARQ & Conselho Nacional de Arquivos. \\
\hline CONCAR & Comissão Nacional de Cartografia. \\
\hline CONDEC & $\begin{array}{l}\text { Conselho Nacional de Defesa Civil (Sistema Nacional de Defesa } \\
\text { Civil). }\end{array}$ \\
\hline CONDECINE & $\begin{array}{l}\text { Contribuição para o Desenvolvimento da Indústria Cinematográfica } \\
\text { Nacional. }\end{array}$ \\
\hline CONFAZ & Conselho Nacional de Política Fazendária. \\
\hline CONFECOM & Conferência Nacional de Comunicação. \\
\hline CONTCOP & $\begin{array}{l}\text { Confederação Nacional dos Trabalhadores em Comunicações e } \\
\text { Publicidade (Representação profissional). }\end{array}$ \\
\hline CONTEL & Conselho Nacional de Telecomunicações (Extinto em 25/02/1967). \\
\hline $\mathrm{COP}$ & Cabo Óptico "Plenum". \\
\hline CoPol & Copolar (Antena). \\
\hline COR & Cabo Óptico "Riser". \\
\hline CORDE & $\begin{array}{l}\text { Coordenadoria Nacional para Integração da Pessoa Portadora de } \\
\text { Deficiência. }\end{array}$ \\
\hline CORDEC & $\begin{array}{l}\text { Coordenadoria Regional de Defesa Civil (Sistema Nacional de Defesa } \\
\text { Civil). }\end{array}$ \\
\hline $\mathrm{CP}$ & Código Penal. \\
\hline $\mathrm{CP}$ & Consulta Pública. \\
\hline CPADS & Comissão Permanente de Avaliação de Documentos Sigilosos. \\
\hline $\mathrm{CPC}$ & Código de Processo Civil. \\
\hline СPCT & Central Privada de Comutação Telefônica. \\
\hline СРCT & $\begin{array}{l}\text { Central Privativa de Comutação Telefônica (Serviço Telefônico Fixo } \\
\text { Comutado). }\end{array}$ \\
\hline
\end{tabular}




\begin{tabular}{|c|c|}
\hline CPGF & Cartão de Pagamento do Governo Federal. \\
\hline CPI & Comissão Parlamentar de Inquérito. \\
\hline CPLP & Comunidade de Países de Língua Portuguesa. \\
\hline CPP & Código de Processo Penal. \\
\hline $\mathrm{CPP}$ & Contribuição Patronal Previdenciária (Seguridade Social). \\
\hline $\mathrm{CPqD}$ & CPqD. \\
\hline $\mathrm{CPqD}$ & $\begin{array}{l}\text { Fundação CPqD Centro de Pesquisa e Desenvolvimento em } \\
\text { Telecomunicações. }\end{array}$ \\
\hline $\mathrm{Cr} 0,25$ & $\begin{array}{l}\text { Capacidade real em regime nominal para alta intensidade de descarga } \\
(\mathrm{Cr} 0,25) \text {. }\end{array}$ \\
\hline Cr10 & $\begin{array}{l}\text { Capacidade real em regime nominal para média intensidade de } \\
\text { descarga (Cr10). }\end{array}$ \\
\hline Cr120 & $\begin{array}{l}\text { Capacidade real em regime nominal para baixa intensidade de descarga } \\
\text { (Cr120). }\end{array}$ \\
\hline CRASA & Communications Regulators' Association of Southern Africa. \\
\hline CRE & Contrato de Receita Extraordinária (Concessionária de Rodovia). \\
\hline CREA & Conselho Regional de Engenharia e Arquitetura. \\
\hline CSLL & Contribuição Social sobre o Lucro Líquido. \\
\hline CSP & Código de Seleção de Prestadora. \\
\hline СТВC & Companhia de Telecomunicações do Brasil Central. \\
\hline CTs-SGT.1-MERCOSUL & $\begin{array}{l}\text { Comissões Temáticas do Subgrupo de Trabalho de Comunicações do } \\
\text { MERCOSUL. }\end{array}$ \\
\hline CVM & Comissão de Valores Mobiliários. \\
\hline CVR & Relações Custo-Volume (Separação e Alocação de Contas). \\
\hline D-AMPS & Digital Advanced Mobile Phone System. \\
\hline $\mathrm{DAC}$ & Departamento de Aviação Civil. \\
\hline DAS & Direção e Assessoramento Superiores. \\
\hline $\mathrm{dB}$ & Decibel. \\
\hline $\mathrm{dB}$ SPL & Decibel relativo a $20 \mu \mathrm{Pa}$. \\
\hline dB SPL(A) & Decibel relativo a $20 \mu \mathrm{Pa}$ medido com ponderação A (IEC 60651). \\
\hline dB V & Decibel Relativo a $1 \mathrm{~V}$. \\
\hline dBA & dBA. \\
\hline DBDG & Diretório Brasileiro de Dados Geoespaciais (DBDG). \\
\hline $\mathrm{dBk}$ & Potência, em dB, relativa a $1 \mathrm{~kW}$. \\
\hline $\mathrm{dBmp}$ & Decibel medido com ponderação psofométrica (Rec. O.41 da ITU-T). \\
\hline $\mathrm{dBPa}$ & Decibel Relativo a 1 Pascal. \\
\hline $\mathrm{dBPa}(\mathrm{A})$ & Decibel relativo a 1 Pa medido com ponderação A (IEC 60651). \\
\hline $\mathrm{dB} \mu$ & Decibel Relativo a $1 \mathrm{~mW}$. \\
\hline $\mathrm{dB} \mu$ & Intensidade de campo, em dB, relativa a $1 \mu \mathrm{V} / \mathrm{m}$. \\
\hline DCOR & Diretoria de Concessões e Operações Rodoviárias. \\
\hline DCS & Digital Cellular Network. \\
\hline DDG & Discagem Direta Gratuita. \\
\hline
\end{tabular}


DDI

DDR

DEA

DECEA

DECT

DEICT

DEINT

DENTEL

DEPEN

DEPV

DETRAF

DG

DIC

DISTV

DJ

DJe

DLC

DNER

DNS

DOP

DPDC

DRM

DS-CDMA

DSAC

DSB

DSC

DSL

DTH

DTMF

DVB

DVB-H

e-DJF1

e.i.r.p.

e.r.p.

e.r.p.
Discagem Direta Internacional.

Discagem Direta a Ramal.

Data Envelopment Analysis.

Departamento de Controle do Espaço Aéreo.

DECT.

Departamento de Indústria, Ciência e Tecnologia, da Secretaria de Telecomunicações (Ministério das Comunicações).

Departamento de Negociações Internacionais da Secretaria de Comércio Exterior do Ministério da Indústria, do Comércio e do Turismo.

Departamento Nacional de Telecomunicações (Extinto em 15/03/1990).

Departamento Penitenciário Nacional.

Diretoria de Eletrônica e Proteção ao Vôo (Min. Aeronáutica), substituída pelo DECEA.

Documento de Declaração de Tráfego e de Prestação de Serviços.

Distribuidor Geral (Serviço Telefônico Fixo Comutado).

Discagem Interurbana a Cobrar.

Serviço de Distribuição de Sinais de TV por Meios Físicos.

Diário da Justiça (Imprensa Nacional).

Diário da Justiça eletrônico.

Discagem Local a Cobrar.

Departamento Nacional de Estradas de Rodagem.

Domain Name System.

Documento Operacional de Prazos da Portabilidade.

Departamento de Proteção e Defesa do Consumidor.

Digital Radio Mondiale (padrão europeu de rádio digital).

Múltiplo Acesso por Divisão em Código com Sequiência Direta.

Documento de Separação e Alocação de Contas.

Double Side Band 'Modulation' (Modulação em Faixa Lateral Dupla).

Documento Sigiloso Controlado.

Digital Subscriber Line.

Direct-to-Home (Serviço de Distribuição de Sinais de Televisão e de Áudio por Assinatura Via Satélite).

Dual Tone Multi-Frequency.

Digital Video Broadcasting (Padrão de TV Digital - União Européia).

Digital Video Broadcasting Handheld.

Diário da Justiça Federal da Primeira Região eletrônico (TRF $1^{\text {a }}$ Região).

Potência Equivalente Isotropicamente Radiada.

Potência Efetiva Radiada (Campo Eletromagnético).

Potência Efetivamente Irradiada. 
E1

EACO

EARPTO

EB

EBC

EBITDA

EC

$\mathrm{Ec} / \mathrm{ec}$

ECA

ECAD

ECD

ECT

EDGE

EEII

EESPT

EHF

EILD

ELI

ELR

EM

Enom / enom

ENUM

EPMU

EPON

ER

ER

ERB

ERC

ERG

ERP

ERUE

ESC

ESV

ESV

ET

ETA

ETD

ETIR
E1.

East African Communications Organisation.

East Africa Regulatory, Postal and Telecommunications Organization.

Estação Base.

Empresa Brasil de Comunicação.

Earning Before Interest, Tax, Depreciation and Amortization.

Estação de Controle.

Campo Característico, respectivamente em $\mathrm{dB} \mu \mathrm{e} \mathrm{mV} / \mathrm{m}$.

Estatuto da Criança e do Adolescente.

Escritório Central de Arrecadação e Distribuição.

Equipamento de Comunicação de Dados.

Empresa Brasileira de Correios e Telégrafos.

Enhanced Data Rates for Global Evolution (Rede celular 2.5G).

Empresa Exploradora de Troncos Interestaduais e Internacionais.

Entidade Exploradora de Serviços Públicos de Telecomunicações (em desuso).

Extremely High Frequency.

Exploração Industrial de Linha Dedicada.

Estágio de Linha Integrado.

Estágio de Linha Remoto.

Estação Móvel.

Intensidade de campo nominal utilizável, respectivamente em $\mathrm{dB} \mu \mathrm{e}$ $\mathrm{mV} / \mathrm{m}$.

Telephony Numbering Mapping (Protocolo desenvolvido pela IETF).

Equal Proporcionate Mark Up (Alocação Proporcional e Equiitativa - Separação e Alocação de Contas).

Ethernet Passive Optical Network.

Estação Repetidora.

Estágio Remoto (Serviço Telefônico Fixo Comutado).

Estação Rádio Base.

Estação Radioelétrica Central.

European Regulators Group.

Potência Efetivamente Radiada.

Eficiência Relativa de Uso do Espectro (ERUE).

Equipamento a Ser Certificado.

Earth Station on Board Vessel.

Estação Terrena a Bordo de Embarcação.

Estação Terminal.

Estação Terminal de Acesso.

Equipamento Terminal de Dados.

Equipe de Tratamento e Resposta a Incidentes de Segurança da Informação (ANATEL). 
ETSI

$\mathrm{Eu} / \mathrm{eu}$

EUE

FA

FAC

FCC

FCPT

FCT

FCT

FDD

FDMA

FEBRAPEL

FENAJ

FGP

FGTS

FH-CDMA

FIFA

FINEP

FINSOCIAL

FISTEL

FITTEL

FM

FMCA

FNC

FNDCT

FNPJ

FNT

Fonacate

FORCINE

FS

FTTB

FTTC

FTTH

FTTN

FUNCAP

Fundomic

Funtec
European Telecommunications Standards Institute.

Intensidade de campo utilizável, respectivamente em $\mathrm{dB} \mu$ e $\mathrm{mV} / \mathrm{m}$.

Eficiência de Uso do Espectro (EUE).

Fator de Amortecimento.

Fully Allocated Costs (Custos Totalmente Alocados).

Federal Communications Commission (United States of America).

Fórum de Certificação de Produtos para Telecomunicações.

Função Comissionada Técnica.

Funções Comissionadas de Telecomunicações.

Frequency Division Duplexing (Duplexação por Divisão na Frequência).

Frequency Division Multiple Access (Múltiplo Acesso por Divisão em Frequência).

Federação Brasileira de Telecomunicações (Representação empresarial).

Federação Nacional dos Jornalistas.

Fundo Garantidor de Parcerias Público-Privadas.

Fundo de Garantia por Tempo de Serviço.

Múltiplo Acesso por Divisão em Código com Saltos de Freqüência.

Fédération Internationale de Football Association.

Financiadora de Estudos e Projetos.

Fundo de Investimento Social.

Fundo de Fiscalização das Telecomunicações.

Federação Interestadual dos Trabalhadores em Telecomunicações.

Frequência Modulada.

Fixed-Mobile Convergence Alliance.

Fundo Nacional da Cultura.

Fundo Nacional de Desenvolvimento Científico e Tecnológico.

Fórum Nacional de Professores de Jornalismo.

Fundo Nacional de Telecomunicações.

Fórum Nacional Permanente de Carreiras Típicas de Estado.

Fórum Brasileiro de Ensino de Cinema e Audiovisual.

Fornecedora de Sinal.

Fiber to the Building.

Fiber to the Curb.

Fiber to the Home.

Fiber to the Node.

Fundo Especial para Calamidades Públicas (Sistema Nacional de Defesa Civil).

Fundo de Universalização do Acesso a Serviços de Telecomunicação (Minas Gerais).

Fundo Tecnológico (BNDES). 
FUNTTEL

FUST

FWA

GCOM

GESAC

GETEL

GGSN

GIP

GIP

GIPAQ

GMC

GMDSS

GNR

GPON

GPRS

GPS

GSM

GTI

HCA

HCA

HCI

$\mathrm{HF}$

HFBC

HMM

HNMT

HNMT

HSDPA

HSPA

HSUPA

IAF

IAMCR

IAP

IAP

IARP

IARU
Fundo para o Desenvolvimento Tecnológico das Telecomunicações.

Fundo de Universalização dos Serviços de Telecomunicações.

Fixed Wireless Access.

Grupo Interdisciplinar de Políticas, Direito, Economia e Tecnologias das Comunicações (UnB).

Governo Eletrônico - Serviço de Atendimento ao Cidadão.

Grupo de Estudos em Direito das Telecomunicações (UnB).

Gateway GPRS Support Node.

Grupo de Implantação da Portabilidade.

Grupo de Implementação da Portabilidade.

Grupo de Implantação de Processos de Aferição da Qualidade.

Grupo Mercado Comum.

Sistema Global Marítimo de Socorro e Segurança.

Guia Nacional de Recolhimento de Tributos Estaduais.

Gigabit Passive Optical Network.

General Packet Radio Service (Rede celular 2.5G).

Global Positioning System (Sistema de Posicionamento Global).

Global System Mobile -Global System for Mobile Communications (Originariamente Groupe Spécial Mobile).

Grupo de Trabalho Interministerial.

Base de Custos Históricos ( Separação e Alocação de Contas).

Historical Cost Accounting (Base de Custos Históricos na Separação e Alocação de Contas).

Altura do Centro de Fase do Sistema Irradiante.

High Frequency (Alta Freqüência).

Conferência Administrativa Mundial de Radiocomunicações para o planejamento das faixas de ondas decamétricas atribuídas ao serviço de radiodifusão, realizada em 1987.

Hora de Maior Movimento.

Altura da Antena sobre o Nível Médio do Terreno.

Altura do Sistema Irradiante em Relação ao Nível Médio do Terreno (Radiodifusão).

High Speed Downlink Packet Access (Rede celular 3G).

High-Speed Packet Access (tipo de padrão de telefonia móvel por dados) (Rede celular 3G).

High Speed Uplink Packet Access (Rede celular 3G).

International Accreditation Forum (Certificação e Homologação).

International Association for Media and Communication Research.

Índice de Atendimento Pessoal.

Interamerican Proposal.

International Amateur Radio Permission (Permissão Internacional de Radioamador).

União Internacional de Radioamadores. 
IBGE

IBICT

IBOC

ICANN

ICAO

ICC

ICCo

ICMS

ICNIRP

ICP-Brasil

ICR

ICT

ICT4D

IDA

IDDF

IDEC

IDH

IDQ

IEC

IEEE

IETF

IFCA

Ifd

IFRB

IFS

IGF

IGP-DI

IGP-M

IGQO

IGQP

II

IIS

IITS

ILA
Instituto Brasileiro de Geografia e Estatística.

Instituto Brasileiro de Informação em Ciência e Tecnologia.

In-Band On-Channel (padrão norte-americano de rádio digital).

Internet Corporation for Assigned Names and Numbers (Corporação da Internet para a Atribuição de Nomes e Números).

Organização Internacional de Aviação Civil.

Índice de Chamadas Completadas.

Índice de Cessação de Cobrança.

Imposto sobre Operações Relativas à Circulação de Mercadorias e Sobre Prestações de Serviços de Transporte Interestadual, Intermunicipal e de Comunicações.

International Commission on Non Ionizing Radiation Protection (Comissão Internacional de Proteção Contra Radiações Não Ionizantes).

Infraestrutura de Chaves Públicas Brasileira.

Índice de Correspondências Respondidas.

Instituição Científica e Tecnológica.

Information and Communication Technologies for Development.

Índice de Desempenho no Atendimento (aplicado ao STFC).

Informações de Demanda e Dados Físicos (Separação e Alocação de Contas).

Instituto de Defesa do Consumidor.

Índice de Desenvolvimento Humano.

Índice de Desempenho de Qualidade (aplicado ao STFC).

International Electrotechnical Commission.

Institute of Electrical and Electronics Engineers.

Internet Engineering Task Force (Força Tarefa de Engenharia da Internet).

International Federation of Mass Communication Associations.

Fator de Degradação.

Junta Internacional de Registro de Frequências.

Serviço Franqueado Internacional.

Internet Governance Fórum (Fórum de Governança da Internet vinculado à $\mathrm{ONU}$ ).

Índice Geral de Preços - Disponibilidade Interna.

Índice Geral de Preços - Mercado.

Índice Geral de Qualidade Operacional (aplicado ao STFC).

Índice Geral de Qualidade Percebida (aplicado ao STFC).

Imposto de Importação.

Índice de Instalação do Serviço.

Índice de Interrupções Solucionadas.

Índice de Ligações Atendidas. 


\section{ILAC}

IME

IMO

IMSI

IMT-2000

IMT-Advanced

INDE

INFRAERO

INI

INMARSAT

INMETRO

INTELSAT

Intercom

IP

IP

IPAOG/FGV

IPCA/IBGE

IPI

IPTF

IPTF DEA

IPTF F

IPTF F

IPTV

IQF

IQP

IQP

IR

IREDC

IRPJ

IRS

ISAN

ISDB

ISDB-C

ISDB-S

ISDB-T
International Laboratories Accreditation Cooperation (Certificação e Homologação).

Índice Mínimo de EUE (IME).

Organização Marítima Internacional.

International Mobile Subscriber Identity (Identificação Internacional de Acesso Móvel).

International Mobile Telecommunications-2000.

International Mobile Telecommunication Advanced (requisitos UIT).

Infraestrutura Nacional de Dados Espaciais (INDE).

Empresa Brasileira de Infra-estrutura Aeroportuária.

Infraestrutura Nacional de Informações.

Organização Internacional de Telecomunicações Marítimas por Satélite.

Instituto Nacional de Metrologia, Normalização e Qualidade Industrial. International Telecommunications Satellite Consortium (Organização Internacional de Telecomunicações por Satélite).

Sociedade Brasileira de Estudos Interdisciplinares da Comunicação. Índice de Preços.

Internet Protocol (Protocolo de Internet).

Índice de Preços por Atacado - Oferta Global.

Índice de Preços ao Consumidor Amplo.

Imposto sobre Produtos Industrializados.

IPTF F.

Índice de Produtividade Total de Fatores DEA.

Índice de Produtividade Total de Fatores Fisher.

Índice de Produtividade Total de Fatores Fisher (Reajuste Tarifário do STFC).

Internet Protocol TV.

Índice de Quantidade dos Fatores de Produção (Reajuste Tarifário do STFC).

Índice de Fator de Produção.

Índice de Quantidade dos Produtos (Reajuste Tarifário do STFC).

Imposto de Renda.

Índice de Reclamação por Erro em Documento de Cobrança.

Imposto sobre a Renda da Pessoa Jurídica.

Índice de Reclamação do Serviço.

International Standard Audiovisual Number.

Integrated Services Digital Broadcasting.

Integrated Services Digital Broadcasting Cable.

Integrated Services Digital Broadcasting Satellite Television.

Integrated Services Digital Broadcasting Terrestrial (Serviços Integrados de Radiodifusão Digital Terrestre). 
ISDTV

ISM

ISO

ISP

ISRA

ISS

IST

ISYDS

ITE

ITI

ITU

1

LAN

LaPCom

LBS

LDI

LDN

LED

LEP

LF

LGT

LIBRAS

LLU

LMDS

LPFM

LRGP

LRIC

LSI

LSZH

LTE

LTOG

LUSOCOM

M2M

MAN

MdE

MDGs

MEF

MERCOSUL

MF
International System for Digital TV (novo nome do SBTVD).

Aplicações Industriais, Científicas e Médicas.

International Standards Organisation.

Internet Service Provider (vide PSCI).

Índice de Solicitações de Reparos Atendidas.

Imposto sobre Serviços de Qualquer Natureza.

Índice de Serviços de Telecomunicações.

Integrated System for Decision Support (vide SIAD).

Índice Temporal de EUE.

Instituto Nacional de Tecnologia da Informação (Autarquia vinculada à Casa Civil da Presidência da República).

International Telecommunication Union (União Internacional de Telecomunicações).

Comprimento de Onda.

Local Area Network.

Laboratório de Políticas de Comunicação da UnB.

Location Based Services.

Longa Distância Internacional.

Longa Distância Nacional.

Light Emitting Diode (Diodo Emissor de Luz).

Lei de Execuções Penais.

Low Frequency.

Lei Geral de Telecomunicações.

Língua Brasileira de Sinais.

Local Loop Unbundling.

Local Point-Multipoint Distribution Service.

Low-Power FM stations (Rádios Comunitárias).

Loudness Rating Guard-Ring Position.

Long Run Incremental Costs (Custos Incrementais de Longo Prazo)

(Serviço Telefônico Fixo Comutado).

Laboratório de Sistemas Integráveis da USP.

"Low Smoke and Zero Halogen".

Long Term Evolution (Rede Celular 3G).

Lista Telefônica Obrigatória e Gratuita.

Federação Lusófona de Ciências da Comunicação.

Machine to Machine (comunicação entre máquinas).

Metropolitan Area Network.

Memorando de Entendimento - MdE.

Millenium Development Goals (UN Millenium Summit 2000).

Mobile Entertainment Forum.

Mercado Comum do Sul.

Medium Frequency (Média Freqüência). 
MICS

MIFR

MIN

MINFRA

MMDS

MMS

$\mathrm{MNO}$

MOB

MOB-87

MOS

MSCID

MT

MVNO

MVPD

NBM

$\mathrm{NC}$

NCL

NCM

NFC

NFST

NGN

NGT

NOPRED

NPOESS

NRA

NSR

NUDEC

NWA

OCC

OCD

OCDE

OECD

OFDM

OFDMA

OIT
Sistemas de Comunicações de Implantes Médicos.

Master International Frequency Register (Registro Mestre da UIT).

Valor do Minuto de Tarifação (Serviço Telefônico Fixo Comutado).

Ministério da Infraestrutura (Extinto pela Lei 8.422, de 13/05/1992).

Multichannel Multipoint Distribution Service (Serviço de Distribuição de Sinais Multiponto Multicanal).

Multimedia Message.

Mobile Network Operator (Operador de Rede Móvel).

Conferência Administrativa Mundial de Radiocomunicações para os serviços móveis.

Conferência Administrativa Mundial de Radiocomunicações para os Serviços Móveis, realizada em 1987.

Mean Opinion Score (Pontuação Média de Opinião).

Mobile Switching Center Identification.

Linha de distribuição de Média Tensão.

Mobile Virtual Network Operator (Operador de Rede Virtual Móvel). MVPD.

Nomenclatura Brasileira de Mercadorias.

Noise Criteria.

Nested Context Language (Interatividade do ISDB-T: linguagem do ambiente Ginga-NCL).

Nomenclatura Comum do Mercosul.

Near Field Communications.

Nota Fiscal de Serviço de Telecomunicações.

Next Generation Network.

Norma Geral de Telecomunicações (Ministério das Comunicações).

Notificação Preliminar de Desastres - Formulário (Sistema Nacional de Defesa Civil).

National Polar-Orbiting Environmental Satellite System.

National Regulatory Authorities (União Européia).

Nível do Sinal Recebido.

Núcleo Comunitário de Defesa Civil (Sistema Nacional de Defesa Civil).

Nomadic Wireless Access (Aplicação Nomádica).

Organismo de Certificação Credenciado.

Organismo de Certificação Designado.

Organização para Cooperação e Desenvolvimento Econômico.

Organisation for Economic Co-operation and Development (Organização para Cooperação e Desenvolvimento Econômico).

Orthogonal Frequency Division Multiplexing (Multiplexação Ortogonal por Divisão de Frequiência).

Orthogonal Frequency-Division Multiple Access.

Oxidative Induction Time (Tempo de Indução Oxidativa). 
OL

$\mathrm{OM}$

OMC

OPGW

ORB-85

OSCIP

OT

OTI

P\&D

PAC

PAC

PADIS

PADO

PAF

PAR

PAR-C

PAR-F

PAR-S

PASEP

PASI

PASOO

PAT

PATVD

PATVD

PBFM

PBOC

PBOM

PBOT

PBRTV

PBTV

PBTVA

PBTVD
Oscilador Local.

Onda Média.

Organização Mundial do Comércio.

Optical Ground Wire (Cabos Pára-raios com Fibras Ópticas).

Conferência Administrativa Mundial de Radiocomunicações para uso da Órbita de Satélites Geoestacionários e o Planejamento dos Serviços Espaciais que a Utilizam, realizada em 1985.

Organização da Sociedade Civil de Interesse Público.

Onda Tropical.

Organización de Televisión Iberoamericana.

Pesquisa e Desenvolvimento.

Plano Anual de Capacitação (Capacitação Profissional nas Agências Reguladoras).

Programa de Aceleração do Crescimento (Programa de Governo de Janeiro de 2007).

Programa de Apoio ao Desenvolvimento Tecnológico da Indústria de Semicondutores (PADIS).

Procedimento Administrativo para Apuração de Descumprimento de Obrigações (Agência Nacional de Telecomunicações).

Processo Administrativo Fiscal (ANATEL).

Plano de Aplicação de Recursos (FUNTTEL).

Plano de Atendimento Rural Complementar (STFC).

Plano de Atendimento Rural Facultativo (STFC).

Plano de Atendimento Rural Suplementar (STFC).

Programa de Formação do Patrimônio do Servidor Público.

Provedor de Acesso a Serviços de Internet.

Plano Alternativo de Serviço de Oferta Obrigatória.

Parcela Adicional de Transição.

Programa de Apoio ao Desenvolvimento Tecnológico da Indústria de Equipamentos para a TV Digital.

Programa de Incentivos ao Setor da TV Digital (Integrante do PAC). Plano Básico de Distribuição de Canais de Radiodifusão Sonora em Frequiência Modulada.

Plano Básico de Distribuição de Canais de Radiodifusão Sonora em Onda Curta.

Plano Básico de Distribuição de Canais de Radiodifusão Sonora em Onda Média.

Plano Básico de Distribuição de Canais de Radiodifusão Sonora em Onda Tropical.

Plano Básico de Distribuição de Canais de Retransmissão de Televisão em VHF e UHF.

Plano Básico de Distribuição de Canais de Televisão em VHF e UHF.

Plano Básico de Distribuição de Canais de Televisão por Assinatura.

Plano Básico de Distribuição de Canais de Televisão Digital. 
PBX

PCNR

PCS

PDE

PDG

PDP

PDRTVD

PDTVD

PEP

PF

PGA

PGA-SME

PGA-SMP

PGCN

PGMC

PGMQ

PGMQ-2006

PGMQ-SMP

PGMU

PGMU-2006

PGO

PGR

PICT

PIS

PISP

PLC

PMD

PMM

PMM1

PMM2

PMS

PMT

PNBL

POI

POP
Private Branch Exchange.

Parcela de Custo Não Recuperável pela Exploração Eficiente do

Serviço (Fundo de Universalização dos Serviços de Telecomunicações).

Personal Communication Service.

Plano de Desenvolvimento da Educação.

Programa de Dispêndios Globais (Empresas Estatais Federais).

Plasma Display Pannel (Painel Mostrador de Plasma).

Plano de Designação de Canais de Retransmissão de Televisão Digital.

Plano de Designação de Canais de Televisão Digital.

Peak Envelope Power (Potência de Pico da Envoltória).

Procuradoria Federal no Estado.

Plano Geral de Autorizações.

Plano Geral de Autorizações do Serviço Móvel Especializado.

Plano Geral de Autorizações do Serviço Móvel Pessoal.

Plano Geral de Códigos Nacionais.

Plano Geral de Metas de Competição.

Plano Geral de Metas de Qualidade.

Plano Geral de Metas de Qualidade do STFC para a Renovação dos Contratos de Concessão.

Plano Geral de Metas de Qualidade para o Serviço Móvel Pessoal.

Plano Geral de Metas de Universalização.

Plano Geral de Metas para Universalização do STFC no Regime Público para a Renovação dos Contratos de Concessão.

Plano Geral de Outorgas.

Plano Geral de Atualização da Regulamentação das Telecomunicações no Brasil.

Projeto de Proteção da Infraestrutura Crítica de Telecomunicações (Anatel e CPqD).

Programa de Integração Social.

Plano de Indenização por Serviços Prestados (Telebras).

Power Line Communications.

Polarization Mode Dispersion (Modo de Polarização por Dispersão)

(Cabo de Fibra Óptica).

Período de Maior Movimento (Televisão por Assinatura (Gênero)).

Período de Maior Movimento diurno, das $9 \mathrm{~h}$ às $11 \mathrm{~h}$ (STFC).

Período de Maior Movimento noturno, das 20h às 22h (STFC).

Poder de Mercado Significativo.

Período de Maior Tráfego (PMT).

Programa Nacional de Banda Larga.

Ponto de Interconexão.

Post Office Protocol (INTERNET). 


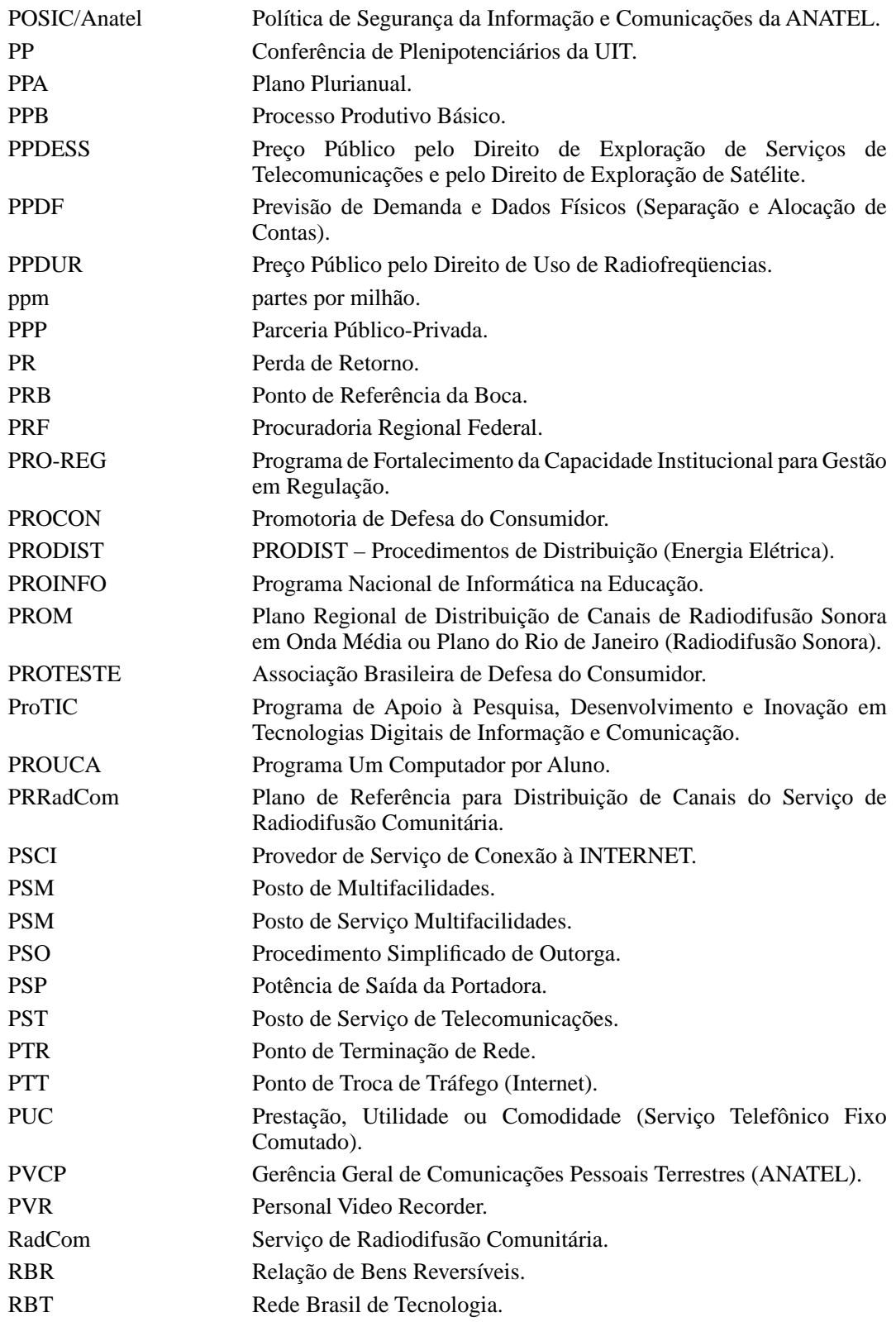


RBT

RCBR

RDSI

RDSI-FE

RDSI-FL

RE

RECAP

RECOMPE

REDEC

REGISTRO.br

REGULATEL

REICOMP

RENEC

REPES

REPNBL-Redes

REsp

RF

$\mathrm{RF}$

RFID

RGP

RGQ-SCM

RGQ-SMP

RIQ

RITU

RLL

RMT

RNI

RNP

RNR

ROL

RPF

RpTV

RR
Rede de distribuição de Baixa Tensão.

Regulamento de Controle de Bens Reversíveis.

Rede Digital de Serviços Integrados.

Rede Digital de Serviços Integrados - Faixa Estreita.

Rede Digital de Serviços Integrados - Faixa Larga.

Recurso Extraordinário.

Regime Especial de Aquisição de Bens de Capital para Empresas Exportadoras.

Regime Especial de Aquisição de Computadores para Uso Educacional.

Regional Estadual de Defesa Civil (Sistema Nacional de Defesa Civil). Registro de Domínios para a Internet no Brasil (Comitê Gestor da Internet no Brasil).

Foro Latino-Americano de Autoridades Reguladoras das Telecomunicações.

Regime Especial de Incentivo a Computadores para Uso Educacional. Rede Nacional de Estações Costeiras.

Regime Especial de Tributação para a Plataforma de Exportação de Serviços de Tecnologia da Informação.

Regime Especial de Tributação do Programa Nacional de Banda Larga para Implantação de Redes de Telecomunicações.

Recurso Especial.

Radiofrequência.

Radiofrequência (Campo Eletromagnético).

Radio Frequency Identification Device (Sistema de Identificação por Radiofrequiência).

Regulamento Geral de Portabilidade.

Regulamento de Gestão da Qualidade do Serviço de Comunicação Multimídia.

Regulamento de Gestão da Qualidade da Prestação do Serviço Móvel Pessoal.

Regulamento de Indicadores de Qualidade do Serviço Telefônico Fixo Comutado.

Rede de Intercâmbio de Televisão Universitária.

Radio in the Local Loop.

Rede de distribuição de Média Tensão.

Radiação Não Ionizante (Campo Eletromagnético).

Rede Nacional de Pesquisa.

Rede Nacional de Radiovideometria.

Receita Operacional Líquida.

Request for Proposal.

Serviço de Repetição de Televisão.

Regulamento de Radiocomunicações da UIT. 
RRD

RRV-SMP

RSAC

RSQ

RTFM

RTV

RUE

RVU-M

SA

SAC

SAC

SACP

SAM

SAMU

SAP

SAPN

SAR

SARC

SART

SATVA

SBC

SBPJOR

SBRD

SBTVD

SBTVD-T

SCI

SCM

SCMa

SCR

SDE

SDK

SDN

SeAC

SEAE

SECEX

SEDH

SEFID

SELIC
Restricted Radiation Device.

SMP por meio de Rede Virtual.

Regulamento de Separação e Alocação de Contas.

Raiz quadrada da soma dos quadrados.

Regulamento Técnico para Emissoras de Radiodifusão Sonora em Frequência Modulada.

Serviço de Retransmissão de Televisão.

Regulamento de Uso do Espectro de Radiofrequências.

Valor de Referência de VU-M.

Specific Absorption (Absorção Específica).

Serviço de Atendimento ao Consumidor.

Stand Alone Cost (Custo Total Individual - Separação e Alocação de Contas).

Sistema de Acompanhamento de Consulta Pública.

Serviço Avançado de Mensagens.

Serviço de Atendimento Móvel de Urgência.

Secondary Audio Programming (Programa Secundário de Áudio).

Sistema de Administração dos Recursos de Numeração.

Specific Absorption Rate (Taxa de Absorção Específica).

Serviço Auxiliar de Radiodifusão e Correlatos.

Transponder de busca e salvamento.

Sistema de Acompanhamento das Obrigações das Prestadoras de TV por Assinatura.

Sistema Brasileiro de Certificação.

Sociedade Brasileira de Pesquisadores em Jornalismo.

Sistema Brasileiro de Rádio Digital.

Sistema Brasileiro de Televisão Digital.

Sistema Brasileiro de Televisão Digital Terrestre.

Serviço de Conexão à INTERNET.

Serviço de Comunicação Multimídia.

Serviço de Comunicação de Massa por assinatura.

Serviço de Comunicações de Interesse Restrito.

Secretaria de Direito Econômico (Ministério da Justiça).

Software Development Kit.

Software Defined Networking.

Serviço de Acesso Condicionado.

Secretaria de Acompanhamento Econômico (Ministério da Fazenda).

Secretaria de Controle Externo (Tribunal de Contas da União).

Secretaria Especial de Direitos Humanos da Presidência da República.

Secretaria de Fiscalização de Desestatização (Tribunal de Contas da União).

Sistema Especial de Liquidação e Custódia. 
SER

SERDS

SET

SETA

SFS

SGAL

SGB

SGB

SGDC

SGIQ

SGME

SGT.1

SHF

SI

SIAD

SIAFI

SIC

SICAP

SICI

SICOM

SIGAnatel

SIGEC

SINAMOB

SINAPI/IBGE

SINAR

SINCAB

SINDEC

SINDEC

SINDER

SINDESB

SINDISAT

SINDITELEBRASIL
Serviço Especial de Radiochamada, Regime Regulatório.

Serviço Especial de Radiodeterminação por Satélite.

Sociedade Brasileira de Engenharia de Televisão.

Sindicato Nacional das Empresas Operadoras de Sistemas de Televisão por Assinatura (Representação empresarial).

Serviço Fixo por Satélite.

Sistema de Gerenciamento de Áreas Locais.

Sistema Geodésico Brasileiro.

Sistema Geoestacionário Brasileiro.

Satélite Geoestacionário de Defesa e Comunicações Estratégicas.

Sistema de Gerenciamento de Indicadores de Qualidade.

Sistema de Gestão e Monitoragem do Espectro.

Subgrupo de Trabalho $n^{\circ} 1$ - Comunicações do Mercosul.

Super High Frequency.

Sociedade da Informação.

Sistema Integrado de Apoio à Decisão (Programa para obtenção dos Valores de Eficiência DEA).

Sistema Integrado de Administração Financeira do Governo Federal. Segurança da Informação e Comunicações (ANATEL).

Sistema de Controle de Rastreamento de Documentos e Processos.

Sistema de Coleta de Informação.

Sistema de Comunicação de Governo do Poder Executivo (Publicidade da Administração Pública Federal).

Sistema de Informações Geográficas do Brasil.

Sistema Integrado de Gestão de Créditos da ANATEL.

Sistema Nacional de Mobilização.

Sistema Nacional de Pesquisa de Custos e Índices da Construção Civil.

Sistema Nacional de Arquivos.

Sindicato Nacional dos Trabalhadores em Sistemas de TV por Assinatura e Serviços Especiais de Telecomunicações (Representação profissional).

Sistema Nacional de Defesa Civil.

Sistema Nacional de Defesa do Consumidor.

Sindicato Nacional das Empresas de Radiocomunicações (Representação empresarial).

Sistema de Informações sobre Desastres no Brasil (Sistema Nacional de Defesa Civil).

Sindicato Nacional das Empresas de Telecomunicações por Satélite (Representação empresarial).

Sindicato Nacional das Empresas Operadoras de Serviços de Telecomunicações (Representação empresarial). 
SINSTAL

SINTEIS

SIT

SITARWEB

SLD

SLDA

SLDD

SLDT

SLE

SLMP

SLP

SLPR

SMA

SMC

SMD

SME

SMGS

SMM

SMP

SMS

SMS

SMT

SNC

SNOA

Socicom

SOCINE

SOR

SPV

SRA

SRC

SRD

SRE

SRT

SRTT

SSB

STE
Sindicato Nacional das Empresas Instaladoras de Sistemas e Redes de TV por Assinatura e Telecomunicações (Representação empresarial).

Sindicatos Estaduais dos Trabalhadores em Telecomunicações (Representação profissional).

Sistema com Transponder Interrogador.

Sistema de Informações Técnicas para Administração das Radiocomunicações WEB.

Serviço por Linha Dedicada.

Serviço por Linha Dedicada para Sinais Analógicos.

Serviço por Linha Dedicada para Sinais Digitais.

Serviço por Linha Dedicada para Sinais Telegráficos.

Serviço Limitado Especializado.

Serviço Limitado Móvel Privativo.

Serviço Limitado Privado.

Serviço Limitado Privado de Radiochamada.

Serviço Móvel Aeronáutico.

Serviço Móvel Celular.

Surface Mounted Device.

Serviço Móvel Especializado.

Serviço Móvel Global por Satélite.

Serviço Móvel Marítimo.

Serviço Móvel Pessoal.

Serviço Móvel por Satélite.

Short Message Service.

Surface Mounted Technology.

Secretaria Nacional de Comunicações (MINFRA).

Sistema de Negociação das Ofertas de Atacado (PGMC).

Federação Brasileira das Associações Científicas e Acadêmicas de Comunicação.

Sociedade Brasileira de Estudos de Cinema.

Superintendência de Outorga e Recursos à Prestação (ANATEL).

Superintendência de Serviços Privados.

Serviço de Radiocomunicação Aeronáutica Público-Restrito.

Superintendência de Relações com Consumidores.

Short Range Device.

Serviço de Radiotáxi Especializado, Regime Regulatório.

Serviço de Radiotáxi.

Serviço de Rede de Transporte de Telecomunicações.

Single Side Band 'Modulation' (Modulação em Faixa Lateral Simples).

Secretaria de Telecomunicações (Ministério das Comunicações). 
STEL

STF

STFC

STJ

STM

STP

STS

SUDAM

SUFRAMA

SVA

TAB

TAC

TAP

TAP

TAP

TBSMC

TCD

TCP

TCU

TDD

TDMA

TEB

TEC

TelComp

TELEBRAS

TELEBRASIL

TELEX

TFEL

TFF

TFI

THD

TIC

TIPI

TISA

TMC

TME

TMN

TOE
Sistema de Serviços de Telecomunicações.

Supremo Tribunal Federal.

Serviço Telefônico Fixo Comutado Destinado ao Uso do Público em Geral.

Superior Tribunal de Justiça.

Superior Tribunal Militar.

Serviço Telefônico Público (em desuso).

Serviço de Transporte de Sinais de Telecomunicações por Satélite.

SUDAM.

Superintendência da Zona Franca de Manaus.

Serviço de Valor Adicionado.

Tarifa Aduaneira do Brasil.

Termo de Compromisso de Ajustamento de Conduta.

Television Association of Programmers (Estados Unidos da América).

Terminal de Acesso Público.

Terminal de Acesso Público (Serviço Telefônico Fixo Comutado).

Tarifa Básica do Serviço Móvel Celular.

Termo de Compromisso de Desempenho.

Transport Control Protocol (INTERNET).

Tribunal de Contas da União.

Time Division Duplexing (Duplexação por Divisão no Tempo).

Time Division Multiple Access (Múltiplo Acesso por Divisão em Tempo).

Taxa de Erro de Bits.

Tarifa Externa Comum.

Associação Brasileira das Prestadoras de Serviços de Telecomunicações Competitivas.

Telecomunicações Brasileiras S.A..

Associação Brasileira de Telecomunicações.

Comutação Telegráfica.

Thin-Film Electroluminescent (Displays Eletroluminescentes a Filme Fino).

Taxa de Fiscalização do Funcionamento.

Taxa de Fiscalização da Instalação.

Distorção harmônica total.

Information and Communication Technology.

Tabela de Incidência do Imposto sobre Produtos Industrializados.

Traveller Information Services Association.

- Traffic Message Channel (Canal de Mensagem de Trânsito).

Tarifa de Mudança de Endereço (Serviço Telefônico Fixo Comutado).

Telecommunications Management Network.

Taxa de Onda. 
TR

TRASA

TRD

TRF

TRF1

TRI

TRX

TSC

TSC

TSE

TST

TT

TU

TU-COM

TU-M

TU-RIU

TU-RIU1

TU-RIU2

TU-RL

TUP

TUP

TVA

TVA

TVC

UAC

UCS

UHDTV

UHF

UIT

UIT-R

UIT-R-SA

ULEPICC

UMB

UMTS

UNE-P

UNICEF
Taxa Referencial.

Telecommunications Regulators' Association of Southern Africa.

Taxa Referencial Diária.

Tribunal Regional Federal.

Tribunal Regional Federal da $1^{\mathrm{a}}$ Região.

Termo de Responsabilidade de Instalação.

Transceptor.

Terminal Móvel de Acesso a Ser Certificado.

Terminal Portátil a Ser Certificado.

Tribunal Superior Eleitoral.

Tribunal Superior do Trabalho.

Tronco/Canal Telefônico de Entrada.

Tarifa de Uso (Serviço Telefônico Fixo Comutado).

Tarifa de Uso de Comutação (Serviço Telefônico Fixo Comutado).

Tarifa de Uso Móvel.

Tarifa de Uso de Rede Interurbana.

Tarifa de Uso de Rede Interurbana Nível 1 (Serviço Telefônico Fixo Comutado).

Tarifa de Uso de Rede Interurbana Nível 2.

Tarifa de Uso de Rede Local.

Telefone de Uso Público.

Telefone de Uso Público (Serviço Telefônico Fixo Comutado).

Serviço Especial de Televisão por Assinatura.

Televisão por Assinatura (Espécie de Serviço Especial).

TV a Cabo.

Unidade de Atendimento de Cooperativa.

Unidade de Controle do Sistema (Sistemas de Acesso sem Fio do STFC).

Ultra High Definition Television (Radiodifusão 8K).

Ultra High Frequency (Freqüência Ultra Alta).

União Internacional de Telecomunicações (Union Internationale des Télécommunications / Unión Internacional de Telecommunicaciones).

Setor de Radiocomunicações da União Internacional de Telecomunicações.

Recomendações da UIT sobre Aplicações Espaciais e Meteorologia.

Unión Latina de Economía Política de la Información, la Comunicación y la Cultura.

Ultra Mobile Broadband.

Universal Mobile Telecommunications Service (Rede celular 3G).

Desagregação de Plataforma.

United Nations Children's Fund (Fundo das Nações Unidas para a Infância). 
UO

UPS

UR

URA

URA

URA

URD

URV

USG

USSD

UTP

UTRAN

UWB

UWIA

VBI

VC

VC-1

VC-2

VC-3

VC-T

VC-VST-R

VC1

VCA

VELOX

VHF

VIGP

VLF

VM

VMA

VMA

VPA

Vpe

VR

VSAT

VSAT

VSWR
Unidade Operacional.

Uninterruptable Power Supply.

Unidade Retificadora.

Unidade de Resposta Audível (SMP - Gestão da Qualidade).

Unidade de Resposta Automática.

Unidade Remota de Assinante.

Unidade Receptora Decodificadora (Serviço de Acesso Condicionado).

Unidade Real de Valor.

Unidade de Supervisão e Gerência (Sistemas de Acesso sem Fio do STFC).

Unstructured Supplementary Service Data (Redes Móveis).

Unidade de Tarifação para TUP e TAP (Serviço Telefônico Fixo Comutado).

Universal Terrestrial Radio Access Network.

Ultrawideband.

Ubiquitous Wireless Internet Access.

Vertical Blanking Interval (Intervalo de Apagamento Vertical).

Valor de Comunicação (Serviço Telefônico Fixo Comutado).

Valor de Comunicação 1.

Valor de Comunicação 2.

Valor de Comunicação 3.

Valor de Comunicação (Serviço Móvel Especializado).

Valor de Comunicação do Visitante em Roaming.

Valor de Comunicação 1 (Serviço Móvel Pessoal).

Valor de Chamada Atendida (Serviço Telefônico Fixo Comutado).

Serviço de acesso à internet de banda larga comercializado pela empresa Oi.

Very High Frequency (Freqüência Muito Alta).

Variação do Índice Geral de Preços - Disponibilidade Interna.

Very Low Frequency.

Valor da Multa (Radiodifusão - Regulamento de Sanções Administrativas).

Valor de Uso de Meio Adicional (STFC fora da Área de Tarifa Básica).

Valor de Utilização de Meios Adicionais.

Valor Patrimonial da Ação.

Volt por elemento.

Valor de Referência (Radiodifusão - Regulamento de Sanções Administrativas).

Estação Terrena de Pequeno Porte.

Very Small Aperture Terminal (Certificação).

Relação de Onda Estacionária. 
VTP

VU-M

VU-M

VU-T

WACC

WAN

WAP

WATRA

WCDMA

WDM

WDMA

Wi-Fi

WIMAX

WiMesh

WISP

WLAN

WLL

WMAN

WSIS

WTPF-09

WTPF-09

xDSL

XPOL

$\theta$ ini
Valor da Unidade de Tarifação para TUP e TAP (Serviço Telefônico Fixo Comutado).

Valor de Remuneração de Uso de Rede do SMP.

Valor de Uso de Rede Móvel.

Valor de Remuneração de Uso de Rede do SME.

Weighted Average Cost of Capital (Custo Médio Ponderado de Capital na Separação e Alocação de Contas).

Wide Area Network.

Wireless Application Protocol.

West Africa Telecommunications Regulators Assembly.

Wideband CDMA (CDMA de banda larga).

Wavelength Division Multiplexing (Multiplexação por Divisão de Comprimento de Onda).

Wavelegth Division Multiple Access (Acesso Múltiplo por Divisão de Comprimento de Onda).

Wireless Fidelity (padrão IEEE 802.11).

Worldwide Interoperability for Microwave Access.

WiMesh - Wireless Mesh.

Wireless Internet Service Provider.

Wireless Local Area Network.

Wireless Local Loop (Rede Local sem Fio).

Wireless Metropolitan Area Network.

World Summit on the Information Society (Cúpula Mundial sobre a Sociedade da Informação - CMSI).

Fórum Mundial sobre Políticas de Telecomunicações.

World Telecommunication Policy Forum.

x Digital Subscriber Line.

Polarização Cruzada.

Ângulo Teta Inicial. 


\section{Normas e Atos de 2013}

Fundamentos

\section{Aspectos Históricos}

$1 /$ Atos

VR Relatório da Ouvidoria da ANATEL 2013

Direito à Privacidade

Tema Conexo: Políticas de Telecomunicações : Sigilo em Telecomunicações.

\section{Infraestrutura e Recursos do Setor de Telecomunicações}

\section{Infraestrutura de Telecomunicações}

\section{Normatização}

Decreto n 8.135, de 4 de novembro de 2013 - Dispõe sobre as comunicações de dados da administração pública federal direta, autárquica e fundacional, e sobre a dispensa de licitação nas contratações que possam comprometer a segurança nacional.

$\checkmark$ Requisitos dos programas e equipamentos destinados às comunicações de dados da administração pública federal.

\section{Redes de Telecomunicações}

\section{Normatização}

Decreto $n^{\circ}$ 8.135, de 4 de novembro de 2013 - Dispõe sobre as comunicações de dados da administração pública federal direta, autárquica e fundacional, e sobre a dispensa de licitação nas contratações que possam comprometer a segurança nacional.

$\checkmark$ Requisitos dos programas e equipamentos destinados às comunicações de dados da administração pública federal.

Resolução da ANATEL n⿳ 607, de 13 de março de 2013 - Alteração no Regulamento de Numeração do Serviço Telefônico Fixo Comutado, aprovado pela Resolução no 86, de 30 de dezembro de 1998, e no Regulamento de Administração dos Recursos de Numeração, aprovado pela Resolução $n^{\circ}$ 84, de 30 de dezembro de 1998.

$\rightarrow$ Anexo - Alterações no Regulamento de Numeração do Serviço Telefônico Fixo Comutado e no Regulamento de Administração dos Recursos de Numeração. 
Resolução da ANATEL no 624, de 30 de outubro de 2013 - Aprova o Regulamento para Uso de Femtocélulas em Redes do Serviço Móvel Pessoal, do Serviço Móvel Especializado e do Serviço de Comunicação Multimídia.

$\rightarrow$ Anexo - Regulamento para Uso de Femtocélulas em Redes do Serviço Móvel Pessoal, do Serviço Móvel Especializado e do Serviço de Comunicação Multimídia.

\section{Numeração dos Serviços}

\section{Normatização}

Resolução da ANATEL no 607, de 13 de março de 2013 - Alteração no Regulamento de Numeração do Serviço Telefônico Fixo Comutado, aprovado pela Resolução $n^{\circ} 86$, de 30 de dezembro de 1998, e no Regulamento de Administração dos Recursos de Numeração, aprovado pela Resolução no 84, de 30 de dezembro de 1998.

$\rightarrow$ Anexo - Alterações no Regulamento de Numeração do Serviço Telefônico Fixo Comutado e no Regulamento de Administração dos Recursos de Numeração.

Resolução da ANATEL $\mathbf{n}^{\circ}$ 614, de 28 de maio de 2013 - Aprova o Regulamento do Serviço de Comunicação Multimídia e altera os Anexos I e III do Regulamento de Cobrança de Preço Público pelo Direito de Exploração de Serviços de Telecomunicações e pelo Direito de Exploração de Satélite.

$\rightarrow$ Anexo - Regulamento do Serviço de Comunicação Multimídia.

$\checkmark$ Fixação de parâmetros de qualidade do Serviço de Comunicação Multimídia e exigência de gratuidade pela conexão à internet por prestadora de SCM que oferte planos para conexão à internet.

\section{Equipamentos de Telecomunicações}

\section{Normatização}

Decreto $n^{\circ}$ 7.903, de 4 de fevereiro de 2013 - Estabelece a aplicação de margem de preferência em licitações realizadas no âmbito da administração pública federal para aquisição de equipamentos de tecnologia da informação e comunicação que menciona.

$\Rightarrow$ Anexo - Percentuais e Descrições de Equipamentos de Tecnologia da Informação e Comunicação sujeitos a margens de preferência.

$\checkmark$ O Decreto 7.903/2013 regulamenta a aplicação de margens de preferência em licitações para aquisição de equipamentos de tecnologia da informação e comunicação, dentre eles, trunking, switches, tranceivers, hubs, modems, gateways, terminais fixos, receptores pessoais de radiomensagens, aparelhos transmissores e terminais portáteis.

Decreto $n^{\circ}$ 8.135, de 4 de novembro de 2013 - Dispõe sobre as comunicações de dados da administração pública federal direta, autárquica e fundacional, e 
sobre a dispensa de licitação nas contratações que possam comprometer a segurança nacional.

$\checkmark$ Requisitos dos programas e equipamentos destinados às comunicações de dados da administração pública federal.

Resolução da ANATEL no 624, de 30 de outubro de 2013 - Aprova o Regulamento para Uso de Femtocélulas em Redes do Serviço Móvel Pessoal, do Serviço Móvel Especializado e do Serviço de Comunicação Multimídia.

$\Rightarrow$ Anexo - Regulamento para Uso de Femtocélulas em Redes do Serviço Móvel Pessoal, do Serviço Móvel Especializado e do Serviço de Comunicação Multimídia.

\section{Antenas}

Normatização

Resolução da ANATEL no 609, de 18 de abril de 2013 - Norma para Certificação e Homologação de Antenas para Uso em Aplicações Ponto-aPonto.

$\Rightarrow$ Anexo - Norma para Certificação e Homologação de Antenas para Uso em Aplicações Ponto-a-Ponto.

Resolução da ANATEL no 610, de 18 de abril de 2013 - Norma para Certificação e Homologação de Antenas para Uso em Aplicações Ponto-Área Bidirecionais.

- Anexo - Norma para Certificação e Homologação de Antenas para Uso em Aplicações Ponto-Área Bidirecionais.

\section{Estações de Telecomunicações}

\section{Normatização}

Resolução da ANATEL no 610, de 18 de abril de 2013 - Norma para Certificação e Homologação de Antenas para Uso em Aplicações Ponto-Área Bidirecionais.

$\rightarrow$ Anexo - Norma para Certificação e Homologação de Antenas para Uso em Aplicações Ponto-Área Bidirecionais.

\section{Terminais}

\section{Normatização}

Lei $\mathbf{n}^{\mathbf{0}} \mathbf{1 2 . 8 3 7}$, de 9 de julho de 2013 - Altera as Leis nos 6.704, de 26 de outubro de 1979, para dispor sobre o Seguro de Crédito à Exportação nas operações relativas a exportações do setor aeronáutico, 11.494, de 20 de junho de 2007, para dispor sobre o cômputo no Fundo de Manutenção e Desenvolvimento da Educação Básica e de Valorização dos Profissionais da Educação - FUNDEB das matrículas em pré-escolas conveniadas com o poder público, 12.715, de 17 de setembro de 2012, para estender a data-limite para 
adesão ao Regime Especial de Tributação do Programa Nacional de Banda Larga para Implantação de Redes de Telecomunicações - REPNBL-Redes, 11.096, de 13 de janeiro de 2005, e 12.513, de 26 de outubro de 2011.

Lei n⿳ 12.865, de 9 de outubro de 2013 - Autoriza o pagamento de subvenção econômica aos produtores da safra 2011/2012 de cana-de-açúcar e de etanol que especifica e o financiamento da renovação e implantação de canaviais com equalização da taxa de juros; dispõe sobre os arranjos de pagamento e as instituições de pagamento integrantes do Sistema de Pagamentos Brasileiro (SPB); autoriza a União a emitir, sob a forma de colocação direta, em favor da Conta de Desenvolvimento Energético (CDE), títulos da dívida pública mobiliária federal; estabelece novas condições para as operações de crédito rural oriundas de, ou contratadas com, recursos do Fundo Constitucional de Financiamento do Nordeste (FNE); altera os prazos previstos nas Leis no 11.941, de 27 de maio de 2009, e no 12.249, de 11 de junho de 2010; autoriza a União a contratar o Banco do Brasil S.A. ou suas subsidiárias para atuar na gestão de recursos, obras e serviços de engenharia relacionados ao desenvolvimento de projetos, modernização, ampliação, construção ou reforma da rede integrada e especializada para atendimento da mulher em situação de violência; disciplina o documento digital no Sistema Financeiro Nacional; disciplina a transferência, no caso de falecimento, do direito de utilização privada de área pública por equipamentos urbanos do tipo quiosque, trailer, feira e banca de venda de jornais e de revistas; altera a incidência da Contribuição para o PIS/Pasep e da Cofins na cadeia de produção e comercialização da soja e de seus subprodutos; altera as Leis nos 12.666, de 14 de junho de 2012, 5.991, de 17 de dezembro de 1973, 11.508, de 20 de julho de 2007, 9.503, de 23 de setembro de 1997, 9.069, de 29 de junho de $1995,10.865$, de 30 de abril de 2004, 12.587, de 3 de janeiro de 2012, 10.826, de 22 de dezembro de 2003, 10.925, de 23 de julho de 2004, 12.350, de 20 de dezembro de 2010, 4.870, de 1o de dezembro de 1965 e 11.196 , de 21 de novembro de 2005, e o Decreto no 70.235, de 6 de março de 1972; revoga dispositivos das Leis nos 10.865, de 30 de abril de 2004, 10.925, de 23 de julho de 2004, 12.546, de 14 de dezembro de 2011, e 4.870, de 1o de dezembro de 1965; e dá outras providências.

Decreto $n^{\circ}$ 7.903, de 4 de fevereiro de 2013 - Estabelece a aplicação de margem de preferência em licitações realizadas no âmbito da administração pública federal para aquisição de equipamentos de tecnologia da informação e comunicação que menciona.

$\rightarrow$ Anexo - Percentuais e Descrições de Equipamentos de Tecnologia da Informação e Comunicação sujeitos a margens de preferência.

$\boldsymbol{\sim}$ O Decreto 7.903/2013 regulamenta a aplicação de margens de preferência em licitações para aquisição de equipamentos de tecnologia da informação e comunicação, dentre eles, trunking, switches, tranceivers, hubs, modems, gateways, terminais fixos, receptores pessoais de radiomensagens, aparelhos transmissores e terminais portáteis.

Resolução da ANATEL no 613, de 9 de maio de 2013 - Altera o art. 48 do Regulamento da Interface Usuário - Rede e de Terminais do Serviço Telefônico Fixo Comutado, aprovado pela Resolução no 473, de 27 de julho de 2007. 
A Res. 613/2013 dispensa terminais de voz que utilizem tecnologia de tela sensível ao toque da exigência de disposição física das teclas para identificação por deficientes visuais.

\section{Certificação / Homologação}

Normatização

Resolução da ANATEL n⿳ 609, de 18 de abril de 2013 - Norma para Certificação e Homologação de Antenas para Uso em Aplicações Ponto-aPonto.

$\rightarrow$ Anexo - Norma para Certificação e Homologação de Antenas para Uso em Aplicações Ponto-a-Ponto.

Resolução da ANATEL no 610, de 18 de abril de 2013 - Norma para Certificação e Homologação de Antenas para Uso em Aplicações Ponto-Área Bidirecionais.

$\rightarrow$ Anexo - Norma para Certificação e Homologação de Antenas para Uso em Aplicações Ponto-Área Bidirecionais.

Resolução da ANATEL no 613, de 9 de maio de 2013 - Altera o art. 48 do Regulamento da Interface Usuário - Rede e de Terminais do Serviço Telefônico Fixo Comutado, aprovado pela Resolução n 473, de 27 de julho de 2007.

$\checkmark$ A Res. 613/2013 dispensa terminais de voz que utilizem tecnologia de tela sensível ao toque da exigência de disposição física das teclas para identificação por deficientes visuais.

Resolução da ANATEL no 626, de 20 de novembro de 2013 - Acrescenta o item 8.1.7 na Norma para Certificação de Produtos para Telecomunicações, aprovada pela Resolução no 323, de 7 de novembro de 2002.

\section{Espectro de Radiofrequência}

\section{Atribuição, Destinação e Distribuição de Radiofrequência}

\section{Normatização}

Portaria MC no 14, de 6 de fevereiro de 2013 - Estabelece diretrizes para a aceleração do acesso ao Sistema Brasileiro de Televisão Digital Terrestre SBTVD-T e para a ampliação da disponibilidade de espectro de radiofrequência para atendimento dos objetivos do Programa Nacional de Banda Larga - PNBL.

Resolução da ANATEL no 625, de 11 de novembro de 2013 - Aprova a Atribuição, a Destinação e o Regulamento sobre Condições de Uso de Radiofrequências na Faixa de $698 \mathrm{MHz}$ a $806 \mathrm{MHz}$.

$\Rightarrow$ Anexo - Regulamento sobre Condições de Uso de Radiofrequências na Faixa de $698 \mathrm{MHz}$ a $806 \mathrm{MHz}$. 
Atos

Ato do Conselho Diretor da ANATEL no 1.724, de 11 de março de 2013 Aprova a Edição 2013 do Plano de Atribuição, Destinação e Distribuição de Faixas de Frequências no Brasil.

$\Rightarrow$ Anexo - Plano de Atribuição, Destinação e Distribuição de Faixas de Frequências no Brasil.

\section{Condições de Uso de Radiofrequência e Canalização (Distribuição de Canais)}

\section{Normatização}

Resolução da ANATEL n' 628, de 6 de dezembro de 2013 - Aprova a alteração do Regulamento sobre Condições de Uso de Radiofrequências, na Faixa de $450 \mathrm{MHz}$ a $470 \mathrm{MHz}$, pelo Serviço Limitado Privado no Âmbito dos Aeroportos Nacionais.

- Anexo - Regulamento sobre Condições de Uso de Radiofrequências, na Faixa de $450 \mathrm{MHz}$ a $470 \mathrm{MHz}$, pelo Serviço Limitado Privado "no Âmbito dos Aeroportos Nacionais.

\section{Órbita e Satélite}

\section{Normatização}

Resolução da ANATEL n 616, de 18 de junho de 2013 - Aprova a alteração do Regulamento de Cobrança de Preço Público pelo Direito de Exploração de Serviços de Telecomunicações e pelo Direito de Exploração de Satélite, aprovado pela Resolução n ${ }^{\mathbf{3}} 386$, de 3 de novembro de 2004 , e alterado pela Resolução no 484, de 5 de novembro de 2007.

$\rightarrow$ Anexo - Alteração do art. 12 do Regulamento de Cobrança de Preço Público pelo Direito de Exploração de Serviços de Telecomunicações e pelo Direito de Exploração de Satélite.

\section{Administração do Setor de Telecomunicações}

\section{Fiscalização das Telecomunicações}

\section{Normatização}

Portaria MC no 112, de 22 de abril de 2013 - Aprova o Regulamento de Sanções Administrativas aplicáveis a entidades prestadoras dos serviços de radiodifusão, seus ancilares e auxiliares.

$\Rightarrow$ Anexo 1 - Fator Relativo ao Tipo de Serviço/Classe da Emissora (K1).

$\Rightarrow$ Anexo 2 - Fator Relativo ao Porte do Município (K2).

$\rightarrow$ Anexo 3 - Fator Relativo à Gravidade da Infração (K3). 
Portaria MC n⿳ 197, de $\mathbf{1}^{\circ}$ julho de 2013 - Estabelece data limite para a apresentação de pedido de renovação de outorga de serviço de radiodifusão comunitária e altera a Norma $n^{\circ} 1 / 2011$, aprovada pela Portaria ${ }^{\circ} 462$, de 14 de outubro de 2011.

- Anexo 1 - Alterações ao Anexo II à Norma nº 01/2011, aprovada pela Portaria $n^{\circ} 462$, de 2011.

$\rightarrow$ Anexo 2 - Alterações ao Anexo XII à Norma nº1/2011, aprovada pela Portaria $\mathrm{n}^{\mathrm{o}}$ 462, de 2011.

Resolução da ANATEL n 608, de 5 de abril de 2013 - Aprova alteração nos Apêndices C e D do Anexo I do Regulamento de Separação e Alocação Contas - RSAC, aprovado pela Resolução no 396, de 31 de março de 2005, alterado pela Resolução $n^{\circ} 419$, de 24 de novembro de 2005, pela Resolução $n^{\circ} 464$, de 27 de abril de 2007, pela Resolução $n^{\circ} 480$, de 14 de agosto de 2007, pela Resolução $n^{\circ} 483$, de 24 de outubro de 2007, e pela Resolução ${ }^{\circ} 503$, de 25 de abril de 2008, e define novo prazo para entrega dos dados dos exercícios de 2011 e 2012 e do primeiro trimestre de 2013.

$\rightarrow$ Anexo - Apêndice C (Plano Geral para Separação e Alocação de Contas).

Resolução da ANATEL $\mathbf{n}^{\circ}$ 619, de 8 de agosto de 2013 - Alterações dos Anexos I e II do Regulamento de Separação e Alocação de Contas - RSAC, aprovado pela Resolução $\mathrm{n}^{\circ} 396$, de 31 de março de 2005, alterado pela Resolução $n^{\circ} 419$, de 24 de novembro de 2005, pela Resolução n ${ }^{\circ} 464$, de 27 de abril de 2007, pela Resolução $n^{\circ} 480$, de 14 de agosto de 2007, pela Resolução $\mathrm{n}^{\circ} 483$, de 24 de outubro de 2007, pela Resolução n ${ }^{\circ} 503$, de 25 de abril de 2008, e pela Resolução n ${ }^{\circ} 608$, de 5 de abril de 2013.

$\rightarrow$ Anexo - Alterações dos Anexos I e II do Regulamento de Separação e Alocação de Contas (RSAC).

Resolução da ANATEL $\mathbf{n}^{\circ}$ 624, de 30 de outubro de 2013 - Aprova o Regulamento para Uso de Femtocélulas em Redes do Serviço Móvel Pessoal, do Serviço Móvel Especializado e do Serviço de Comunicação Multimídia.

- Anexo - Regulamento para Uso de Femtocélulas em Redes do Serviço Móvel Pessoal, do Serviço Móvel Especializado e do Serviço de Comunicação Multimídia.

Resolução da ANATEL no 629, de 16 de dezembro de 2013 - Aprova o Regulamento de celebração e acompanhamento de Termo de Compromisso de Ajustamento de Conduta (TAC).

$\rightarrow$ Anexo - Regulamento de celebração e acompanhamento de Termo de Compromisso de Ajustamento de Conduta.

Atos

Th Portaria ANATEL $n^{\circ}$ 448, de 4 de junho de 2013 - Atribui a competência decorrente de Acordo de Cooperação Técnica celebrado entre o Ministério das Comunicações e a Agência Nacional de Telecomunicações (ANATEL).

$\checkmark$ A Portaria ANATEL n ${ }^{\circ}$ 448/2013 atribui competência delegada do Ministério das Comunicações para a ANATEL e convalida prática dos atos necessários à 
análise de processos técnicos de engenharia nos procedimentos de pós-outorga dos serviços de radiodifusão, seus ancilares e auxiliares.

Súmula da ANATEL $\mathbf{n}^{\circ}$ 14, de 28 de junho de 2013 - O Pedido de Reconsideração em face de decisão proferida pelo Conselho Diretor da Anatel, quando da deliberação de Recurso Administrativo, apenas será cabível caso a referida deliberação tenha ocorrido até o dia $1^{\circ}$ de maio de 2013.

\section{Tributação no Setor de Telecomunicações}

\section{Normatização}

Decreto $\mathbf{n}^{\mathbf{0}}$ 7.981, de 8 de abril de 2013 - Altera o Decreto $\mathrm{n}^{\circ} 5.602$, de 6 de dezembro de 2005, que regulamenta o Programa de Inclusão Digital instituído pela Lei n ${ }^{\circ} 11.196$, de 21 de novembro de 2005.

Portaria MC n 87, de 10 de abril de 2013 - Estabelece os requisitos técnicos mínimos dos telefones portáteis que possibilitam o acesso à internet em alta velocidade do tipo smartphone, beneficiados pela desoneração fiscal instituída pela Lei n n $^{\circ} 11.196$, de 21 de novembro de 2005 e regulamentada pelo Decreto $\mathrm{n}^{\circ} 5.602$, de 6 de dezembro de 2005 .

\section{Prestação de Serviços}

\section{Licitação}

\section{Normatização}

Decreto $n^{\circ}$ 8.135, de 4 de novembro de 2013 - Dispõe sobre as comunicações de dados da administração pública federal direta, autárquica e fundacional, e sobre a dispensa de licitação nas contratações que possam comprometer a segurança nacional.

$\checkmark$ Dispensa de licitação nas contratações de comunicação de dados que possam comprometer a segurança nacional.

\section{Espécies de Outorga}

\section{Concessão (regras aplicáveis)}

\section{Normatização}

Portaria MC no 112, de 22 de abril de 2013 - Aprova o Regulamento de Sanções Administrativas aplicáveis a entidades prestadoras dos serviços de radiodifusão, seus ancilares e auxiliares.

$\rightarrow$ Anexo 1 - Fator Relativo ao Tipo de Serviço/Classe da Emissora (K1).

$\rightarrow$ Anexo 2 - Fator Relativo ao Porte do Município (K2).

$\rightarrow$ Anexo 3 - Fator Relativo à Gravidade da Infração (K3).

Resolução da ANATEL no 611, de 25 de abril de 2013 - Aprova alteração do Anexo I do Regulamento de Tarifação do Serviço Telefônico Fixo Comutado 
Destinado ao Uso do Público em Geral - STFC Prestado no Regime Público, aprovado pela Resolução no 424, de 6 de dezembro de 2005, para adequação das áreas de tarifação à nova configuração de áreas locais disposta na Resolução $\mathrm{n}^{\mathrm{o}} 560$, de 21 de janeiro de 2011.

$\rightarrow$ Anexo - Alteração de áreas de tarifação do Regulamento de Tarifação do Serviço Telefônico Fixo Comutado Destinado ao Uso do Público em Geral - STFC Prestado no Regime Público, aprovado pela Resolução nº 424, de 6 de dezembro de 2005.

Resolução da ANATEL n 616, de 18 de junho de 2013 - Aprova a alteração do Regulamento de Cobrança de Preço Público pelo Direito de Exploração de Serviços de Telecomunicações e pelo Direito de Exploração de Satélite, aprovado pela Resolução n $^{\circ} 386$, de 3 de novembro de 2004, e alterado pela Resolução $n^{\circ} 484$, de 5 de novembro de 2007.

$\rightarrow$ Anexo - Alteração do art. 12 do Regulamento de Cobrança de Preço Público pelo Direito de Exploração de Serviços de Telecomunicações e pelo Direito de Exploração de Satélite.

Resolução da ANATEL no 623, de 18 de outubro de 2013 - Aprova o Regulamento de Conselho de Usuários.

$\Rightarrow$ Anexo - Regulamento de Conselho de Usuários.

\section{Permissão (regras aplicáveis)}

\section{Normatização}

Portaria MC no 112, de 22 de abril de 2013 - Aprova o Regulamento de Sanções Administrativas aplicáveis a entidades prestadoras dos serviços de radiodifusão, seus ancilares e auxiliares.

$\Rightarrow$ Anexo 1 - Fator Relativo ao Tipo de Serviço/Classe da Emissora (K1).

$\rightarrow$ Anexo 2 - Fator Relativo ao Porte do Município (K2).

$\Rightarrow$ Anexo 3 - Fator Relativo à Gravidade da Infração (K3).

\section{Autorização (regras aplicáveis)}

\section{Normatização}

Portaria MC no 112, de 22 de abril de 2013 - Aprova o Regulamento de Sanções Administrativas aplicáveis a entidades prestadoras dos serviços de radiodifusão, seus ancilares e auxiliares.

$\Rightarrow$ Anexo 1 - Fator Relativo ao Tipo de Serviço/Classe da Emissora (K1).

$\rightarrow$ Anexo 2 - Fator Relativo ao Porte do Município (K2).

$\rightarrow$ Anexo 3 - Fator Relativo à Gravidade da Infração (K3).

Resolução da ANATEL $\mathbf{n}^{\circ}$ 614, de 28 de maio de 2013 - Aprova o Regulamento do Serviço de Comunicação Multimídia e altera os Anexos I e III do Regulamento de Cobrança de Preço Público pelo Direito de Exploração de Serviços de Telecomunicações e pelo Direito de Exploração de Satélite. 
Anexo - Regulamento do Serviço de Comunicação Multimídia.

$\checkmark$ Fixação de parâmetros de qualidade do Serviço de Comunicação Multimídia e exigência de gratuidade pela conexão à internet por prestadora de SCM que oferte planos para conexão à internet.

Resolução da ANATEL n 616, de 18 de junho de 2013 - Aprova a alteração do Regulamento de Cobrança de Preço Público pelo Direito de Exploração de Serviços de Telecomunicações e pelo Direito de Exploração de Satélite, aprovado pela Resolução no 386 , de 3 de novembro de 2004 , e alterado pela Resolução no 484, de 5 de novembro de 2007.

$\rightarrow$ Anexo - Alteração do art. 12 do Regulamento de Cobrança de Preço Público pelo Direito de Exploração de Serviços de Telecomunicações e pelo Direito de Exploração de Satélite.

Resolução da ANATEL no 623, de 18 de outubro de 2013 - Aprova o Regulamento de Conselho de Usuários.

$\rightarrow$ Anexo - Regulamento de Conselho de Usuários.

$1 /$ Atos

Tr Portaria ANATEL/SOR no 639, de 25 de julho de 2013 - Estabelece o Procedimento Simplificado de Outorga - PSO, com a finalidade de outorga simultânea para explorar o Serviço de Comunicação Multimídia, o Serviço Telefônico Fixo Comutado Destinado ao Uso do Público em Geral e/ou o Serviço de Acesso Condicionado.

\section{Preço Público e Preço Privado}

\section{Normatização}

Resolução da ANATEL $n^{\circ}$ 606, de 4 de fevereiro de 2013 - Aprova alteração do Anexo I do Regulamento de Tarifação do Serviço Telefônico Fixo Comutado Destinado ao Uso do Público em Geral - STFC Prestado no Regime Público, aprovado pela Resolução no 424, de 6 de dezembro de 2005, e do Plano Geral de Códigos Nacionais - PGCN, Anexo II à Resolução nº 263, de 08 de junho de 2001, para mudar o município de Santana do Paraíso, no estado de Minas Gerais, da Área de Tarifação 333 (Caratinga) para a Área de Tarifação 316 (Coronel Fabriciano), e do Código Nacional 33 para o Código Nacional 31.

$\rightarrow$ Anexo 1 - Áreas de Tarifação do STFC.

$\rightarrow$ Anexo 2 - Alteração do Plano Geral de Códigos Nacionais.

Resolução da ANATEL n 616, de 18 de junho de 2013 - Aprova a alteração do Regulamento de Cobrança de Preço Público pelo Direito de Exploração de Serviços de Telecomunicações e pelo Direito de Exploração de Satélite, aprovado pela Resolução no 386 , de 3 de novembro de 2004 , e alterado pela Resolução $n^{\circ} 484$, de 5 de novembro de 2007.

- Anexo - Alteração do art. 12 do Regulamento de Cobrança de Preço Público pelo Direito de Exploração de Serviços de Telecomunicações e pelo Direito de Exploração de Satélite. 
Resolução da ANATEL no 621, de 14 de agosto de 2013 - Aprova alteração do Anexo I do Regulamento de Tarifação do Serviço Telefônico Fixo Comutado Destinado ao Uso do Público em Geral - STFC Prestado no Regime Público, aprovado pela Resolução no 424, de 6 de dezembro de 2005, e do Plano Geral de Códigos Nacionais - PGCN, anexo ao Regulamento de Numeração do STFC, aprovado pela Resolução $n^{\circ} 86$, de 30 de dezembro de 1998, alterado pela Resolução $n^{\circ} 263$, de 8 de junho de 2001, para mudar o município de Sabáudia, no estado do Paraná, da Área de Tarifação 442 (Maringá) para a Área de Tarifação 432 (Londrina) e do Código Nacional 44 para o Código Nacional 43.

$\rightarrow$ Anexo 1 - Alterações ao Regulamento de Tarifação do Serviço Telefônico Fixo Comutado.

$\rightarrow$ Anexo 2 - Alterações ao Plano Geral de Códigos Nacionais, anexo ao Regulamento de Numeração do STFC.

\section{Planos de Serviços}

\section{Normatização}

Resolução da ANATEL $\mathbf{n}^{\circ}$ 606, de 4 de fevereiro de 2013 - Aprova alteração do Anexo I do Regulamento de Tarifação do Serviço Telefônico Fixo Comutado Destinado ao Uso do Público em Geral - STFC Prestado no Regime Público, aprovado pela Resolução no 424, de 6 de dezembro de 2005, e do Plano Geral de Códigos Nacionais - PGCN, Anexo II à Resolução no 263, de 08 de junho de 2001, para mudar o município de Santana do Paraíso, no estado de Minas Gerais, da Área de Tarifação 333 (Caratinga) para a Área de Tarifação 316 (Coronel Fabriciano), e do Código Nacional 33 para o Código Nacional 31.

$\rightarrow$ Anexo 1 - Áreas de Tarifação do STFC.

$\rightarrow$ Anexo 2 - Alteração do Plano Geral de Códigos Nacionais.

Resolução da ANATEL n⿳ 621, de 14 de agosto de 2013 - Aprova alteração do Anexo I do Regulamento de Tarifação do Serviço Telefônico Fixo Comutado Destinado ao Uso do Público em Geral - STFC Prestado no Regime Público, aprovado pela Resolução $n^{\circ} 424$, de 6 de dezembro de 2005, e do Plano Geral de Códigos Nacionais - PGCN, anexo ao Regulamento de Numeração do STFC, aprovado pela Resolução $n^{\circ} 86$, de 30 de dezembro de 1998, alterado pela Resolução $n^{\circ} 263$, de 8 de junho de 2001, para mudar o município de Sabáudia, no estado do Paraná, da Área de Tarifação 442 (Maringá) para a Área de Tarifação 432 (Londrina) e do Código Nacional 44 para o Código Nacional 43.

$\rightarrow$ Anexo 1 - Alterações ao Regulamento de Tarifação do Serviço Telefônico Fixo Comutado.

$\rightarrow$ Anexo 2 - Alterações ao Plano Geral de Códigos Nacionais, anexo ao Regulamento de Numeração do STFC. 


\section{Políticas de Telecomunicações}

\section{Política Tarifária}

\section{Normatização}

Resolução da ANATEL n 606, de 4 de fevereiro de 2013 - Aprova alteração do Anexo I do Regulamento de Tarifação do Serviço Telefônico Fixo Comutado Destinado ao Uso do Público em Geral - STFC Prestado no Regime Público, aprovado pela Resolução n ${ }^{\circ} 424$, de 6 de dezembro de 2005, e do Plano Geral de Códigos Nacionais - PGCN, Anexo II à Resolução no 263, de 08 de junho de 2001, para mudar o município de Santana do Paraíso, no estado de Minas Gerais, da Área de Tarifação 333 (Caratinga) para a Área de Tarifação 316 (Coronel Fabriciano), e do Código Nacional 33 para o Código Nacional 31.

$\rightarrow$ Anexo 1 - Áreas de Tarifação do STFC.

$\rightarrow$ Anexo 2 - Alteração do Plano Geral de Códigos Nacionais.

Resolução da ANATEL no 611, de 25 de abril de 2013 - Aprova alteração do Anexo I do Regulamento de Tarifação do Serviço Telefônico Fixo Comutado Destinado ao Uso do Público em Geral - STFC Prestado no Regime Público, aprovado pela Resolução $n^{\circ} 424$, de 6 de dezembro de 2005, para adequação das áreas de tarifação à nova configuração de áreas locais disposta na Resolução $\mathrm{n}^{\circ} 560$, de 21 de janeiro de 2011.

$\rightarrow$ Anexo - Alteração de áreas de tarifação do Regulamento de Tarifação do Serviço Telefônico Fixo Comutado Destinado ao Uso do Público em Geral - STFC Prestado no Regime Público, aprovado pela Resolução nº 424, de 6 de dezembro de 2005.

Resolução da ANATEL no 621, de 14 de agosto de 2013 - Aprova alteração do Anexo I do Regulamento de Tarifação do Serviço Telefônico Fixo Comutado Destinado ao Uso do Público em Geral - STFC Prestado no Regime Público, aprovado pela Resolução n ${ }^{\circ} 424$, de 6 de dezembro de 2005, e do Plano Geral de Códigos Nacionais - PGCN, anexo ao Regulamento de Numeração do STFC, aprovado pela Resolução $\mathrm{n}^{\circ} 86$, de 30 de dezembro de 1998, alterado pela Resolução no 263, de 8 de junho de 2001, para mudar o município de Sabáudia, no estado do Paraná, da Área de Tarifação 442 (Maringá) para a Área de Tarifação 432 (Londrina) e do Código Nacional 44 para o Código Nacional 43.

$\rightarrow$ Anexo 1 - Alterações ao Regulamento de Tarifação do Serviço Telefônico Fixo Comutado.

$\rightarrow$ Anexo 2 - Alterações ao Plano Geral de Códigos Nacionais, anexo ao Regulamento de Numeração do STFC. 


\section{Política Industrial}

Normatização

Decreto $n^{0}$ 7.903, de 4 de fevereiro de 2013 - Estabelece a aplicação de margem de preferência em licitações realizadas no âmbito da administração pública federal para aquisição de equipamentos de tecnologia da informação e comunicação que menciona.

$\rightarrow$ Anexo - Percentuais e Descrições de Equipamentos de Tecnologia da Informação e Comunicação sujeitos a margens de preferência.

Decreto $\mathrm{n}^{\mathbf{0}}$ 7.913, de 7 de fevereiro de 2013 - Altera o Anexo III ao Decreto $\mathrm{n}^{\circ}$ 6.233, de 11 de outubro de 2007, que estabelece critérios para efeito de habilitação ao Programa de Apoio ao Desenvolvimento Tecnológico da Indústria de Semicondutores - PADIS, que concede isenção do imposto de renda e reduz a zero as alíquotas da Contribuição para o PIS/PASEP, da COFINS e do IPI.

$\rightarrow$ Anexo - Alterações do Anexo III do Decreto 6.233, de 11 de outubro de 2007.

Decreto $\mathbf{n}^{\mathbf{0}} \mathbf{7 . 9 8 1}$, de 8 de abril de 2013 - Altera o Decreto $\mathrm{n}^{\circ} 5.602$, de 6 de dezembro de 2005, que regulamenta o Programa de Inclusão Digital instituído pela Lei ${ }^{\circ} 11.196$, de 21 de novembro de 2005 .

Portaria MC n⿳ 87, de 10 de abril de 2013 - Estabelece os requisitos técnicos mínimos dos telefones portáteis que possibilitam o acesso à internet em alta velocidade do tipo smartphone, beneficiados pela desoneração fiscal instituída pela Lei $\mathrm{n}^{\circ} 11.196$, de 21 de novembro de 2005 e regulamentada pelo Decreto no 5.602 , de 6 de dezembro de 2005 .

\section{Concorrência no Setor de Telecomunicações}

- Concorrência no Setor de Telecomunicações

O Serviço de Comunicação Multimídia apresenta-se como serviço convergente com pretensão de introduzir utilidades concorrentes às fornecidas por serviços tradicionais do setor.

\section{Normatização}

Decreto $\mathbf{n}^{\mathbf{0}} \mathbf{8 . 1 7 4}$, de 26 de dezembro de 2013 - Altera os Anexos I e II ao Decreto $n^{\circ} 7.867$, de 19 de dezembro de 2012, relativos ao Programa de Dispêndios Globais - PDG das empresas estatais federais para 2013.

Portaria MC no 275, de 17 de setembro de 2013 - Estabelece política para a disponibilização de faixas de radiofrequência para prestação de acesso à Internet em banda larga por prestadores de serviços de telecomunicações de pequeno porte e por novos competidores. 


\section{Universalização e Massificação}

\section{Normatização}

Portaria MC no 275, de 17 de setembro de 2013 - Estabelece política para a disponibilização de faixas de radiofrequência para prestação de acesso à Internet em banda larga por prestadores de serviços de telecomunicações de pequeno porte e por novos competidores.

\section{Acesso às Telecomunicações}

\section{Normatização}

Portaria MC $\mathbf{n}^{\circ} \mathbf{1 3}$, de $\mathbf{1}^{\circ}$ de fevereiro de 2013 - Institui o processo de habilitação e seleção de propostas para o Projeto das Cidades Digitais para o exercício de 2013.

- Anexo - Tabela de Prazos.

Portaria MC n $\mathbf{0} 305$, de 24 de outubro de 2013 - Altera a minuta de Acordo de Cooperação Técnica da Portaria $\mathrm{n}^{\circ} 13$, de $1^{\circ}$ de fevereiro de 2013, que instituiu o processo de habilitação e seleção de propostas para o Projeto das Cidades Digitais.

$\rightarrow$ Anexo - Acordo de Cooperação Técnica.

\section{Portador de Deficiência}

\section{Normatização}

Resolução da ANATEL no 613, de 9 de maio de 2013 - Altera o art. 48 do Regulamento da Interface Usuário - Rede e de Terminais do Serviço Telefônico Fixo Comutado, aprovado pela Resolução no 473, de 27 de julho de 2007.

$\checkmark$ A Res. 613/2013 dispensa terminais de voz que utilizem tecnologia de tela sensível ao toque da exigência de disposição física das teclas para identificação por deficientes visuais.

\section{Educação e Pesquisa}

\section{Normatização}

Lei $\mathbf{n}^{\mathbf{0}} \mathbf{1 2 . 8 3 7}$, de 9 de julho de 2013 - Altera as Leis nos 6.704, de 26 de outubro de 1979, para dispor sobre o Seguro de Crédito à Exportação nas operações relativas a exportações do setor aeronáutico, 11.494, de 20 de junho de 2007, para dispor sobre o cômputo no Fundo de Manutenção e Desenvolvimento da Educação Básica e de Valorização dos Profissionais da Educação - FUNDEB das matrículas em pré-escolas conveniadas com o poder público, 12.715, de 17 de setembro de 2012, para estender a data-limite para adesão ao Regime Especial de Tributação do Programa Nacional de Banda Larga para Implantação de Redes de Telecomunicações - REPNBL-Redes, 11.096, de 13 de janeiro de 2005, e 12.513, de 26 de outubro de 2011. 
Portaria MC $\mathbf{n}^{\mathbf{0}} \mathbf{1 3}$, de $1^{\circ}$ de fevereiro de 2013 - Institui o processo de habilitação e seleção de propostas para o Projeto das Cidades Digitais para o exercício de 2013.

$\Rightarrow$ Anexo - Tabela de Prazos.

Portaria MC no 305, de 24 de outubro de 2013 - Altera a minuta de Acordo de Cooperação Técnica da Portaria $n^{\circ} 13$, de $1^{\circ}$ de fevereiro de 2013, que instituiu o processo de habilitação e seleção de propostas para o Projeto das Cidades Digitais.

$\Rightarrow$ Anexo - Acordo de Cooperação Técnica.

\section{Financiamento da Universalização}

\section{Normatização}

Decreto no 7.981, de 8 de abril de 2013 - Altera o Decreto $n^{\circ} 5.602$, de 6 de dezembro de 2005, que regulamenta o Programa de Inclusão Digital instituído pela Lei no 11.196 , de 21 de novembro de 2005.

Portaria MC n⿳ 87, de 10 de abril de 2013 - Estabelece os requisitos técnicos mínimos dos telefones portáteis que possibilitam o acesso à internet em alta velocidade do tipo smartphone, beneficiados pela desoneração fiscal instituída pela Lei $\mathrm{n}^{\circ} 11.196$, de 21 de novembro de 2005 e regulamentada pelo Decreto $\mathrm{n}^{\circ} 5.602$, de 6 de dezembro de 2005 .

\section{Metas de Universalização}

\section{Normatização}

Resolução da ANATEL $\mathbf{n}^{\circ}$ 622, de 23 de agosto de 2013 - Aprova o Regulamento sobre a Prestação do Serviço Telefônico Fixo Comutado Destinado ao Público em Geral (STFC) Fora da Área de Tarifa Básica (ATB).

$\rightarrow$ Anexo - Regulamento sobre a Prestação do Serviço Telefônico Fixo Comutado Destinado ao Público em Geral (STFC) Fora da Área de Tarifa Básica (ATB).

\section{Pesquisa \& Desenvolvimento}

\section{Normatização}

Decreto $n^{0}$ 7.903, de 4 de fevereiro de 2013 - Estabelece a aplicação de margem de preferência em licitações realizadas no âmbito da administração pública federal para aquisição de equipamentos de tecnologia da informação e comunicação que menciona.

$\rightarrow$ Anexo - Percentuais e Descrições de Equipamentos de Tecnologia da Informação e Comunicação sujeitos a margens de preferência.

$\checkmark$ O Decreto 7.903/2013 regulamenta a aplicação de margens de preferência em licitações para aquisição de equipamentos de tecnologia da informação e comunicação, com fundamento, dentre outros, na previsão do art. $3^{\circ}, \S 2^{\circ}$, IV 
da Lei 8.666/1993, de preferência a bens e serviços produzidos ou prestados por empresas que invistam em pesquisa e desenvolvimento de tecnologia no Brasil.

Decreto $\mathbf{n}^{\mathbf{0}}$ 7.913, de 7 de fevereiro de 2013 - Altera o Anexo III ao Decreto $n^{\circ} 6.233$, de 11 de outubro de 2007, que estabelece critérios para efeito de habilitação ao Programa de Apoio ao Desenvolvimento Tecnológico da Indústria de Semicondutores - PADIS, que concede isenção do imposto de renda e reduz a zero as alíquotas da Contribuição para o PIS/PASEP, da COFINS e do IPI.

$\rightarrow$ Anexo - Alterações do Anexo III do Decreto 6.233, de 11 de outubro de 2007.

Portaria MC $\mathbf{n}^{\mathbf{0}}$ 13, de $1^{\circ}$ de fevereiro de 2013 - Institui o processo de habilitação e seleção de propostas para o Projeto das Cidades Digitais para o exercício de 2013.

$\rightarrow$ Anexo - Tabela de Prazos.

Portaria MC no 305, de 24 de outubro de 2013 - Altera a minuta de Acordo de Cooperação Técnica da Portaria $n^{\circ} 13$, de $1^{\circ}$ de fevereiro de 2013 , que instituiu o processo de habilitação e seleção de propostas para o Projeto das Cidades Digitais.

$\rightarrow$ Anexo - Acordo de Cooperação Técnica.

\section{Qualidade do Serviço}

\section{Normatização}

Resolução da ANATEL $\mathbf{n}^{\circ}$ 614, de 28 de maio de 2013 - Aprova o Regulamento do Serviço de Comunicação Multimídia e altera os Anexos I e III do Regulamento de Cobrança de Preço Público pelo Direito de Exploração de Serviços de Telecomunicações e pelo Direito de Exploração de Satélite.

$\rightarrow$ Anexo - Regulamento do Serviço de Comunicação Multimídia.

$\checkmark$ Fixação de parâmetros de qualidade do Serviço de Comunicação Multimídia e exigência de gratuidade pela conexão à internet por prestadora de SCM que oferte planos para conexão à internet.

Resolução da ANATEL no 615, de 7 de junho de 2013 - Aprova alteração no Regulamento do Serviço Telefônico Fixo Comutado - STFC, aprovado pela Resolução $n^{\circ} 426$, de 9 de dezembro de 2005, alterado pela Resolução no 432 , de 23 de fevereiro de 2006, e pela Resolução n ${ }^{\circ}$ 567, de 24 de maio de 2011.

$\rightarrow$ Anexo - Alterações do Regulamento do Serviço Telefônico Fixo Comutado (STFC).

$\checkmark$ A Resolução ANATEL n ${ }^{\circ}$ 615/2013 altera o Regulamento do STFC para disciplinar com maior detalhamento os direitos dos usuários/consumidores do STFC, em especial no tocante à portabilidade numérica, ao atendimento pessoal às reclamações, ao acesso gratuito à central de informações e de atendimento ao usuário, de terceirização do serviço de atendimento pessoal aos usuários, de prazo máximo para atendimento pessoal, dentre outras alterações. 
Resolução da ANATEL no 629, de 16 de dezembro de 2013 - Aprova o Regulamento de celebração e acompanhamento de Termo de Compromisso de Ajustamento de Conduta (TAC).

$\rightarrow$ Anexo - Regulamento de celebração e acompanhamento de Termo de Compromisso de Ajustamento de Conduta.

\section{Controle Social, Hierárquico e Interorgânico}

Normatização

Resolução no 4 do Senado Federal, de 2013 - Altera o Regimento Interno do Senado Federal para dispor sobre o comparecimento de Ministros de Estado e dirigentes das agências reguladoras ao Senado Federal, em periodicidade anual.

Atos

حT Relatório da Ouvidoria da ANATEL 2013

Súmula da ANATEL $\mathbf{n}^{\circ}$ 14, de 28 de junho de 2013 - O Pedido de Reconsideração em face de decisão proferida pelo Conselho Diretor da Anatel, quando da deliberação de Recurso Administrativo, apenas será cabível caso a referida deliberação tenha ocorrido até o dia $1^{\circ}$ de maio de 2013.

\section{Sigilo em Telecomunicações}

Tema Conexo: Fundamentos : Conceitos Fundamentais : Direito à Privacidade.

\section{Normatização}

Decreto $n^{\circ}$ 8.135, de 4 de novembro de 2013 - Dispõe sobre as comunicações de dados da administração pública federal direta, autárquica e fundacional, e sobre a dispensa de licitação nas contratações que possam comprometer a segurança nacional.

$\checkmark$ Garantia de inviolabilidade das comunicações de dados da administração pública federal.

\section{Classificações de Serviços no Setor de Telecomunicações}

\section{Quanto ao Interesse}

\section{Serviço de Interesse Restrito}

Normatização

Resolução da ANATEL $n^{\circ}$ 617, de 19 de junho de 2013 - Aprova o Regulamento do Serviço Limitado Privado.

$\Rightarrow$ Anexo - Regulamento do Serviço Limitado Privado. 
A Resolução n ${ }^{\circ}$ 617/2013 submeteu ao regime regulatório do Regulamento do Serviço Limitado Privado o Serviço Limitado Especializado de interesse restrito em todas as suas submodalidades.

\section{Quanto ao Gênero}

\section{Serviço Limitado}

\section{Serviço Limitado Privado}

\section{Normatização}

Resolução da ANATEL $n^{\circ}$ 617, de 19 de junho de 2013 - Aprova o Regulamento do Serviço Limitado Privado.

$\Rightarrow$ Anexo - Regulamento do Serviço Limitado Privado.

$\checkmark$ Inaplicabilidade do Regulamento de Serviço Limitado ao Serviço Limitado Privado - SLP.

Resolução da ANATEL $\mathbf{n}^{\circ}$ 628, de 6 de dezembro de 2013 - Aprova a alteração do Regulamento sobre Condições de Uso de Radiofrequências, na Faixa de $450 \mathrm{MHz}$ a $470 \mathrm{MHz}$, pelo Serviço Limitado Privado no Âmbito dos Aeroportos Nacionais.

$\rightarrow$ Anexo - Regulamento sobre Condições de Uso de Radiofrequências, na Faixa de $450 \mathrm{MHz}$ a $470 \mathrm{MHz}$, pelo Serviço Limitado Privado "no Âmbito dos Aeroportos Nacionais.

\section{Serviço Limitado Especializado}

\section{Normatização}

Resolução da ANATEL no 617, de 19 de junho de 2013 - Aprova o Regulamento do Serviço Limitado Privado.

$\rightarrow$ Anexo - Regulamento do Serviço Limitado Privado.

Adaptação do Serviço Limitado Especializado ao regime regulatório do Regulamento do Serviço Limitado Privado.

\section{Atos}

Ato do Conselho Diretor da ANATEL no 3.833, de 20 de junho de 2013 Aprova a classificação dos serviços de telecomunicações quanto aos interesses a que atendem.

$\Rightarrow$ Anexo - Classificação dos Serviços de Telecomunicações Quanto aos Interesses que Atendem.

Sua classificação como serviço de interesse coletivo. 


\section{Serviço Especial}

Normatização

Resolução da ANATEL $\mathbf{n}^{\circ}$ 617, de 19 de junho de 2013 - Aprova o Regulamento do Serviço Limitado Privado.

- Anexo - Regulamento do Serviço Limitado Privado.

$\checkmark$ A Resolução nº 617/2013 agrupou vários serviços classificados como de interesse restrito sob a terminologia de Serviço Limitado Privado - SLP.

\section{Serviço de Valor Adicionado}

\section{Normatização}

Lei $\mathbf{n}^{0} \mathbf{1 2 . 8 6 5}$, de 9 de outubro de 2013 - Autoriza o pagamento de subvenção econômica aos produtores da safra 2011/2012 de cana-de-açúcar e de etanol que especifica e o financiamento da renovação e implantação de canaviais com equalização da taxa de juros; dispõe sobre os arranjos de pagamento e as instituições de pagamento integrantes do Sistema de Pagamentos Brasileiro (SPB); autoriza a União a emitir, sob a forma de colocação direta, em favor da Conta de Desenvolvimento Energético (CDE), títulos da dívida pública mobiliária federal; estabelece novas condições para as operações de crédito rural oriundas de, ou contratadas com, recursos do Fundo Constitucional de Financiamento do Nordeste (FNE); altera os prazos previstos nas Leis no 11.941, de 27 de maio de 2009, e no 12.249, de 11 de junho de 2010; autoriza a União a contratar o Banco do Brasil S.A. ou suas subsidiárias para atuar na gestão de recursos, obras e serviços de engenharia relacionados ao desenvolvimento de projetos, modernização, ampliação, construção ou reforma da rede integrada e especializada para atendimento da mulher em situação de violência; disciplina o documento digital no Sistema Financeiro Nacional; disciplina a transferência, no caso de falecimento, do direito de utilização privada de área pública por equipamentos urbanos do tipo quiosque, trailer, feira e banca de venda de jornais e de revistas; altera a incidência da Contribuição para o PIS/Pasep e da Cofins na cadeia de produção e comercialização da soja e de seus subprodutos; altera as Leis nos 12.666, de 14 de junho de 2012, 5.991, de 17 de dezembro de 1973, 11.508, de 20 de julho de 2007, 9.503, de 23 de setembro de 1997, 9.069, de 29 de junho de 1995, 10.865, de 30 de abril de 2004, 12.587, de 3 de janeiro de 2012, 10.826, de 22 de dezembro de 2003, 10.925, de 23 de julho de 2004, 12.350, de 20 de dezembro de 2010, 4.870, de 1o de dezembro de 1965 e 11.196, de 21 de novembro de 2005, e o Decreto no 70.235, de 6 de março de 1972; revoga dispositivos das Leis nos 10.865 , de 30 de abril de 2004, 10.925, de 23 de julho de 2004, 12.546, de 14 de dezembro de 2011, e 4.870, de 1 o de dezembro de 1965; e dá outras providências.

\section{Serviço de Radiodifusão}

Tema Conexo: Serviços no Setor de Telecomunicações : Radiodifusão. 


\section{Serviços no Setor de Telecomunicações}

\section{Internet}

\section{Normatização}

Lei no 12.837, de 9 de julho de 2013 - Altera as Leis nos 6.704, de 26 de outubro de 1979, para dispor sobre o Seguro de Crédito à Exportação nas operações relativas a exportações do setor aeronáutico, 11.494, de 20 de junho de 2007, para dispor sobre o cômputo no Fundo de Manutenção e Desenvolvimento da Educação Básica e de Valorização dos Profissionais da Educação - FUNDEB das matrículas em pré-escolas conveniadas com o poder público, 12.715, de 17 de setembro de 2012, para estender a data-limite para adesão ao Regime Especial de Tributação do Programa Nacional de Banda Larga para Implantação de Redes de Telecomunicações - REPNBL-Redes, 11.096, de 13 de janeiro de 2005, e 12.513, de 26 de outubro de 2011.

Decreto no 7.921, de 15 de fevereiro de 2013 - Regulamenta a aplicação do Regime Especial de Tributação do Programa Nacional de Banda Larga para Implantação de Redes de Telecomunicações - REPNBL-Redes, de que trata a Lei $\mathrm{n}^{\circ} 12.715$, de 17 de setembro de 2012.

Decreto $\mathbf{n}^{\mathbf{0}} \mathbf{7 . 9 6 2}$, de 15 de março de 2013 - Regulamenta a Lei $\mathrm{n}^{\circ}$ 8.078, de 11 de setembro de 1990, para dispor sobre a contratação no comércio eletrônico.

Decreto $n^{\circ}$ 8.135, de 4 de novembro de 2013 - Dispõe sobre as comunicações de dados da administração pública federal direta, autárquica e fundacional, e sobre a dispensa de licitação nas contratações que possam comprometer a segurança nacional.

Portaria MC no 55, de 12 de março de 2013 [ (1) ] - Regulamenta os procedimentos para submissão, análise, aprovação, acompanhamento e fiscalização dos projetos apresentados ao Ministério das Comunicações referentes ao Regime Especial de Tributação do Programa Nacional de Banda Larga para Implantação de Redes de Telecomunicações - REPNBL-Redes, de que trata a Lei $\mathrm{n}^{\circ} 12.715$, de 17 de setembro de 2012 e o Decreto $n^{\circ} 7.921$, de 15 de fevereiro de 2013.

$\rightarrow$ Anexo 1 [ (1) ] - Descrição dos equipamentos contemplados segundo a Nomenclatura Comum do Mercosul.

$\rightarrow$ Anexo 2 [ (1) ] - Percentuais mínimos para equipamentos e componentes de redes produzidos de acordo com o respectivo PPB e desenvolvidos com tecnologia nacional.

Portaria MC no 303, de 16 de outubro de 2013 - Altera a Portaria $n^{\circ}$ 55, de 12 de março de 2013, do Ministério das Comunicações, que regulamenta os procedimentos para submissão, análise, aprovação, acompanhamento e fiscalização dos projetos apresentados ao Ministério das Comunicações referentes ao Regime Especial de Tributação do Programa Nacional de Banda Larga para Implantação de Redes de Telecomunicações - REPNBL - Redes. 
$\rightarrow$ Anexo 1 - Alterações à descrição dos equipamentos contemplados segundo a Nomenclatura Comum do Mercosul.

- Anexo 2 - Alterações dos percentuais mínimos para equipamentos e componentes de redes produzidos de acordo com o respectivo PPB e desenvolvidos com tecnologia nacional.

Resolução da ANATEL $\mathbf{n}^{\circ}$ 614, de 28 de maio de 2013 - Aprova o Regulamento do Serviço de Comunicação Multimídia e altera os Anexos I e III do Regulamento de Cobrança de Preço Público pelo Direito de Exploração de Serviços de Telecomunicações e pelo Direito de Exploração de Satélite.

$\rightarrow$ Anexo - Regulamento do Serviço de Comunicação Multimídia.

Fixação de parâmetros de qualidade do Serviço de Comunicação Multimídia e exigência de gratuidade pela conexão à internet por prestadora de SCM que oferte planos para conexão à internet.

Atos

רN Enunciado CJF no 531, de abril de 2013 - A tutela da dignidade da pessoa humana na sociedade da informação inclui o direito ao esquecimento (Código Civil, art. 11: "Com exceção dos casos previstos em lei, os direitos da personalidade são intransmissíveis e irrenunciáveis, não podendo o seu exercício sofrer limitação voluntária.” Justificativa do Enunciado: Os danos provocados pelas novas tecnologias de informação vêm-se acumulando nos dias atuais. $\mathrm{O}$ direito ao esquecimento tem sua origem histórica no campo das condenações criminais. Surge como parcela importante do direito do ex-detento à ressocialização. Não atribui a ninguém o direito de apagar fatos ou reescrever a própria história, mas apenas assegura a possibilidade de discutir o uso que é dado aos fatos pretéritos, mais especificamente o modo e a finalidade com que são lembrados.)

\section{Radioamador}

\section{Normatização}

Resolução da ANATEL no 617, de 19 de junho de 2013 - Aprova o Regulamento do Serviço Limitado Privado.

$\Rightarrow$ Anexo - Regulamento do Serviço Limitado Privado.

A Res. 617/2013 define o momento em que o preço público referente às autorizações para execução dos serviços de Radioamador, Rádio do Cidadão, Móvel Marítimo e Móvel Aeronáutico é devido, ou seja, o momento da primeira emissão da Licença para Funcionamento de Estação, que é o instrumento que formaliza a autorização para execução do serviço. 


\section{Radiodifusão}

Temas Conexos: Classificações de Serviços no Setor de Telecomunicações : Quanto ao Gênero : Serviço de Radiodifusão e Atores no Setor de Telecomunicações : Poder Executivo : Ministério das Comunicações.

Competência da Presidência da República para outorgar, por meio de concessão, a exploração dos serviços de radiodifusão de sons e imagens, e do Ministério das Comunicações para outorgar, por meio de concessão, permissão ou autorização, a exploração dos serviços de radiodifusão sonora.

\section{Normatização}

Decreto $\mathbf{n}^{0}$ 7.932, de 19 de fevereiro de 2013 - Altera o Estatuto Social da Empresa Brasil de Comunicação, aprovado pelo Decreto ${ }^{\circ}$ 6.689, de 11 de dezembro de 2008.

Decreto $^{\circ} \mathbf{8 . 0 6 1}$, de 29 de julho de 2013 - Altera o Decreto ${ }^{\circ} 5.820$, de 29 de junho de 2006, o Regulamento dos Serviços de Radiodifusão, aprovado pelo Decreto $\mathrm{n}^{\circ} 52.795$, de 31 de outubro de 1963 , e dá outras providências.

Decreto n ${ }^{\circ}$ 8.139, de 7 de novembro de 2013 - Dispõe sobre as condições para extinção do serviço de radiodifusão sonora em ondas médias de caráter local, sobre a adaptação das outorgas vigentes para execução deste serviço e dá outras providências.

Portaria MC no 112, de 22 de abril de 2013 - Aprova o Regulamento de Sanções Administrativas aplicáveis a entidades prestadoras dos serviços de radiodifusão, seus ancilares e auxiliares.

- Anexo 1 - Fator Relativo ao Tipo de Serviço/Classe da Emissora (K1).

- Anexo 2 - Fator Relativo ao Porte do Município (K2).

$\rightarrow$ Anexo 3 - Fator Relativo à Gravidade da Infração (K3).

Portaria MC no 159, de 11 de junho de 2013 - Autoriza o funcionamento, em caráter provisório, de entidades prestadoras de serviços de radiodifusão e seus ancilares previamente outorgadas via decreto legislativo ou ato de outorga, detenham contrato de concessão ou permissão celebrado com o Ministério das Comunicações e tenham protocolizado requerimento de aprovação dos locais de instalação e uso de equipamentos.

Portaria MC $\mathbf{n}^{0}$ 231, de 7 de agosto de 2013 - Estabelece regras para a autorização de alteração de características técnicas de operação das emissoras de serviços de radiodifusão e seus ancilares que resultem em alteração da classe e grupo de enquadramento.

$\rightarrow$ Anexo - Quadros de Grupos e Classes do Serviço de Radiodifusão.

Portaria MC no 282, de 25 de setembro de 2013 - Institui força tarefa e procedimento específico para outorga do Serviço de Retransmissão de Televisão - RTV, em caráter secundário.

- Anexo 1 - Formulário Padronizado para Solicitação de RTV Secundária. 
$\rightarrow$ Anexo 2 - Formulário Padronizado para Projeto Técnico.

Portaria MC no 299, de 7 de outubro de 2013 - Institui, no âmbito da Secretaria de Serviços de Comunicação Eletrônica, grupos de trabalho de Radiodifusão Comercial, de Radiodifusão Educativa e Consignações, de Radiodifusão Ancilar, de TV Digital, e de Documentação e Informação.

Atos

Enunciado CJF $\mathbf{n}^{0}$ 531, de abril de 2013 - A tutela da dignidade da pessoa humana na sociedade da informação inclui o direito ao esquecimento (Código Civil, art. 11: "Com exceção dos casos previstos em lei, os direitos da personalidade são intransmissíveis e irrenunciáveis, não podendo o seu exercício sofrer limitação voluntária.” Justificativa do Enunciado: Os danos provocados pelas novas tecnologias de informação vêm-se acumulando nos dias atuais. $\mathrm{O}$ direito ao esquecimento tem sua origem histórica no campo das condenações criminais. Surge como parcela importante do direito do ex-detento à ressocialização. Não atribui a ninguém o direito de apagar fatos ou reescrever a própria história, mas apenas assegura a possibilidade de discutir o uso que é dado aos fatos pretéritos, mais especificamente o modo e a finalidade com que são lembrados.)

Portaria ANATEL $n^{\circ}$ 448, de 4 de junho de 2013 - Atribui a competência decorrente de Acordo de Cooperação Técnica celebrado entre o Ministério das Comunicações e a Agência Nacional de Telecomunicações (ANATEL).

$\checkmark$ A Portaria ANATEL no 448/2013 atribui competência delegada do Ministério das Comunicações para a ANATEL e convalida prática dos atos necessários à análise de processos técnicos de engenharia nos procedimentos de pós-outorga dos serviços de radiodifusão, seus ancilares e auxiliares.

\section{Radiodifusão Comunitária}

\section{Normatização}

Portaria MC no 197, de $\mathbf{1}^{\circ}$ julho de 2013 - Estabelece data limite para a apresentação de pedido de renovação de outorga de serviço de radiodifusão comunitária e altera a Norma $n^{\circ} 1 / 2011$, aprovada pela Portaria n ${ }^{\circ} 462$, de 14 de outubro de 2011.

$\rightarrow$ Anexo 1 - Alterações ao Anexo II à Norma nº 01/2011, aprovada pela Portaria $\mathrm{n}^{\mathrm{o}}$ 462, de 2011.

$\rightarrow$ Anexo 2 - Alterações ao Anexo XII à Norma nº 01/2011, aprovada pela Portaria n ${ }^{\circ} 462$, de 2011.

\section{Serviço Auxiliar de Radiodifusão e Correlatos (SARC)}

\section{Normatização}

Portaria MC n' 252, de 8 de agosto de 2013 - Disciplina a natureza, as condições de prestação, e a competência para outorga, exploração e condições 
de uso de radiofrequência associadas aos Serviços Auxiliares de Radiodifusão e Correlatos (SARC).

$\checkmark$ Competência da ANATEL para processar solicitações de outorga e alterações das condições de outorga dos Serviços Auxiliares de Radiodifusão e Correlatos (SARC), bem como para emissão de regulamentação sobre a outorga, exploração e condições de uso de radiofrequencia associada ao SARC, afirmada a política ministerial de que a Agência considerasse a possibilidade de unificar a regulamentação do SARC com a de outros serviços convergentes de telecomunicações de interesse restrito.

\section{Televisão Aberta}

\section{TV Digital}

\section{Normatização}

Decreto n* 8.061, de 29 de julho de 2013 - Altera o Decreto n ${ }^{\circ} 5.820$, de 29 de junho de 2006, o Regulamento dos Serviços de Radiodifusão, aprovado pelo Decreto $\mathrm{n}^{\circ} 52.795$, de 31 de outubro de 1963, e dá outras providências.

Portaria MC no 14, de 6 de fevereiro de 2013 - Estabelece diretrizes para a aceleração do acesso ao Sistema Brasileiro de Televisão Digital Terrestre SBTVD-T e para a ampliação da disponibilidade de espectro de radiofrequência para atendimento dos objetivos do Programa Nacional de Banda Larga - PNBL.

Portaria MC no 57, de 13 de março de 2013 - Altera a Norma Regulamentar do Canal da Cidadania, aprovada pela Portaria $\mathrm{MC} \mathrm{n}^{\circ} 489$, de 18 de dezembro de 2012.

Resolução da ANATEL $\mathbf{n}^{\circ}$ 625, de 11 de novembro de 2013 - Aprova a Atribuição, a Destinação e o Regulamento sobre Condições de Uso de Radiofrequências na Faixa de $698 \mathrm{MHz}$ a $806 \mathrm{MHz}$.

$\rightarrow$ Anexo - Regulamento sobre Condições de Uso de Radiofrequências na Faixa de $698 \mathrm{MHz}$ a $806 \mathrm{MHz}$.

\section{Serviço Avançado de Mensagens (SAM)}

\section{Normatização}

Resolução da ANATEL no 617, de 19 de junho de 2013 - Aprova o Regulamento do Serviço Limitado Privado.

$\rightarrow$ Anexo - Regulamento do Serviço Limitado Privado.

$\checkmark$ Adaptação do Serviço Avançado de Mensagens ao regime regulatório do Regulamento do Serviço Limitado Privado. 


\section{Serviço Especial de Radiodeterminação por Satélite (SERDS)}

Atos

Ato do Conselho Diretor da ANATEL no 3.833, de 20 de junho de 2013 Aprova a classificação dos serviços de telecomunicações quanto aos interesses a que atendem.

$\Rightarrow$ Anexo - Classificação dos Serviços de Telecomunicações Quanto aos Interesses que Atendem.

$\checkmark$ Sua classificação como serviço de interesse coletivo ou restrito.

\section{Serviço Especial de Boletim Metereológico}

Atos

Ato do Conselho Diretor da ANATEL no 3.833, de 20 de junho de 2013 -

Aprova a classificação dos serviços de telecomunicações quanto aos interesses a que atendem.

$\rightarrow$ Anexo - Classificação dos Serviços de Telecomunicações Quanto aos Interesses que Atendem.

$\checkmark$ Sua classificação como serviço de interesse coletivo.

\section{Serviço Especial de Frequência Padrão}

Atos

Ato do Conselho Diretor da ANATEL no 3.833, de 20 de junho de 2013 -

Aprova a classificação dos serviços de telecomunicações quanto aos interesses a que atendem.

$\Rightarrow$ Anexo - Classificação dos Serviços de Telecomunicações Quanto aos Interesses que Atendem.

$\checkmark$ Sua classificação como serviço de interesse coletivo.

\section{Serviço Especial de Radioautocine}

Normatização

Resolução da ANATEL $n^{\circ}$ 617, de 19 de junho de 2013 - Aprova o Regulamento do Serviço Limitado Privado.

$\Rightarrow$ Anexo - Regulamento do Serviço Limitado Privado.

Adaptação do Serviço Especial de Radioautocine ao regime regulatório do Regulamento do Serviço Limitado Privado. 


\section{Serviço Especial de Radiochamada (SER) - ou Serviço Móvel Especial de Radiochamada}

\section{Normatização}

Resolução da ANATEL $n^{0}$ 617, de 19 de junho de 2013 - Aprova o Regulamento do Serviço Limitado Privado.

$\rightarrow$ Anexo - Regulamento do Serviço Limitado Privado.

Adaptação do Serviço Especial de Radiochamada ao regime regulatório do Regulamento do Serviço Limitado Privado.

\section{Serviço Especial de Radiorrecado}

\section{Normatização}

Resolução da ANATEL $\mathbf{n}^{0}$ 617, de 19 de junho de 2013 - Aprova o Regulamento do Serviço Limitado Privado.

- Anexo - Regulamento do Serviço Limitado Privado.

Adaptação do Serviço Especial de Radiorrecado ao regime regulatório do Regulamento do Serviço Limitado Privado.

\section{Serviço Especial de Rádio Acesso}

\section{Normatização}

Resolução da ANATEL $n^{0}$ 617, de 19 de junho de 2013 - Aprova o Regulamento do Serviço Limitado Privado.

- Anexo - Regulamento do Serviço Limitado Privado.

$\checkmark$ Adaptação do Serviço Especial de Rádio Acesso ao regime regulatório do Regulamento do Serviço Limitado Privado.

\section{Serviço Especial de Sinais Horários}

\section{Atos}

Ato do Conselho Diretor da ANATEL no 3.833, de 20 de junho de 2013 Aprova a classificação dos serviços de telecomunicações quanto aos interesses a que atendem.

- Anexo - Classificação dos Serviços de Telecomunicações Quanto aos Interesses que Atendem.

$\checkmark$ Sua classificação como serviço de interesse coletivo. 


\section{Serviço Especial de Supervisão e Controle}

\section{Normatização}

Resolução da ANATEL $\mathbf{n}^{\circ}$ 617, de 19 de junho de 2013 - Aprova o Regulamento do Serviço Limitado Privado.

$\Rightarrow$ Anexo - Regulamento do Serviço Limitado Privado.

Adaptação do Serviço Especial de Supervisão e Controle ao regime regulatório do Regulamento do Serviço Limitado Privado.

\section{Serviço Limitado Especializado (SLE)}

\section{Serviço de Circuito Especializado}

\section{Atos}

Tr Ato do Conselho Diretor da ANATEL no 3.833, de 20 de junho de 2013 Aprova a classificação dos serviços de telecomunicações quanto aos interesses a que atendem.

$\Rightarrow$ Anexo - Classificação dos Serviços de Telecomunicações Quanto aos Interesses que Atendem.

$\checkmark$ Sua classificação como serviço de interesse coletivo.

\section{Serviço Limitado Móvel Privado}

\section{Normatização}

Resolução da ANATEL no 617, de 19 de junho de 2013 - Aprova o Regulamento do Serviço Limitado Privado.

$\rightarrow$ Anexo - Regulamento do Serviço Limitado Privado.

Adaptação do Serviço Limitado Móvel Privativo ao regime regulatório do Regulamento do Serviço Limitado Privado.

\section{Serviço Limitado Privado de Radiochamada (SLPR)}

\section{Normatização}

Resolução da ANATEL no 617, de 19 de junho de 2013 - Aprova o Regulamento do Serviço Limitado Privado.

$\Rightarrow$ Anexo - Regulamento do Serviço Limitado Privado.

$\checkmark$ Adaptação do Serviço Limitado Privado de Radiochamada ao regime regulatório do Regulamento do Serviço Limitado Privado. 


\section{Serviço Limitado de Estações com Operação Itinerante}

Normatização

Resolução da ANATEL $n^{0}$ 617, de 19 de junho de 2013 - Aprova o Regulamento do Serviço Limitado Privado.

$\rightarrow$ Anexo - Regulamento do Serviço Limitado Privado.

Adaptação do Serviço Limitado de Estações com Operação Itinerante ao regime regulatório do Regulamento do Serviço Limitado Privado.

\section{Serviço Limitado de Radioestrada}

\section{Normatização}

Resolução da ANATEL $n^{0}$ 617, de 19 de junho de 2013 - Aprova o Regulamento do Serviço Limitado Privado.

$\rightarrow$ Anexo - Regulamento do Serviço Limitado Privado.

Adaptação do Serviço Limitado de Radioestrada ao regime regulatório do Regulamento do Serviço Limitado Privado.

\section{Serviço Móvel Especializado ou Trunking ou Trunk ou Sistema Troncalizado}

\section{Normatização}

Resolução da ANATEL $\mathbf{n}^{\circ}$ 623, de 18 de outubro de 2013 - Aprova o Regulamento de Conselho de Usuários.

$\rightarrow$ Anexo - Regulamento de Conselho de Usuários.

Resolução da ANATEL $\mathbf{n}^{\circ}$ 624, de 30 de outubro de 2013 - Aprova o Regulamento para Uso de Femtocélulas em Redes do Serviço Móvel Pessoal, do Serviço Móvel Especializado e do Serviço de Comunicação Multimídia.

$\rightarrow$ Anexo - Regulamento para Uso de Femtocélulas em Redes do Serviço Móvel Pessoal, do Serviço Móvel Especializado e do Serviço de Comunicação Multimídia.

\section{Serviço Móvel Global por Satélite (SMGS)}

\section{Atos}

Ato do Conselho Diretor da ANATEL no 3.833, de 20 de junho de 2013 Aprova a classificação dos serviços de telecomunicações quanto aos interesses a que atendem.

$\rightarrow$ Anexo - Classificação dos Serviços de Telecomunicações Quanto aos Interesses que Atendem.

Sua classificação como serviço de interesse coletivo. 


\title{
Serviço Móvel Marítimo
}

\author{
Normatização
}

Resolução da ANATEL no 617, de 19 de junho de 2013 - Aprova o Regulamento do Serviço Limitado Privado.

$\rightarrow$ Anexo - Regulamento do Serviço Limitado Privado.

A Res. 617/2013 define o momento em que o preço público referente às autorizações para execução dos serviços de Radioamador, Rádio do Cidadão, Móvel Marítimo e Móvel Aeronáutico é devido, ou seja, o momento da primeira emissão da Licença para Funcionamento de Estação, que é o instrumento que formaliza a autorização para execução do serviço.

\section{Atos}

Ato do Conselho Diretor da ANATEL no 3.833, de 20 de junho de 2013 Aprova a classificação dos serviços de telecomunicações quanto aos interesses a que atendem.

$\Rightarrow$ Anexo - Classificação dos Serviços de Telecomunicações Quanto aos Interesses que Atendem.

$\checkmark$ Sua classificação como serviço de interesse coletivo ou restrito.

\section{Serviço Móvel Pessoal (SMP)}

\section{Normatização}

Lei $n^{0}$ 12.865, de 9 de outubro de 2013 - Autoriza o pagamento de subvenção econômica aos produtores da safra 2011/2012 de cana-de-açúcar e de etanol que especifica e o financiamento da renovação e implantação de canaviais com equalização da taxa de juros; dispõe sobre os arranjos de pagamento e as instituições de pagamento integrantes do Sistema de Pagamentos Brasileiro (SPB); autoriza a União a emitir, sob a forma de colocação direta, em favor da Conta de Desenvolvimento Energético (CDE), títulos da dívida pública mobiliária federal; estabelece novas condições para as operações de crédito rural oriundas de, ou contratadas com, recursos do Fundo Constitucional de Financiamento do Nordeste (FNE); altera os prazos previstos nas Leis no 11.941, de 27 de maio de 2009, e no 12.249, de 11 de junho de 2010; autoriza a União a contratar o Banco do Brasil S.A. ou suas subsidiárias para atuar na gestão de recursos, obras e serviços de engenharia relacionados ao desenvolvimento de projetos, modernização, ampliação, construção ou reforma da rede integrada e especializada para atendimento da mulher em situação de violência; disciplina o documento digital no Sistema Financeiro Nacional; disciplina a transferência, no caso de falecimento, do direito de utilização privada de área pública por equipamentos urbanos do tipo quiosque, trailer, feira e banca de venda de jornais e de revistas; altera a incidência da Contribuição para o PIS/Pasep e da Cofins na cadeia de produção e comercialização da soja e de seus subprodutos; altera as Leis nos 12.666, de 14 de junho de 2012, 5.991, de 17 de dezembro de 1973, 
11.508, de 20 de julho de 2007, 9.503, de 23 de setembro de 1997, 9.069, de 29 de junho de $1995,10.865$, de 30 de abril de 2004, 12.587, de 3 de janeiro de 2012, 10.826, de 22 de dezembro de 2003, 10.925, de 23 de julho de 2004, 12.350, de 20 de dezembro de 2010, 4.870, de lo de dezembro de 1965 e 11.196 , de 21 de novembro de 2005, e o Decreto no 70.235, de 6 de março de 1972; revoga dispositivos das Leis nos 10.865, de 30 de abril de 2004, 10.925, de 23 de julho de 2004, 12.546, de 14 de dezembro de 2011, e 4.870, de 1 o de dezembro de 1965; e dá outras providências.

Portaria MC no 14, de 6 de fevereiro de 2013 - Estabelece diretrizes para a aceleração do acesso ao Sistema Brasileiro de Televisão Digital Terrestre SBTVD-T e para a ampliação da disponibilidade de espectro de radiofrequência para atendimento dos objetivos do Programa Nacional de Banda Larga - PNBL.

Resolução da ANATEL $n^{\circ}$ 608, de 5 de abril de 2013 - Aprova alteração nos Apêndices C e D do Anexo I do Regulamento de Separação e Alocação Contas - RSAC, aprovado pela Resolução no 396, de 31 de março de 2005, alterado pela Resolução no 419, de 24 de novembro de 2005, pela Resolução no 464, de 27 de abril de 2007, pela Resolução n ${ }^{\circ} 480$, de 14 de agosto de 2007, pela Resolução $n^{\circ} 483$, de 24 de outubro de 2007, e pela Resolução $n^{\circ} 503$, de 25 de abril de 2008, e define novo prazo para entrega dos dados dos exercícios de 2011 e 2012 e do primeiro trimestre de 2013.

$\rightarrow$ Anexo - Apêndice C (Plano Geral para Separação e Alocação de Contas).

Resolução da ANATEL no 619, de 8 de agosto de 2013 - Alterações dos Anexos I e II do Regulamento de Separação e Alocação de Contas - RSAC, aprovado pela Resolução n ${ }^{\circ} 396$, de 31 de março de 2005, alterado pela Resolução no 419, de 24 de novembro de 2005, pela Resolução n 464, de 27 de abril de 2007, pela Resolução n ${ }^{\circ} 480$, de 14 de agosto de 2007, pela Resolução $n^{\circ} 483$, de 24 de outubro de 2007, pela Resolução no 503, de 25 de abril de 2008, e pela Resolução n ${ }^{\circ} 608$, de 5 de abril de 2013.

$\rightarrow$ Anexo - Alterações dos Anexos I e II do Regulamento de Separação e Alocação de Contas (RSAC).

Resolução da ANATEL $\mathbf{n}^{\circ}$ 623, de 18 de outubro de 2013 - Aprova o Regulamento de Conselho de Usuários.

$\rightarrow$ Anexo - Regulamento de Conselho de Usuários.

Resolução da ANATEL $\mathbf{n}^{\circ}$ 624, de 30 de outubro de 2013 - Aprova o Regulamento para Uso de Femtocélulas em Redes do Serviço Móvel Pessoal, do Serviço Móvel Especializado e do Serviço de Comunicação Multimídia.

$\rightarrow$ Anexo - Regulamento para Uso de Femtocélulas em Redes do Serviço Móvel Pessoal, do Serviço Móvel Especializado e do Serviço de Comunicação Multimídia.

Resolução da ANATEL $\mathbf{n}^{\circ}$ 625, de 11 de novembro de 2013 - Aprova a Atribuição, a Destinação e o Regulamento sobre Condições de Uso de Radiofrequências na Faixa de $698 \mathrm{MHz}$ a $806 \mathrm{MHz}$.

$\Rightarrow$ Anexo - Regulamento sobre Condições de Uso de Radiofrequências na Faixa de $698 \mathrm{MHz}$ a $806 \mathrm{MHz}$. 
Resolução da ANATEL n' 627, de 28 de novembro de 2013 - Altera o Regulamento do Serviço Móvel Pessoal, aprovado pela Resolução no 477, de 7 de agosto de 2007.

$\rightarrow$ Anexo - Alterações ao Regulamento do Serviço Móvel Pessoal.

\section{Serviço Rádio do Cidadão}

\section{Normatização}

Resolução da ANATEL no 617, de 19 de junho de 2013 - Aprova o Regulamento do Serviço Limitado Privado.

$\rightarrow$ Anexo - Regulamento do Serviço Limitado Privado.

$\checkmark$ A Res. 617/2013 define o momento em que o preço público referente às autorizações para execução dos serviços de Radioamador, Rádio do Cidadão, Móvel Marítimo e Móvel Aeronáutico é devido, ou seja, o momento da primeira emissão da Licença para Funcionamento de Estação, que é o instrumento que formaliza a autorização para execução do serviço.

\section{Serviço Telefônico Fixo Comutado (STFC)}

\section{Normatização}

Resolução da ANATEL $\mathbf{n}^{\circ}$ 606, de 4 de fevereiro de 2013 - Aprova alteração do Anexo I do Regulamento de Tarifação do Serviço Telefônico Fixo Comutado Destinado ao Uso do Público em Geral - STFC Prestado no Regime Público, aprovado pela Resolução n $^{\circ} 424$, de 6 de dezembro de 2005, e do Plano Geral de Códigos Nacionais - PGCN, Anexo II à Resolução no 263, de 08 de junho de 2001, para mudar o município de Santana do Paraíso, no estado de Minas Gerais, da Área de Tarifação 333 (Caratinga) para a Área de Tarifação 316 (Coronel Fabriciano), e do Código Nacional 33 para o Código Nacional 31.

$\rightarrow$ Anexo 1 - Áreas de Tarifação do STFC.

$\rightarrow$ Anexo 2 - Alteração do Plano Geral de Códigos Nacionais.

Resolução da ANATEL no 607, de 13 de março de 2013 - Alteração no Regulamento de Numeração do Serviço Telefônico Fixo Comutado, aprovado pela Resolução $n^{\circ} 86$, de 30 de dezembro de 1998, e no Regulamento de Administração dos Recursos de Numeração, aprovado pela Resolução $n^{\circ}$ 84, de 30 de dezembro de 1998.

- Anexo - Alterações no Regulamento de Numeração do Serviço Telefônico Fixo Comutado e no Regulamento de Administração dos Recursos de Numeração.

Resolução da ANATEL n 608, de 5 de abril de 2013 - Aprova alteração nos Apêndices C e D do Anexo I do Regulamento de Separação e Alocação Contas - RSAC, aprovado pela Resolução no 396, de 31 de março de 2005, alterado pela Resolução n ${ }^{\circ} 419$, de 24 de novembro de 2005 , pela Resolução n ${ }^{\circ} 464$, de 27 de abril de 2007, pela Resolução n ${ }^{\circ} 480$, de 14 de agosto de 2007, pela Resolução n 483, de 24 de outubro de 2007, e pela Resolução n ${ }^{\circ} 503$, de 25 
de abril de 2008, e define novo prazo para entrega dos dados dos exercícios de 2011 e 2012 e do primeiro trimestre de 2013.

$\rightarrow$ Anexo - Apêndice C (Plano Geral para Separação e Alocação de Contas).

Resolução da ANATEL n$^{\circ}$ 611, de 25 de abril de 2013 - Aprova alteração do Anexo I do Regulamento de Tarifação do Serviço Telefônico Fixo Comutado Destinado ao Uso do Público em Geral - STFC Prestado no Regime Público, aprovado pela Resolução no 424, de 6 de dezembro de 2005, para adequação das áreas de tarifação à nova configuração de áreas locais disposta na Resolução $\mathrm{n}^{\mathrm{o}} 560$, de 21 de janeiro de 2011.

$\rightarrow$ Anexo - Alteração de áreas de tarifação do Regulamento de Tarifação do Serviço Telefônico Fixo Comutado Destinado ao Uso do Público em Geral - STFC Prestado no Regime Público, aprovado pela Resolução n 424, de 6 de dezembro de 2005.

Resolução da ANATEL no 613, de 9 de maio de 2013 - Altera o art. 48 do Regulamento da Interface Usuário - Rede e de Terminais do Serviço Telefônico Fixo Comutado, aprovado pela Resolução no 473, de 27 de julho de 2007.

$\checkmark$ A Res. 613/2013 dispensa terminais de voz que utilizem tecnologia de tela sensível ao toque da exigência de disposição física das teclas para identificação por deficientes visuais.

Resolução da ANATEL n$^{\circ}$ 615, de 7 de junho de 2013 - Aprova alteração no Regulamento do Serviço Telefônico Fixo Comutado - STFC, aprovado pela Resolução $n^{\circ} 426$, de 9 de dezembro de 2005, alterado pela Resolução $n^{\circ} 432$, de 23 de fevereiro de 2006, e pela Resolução n 567 , de 24 de maio de 2011.

$\rightarrow$ Anexo - Alterações do Regulamento do Serviço Telefônico Fixo Comutado (STFC).

$\checkmark$ A Resolução ANATEL no 615/2013 altera o Regulamento do STFC para disciplinar com maior detalhamento os direitos dos usuários/consumidores do STFC, em especial no tocante à portabilidade numérica, ao atendimento pessoal às reclamações, ao acesso gratuito à central de informações e de atendimento ao usuário, de terceirização do serviço de atendimento pessoal aos usuários, de prazo máximo para atendimento pessoal, dentre outras alterações.

Resolução da ANATEL $\mathbf{n}^{\circ}$ 619, de 8 de agosto de 2013 - Alterações dos Anexos I e II do Regulamento de Separação e Alocação de Contas - RSAC, aprovado pela Resolução $\mathrm{n}^{\circ} 396$, de 31 de março de 2005, alterado pela Resolução $n^{\circ} 419$, de 24 de novembro de 2005, pela Resolução n 464, de 27 de abril de 2007, pela Resolução $n^{\circ} 480$, de 14 de agosto de 2007, pela Resolução $n^{\circ} 483$, de 24 de outubro de 2007, pela Resolução no 503 , de 25 de abril de 2008, e pela Resolução n ${ }^{\circ} 608$, de 5 de abril de 2013.

$\rightarrow$ Anexo - Alterações dos Anexos I e II do Regulamento de Separação e Alocação de Contas (RSAC).

Resolução da ANATEL $\mathbf{n}^{\circ}$ 620, de 9 de agosto de 2013 - Altera os Anexos I e II do Regulamento sobre Áreas Locais para o Serviço Telefônico Fixo Comutado Destinado ao Uso do Público em Geral - STFC.

$\rightarrow$ Anexo 1 - Alterações ao Anexo I do Regulamento sobre Áreas Locais para o STFC. 
$\rightarrow$ Anexo 2 - Alterações ao Anexo II do Regulamento sobre Áreas Locais para o STFC.

$\rightarrow$ Anexo 3 - Alterações ao Anexo II do Regulamento sobre Áreas Locais para o STFC.

$\rightarrow$ Anexo 4 - Alterações ao Anexo II do Regulamento sobre Áreas Locais para o STFC.

$\rightarrow$ Anexo 5 - Alterações ao Anexo II do Regulamento sobre Áreas Locais para o STFC.

Resolução da ANATEL $\mathbf{n}^{\circ}$ 621, de 14 de agosto de 2013 - Aprova alteração do Anexo I do Regulamento de Tarifação do Serviço Telefônico Fixo Comutado Destinado ao Uso do Público em Geral - STFC Prestado no Regime Público, aprovado pela Resolução n n $^{\text {424, de }} 6$ de dezembro de 2005, e do Plano Geral de Códigos Nacionais - PGCN, anexo ao Regulamento de Numeração do STFC, aprovado pela Resolução $n^{\circ} 86$, de 30 de dezembro de 1998, alterado pela Resolução n 263 , de 8 de junho de 2001, para mudar o município de Sabáudia, no estado do Paraná, da Área de Tarifação 442 (Maringá) para a Área de Tarifação 432 (Londrina) e do Código Nacional 44 para o Código Nacional 43.

$\Rightarrow$ Anexo 1 - Alterações ao Regulamento de Tarifação do Serviço Telefônico Fixo Comutado.

$\Rightarrow$ Anexo 2 - Alterações ao Plano Geral de Códigos Nacionais, anexo ao Regulamento de Numeração do STFC.

Resolução da ANATEL no 622, de 23 de agosto de 2013 - Aprova o Regulamento sobre a Prestação do Serviço Telefônico Fixo Comutado Destinado ao Público em Geral (STFC) Fora da Área de Tarifa Básica (ATB).

$\rightarrow$ Anexo - Regulamento sobre a Prestação do Serviço Telefônico Fixo Comutado Destinado ao Público em Geral (STFC) Fora da Área de Tarifa Básica (ATB).

Resolução da ANATEL no 623, de 18 de outubro de 2013 - Aprova o Regulamento de Conselho de Usuários.

$\rightarrow$ Anexo - Regulamento de Conselho de Usuários.

Resolução da ANATEL no 625, de 11 de novembro de 2013 - Aprova a Atribuição, a Destinação e o Regulamento sobre Condições de Uso de Radiofrequências na Faixa de $698 \mathrm{MHz}$ a $806 \mathrm{MHz}$.

$\rightarrow$ Anexo - Regulamento sobre Condições de Uso de Radiofrequências na Faixa de $698 \mathrm{MHz}$ a $806 \mathrm{MHz}$.

\section{Atos}

Portaria ANATEL/SOR no 639, de 25 de julho de 2013 - Estabelece o Procedimento Simplificado de Outorga - PSO, com a finalidade de outorga simultânea para explorar o Serviço de Comunicação Multimídia, o Serviço Telefônico Fixo Comutado Destinado ao Uso do Público em Geral e/ou o Serviço de Acesso Condicionado. 


\section{Serviço de Acesso Condicionado (SeAC)}

\section{Normatização}

Resolução da ANATEL n $^{\circ}$ 608, de 5 de abril de 2013 - Aprova alteração nos Apêndices C e D do Anexo I do Regulamento de Separação e Alocação Contas - RSAC, aprovado pela Resolução no 396, de 31 de março de 2005, alterado pela Resolução n 419 , de 24 de novembro de 2005 , pela Resolução $n^{\circ} 464$, de 27 de abril de 2007, pela Resolução n ${ }^{\circ} 480$, de 14 de agosto de 2007, pela Resolução no 483, de 24 de outubro de 2007, e pela Resolução no 503, de 25 de abril de 2008, e define novo prazo para entrega dos dados dos exercícios de 2011 e 2012 e do primeiro trimestre de 2013.

$\rightarrow$ Anexo - Apêndice C (Plano Geral para Separação e Alocação de Contas).

Resolução da ANATEL no 618, de 24 de julho de 2013 - Altera o Regulamento do Serviço de Acesso Condicionado (SeAC), aprovado pela Resolução $n^{\circ} 581$, de 26 de março de 2012.

Resolução da ANATEL $\mathbf{n}^{\mathbf{0}}$ 619, de 8 de agosto de 2013 - Alterações dos Anexos I e II do Regulamento de Separação e Alocação de Contas - RSAC, aprovado pela Resolução $\mathrm{n}^{\circ} 396$, de 31 de março de 2005, alterado pela Resolução no 419, de 24 de novembro de 2005, pela Resolução no 464, de 27 de abril de 2007, pela Resolução n ${ }^{\circ} 480$, de 14 de agosto de 2007, pela Resolução $\mathrm{n}^{\circ} 483$, de 24 de outubro de 2007, pela Resolução no 503 , de 25 de abril de 2008, e pela Resolução n ${ }^{\circ} 608$, de 5 de abril de 2013.

$\Rightarrow$ Anexo - Alterações dos Anexos I e II do Regulamento de Separação e Alocação de Contas (RSAC).

\section{Atos}

Enunciado CJF $\mathbf{n}^{\circ}$ 531, de abril de 2013 - A tutela da dignidade da pessoa humana na sociedade da informação inclui o direito ao esquecimento (Código Civil, art. 11: "Com exceção dos casos previstos em lei, os direitos da personalidade são intransmissíveis e irrenunciáveis, não podendo o seu exercício sofrer limitação voluntária." Justificativa do Enunciado: Os danos provocados pelas novas tecnologias de informação vêm-se acumulando nos dias atuais. $\mathrm{O}$ direito ao esquecimento tem sua origem histórica no campo das condenações criminais. Surge como parcela importante do direito do ex-detento à ressocialização. Não atribui a ninguém o direito de apagar fatos ou reescrever a própria história, mas apenas assegura a possibilidade de discutir o uso que é dado aos fatos pretéritos, mais especificamente o modo e a finalidade com que são lembrados.)

Portaria ANATEL no 238, de 9 de abril de 2013 - Delega ao Superintendente de Serviços de Comunicação de Massa a competência para decidir sobre os pedidos de dispensa de que tratam os $\S \S 7^{\circ}$ e $8^{\circ}$ do art. 32 da Lei $n^{\circ} 12.485$, de 12 de setembro de 2011.

Portaria ANATEL/SOR no 639, de 25 de julho de 2013 - Estabelece o Procedimento Simplificado de Outorga - PSO, com a finalidade de outorga 
simultânea para explorar o Serviço de Comunicação Multimídia, o Serviço Telefônico Fixo Comutado Destinado ao Uso do Público em Geral e/ou o Serviço de Acesso Condicionado.

\section{Serviço de Comunicação Multimída (SCM)}

\section{Normatização}

Decreto $n^{\circ}$ 8.135, de 4 de novembro de 2013 - Dispõe sobre as comunicações de dados da administração pública federal direta, autárquica e fundacional, e sobre a dispensa de licitação nas contratações que possam comprometer a segurança nacional.

Resolução da ANATEL n 608, de 5 de abril de 2013 - Aprova alteração nos Apêndices C e D do Anexo I do Regulamento de Separação e Alocação Contas - RSAC, aprovado pela Resolução no 396, de 31 de março de 2005, alterado pela Resolução $n^{\circ} 419$, de 24 de novembro de 2005 , pela Resolução $n^{\circ} 464$, de 27 de abril de 2007, pela Resolução n ${ }^{\circ} 480$, de 14 de agosto de 2007, pela Resolução no 483, de 24 de outubro de 2007, e pela Resolução ${ }^{\circ}$ 503, de 25 de abril de 2008, e define novo prazo para entrega dos dados dos exercícios de 2011 e 2012 e do primeiro trimestre de 2013.

$\Rightarrow$ Anexo - Apêndice C (Plano Geral para Separação e Alocação de Contas).

Resolução da ANATEL $\mathbf{n}^{\circ}$ 614, de 28 de maio de 2013 - Aprova o Regulamento do Serviço de Comunicação Multimídia e altera os Anexos I e III do Regulamento de Cobrança de Preço Público pelo Direito de Exploração de Serviços de Telecomunicações e pelo Direito de Exploração de Satélite.

$\rightarrow$ Anexo - Regulamento do Serviço de Comunicação Multimídia.

$\checkmark$ Fixação de parâmetros de qualidade do Serviço de Comunicação Multimídia e exigência de gratuidade pela conexão à internet por prestadora de SCM que oferte planos para conexão à internet.

Resolução da ANATEL $\mathbf{n}^{\circ}$ 619, de 8 de agosto de 2013 - Alterações dos Anexos I e II do Regulamento de Separação e Alocação de Contas - RSAC, aprovado pela Resolução $\mathrm{n}^{\circ} 396$, de 31 de março de 2005, alterado pela Resolução $n^{\circ} 419$, de 24 de novembro de 2005, pela Resolução n ${ }^{\circ} 464$, de 27 de abril de 2007, pela Resolução n ${ }^{\circ} 480$, de 14 de agosto de 2007, pela Resolução $\mathrm{n}^{\circ} 483$, de 24 de outubro de 2007, pela Resolução n ${ }^{\circ} 503$, de 25 de abril de 2008 , e pela Resolução n ${ }^{\circ} 608$, de 5 de abril de 2013.

$\Rightarrow$ Anexo - Alterações dos Anexos I e II do Regulamento de Separação e Alocação de Contas (RSAC).

Resolução da ANATEL $\mathbf{n}^{\circ}$ 623, de 18 de outubro de 2013 - Aprova o Regulamento de Conselho de Usuários.

$\Rightarrow$ Anexo - Regulamento de Conselho de Usuários.

Resolução da ANATEL $\mathbf{n}^{\circ}$ 624, de 30 de outubro de 2013 - Aprova o Regulamento para Uso de Femtocélulas em Redes do Serviço Móvel Pessoal, do Serviço Móvel Especializado e do Serviço de Comunicação Multimídia. 
-Anexo - Regulamento para Uso de Femtocélulas em Redes do Serviço Móvel Pessoal, do Serviço Móvel Especializado e do Serviço de Comunicação Multimídia.

Resolução da ANATEL $\mathbf{n}^{\circ}$ 625, de 11 de novembro de 2013 - Aprova a Atribuição, a Destinação e o Regulamento sobre Condições de Uso de Radiofrequências na Faixa de $698 \mathrm{MHz}$ a $806 \mathrm{MHz}$.

$\rightarrow$ Anexo - Regulamento sobre Condições de Uso de Radiofrequências na Faixa de $698 \mathrm{MHz}$ a $806 \mathrm{MHz}$.

\section{Serviço de Radiotáxi}

\section{Serviço de Radiotáxi Especializado}

\section{Normatização}

Resolução da ANATEL $n^{\circ}$ 617, de 19 de junho de 2013 - Aprova o Regulamento do Serviço Limitado Privado.

$\rightarrow$ Anexo - Regulamento do Serviço Limitado Privado.

$\checkmark$ Adaptação do Serviço de Radiotáxi Especializado ao regime regulatório do Regulamento do Serviço Limitado Privado.

\section{Serviço de Rede}

\section{Serviço de Rede Especializado}

11 Atos

Tr Ato do Conselho Diretor da ANATEL no 3.833, de 20 de junho de 2013 Aprova a classificação dos serviços de telecomunicações quanto aos interesses a que atendem.

$\rightarrow$ Anexo - Classificação dos Serviços de Telecomunicações Quanto aos Interesses que Atendem.

$\checkmark$ Sua classificação como serviço de interesse coletivo.

\section{Serviço de Rede de Transporte de Telecomunicações (SRTT)}

\section{Atos}

Ato do Conselho Diretor da ANATEL no 3.833, de 20 de junho de 2013 Aprova a classificação dos serviços de telecomunicações quanto aos interesses a que atendem.

$\rightarrow$ Anexo - Classificação dos Serviços de Telecomunicações Quanto aos Interesses que Atendem.

Sua classificação como serviço de interesse coletivo. 


\section{Serviço de Telecomunicações Aeronáuticas}

\section{Serviço Móvel Aeronáutico}

Normatização

Resolução da ANATEL no 617, de 19 de junho de 2013 - Aprova o Regulamento do Serviço Limitado Privado.

$\rightarrow$ Anexo - Regulamento do Serviço Limitado Privado.

$\checkmark$ A Res. 617/2013 define o momento em que o preço público referente às autorizações para execução dos serviços de Radioamador, Rádio do Cidadão, Móvel Marítimo e Móvel Aeronáutico é devido, ou seja, o momento da primeira emissão da Licença para Funcionamento de Estação, que é o instrumento que formaliza a autorização para execução do serviço.

Atos

Ato do Conselho Diretor da ANATEL no 3.833, de 20 de junho de 2013 Aprova a classificação dos serviços de telecomunicações quanto aos interesses a que atendem.

$\rightarrow$ Anexo - Classificação dos Serviços de Telecomunicações Quanto aos Interesses que Atendem.

$\checkmark$ Sua classificação como serviço de interesse restrito.

\section{Serviço de Radiocomunicação Aeronáutico Público Restrito (SRA)}

\section{Atos}

থT Ato do Conselho Diretor da ANATEL no 3.833, de 20 de junho de 2013 Aprova a classificação dos serviços de telecomunicações quanto aos interesses a que atendem.

$\Rightarrow$ Anexo - Classificação dos Serviços de Telecomunicações Quanto aos Interesses que Atendem.

$\checkmark$ Sua classificação como serviço de interesse coletivo.

\section{Serviço de Telestrada ou Serviço Telefônico Público Móvel Rodoviário}

Normatização

Resolução da ANATEL no 617, de 19 de junho de 2013 - Aprova o Regulamento do Serviço Limitado Privado.

$\Rightarrow$ Anexo - Regulamento do Serviço Limitado Privado.

Adaptação do Serviço de Telestrada ao regime regulatório do Regulamento do Serviço Limitado Privado. 


\section{Serviços Científicos}

Normatização

Resolução da ANATEL $n^{\circ}$ 617, de 19 de junho de 2013 - Aprova o Regulamento do Serviço Limitado Privado.

$\rightarrow$ Anexo - Regulamento do Serviço Limitado Privado.

$\checkmark$ O Serviço Limitado Privado abarca as diversas modalidades de Serviços Científicos.

Atos

Ato do Conselho Diretor da ANATEL no 3.833, de 20 de junho de 2013 Aprova a classificação dos serviços de telecomunicações quanto aos interesses a que atendem.

- Anexo - Classificação dos Serviços de Telecomunicações Quanto aos Interesses que Atendem.

Sua classificação como serviço de interesse restrito.

\section{Ramos Jurídicos Afins}

\section{Direito do Consumidor}

\section{- Direito do Consumidor}

O art. $3^{\circ}$ do Regulamento de Aplicação de Sanções Administrativas prevê que as sanções nele dispostas são aplicáveis sem prejuízo das medidas previstas na legislação consumerista e das sanções de natureza civil e penal, inclusive a prevista pelo art.183 da Lei no 9.472/1997.

\section{Normatização}

Decreto $\mathbf{n}^{\circ}$ 7.962, de 15 de março de 2013 - Regulamenta a Lei $n^{\circ}$ 8.078, de 11 de setembro de 1990, para dispor sobre a contratação no comércio eletrônico.

Resolução da ANATEL $n^{0}$ 606, de 4 de fevereiro de 2013 - Aprova alteração do Anexo I do Regulamento de Tarifação do Serviço Telefônico Fixo Comutado Destinado ao Uso do Público em Geral - STFC Prestado no Regime Público, aprovado pela Resolução $n^{\circ} 424$, de 6 de dezembro de 2005, e do Plano Geral de Códigos Nacionais - PGCN, Anexo II à Resolução no 263, de 08 de junho de 2001, para mudar o município de Santana do Paraíso, no estado de Minas Gerais, da Área de Tarifação 333 (Caratinga) para a Área de Tarifação 316 (Coronel Fabriciano), e do Código Nacional 33 para o Código Nacional 31.

$\rightarrow$ Anexo 1 - Áreas de Tarifação do STFC.

- Anexo 2 - Alteração do Plano Geral de Códigos Nacionais.

Resolução da ANATEL $n^{0}$ 615, de 7 de junho de 2013 - Aprova alteração no Regulamento do Serviço Telefônico Fixo Comutado - STFC, aprovado pela 
Resolução n ${ }^{\circ} 426$, de 9 de dezembro de 2005, alterado pela Resolução no 432 , de 23 de fevereiro de 2006, e pela Resolução n ${ }^{\circ}$ 567, de 24 de maio de 2011.

$\rightarrow$ Anexo - Alterações do Regulamento do Serviço Telefônico Fixo Comutado (STFC).

$\checkmark$ A Resolução ANATEL no 615/2013 altera o Regulamento do STFC para disciplinar com maior detalhamento os direitos dos usuários/consumidores do STFC, em especial no tocante à portabilidade numérica, ao atendimento pessoal às reclamações, ao acesso gratuito à central de informações e de atendimento ao usuário, de terceirização do serviço de atendimento pessoal aos usuários, de prazo máximo para atendimento pessoal, dentre outras alterações.

Resolução da ANATEL no 621, de 14 de agosto de 2013 - Aprova alteração do Anexo I do Regulamento de Tarifação do Serviço Telefônico Fixo Comutado Destinado ao Uso do Público em Geral - STFC Prestado no Regime Público, aprovado pela Resolução no 424, de 6 de dezembro de 2005, e do Plano Geral de Códigos Nacionais - PGCN, anexo ao Regulamento de Numeração do STFC, aprovado pela Resolução $n^{\circ}$ 86, de 30 de dezembro de 1998, alterado pela Resolução n 263 , de 8 de junho de 2001, para mudar o município de Sabáudia, no estado do Paraná, da Área de Tarifação 442 (Maringá) para a Área de Tarifação 432 (Londrina) e do Código Nacional 44 para o Código Nacional 43.

- Anexo 1 - Alterações ao Regulamento de Tarifação do Serviço Telefônico Fixo Comutado.

$\rightarrow$ Anexo 2 - Alterações ao Plano Geral de Códigos Nacionais, anexo ao Regulamento de Numeração do STFC.

Resolução da ANATEL n $^{\circ}$ 623, de 18 de outubro de 2013 - Aprova o Regulamento de Conselho de Usuários.

$\rightarrow$ Anexo - Regulamento de Conselho de Usuários.

Resolução da ANATEL $n^{\circ}$ 629, de 16 de dezembro de 2013 - Aprova o Regulamento de celebração e acompanhamento de Termo de Compromisso de Ajustamento de Conduta (TAC).

$\Rightarrow$ Anexo - Regulamento de celebração e acompanhamento de Termo de Compromisso de Ajustamento de Conduta.

\section{Direito Aeroespacial}

\section{Normatização}

Resolução da ANATEL n' 628, de 6 de dezembro de 2013 - Aprova a alteração do Regulamento sobre Condições de Uso de Radiofrequências, na Faixa de $450 \mathrm{MHz}$ a $470 \mathrm{MHz}$, pelo Serviço Limitado Privado no Âmbito dos Aeroportos Nacionais.

- Anexo - Regulamento sobre Condições de Uso de Radiofrequências, na Faixa de $450 \mathrm{MHz}$ a $470 \mathrm{MHz}$, pelo Serviço Limitado Privado "no Âmbito dos Aeroportos Nacionais. 


\title{
Aplicações de Telecomunicações
}

\section{Aplicações Educacionais}

\author{
Normatização
}

Portaria MC n⿳ 57, de 13 de março de 2013 - Altera a Norma Regulamentar do Canal da Cidadania, aprovada pela Portaria $\mathrm{MC} \mathrm{n}^{\circ} 489$, de 18 de dezembro de 2012.

\section{Aplicações de Segurança}

\section{Normatização}

Lei $\mathbf{n}^{0}$ 12.841, de 9 de julho de 2013 - Altera a Lei $n^{\circ} 9.472$, de 16 de julho de 1997 - Lei Geral de Telecomunicações, para estabelecer a possibilidade de utilização das redes de telefonia móvel para localização de pessoas desaparecidas.

\section{Internet}

\section{Normatização}

Decreto $n^{\circ}$ 8.135, de 4 de novembro de 2013 - Dispõe sobre as comunicações de dados da administração pública federal direta, autárquica e fundacional, e sobre a dispensa de licitação nas contratações que possam comprometer a segurança nacional.

Portaria MC no 275, de 17 de setembro de 2013 - Estabelece política para a disponibilização de faixas de radiofrequência para prestação de acesso à Internet em banda larga por prestadores de serviços de telecomunicações de pequeno porte e por novos competidores.

\section{Atos}

Enunciado CJF no 531, de abril de 2013 - A tutela da dignidade da pessoa humana na sociedade da informação inclui o direito ao esquecimento (Código Civil, art. 11: "Com exceção dos casos previstos em lei, os direitos da personalidade são intransmissíveis e irrenunciáveis, não podendo o seu exercício sofrer limitação voluntária.” Justificativa do Enunciado: Os danos provocados pelas novas tecnologias de informação vêm-se acumulando nos dias atuais. O direito ao esquecimento tem sua origem histórica no campo das condenações criminais. Surge como parcela importante do direito do ex-detento à ressocialização. Não atribui a ninguém o direito de apagar fatos ou reescrever a própria história, mas apenas assegura a possibilidade de discutir o uso que é dado aos fatos pretéritos, mais especificamente o modo e a finalidade com que são lembrados.) 


\section{Acesso a Serviços de Interesse Público e Uso de Radiofrequência por tais Serviços}

\section{Normatização}

Resolução da ANATEL $\mathbf{n}^{\circ}$ 627, de 28 de novembro de 2013 - Altera o Regulamento do Serviço Móvel Pessoal, aprovado pela Resolução nº 477, de 7 de agosto de 2007.

- Anexo - Alterações ao Regulamento do Serviço Móvel Pessoal.

\section{Defesa Civil}

\section{Normatização}

Resolução da ANATEL $n^{0}$ 614, de 28 de maio de 2013 - Aprova o Regulamento do Serviço de Comunicação Multimídia e altera os Anexos I e III do Regulamento de Cobrança de Preço Público pelo Direito de Exploração de Serviços de Telecomunicações e pelo Direito de Exploração de Satélite.

$\rightarrow$ Anexo - Regulamento do Serviço de Comunicação Multimídia.

O Regulamento do SCM prevê o dever das prestadoras do serviço de colocarem à disposição das autoridades e dos agentes da defesa civil, nos casos de calamidade pública, todos os meios, sistemas e disponibilidades que lhes forem solicitados com vista a dar-lhes suporte ou a amparar as populações atingidas, na forma da regulamentação.

\section{Tráfego Aéreo}

\section{Normatização}

Resolução da ANATEL $\mathbf{n}^{\circ}$ 628, de 6 de dezembro de 2013 - Aprova a alteração do Regulamento sobre Condições de Uso de Radiofrequências, na Faixa de $450 \mathrm{MHz}$ a $470 \mathrm{MHz}$, pelo Serviço Limitado Privado no Âmbito dos Aeroportos Nacionais.

$\rightarrow$ Anexo - Regulamento sobre Condições de Uso de Radiofrequências, na Faixa de $450 \mathrm{MHz}$ a $470 \mathrm{MHz}$, pelo Serviço Limitado Privado "no Âmbito dos Aeroportos Nacionais.

\section{Radiolocalização}

\section{Normatização}

Lei n⿳ 12.841, de 9 de julho de 2013 - Altera a Lei no 9.472, de 16 de julho de 1997 - Lei Geral de Telecomunicações, para estabelecer a possibilidade de utilização das redes de telefonia móvel para localização de pessoas desaparecidas. 


\section{Banda Larga}

\section{Normatização}

Lei $\mathbf{n}^{\mathbf{0}}$ 12.837, de 9 de julho de 2013 - Altera as Leis nos 6.704, de 26 de outubro de 1979, para dispor sobre o Seguro de Crédito à Exportação nas operações relativas a exportações do setor aeronáutico, 11.494, de 20 de junho de 2007, para dispor sobre o cômputo no Fundo de Manutenção e Desenvolvimento da Educação Básica e de Valorização dos Profissionais da Educação - FUNDEB das matrículas em pré-escolas conveniadas com o poder público, 12.715, de 17 de setembro de 2012, para estender a data-limite para adesão ao Regime Especial de Tributação do Programa Nacional de Banda Larga para Implantação de Redes de Telecomunicações - REPNBL-Redes, 11.096, de 13 de janeiro de 2005, e 12.513, de 26 de outubro de 2011.

Decreto $n^{0}$ 7.921, de 15 de fevereiro de 2013 - Regulamenta a aplicação do Regime Especial de Tributação do Programa Nacional de Banda Larga para Implantação de Redes de Telecomunicações - REPNBL-Redes, de que trata a Lei $\mathrm{n}^{\circ} 12.715$, de 17 de setembro de 2012.

Decreto $n^{\circ}$ 7.962, de 15 de março de 2013 - Regulamenta a Lei $n^{\circ} 8.078$, de 11 de setembro de 1990, para dispor sobre a contratação no comércio eletrônico.

Decreto $n^{\circ}$ 8.135, de 4 de novembro de 2013 - Dispõe sobre as comunicações de dados da administração pública federal direta, autárquica e fundacional, e sobre a dispensa de licitação nas contratações que possam comprometer a segurança nacional.

Portaria MC no 14, de 6 de fevereiro de 2013 - Estabelece diretrizes para a aceleração do acesso ao Sistema Brasileiro de Televisão Digital Terrestre SBTVD-T e para a ampliação da disponibilidade de espectro de radiofrequência para atendimento dos objetivos do Programa Nacional de Banda Larga - PNBL.

Portaria MC no 55, de 12 de março de 2013 [ (1) ] - Regulamenta os procedimentos para submissão, análise, aprovação, acompanhamento e fiscalização dos projetos apresentados ao Ministério das Comunicações referentes ao Regime Especial de Tributação do Programa Nacional de Banda Larga para Implantação de Redes de Telecomunicações - REPNBL-Redes, de que trata a Lei $\mathrm{n}^{\circ} 12.715$, de 17 de setembro de 2012 e o Decreto $n^{\circ} 7.921$, de 15 de fevereiro de 2013.

$\rightarrow$ Anexo 1 [ (1) ] - Descrição dos equipamentos contemplados segundo a Nomenclatura Comum do Mercosul.

$\rightarrow$ Anexo 2 [ (1) ] - Percentuais mínimos para equipamentos e componentes de redes produzidos de acordo com o respectivo PPB e desenvolvidos com tecnologia nacional.

Portaria MC no 275, de 17 de setembro de 2013 - Estabelece política para a disponibilização de faixas de radiofrequência para prestação de acesso à Internet em banda larga por prestadores de serviços de telecomunicações de pequeno porte e por novos competidores. 
Portaria MC no 303, de 16 de outubro de 2013 - Altera a Portaria $n^{\circ}$ 55, de 12 de março de 2013, do Ministério das Comunicações, que regulamenta os procedimentos para submissão, análise, aprovação, acompanhamento e fiscalização dos projetos apresentados ao Ministério das Comunicações referentes ao Regime Especial de Tributação do Programa Nacional de Banda Larga para Implantação de Redes de Telecomunicações - REPNBL - Redes.

$\rightarrow$ Anexo 1 - Alterações à descrição dos equipamentos contemplados segundo a Nomenclatura Comum do Mercosul.

$\rightarrow$ Anexo 2 - Alterações dos percentuais mínimos para equipamentos e componentes de redes produzidos de acordo com o respectivo PPB e desenvolvidos com tecnologia nacional.

Resolução da ANATEL $\mathbf{n}^{\circ}$ 614, de 28 de maio de 2013 - Aprova o Regulamento do Serviço de Comunicação Multimídia e altera os Anexos I e III do Regulamento de Cobrança de Preço Público pelo Direito de Exploração de Serviços de Telecomunicações e pelo Direito de Exploração de Satélite.

$\rightarrow$ Anexo - Regulamento do Serviço de Comunicação Multimídia.

$\checkmark$ Fixação de parâmetros de qualidade do Serviço de Comunicação Multimídia e exigência de gratuidade pela conexão à internet por prestadora de SCM que oferte planos para conexão à internet.

\section{Atores no Setor de Telecomunicações}

\section{ANATEL}

\section{Normatização}

Portaria MC n' 252, de 8 de agosto de 2013 - Disciplina a natureza, as condições de prestação, e a competência para outorga, exploração e condições de uso de radiofrequência associadas aos Serviços Auxiliares de Radiodifusão e Correlatos (SARC).

$\checkmark$ Competência da ANATEL para processar solicitações de outorga e alterações das condições de outorga dos Serviços Auxiliares de Radiodifusão e Correlatos (SARC), bem como para emissão de regulamentação sobre a outorga, exploração e condições de uso de radiofrequencia associada ao SARC, afirmada a política ministerial de que a Agência considerasse a possibilidade de unificar a regulamentação do SARC com a de outros serviços convergentes de telecomunicações de interesse restrito.

Resolução da ANATEL n 612, de 29 de abril de 2013 - Aprova o Regimento Interno da ANATEL.

$\rightarrow$ Anexo - Regimento Interno da Agência Nacional de Telecomunicações ANATEL.

Resolução da ANATEL no 629, de 16 de dezembro de 2013 - Aprova o Regulamento de celebração e acompanhamento de Termo de Compromisso de Ajustamento de Conduta (TAC). 
Anexo - Regulamento de celebração e acompanhamento de Termo de Compromisso de Ajustamento de Conduta.

Resolução no 4 do Senado Federal, de 2013 - Altera o Regimento Interno do Senado Federal para dispor sobre o comparecimento de Ministros de Estado e dirigentes das agências reguladoras ao Senado Federal, em periodicidade anual.

Atos

Portaria ANATEL no 238, de 9 de abril de 2013 - Delega ao Superintendente de Serviços de Comunicação de Massa a competência para decidir sobre os pedidos de dispensa de que tratam os $\$ \S 7^{\circ}$ e $8^{\circ}$ do art. 32 da Lei $n^{\circ} 12.485$, de 12 de setembro de 2011.

Portaria ANATEL no 448, de 4 de junho de 2013 - Atribui a competência decorrente de Acordo de Cooperação Técnica celebrado entre o Ministério das Comunicações e a Agência Nacional de Telecomunicações (ANATEL).

$\checkmark$ A Portaria ANATEL n ${ }^{\circ}$ 448/2013 atribui competência delegada do Ministério das Comunicações para a ANATEL e convalida prática dos atos necessários à análise de processos técnicos de engenharia nos procedimentos de pós-outorga dos serviços de radiodifusão, seus ancilares e auxiliares.

Portaria ANATEL no 559, de 3 de julho de 2013 - Aprova a Política de Segurança da Informação e Comunicações da Agência Nacional de Telecomunicações.

$\rightarrow$ Anexo - Política de Segurança da Informação e Comunicações da Agência Nacional de Telecomunicações.

Portaria ANATEL/SOR no 639, de 25 de julho de 2013 - Estabelece o Procedimento Simplificado de Outorga - PSO, com a finalidade de outorga simultânea para explorar o Serviço de Comunicação Multimídia, o Serviço Telefônico Fixo Comutado Destinado ao Uso do Público em Geral e/ou o Serviço de Acesso Condicionado.

\section{Relatório da Ouvidoria da ANATEL 2013}

Súmula da ANATEL $\mathbf{n}^{\circ}$ 14, de 28 de junho de 2013 - O Pedido de Reconsideração em face de decisão proferida pelo Conselho Diretor da Anatel, quando da deliberação de Recurso Administrativo, apenas será cabível caso a referida deliberação tenha ocorrido até o dia $1^{\circ}$ de maio de 2013.

\section{Poder Legislativo}

\section{Congresso Nacional}

\section{Normatização}

Resolução no 4 do Senado Federal, de 2013 - Altera o Regimento Interno do Senado Federal para dispor sobre o comparecimento de Ministros de Estado e dirigentes das agências reguladoras ao Senado Federal, em periodicidade anual. 


\section{Poder Executivo}

\section{Ministério das Comunicações}

Tema Conexo: Serviços no Setor de Telecomunicações : Radiodifusão.

\section{Normatização}

Portaria MC no 112, de 22 de abril de 2013 - Aprova o Regulamento de Sanções Administrativas aplicáveis a entidades prestadoras dos serviços de radiodifusão, seus ancilares e auxiliares.

$\rightarrow$ Anexo 1 - Fator Relativo ao Tipo de Serviço/Classe da Emissora (K1).

$\rightarrow$ Anexo 2 - Fator Relativo ao Porte do Município (K2).

$\Rightarrow$ Anexo 3 - Fator Relativo à Gravidade da Infração (K3).

Portaria MC n' 252, de 8 de agosto de 2013 - Disciplina a natureza, as condições de prestação, e a competência para outorga, exploração e condições de uso de radiofrequência associadas aos Serviços Auxiliares de Radiodifusão e Correlatos (SARC).

$\checkmark$ Competência da ANATEL para processar solicitações de outorga e alterações das condições de outorga dos Serviços Auxiliares de Radiodifusão e Correlatos (SARC), bem como para emissão de regulamentação sobre a outorga, exploração e condições de uso de radiofrequencia associada ao SARC, afirmada a política ministerial de que a Agência considerasse a possibilidade de unificar a regulamentação do SARC com a de outros serviços convergentes de telecomunicações de interesse restrito.

Portaria MC no 299, de 7 de outubro de 2013 - Institui, no âmbito da Secretaria de Serviços de Comunicação Eletrônica, grupos de trabalho de Radiodifusão Comercial, de Radiodifusão Educativa e Consignações, de Radiodifusão Ancilar, de TV Digital, e de Documentação e Informação.

Resolução no 4 do Senado Federal, de 2013 - Altera o Regimento Interno do Senado Federal para dispor sobre o comparecimento de Ministros de Estado e dirigentes das agências reguladoras ao Senado Federal, em periodicidade anual.

\section{Atos}

Portaria ANATEL $\mathbf{n}^{\circ}$ 448, de 4 de junho de 2013 - Atribui a competência decorrente de Acordo de Cooperação Técnica celebrado entre o Ministério das Comunicações e a Agência Nacional de Telecomunicações (ANATEL).

$\checkmark$ A Portaria ANATEL $n^{\circ}$ 448/2013 atribui competência delegada do Ministério das Comunicações para a ANATEL e convalida prática dos atos necessários à análise de processos técnicos de engenharia nos procedimentos de pós-outorga dos serviços de radiodifusão, seus ancilares e auxiliares. 


\section{Prestadora / Operadora}

\section{Normatização}

Lei $\mathbf{n}^{\mathbf{0}} \mathbf{1 2 . 8 3 7}$, de 9 de julho de 2013 - Altera as Leis nos 6.704, de 26 de outubro de 1979, para dispor sobre o Seguro de Crédito à Exportação nas operações relativas a exportações do setor aeronáutico, 11.494, de 20 de junho de 2007, para dispor sobre o cômputo no Fundo de Manutenção e Desenvolvimento da Educação Básica e de Valorização dos Profissionais da Educação - FUNDEB das matrículas em pré-escolas conveniadas com o poder público, 12.715, de 17 de setembro de 2012, para estender a data-limite para adesão ao Regime Especial de Tributação do Programa Nacional de Banda Larga para Implantação de Redes de Telecomunicações - REPNBL-Redes, 11.096, de 13 de janeiro de 2005, e 12.513, de 26 de outubro de 2011.

Decreto $\mathbf{n}^{\mathbf{0}}$ 8.174, de 26 de dezembro de 2013 - Altera os Anexos I e II ao Decreto $\mathrm{n}^{\circ}$ 7.867, de 19 de dezembro de 2012, relativos ao Programa de Dispêndios Globais - PDG das empresas estatais federais para 2013.

Portaria MC no 275, de 17 de setembro de 2013 - Estabelece política para a disponibilização de faixas de radiofrequência para prestação de acesso à Internet em banda larga por prestadores de serviços de telecomunicações de pequeno porte e por novos competidores.

Resolução da ANATEL $n^{0}$ 606, de 4 de fevereiro de 2013 - Aprova alteração do Anexo I do Regulamento de Tarifação do Serviço Telefônico Fixo Comutado Destinado ao Uso do Público em Geral - STFC Prestado no Regime Público, aprovado pela Resolução $n^{\circ} 424$, de 6 de dezembro de 2005, e do Plano Geral de Códigos Nacionais - PGCN, Anexo II à Resolução nº 263, de 08 de junho de 2001, para mudar o município de Santana do Paraíso, no estado de Minas Gerais, da Área de Tarifação 333 (Caratinga) para a Área de Tarifação 316 (Coronel Fabriciano), e do Código Nacional 33 para o Código Nacional 31.

$\rightarrow$ Anexo 1 - Áreas de Tarifação do STFC.

- Anexo 2 - Alteração do Plano Geral de Códigos Nacionais.

Resolução da ANATEL $n^{\circ}$ 614, de 28 de maio de 2013 - Aprova o Regulamento do Serviço de Comunicação Multimídia e altera os Anexos I e III do Regulamento de Cobrança de Preço Público pelo Direito de Exploração de Serviços de Telecomunicações e pelo Direito de Exploração de Satélite.

- Anexo - Regulamento do Serviço de Comunicação Multimídia.

Fixação de parâmetros de qualidade do Serviço de Comunicação Multimídia e exigência de gratuidade pela conexão à internet por prestadora de SCM que oferte planos para conexão à internet.

Resolução da ANATEL $n^{0}$ 615, de 7 de junho de 2013 - Aprova alteração no Regulamento do Serviço Telefônico Fixo Comutado - STFC, aprovado pela Resolução $n^{\circ} 426$, de 9 de dezembro de 2005, alterado pela Resolução $n^{\circ} 432$, de 23 de fevereiro de 2006, e pela Resolução n ${ }^{\circ}$ 567, de 24 de maio de 2011.

$\rightarrow$ Anexo - Alterações do Regulamento do Serviço Telefônico Fixo Comutado (STFC). 
A Resolução ANATEL no 615/2013 altera o Regulamento do STFC para disciplinar com maior detalhamento os direitos dos usuários/consumidores do STFC, em especial no tocante à portabilidade numérica, ao atendimento pessoal às reclamações, ao acesso gratuito à central de informações e de atendimento ao usuário, de terceirização do serviço de atendimento pessoal aos usuários, de prazo máximo para atendimento pessoal, dentre outras alterações.

Resolução da ANATEL no 616, de 18 de junho de 2013 - Aprova a alteração do Regulamento de Cobrança de Preço Público pelo Direito de Exploração de Serviços de Telecomunicações e pelo Direito de Exploração de Satélite, aprovado pela Resolução n ${ }^{\circ} 386$, de 3 de novembro de 2004, e alterado pela Resolução no 484, de 5 de novembro de 2007.

$\Rightarrow$ Anexo - Alteração do art. 12 do Regulamento de Cobrança de Preço Público pelo Direito de Exploração de Serviços de Telecomunicações e pelo Direito de Exploração de Satélite.

Resolução da ANATEL no 621, de 14 de agosto de 2013 - Aprova alteração do Anexo I do Regulamento de Tarifação do Serviço Telefônico Fixo Comutado Destinado ao Uso do Público em Geral - STFC Prestado no Regime Público, aprovado pela Resolução $\mathrm{n}^{\circ} 424$, de 6 de dezembro de 2005, e do Plano Geral de Códigos Nacionais - PGCN, anexo ao Regulamento de Numeração do STFC, aprovado pela Resolução no 86, de 30 de dezembro de 1998, alterado pela Resolução n 263 , de 8 de junho de 2001, para mudar o município de Sabáudia, no estado do Paraná, da Área de Tarifação 442 (Maringá) para a Área de Tarifação 432 (Londrina) e do Código Nacional 44 para o Código Nacional 43.

- Anexo 1 - Alterações ao Regulamento de Tarifação do Serviço Telefônico Fixo Comutado.

$\rightarrow$ Anexo 2 - Alterações ao Plano Geral de Códigos Nacionais, anexo ao Regulamento de Numeração do STFC.

Resolução da ANATEL no 629, de 16 de dezembro de 2013 - Aprova o Regulamento de celebração e acompanhamento de Termo de Compromisso de Ajustamento de Conduta (TAC).

$\rightarrow$ Anexo - Regulamento de celebração e acompanhamento de Termo de Compromisso de Ajustamento de Conduta.

\section{Atos}

Portaria ANATEL/SOR n 639, de 25 de julho de 2013 - Estabelece o Procedimento Simplificado de Outorga - PSO, com a finalidade de outorga simultânea para explorar o Serviço de Comunicação Multimídia, o Serviço Telefônico Fixo Comutado Destinado ao Uso do Público em Geral e/ou o Serviço de Acesso Condicionado. 


\section{Usuário / Consumidor}

\section{Normatização}

Resolução da ANATEL n $^{\circ}$ 606, de 4 de fevereiro de 2013 - Aprova alteração do Anexo I do Regulamento de Tarifação do Serviço Telefônico Fixo Comutado Destinado ao Uso do Público em Geral - STFC Prestado no Regime Público, aprovado pela Resolução no 424, de 6 de dezembro de 2005, e do Plano Geral de Códigos Nacionais - PGCN, Anexo II à Resolução nº 263, de 08 de junho de 2001, para mudar o município de Santana do Paraíso, no estado de Minas Gerais, da Área de Tarifação 333 (Caratinga) para a Área de Tarifação 316 (Coronel Fabriciano), e do Código Nacional 33 para o Código Nacional 31.

$\rightarrow$ Anexo 1 - Áreas de Tarifação do STFC.

$\rightarrow$ Anexo 2 - Alteração do Plano Geral de Códigos Nacionais.

Resolução da ANATEL $n^{\circ}$ 614, de 28 de maio de 2013 - Aprova o Regulamento do Serviço de Comunicação Multimídia e altera os Anexos I e III do Regulamento de Cobrança de Preço Público pelo Direito de Exploração de Serviços de Telecomunicações e pelo Direito de Exploração de Satélite.

$\rightarrow$ Anexo - Regulamento do Serviço de Comunicação Multimídia.

$\checkmark$ Fixação de parâmetros de qualidade do Serviço de Comunicação Multimídia e exigência de gratuidade pela conexão à internet por prestadora de SCM que oferte planos para conexão à internet.

Resolução da ANATEL no 615, de 7 de junho de 2013 - Aprova alteração no Regulamento do Serviço Telefônico Fixo Comutado - STFC, aprovado pela Resolução $n^{\circ} 426$, de 9 de dezembro de 2005, alterado pela Resolução $n^{\circ} 432$, de 23 de fevereiro de 2006, e pela Resolução n ${ }^{\circ}$ 567, de 24 de maio de 2011.

$\rightarrow$ Anexo - Alterações do Regulamento do Serviço Telefônico Fixo Comutado (STFC).

$\checkmark$ A Resolução ANATEL no 615/2013 altera o Regulamento do STFC para disciplinar com maior detalhamento os direitos dos usuários/consumidores do STFC, em especial no tocante à portabilidade numérica, ao atendimento pessoal às reclamações, ao acesso gratuito à central de informações e de atendimento ao usuário, de terceirização do serviço de atendimento pessoal aos usuários, de prazo máximo para atendimento pessoal, dentre outras alterações.

Resolução da ANATEL no 621, de 14 de agosto de 2013 - Aprova alteração do Anexo I do Regulamento de Tarifação do Serviço Telefônico Fixo Comutado Destinado ao Uso do Público em Geral - STFC Prestado no Regime Público, aprovado pela Resolução $n^{\circ} 424$, de 6 de dezembro de 2005, e do Plano Geral de Códigos Nacionais - PGCN, anexo ao Regulamento de Numeração do STFC, aprovado pela Resolução $n^{\circ}$ 86, de 30 de dezembro de 1998, alterado pela Resolução n ${ }^{\circ}$ 263, de 8 de junho de 2001, para mudar o município de Sabáudia, no estado do Paraná, da Área de Tarifação 442 (Maringá) para a Área de Tarifação 432 (Londrina) e do Código Nacional 44 para o Código Nacional 43.

$\Rightarrow$ Anexo 1 - Alterações ao Regulamento de Tarifação do Serviço Telefônico

Fixo Comutado. 
Anexo 2 - Alterações ao Plano Geral de Códigos Nacionais, anexo ao Regulamento de Numeração do STFC.

Resolução da ANATEL no 623, de 18 de outubro de 2013 - Aprova o Regulamento de Conselho de Usuários.

$\rightarrow$ Anexo - Regulamento de Conselho de Usuários.

\section{Normas Referenciadas}

\section{Lei Ordinária}

Lei n⿳ 12.837, de 9 de julho de 2013 - Altera as Leis nos 6.704, de 26 de outubro de 1979, para dispor sobre o Seguro de Crédito à Exportação nas operações relativas a exportações do setor aeronáutico, 11.494, de 20 de junho de 2007, para dispor sobre o cômputo no Fundo de Manutenção e Desenvolvimento da Educação Básica e de Valorização dos Profissionais da Educação - FUNDEB das matrículas em pré-escolas conveniadas com o poder público, 12.715, de 17 de setembro de 2012, para estender a data-limite para adesão ao Regime Especial de Tributação do Programa Nacional de Banda Larga para Implantação de Redes de Telecomunicações - REPNBL-Redes, 11.096, de 13 de janeiro de 2005, e 12.513, de 26 de outubro de 2011.

\begin{tabular}{|c|c|}
\hline Dispositivos & LGT, Art. $2^{\circ}$, inciso I; LGT, Art. $2^{\circ}$, inciso V. \\
\hline Altera & $\begin{array}{l}\text { Lei no } 6.704 / 1979 \\
\text { Lei no } 11.494 \text {, de } 20 \text { de junho de } 2007 \\
\text { Lei no } 12.715 / 2012 \text { - Altera a alíquota das contribuições previdenciárias sobre a folha } \\
\text { de salários devidas pelas empresas que especifica; institui o Programa de Incentivo à } \\
\text { Inovação Tecnológica e Adensamento da Cadeia Produtiva de Veículos Automotores, } \\
\text { o Regime Especial de Tributação do Programa Nacional de Banda Larga para } \\
\text { Implantação de Redes de Telecomunicações, o Regime Especial de Incentivo a } \\
\text { Computadores para Uso Educacional, o Programa Nacional de Apoio à Atenção } \\
\text { Oncológica e o Programa Nacional de Apoio à Atenção da Saúde da Pessoa com } \\
\text { Deficiência; restabelece o Programa Um Computador por Aluno; altera o Programa } \\
\text { de Apoio ao Desenvolvimento Tecnológico da Indústria de Semicondutores, instituído } \\
\text { pela Lei no } 11.484 \text {, de } 31 \text { de maio de } 2007 \text {; altera as Leis nos } 9.250 \text {, de } 26 \text { de dezembro } \\
\text { de } 1995,11.033 \text {, de } 21 \text { de dezembro de } 2004 \text {, } 9.430 \text {, de } 27 \text { de dezembro de } 1996 \text {, } \\
\text { 10.865, de } 30 \text { de abril de } 2004,11.774 \text {, de } 17 \text { de setembro de } 2008 \text {, } 12.546 \text {, de } 14 \text { de } \\
\text { dezembro de } 2011 \text {, } 11.484 \text {, de } 31 \text { de maio de } 2007,10.637 \text {, de } 30 \text { de dezembro de } \\
\text { 2002, } 11.196 \text {, de } 21 \text { de novembro de } 2005,10.406 \text {, de } 10 \text { de janeiro de } 2002,9.532 \text {, } \\
\text { de } 10 \text { de dezembro de } 1997,12.431 \text {, de } 24 \text { de junho de } 2011,12.414 \text {, de } 9 \text { de junho } \\
\text { de } 2011,8.666 \text {, de } 21 \text { de junho de } 1993,10.925 \text {, de } 23 \text { de julho de } 2004 \text {, os Decretos- } \\
\text { Leis nos } 1.455 \text {, de } 7 \text { de abril de } 1976,1.593 \text {, de } 21 \text { de dezembro de } 1977 \text {, e a Medida } \\
\text { Provisória no } 2.199-14 \text {, de } 24 \text { de agosto de } 2001 \text {; e dá outras providências. }\end{array}$ \\
\hline Publicação & Diário Oficial da União, Seção 1, 10/07/2013 \\
\hline Indexação & $\begin{array}{l}\text { Regime Especial de Tributação do Programa Nacional de Banda Larga para } \\
\text { Implantação de Redes de Telecomunicações, extensão da data-limite para adesão ao }\end{array}$ \\
\hline Temas & $\begin{array}{l}\text { Temas : Aplicações de Telecomunicações : Banda Larga } \\
\text { Temas : Atores no Setor de Telecomunicações : Prestadora / Operadora } \\
\text { Temas : Infraestrutura e Recursos do Setor de Telecomunicações : Equipamentos de } \\
\text { Telecomunicações : Terminais } \\
\text { Temas : Políticas de Telecomunicações : Universalização : Acesso à Telecomunicações } \\
\text { : Educação e Pesquisa }\end{array}$ \\
\hline
\end{tabular}


Temas : Serviços no Setor de Telecomunicações : Internet

Lei $\mathbf{n}^{\circ}$ 12.841, de 9 de julho de 2013 - Altera a Lei $n^{\circ}$ 9.472, de 16 de julho de 1997 - Lei Geral de Telecomunicações, para estabelecer a possibilidade de utilização das redes de telefonia móvel para localização de pessoas desaparecidas.

\begin{tabular}{|l|l|}
\hline Dispositivos & LGT, Art. 130-A, caput. \\
\hline Regulamenta & $\begin{array}{l}\text { Lei no 9.472/1997 - Dispõe sobre a organização dos serviços de telecomunicações, a } \\
\text { criação e funcionamento de um órgão regulador e outros aspectos institucionais, nos } \\
\text { termos da Emenda Constitucional nº 8, de 1995. }\end{array}$ \\
\hline Publicação & Diário Oficial da União, Seção 1, 10/07/2013 \\
\hline Indexação & Lei Geral de Telecomunicações, alteração da \\
\hline Temas & $\begin{array}{l}\text { Temas : Aplicações de Telecomunicações : Aplicações de Segurança } \\
\text { Temas : Aplicações de Telecomunicações : Radiolocalização }\end{array}$ \\
\hline
\end{tabular}

Lei $\mathbf{n}^{\circ}$ 12.865, de 9 de outubro de 2013 - Autoriza o pagamento de subvenção econômica aos produtores da safra 2011/2012 de cana-de-açúcar e de etanol que especifica e o financiamento da renovação e implantação de canaviais com equalização da taxa de juros; dispõe sobre os arranjos de pagamento e as instituições de pagamento integrantes do Sistema de Pagamentos Brasileiro (SPB); autoriza a União a emitir, sob a forma de colocação direta, em favor da Conta de Desenvolvimento Energético (CDE), títulos da dívida pública mobiliária federal; estabelece novas condições para as operações de crédito rural oriundas de, ou contratadas com, recursos do Fundo Constitucional de Financiamento do Nordeste (FNE); altera os prazos previstos nas Leis no 11.941, de 27 de maio de 2009, e no 12.249, de 11 de junho de 2010; autoriza a União a contratar o Banco do Brasil S.A. ou suas subsidiárias para atuar na gestão de recursos, obras e serviços de engenharia relacionados ao desenvolvimento de projetos, modernização, ampliação, construção ou reforma da rede integrada e especializada para atendimento da mulher em situação de violência; disciplina o documento digital no Sistema Financeiro Nacional; disciplina a transferência, no caso de falecimento, do direito de utilização privada de área pública por equipamentos urbanos do tipo quiosque, trailer, feira e banca de venda de jornais e de revistas; altera a incidência da Contribuição para o PIS/Pasep e da Cofins na cadeia de produção e comercialização da soja e de seus subprodutos; altera as Leis nos 12.666, de 14 de junho de 2012, 5.991, de 17 de dezembro de 1973, 11.508, de 20 de julho de 2007, 9.503, de 23 de setembro de 1997, 9.069, de 29 de junho de $1995,10.865$, de 30 de abril de 2004, 12.587, de 3 de janeiro de 2012, 10.826, de 22 de dezembro de 2003, 10.925, de 23 de julho de 2004, 12.350, de 20 de dezembro de 2010, 4.870, de 1o de dezembro de 1965 e 11.196, de 21 de novembro de 2005, e o Decreto no 70.235, de 6 de março de 1972; revoga dispositivos das Leis nos 10.865, de 30 de abril de 2004, 10.925, de 23 de julho de 2004, 12.546, de 14 de dezembro de 2011, e 4.870, de 1o de dezembro de 1965; e dá outras providências.

\begin{tabular}{|c|c|}
\hline Dispositivos & LGT, Art. 60, caput; LGT, Art. 61, $\S 2^{\circ}$. \\
\hline Publicação & Diário Oficial da União, Seção 1, 10/10/2013, pág. p.1 \\
\hline Indexação & $\begin{array}{l}\text { Inclusão Financeira, sua disciplina como integrante do Sistema de Pagamentos } \\
\text { Brasileiro (SPB) } \\
\text { Mobile Payment } \\
\text { Serviço Móvel Pessoal, sua disciplina como integrante do Sistema de Pagamentos } \\
\text { Brasileiro (SPB) } \\
\text { Serviço de Valor Adicionado, sua disciplina como integrante do Sistema de Pagamentos } \\
\text { Brasileiro (SPB) } \\
\text { Sistema de Pagamentos e Transferência de Valores Monetários por meio de } \\
\text { Dispositivos Móveis (STDM) }\end{array}$ \\
\hline Temas & $\begin{array}{l}\text { Temas : Classificações de Serviços no Setor de Telecomunicações : Quanto ao Gênero } \\
\text { : Serviço de Valor Adicionado }\end{array}$ \\
\hline
\end{tabular}


Temas : Infraestrutura e Recursos do Setor de Telecomunicações : Equipamentos de Telecomunicações : Terminais

Temas : Serviços no Setor de Telecomunicações : Serviço Móvel Pessoal (SMP)

\section{Decreto}

Decreto $^{0}$ 7.903, de 4 de fevereiro de 2013 - Estabelece a aplicação de margem de preferência em licitações realizadas no âmbito da administração pública federal para aquisição de equipamentos de tecnologia da informação e comunicação que menciona.

\begin{tabular}{|l|l|}
\hline Anexos & $\begin{array}{l}\text { Anexo - Percentuais e Descrições de Equipamentos de Tecnologia da Informação e } \\
\text { Comunicação sujeitos a margens de preferência. }\end{array}$ \\
\hline Dispositivos & CF, Art. 37, caput; LGT, Art. 76, caput. \\
\hline Correlata & $\begin{array}{l}\text { Lei } \mathrm{n}^{\circ} \text { 8.248/1991 - Dispõe sobre a capacitação e competitividade do setor de } \\
\text { informática e automação, e dá outras providências. } \\
\text { Decreto 7.174, de 12 de maio de 2010 }\end{array}$ \\
\hline Regulamenta & $\begin{array}{l}\text { Lei no 8.666/93 - Regulamenta o artigo 37, inciso XXI, da Constituição Federal, institui } \\
\text { normas para licitações e contratos da Administração Pública e dá outras providências. }\end{array}$ \\
\hline Publicação & Diário Oficial da União, Seção 1, 05-12-2013, pág. 7 \\
\hline Indexação & $\begin{array}{l}\text { Administração Pública Federal, Information and Communication Technology, } \\
\text { regulamentação das margens de preferência em licitações de equipamentos de } \\
\text { Information and Communication Technology, regulamentação das margens de } \\
\text { preferência em licitações de equipamentos de } \\
\text { Política Industrial, Information and Communication Technology, regulamentação das } \\
\text { margens de preferência em licitações de equipamentos de } \\
\text { Política Industrial, Margem de Preferência, regulamentação das margens de preferência } \\
\text { em licitações de equipamentos de tecnologias da informação e comunicação }\end{array}$ \\
\hline Temas & $\begin{array}{l}\text { Temas : Infraestrutura e Recursos do Setor de Telecomunicações : Equipamentos de } \\
\text { Telecomunicações } \\
\text { Temas : Infraestrutura e Recursos do Setor de Telecomunicações : Equipamentos de } \\
\text { Telecomunicações : Terminais } \\
\text { Temas : Políticas de Telecomunicações : Pesquisa \& Desenvolvimento } \\
\text { Temas : Políticas de Telecomunicações : Política Industrial }\end{array}$ \\
\hline
\end{tabular}

Decreto $^{0}$ 7.913, de 7 de fevereiro de 2013 - Altera o Anexo III ao Decreto $n^{\circ} 6.233$, de 11 de outubro de 2007, que estabelece critérios para efeito de habilitação ao Programa de Apoio ao Desenvolvimento Tecnológico da Indústria de Semicondutores - PADIS, que concede isenção do imposto de renda e reduz a zero as alíquotas da Contribuição para o PIS/PASEP, da COFINS e do IPI.

\begin{tabular}{|l|l|}
\hline Anexos & Anexo - Alterações do Anexo III do Decreto 6.233, de 11 de outubro de 2007. \\
\hline Dispositivos & LGT, Art. $2^{\circ}$, caput. \\
\hline Altera & $\begin{array}{l}\text { Decreto } \mathrm{n}^{\circ} \text { 6.233/2007 - Estabelece critérios para efeito de habilitação ao Programa } \\
\text { de Apoio ao Desenvolvimento Tecnológico da Indústria de Semicondutores - PADIS, } \\
\text { que concede isenção do imposto de renda e reduz a zero as alíquotas da Contribuição } \\
\text { para o PIS/PASEP, da COFINS e do IPI, instituído pelos arts. 1o a 11 da Lei no 11.484, } \\
\text { de 31 de maio de 2007. }\end{array}$ \\
\hline Publicação & Diário Oficial da União, Seção 1, 08/02/2013, pág. 2 \\
\hline Indexação & Política Industrial, alteração do anexo III do Decreto 6.233/2007
\end{tabular}




\begin{tabular}{|l|l|}
\hline & $\begin{array}{l}\text { Programa de Apoio ao Desenvolvimento Tecnológico da Indústria de Semicondutores } \\
\text { (PADIS) }\end{array}$ \\
\hline Temas & $\begin{array}{l}\text { Temas : Políticas de Telecomunicações : Pesquisa \& Desenvolvimento } \\
\text { Temas : Políticas de Telecomunicações : Política Industrial }\end{array}$ \\
\hline
\end{tabular}

Decreto $\mathrm{n}^{0}$ 7.921, de 15 de fevereiro de 2013 - Regulamenta a aplicação do Regime Especial de Tributação do Programa Nacional de Banda Larga para Implantação de Redes de Telecomunicações - REPNBL-Redes, de que trata a Lei ${ }^{\circ} 12.715$, de 17 de setembro de 2012.

\begin{tabular}{|c|c|}
\hline Dispositivos & LGT, Art. $2^{\circ}$, inciso I; LGT, Art. $2^{\circ}$, inciso V; LGT, Art. $3^{\circ}$, inciso I. \\
\hline Altera & $\begin{array}{l}\text { Lei n }{ }^{\circ} 12.715 / 2012 \text { - Altera a alíquota das contribuições previdenciárias sobre a folha } \\
\text { de salários devidas pelas empresas que especifica; institui o Programa de Incentivo à } \\
\text { Inovação Tecnológica e Adensamento da Cadeia Produtiva de Veículos Automotores, } \\
\text { o Regime Especial de Tributação do Programa Nacional de Banda Larga para } \\
\text { Implantação de Redes de Telecomunicações, o Regime Especial de Incentivo a } \\
\text { Computadores para Uso Educacional, o Programa Nacional de Apoio à Atenção } \\
\text { Oncológica e o Programa Nacional de Apoio à Atenção da Saúde da Pessoa com } \\
\text { Deficiência; restabelece o Programa Um Computador por Aluno; altera o Programa } \\
\text { de Apoio ao Desenvolvimento Tecnológico da Indústria de Semicondutores, instituído } \\
\text { pela Lei no } 11.484 \text {, de } 31 \text { de maio de } 2007 \text {; altera as Leis nos } 9.250 \text {, de } 26 \text { de dezembro } \\
\text { de } 1995,11.033 \text {, de } 21 \text { de dezembro de } 2004,9.430 \text {, de } 27 \text { de dezembro de } 1996 \text {, } \\
\text { 10.865, de } 30 \text { de abril de } 2004,11.774 \text {, de } 17 \text { de setembro de } 2008 \text {, } 12.546 \text {, de } 14 \text { de } \\
\text { dezembro de } 2011,11.484 \text {, de } 31 \text { de maio de } 2007 \text {, } 10.637 \text {, de } 30 \text { de dezembro de } \\
2002,11.196 \text {, de } 21 \text { de novembro de } 2005,10.406 \text {, de } 10 \text { de janeiro de } 2002 \text {, } 9.532 \text {, } \\
\text { de } 10 \text { de dezembro de } 1997,12.431 \text {, de } 24 \text { de junho de } 2011 \text {, } 12.414 \text {, de } 9 \text { de junho } \\
\text { de } 2011,8.666 \text {, de } 21 \text { de junho de } 1993 \text {, } 10.925 \text {, de } 23 \text { de julho de } 2004 \text {, os Decretos- } \\
\text { Leis nos } 1.455 \text {, de } 7 \text { de abril de } 1976,1.593 \text {, de } 21 \text { de dezembro de } 1977 \text {, e a Medida } \\
\text { Provisória no } 2.199-14 \text {, de } 24 \text { de agosto de } 2001 \text {; e dá outras providências. }\end{array}$ \\
\hline $\begin{array}{l}\text { Regulamentada } \\
\text { por }\end{array}$ & $\begin{array}{l}\text { Portaria MC n } \mathrm{n}^{\circ} 55 \text {, de } 12 \text { de março de } 2013 \text { - Regulamenta os procedimentos para } \\
\text { submissão, análise, aprovação, acompanhamento e fiscalização dos projetos } \\
\text { apresentados ao Ministério das Comunicações referentes ao Regime Especial de } \\
\text { Tributação do Programa Nacional de Banda Larga para Implantação de Redes de } \\
\text { Telecomunicações - REPNBL-Redes, de que trata a Lei } \mathrm{n}^{\circ} 12.715 \text {, de } 17 \text { de setembro } \\
\text { de } 2012 \text { e o Decreto } n^{\circ} 7.921 \text {, de } 15 \text { de fevereiro de } 2013 \text {. } \\
\text { Portaria } n^{\circ} 303 / 2013 \text { - Altera a Portaria } n^{\circ} 55 \text {, de } 12 \text { de março de } 2013 \text {, do Ministério } \\
\text { das Comunicações, que regulamenta os procedimentos para submissão, análise, } \\
\text { aprovação, acompanhamento e fiscalização dos projetos apresentados ao Ministério } \\
\text { das Comunicações referentes ao Regime Especial de Tributação do Programa Nacional } \\
\text { de Banda Larga para Implantação de Redes de Telecomunicações - REPNBL - Redes. }\end{array}$ \\
\hline Publicação & Diário Oficial da União, Seção 1, 18/02/2013, pág. 2 \\
\hline Indexação & $\begin{array}{l}\text { Banda Larga, Regime Especial de Tributação do Programa Nacional de Banda Larga } \\
\text { para Implantação de Redes de Telecomunicações, regulamentação do } \\
\text { INTERNET } \\
\text { Programa Nacional de Banda Larga, Regime Especial de Tributação do Programa } \\
\text { Nacional de Banda Larga para Implantação de Redes de Telecomunicações, } \\
\text { regulamentação do } \\
\text { Regime Especial de Tributação do Programa Nacional de Banda Larga para } \\
\text { Implantação de Redes de Telecomunicações, regulamentação do }\end{array}$ \\
\hline Temas & Larga \\
\hline
\end{tabular}


Temas : Serviços no Setor de Telecomunicações : Internet

\begin{tabular}{|l|l|}
\hline $\begin{array}{l}\text { Decreto } \mathbf{n}^{\circ} \text { 7.932, de } 19 \text { de fevereiro de } 2013 \text { - Altera o Estatuto Social da Empresa Brasil de } \\
\text { Comunicação, aprovado pelo Decreto }{ }^{\circ} \text { 6.689, de } 11 \text { de dezembro de } 2008 .\end{array}$ \\
\hline Dispositivos & CF, Art. 223, caput; LGT, Art. 2 ${ }^{\circ}$, inciso IV; LGT, Art. 211, caput. \\
\hline Altera & Anexo ao Decreto ${ }^{\circ}$ 6.689, de 11 de dezembro de 2008 - Estatuto Social da EBC. \\
\hline Publicação & Diário Oficial da União, Seção 1, 20/02/2013, pág. 9 \\
\hline Indexação & $\begin{array}{l}\text { Empresa Brasil de Comunicação, estatuto social da } \\
\text { RADIOBRÁS }\end{array}$ \\
\hline Temas & Temas : Serviços no Setor de Telecomunicações : Radiodifusão \\
\hline
\end{tabular}

Decreto $^{0}$ 7.962, de 15 de março de 2013 - Regulamenta a Lei no 8.078 , de 11 de setembro de 1990, para dispor sobre a contratação no comércio eletrônico.

\begin{tabular}{|c|c|}
\hline Dispositivos & $\begin{array}{l}\text { CF, Art. } 5^{\circ} \text {, inciso XXXII; LGT, Art. } 2^{\circ} \text {, inciso III; LGT, Art. 19, inciso XVIII; LGT, } \\
\text { Art. } 127 \text {, inciso III. }\end{array}$ \\
\hline Altera & Decreto $^{\circ} 5.903$, de 20 de setembro de 2006 \\
\hline Regulamenta & Lei n ${ }^{\circ} 8.078 / 1990$ - Código de Defesa do Consumidor. \\
\hline Publicação & Diário Oficial da União, Edição Extra, 15/03/2013, pág. 1 \\
\hline Indexação & $\begin{array}{l}\text { Comércio Eletrônico, Direito do Consumidor, regulamentação da Lei 8.078/1990 para } \\
\text { dispor sobre a contratação no comércio eletrônico } \\
\text { Consumidor } \\
\text { Consumidor, Comércio Eletrônico, regulamentação da Lei 8.078/1990 para dispor } \\
\text { sobre a contratação no comércio eletrônico } \\
\text { Consumidor, Direito de Arrependimento, sua previsão na contratação via comércio } \\
\text { eletrônico } \\
\text { Direito de Arrependimento, sua previsão na contratação via comércio eletrônico }\end{array}$ \\
\hline Temas & $\begin{array}{l}\text { Temas : Aplicações de Telecomunicações : Banda Larga } \\
\text { Temas : Ramos Jurídicos Afins : Direito do Consumidor } \\
\text { Temas : Serviços no Setor de Telecomunicações : Internet }\end{array}$ \\
\hline
\end{tabular}

Decreto $\mathrm{n}^{0}$ 7.981, de 8 de abril de 2013 - Altera o Decreto ${ }^{\circ} 5.602$, de 6 de dezembro de 2005, que regulamenta o Programa de Inclusão Digital instituído pela Lei n ${ }^{\circ} 11.196$, de 21 de novembro de 2005.

\begin{tabular}{|l|l|}
\hline Dispositivos & LGT, Art. 79, § $1^{\circ} ;$ LGT, Art. 81, § único, inciso II. \\
\hline Altera & $\begin{array}{l}\text { Decreto }{ }^{\circ} \text { 5.602/2005 - Regulamenta o Programa de Inclusão Digital instituído pela } \\
\text { Lei no } 11.196, \text { de } 21 \text { de novembro de 2005. }\end{array}$ \\
\hline Regulamenta & $\begin{array}{l}\text { Lei do bem - Institui o Regime Especial de Tributação para a Plataforma de Exportação } \\
\text { de Serviços de Tecnologia da Informação - REPES, o Regime Especial de Aquisição } \\
\text { de Bens de Capital para Empresas Exportadoras - RECAP e o Programa de Inclusão } \\
\text { Digital, dentre outras providências. }\end{array}$ \\
\hline Publicação & Diário Oficial da União, Seção 1, 09/04/2013, pág. 2 \\
\hline Indexação & $\begin{array}{l}\text { Banda Larga, INTERNET } \\
\text { Digitalização, Inclusão Digital } \\
\text { Incentivo Fiscal, Inclusão Digital }\end{array}$
\end{tabular}




\begin{tabular}{|l|l|}
\hline & Inclusão Digital, Incentivo Fiscal \\
& Universalização, Inclusão Digital \\
\hline Temas & Temas : Administração do Setor de Telecomunicações : Tributação no Setor de \\
& Telecomunicações \\
& Temas : Políticas de Telecomunicações : Política Industrial \\
& Temas : Políticas de Telecomunicações : Universalização : Financiamento da \\
& Universalização \\
\hline
\end{tabular}

Decreto $\mathbf{n}^{\circ} \mathbf{8 . 0 6 1}$, de 29 de julho de 2013 - Altera o Decreto $\mathrm{n}^{\circ} 5.820$, de 29 de junho de 2006 , o Regulamento dos Serviços de Radiodifusão, aprovado pelo Decreto $n^{\circ} 52.795$, de 31 de outubro de 1963, e dá outras providências.

\begin{tabular}{|c|c|}
\hline Dispositivos & LGT, Art. $1^{\circ}$, caput; LGT, Art. 19, inciso I; LGT, Art. 211, caput. \\
\hline Altera & $\begin{array}{l}\text { Anexo ao Decreto n }{ }^{\circ} 52.795 \text {, de } 31 \text { de outubro de } 1963 \text { - Regulamento dos Serviços } \\
\text { de Radiodifusão. } \\
\text { Anexo ao Decreto n }{ }^{\circ} 2.615 \text {, de } 3 \text { de junho de } 1998 \text { - Regulamento do Serviço de } \\
\text { Radiodifusão Comunitária. } \\
\text { Anexo ao Decreto no } 5.371 \text {, de } 17 \text { de fevereiro de } 2005 \text { - Regulamento do Serviço de } \\
\text { Retransmissão de Televisão e do Serviço de Repetição de Televisão, ancilares ao } \\
\text { Serviço de Radiodifusão de Sons e Imagens. } \\
\text { Decreto no } 5.820 / 2006 \text { - Dispõe sobre a implantação do SBTVD-T, estabelece diretrizes } \\
\text { para a transição do sistema de transmissão analógica para o sistema de transmissão } \\
\text { digital do serviço de radiodifusão de sons e imagens e do serviço de retransmissão de } \\
\text { televisão, e dá outras providências. }\end{array}$ \\
\hline Regulamenta & $\begin{array}{l}\text { Lei n }{ }^{\circ} 4.117 / 1962 \text { - Institui o Código Brasileiro de Telecomunicações. } \\
\text { Lei n }{ }^{\circ} 9.472 / 1997 \text { - Dispõe sobre a organização dos serviços de telecomunicações, a } \\
\text { criação e funcionamento de um órgão regulador e outros aspectos institucionais, nos } \\
\text { termos da Emenda Constitucional n }{ }^{\circ} 8 \text {, de } 1995 \text {. }\end{array}$ \\
\hline Publicação & Diário Oficial da União, Seção 1, 30/07/2013, págs. 1-2 \\
\hline Indexação & $\begin{array}{l}\text { Cronograma de Desligamento da TV analógica, sua alteração para ocorrência no } \\
\text { período de } 1^{\circ} \text { de janeiro de } 2015 \text { a } 31 \text { de dezembro de } 2018 \\
\text { Digitalização, Radiodifusão, sua alteração para ocorrência no período de } 1^{\circ} \text { de janeiro } \\
\text { de } 2015 \text { a } 31 \text { de dezembro de } 2018 \\
\text { Prorrogação da Transição Digital, Cronograma de Desligamento da TV analógica, } \\
\text { sua alteração para ocorrência no período de } 1^{\circ} \text { de janeiro de } 2015 \text { a } 31 \text { de dezembro } \\
\text { de } 2018 \\
\text { Radiodifusão, Cronograma de Desligamento da TV analógica, sua alteração para } \\
\text { ocorrência no período de } 1^{\circ} \text { de janeiro de } 2015 \text { a } 31 \text { de dezembro de } 2018 \\
\text { Sistema Brasileiro de Televisão Digital Terrestre, Cronograma de Desligamento da } \\
\text { TV analógica, sua alteração para ocorrência no período de } 1^{\circ} \text { de janeiro de } 2015 \text { a } 31 \\
\text { de dezembro de } 2018 \\
\text { TV Digital, Cronograma de Desligamento da TV analógica, sua alteração para } \\
\text { ocorrência no período de } 1^{\circ} \text { de janeiro de } 2015 \text { a } 31 \text { de dezembro de } 2018 \\
\text { Transição Analógico-Digital, Radiodifusão, alteração para ocorrência no período de } \\
1^{\circ} \text { de janeiro de } 2015 \text { a } 31 \text { de dezembro de } 2018\end{array}$ \\
\hline Temas & Setor de Telecomunicações : Radiodifusão \\
\hline
\end{tabular}


Temas : Serviços no Setor de Telecomunicações : Radiodifusão : Televisão Aberta :
TV Digital

Decreto $\mathbf{n}^{0}$ 8.135, de 4 de novembro de 2013 - Dispõe sobre as comunicações de dados da administração pública federal direta, autárquica e fundacional, e sobre a dispensa de licitação nas contratações que possam comprometer a segurança nacional.

\begin{tabular}{|c|c|}
\hline Dispositivos & $\begin{array}{l}\text { CF, Art } 5^{\circ} \text {, inciso X; CF, Art. } 5^{\circ} \text {, inciso X; CF, Art. 175, caput; LGT, Art. } 3^{\circ} \text {, inciso } \\
\text { V. }\end{array}$ \\
\hline Regulamenta & $\begin{array}{l}\text { Lei n }{ }^{\circ} \text { 8.666/93 - Regulamenta o artigo 37, inciso XXI, da Constituição Federal, institui } \\
\text { normas para licitações e contratos da Administração Pública e dá outras providências. }\end{array}$ \\
\hline Publicação & Diário Oficial da União, Seção 1, 05/11/2013, pág. p.2 \\
\hline Indexação & $\begin{array}{l}\text { Administração Pública (Lei Geral de Licitações), Dados, sua disciplina na } \\
\text { administração pública federal direta, autárquica e fundacional } \\
\text { Autenticidade das Informações, como requisito dos programas e equipamentos } \\
\text { destinados às comunicações de dados da administração pública federal } \\
\text { Confidencialidade, como requisito dos programas e equipamentos destinados às } \\
\text { comunicações de dados da administração pública federal } \\
\text { Conselho de Defesa Nacional, sua oitiva para edição do Decreto } 8.135 / 2013 \\
\text { Dados, exigência de que as comunicações de dados da administração pública federal } \\
\text { sejam realizadas por redes de telecomunicações e serviços de tecnologia da informação } \\
\text { fornecidos por órgãos ou entidades da administração pública federal, incluindo } \\
\text { empresas públicas e sociedades de economia mista da União e suas subsidiárias } \\
\text { Dados, sua disciplina na administração pública federal direta, autárquica e fundacional } \\
\text { Forma de Telecomunicação } \\
\text { Garantia de Inviolabilidade das Comunicações de Dados, dispensa de licitação nas } \\
\text { contratações de comunicação de dados que possam comprometer a } \\
\text { Integridade, como requisito dos programas e equipamentos destinados às comunicações } \\
\text { de dados da administração pública federal } \\
\text { Inviolabilidade das comunicações de dados, na administração pública federal direta } \\
\text { e indireta } \\
\text { Licitação, dispensa de licitação nas contratações de comunicação de dados que possam } \\
\text { comprometer a } \\
\text { Telecomunicações Brasileiras S.A., Dados, exigência de que tais comunicações sejam } \\
\text { realizadas por redes de telecomunicações e serviços de tecnologia da informação } \\
\text { fornecidos por órgãos ou entidades da administração pública federal, incluindo } \\
\text { empresas públicas e sociedades de economia mista da União e suas subsidiárias }\end{array}$ \\
\hline Temas & $\begin{array}{l}\text { Temas : Administração do Setor de Telecomunicações : Outorgas : Licitação } \\
\text { Temas : Aplicações de Telecomunicações : Banda Larga } \\
\text { Temas : Aplicações de Telecomunicações : Internet } \\
\text { Temas : Infraestrutura e Recursos do Setor de Telecomunicações : Equipamentos de } \\
\text { Telecomunicações } \\
\text { Temas : Infraestrutura e Recursos do Setor de Telecomunicações : Infraestrutura de } \\
\text { Telecomunicações } \\
\text { Temas : Infraestrutura e Recursos do Setor de Telecomunicações : Redes de } \\
\text { Telecomunicações } \\
\text { Temas : Políticas de Telecomunicações : Sigilo em Telecomunicações } \\
\text { Temas : Serviços no Setor de Telecomunicações : Internet }\end{array}$ \\
\hline
\end{tabular}


Temas : Serviços no Setor de Telecomunicações : Serviço de Comunicação Multimídia $(\mathrm{SCM})$

\begin{tabular}{|c|c|}
\hline \multicolumn{2}{|c|}{$\begin{array}{l}\text { Decreto } \mathbf{n}^{\circ} \mathbf{8 . 1 3 9} \text {, de } 7 \text { de novembro de } \mathbf{2 0 1 3} \text { - Dispõe sobre as condições para extinção do serviço } \\
\text { de radiodifusão sonora em ondas médias de caráter local, sobre a adaptação das outorgas vigentes para } \\
\text { execução deste serviço e dá outras providências. }\end{array}$} \\
\hline Dispositivos & CF, Art. 21, inciso XII, alínea a (em 15/08/1995); LGT, Art. 211, caput. \\
\hline egulamenta & $\begin{array}{l}\text { Lei no } 4.117 / 1962 \text { - Institui o Código Brasileiro de Telecomunicações. } \\
\text { Anexo ao Decreto n }{ }^{\circ} 52.795 \text {, de } 31 \text { de outubro de } 1963 \text { - Regulamento dos Serviços } \\
\text { de Radiodifusão. }\end{array}$ \\
\hline Publicação & Diário Oficial da União, Seção 1, 08/11/2013, pág. p.1 \\
\hline ide & $\begin{array}{l}\text { Frequência Modulada, Rádio FM, disciplina da extinção do serviço de radiodifusão } \\
\text { sonora em ondas médias e sua possível adaptação de instrumentos de outorgas para } \\
\text { os de execução do serviço de radiodifusão sonoram em frequência modulada } \\
\text { Ondas Médias, Rádio AM, disciplina da extinção do serviço de radiodifusão sonora } \\
\text { em ondas médias e sua possível adaptação de instrumentos de outorgas para os de } \\
\text { execução do serviço de radiodifusão sonoram em frequência modulada } \\
\text { Radiodifusão Sonora, Ondas Médias, disciplina da extinção do serviço de radiodifusão } \\
\text { sonora em ondas médias e sua possível adaptação de instrumentos de outorgas para } \\
\text { os de execução do serviço de radiodifusão sonoram em frequência modulada } \\
\text { Radiodifusão Sonora, Rádio AM, disciplina da extinção do serviço de radiodifusão } \\
\text { sonora em ondas médias e sua possível adaptação de instrumentos de outorgas para } \\
\text { os de execução do serviço de radiodifusão sonoram em frequência modulada }\end{array}$ \\
\hline Iemas & de Telecomunicações : Radiodifusão \\
\hline
\end{tabular}

Decreto $\mathbf{n}^{\circ} \mathbf{8 . 1 7 4}$, de 26 de dezembro de 2013 - Altera os Anexos I e II ao Decreto no 7.867, de 19 de dezembro de 2012, relativos ao Programa de Dispêndios Globais - PDG das empresas estatais federais para 2013.

\begin{tabular}{|l|l|}
\hline Dispositivos & LGT, Art. 186, caput. \\
\hline Altera & $\begin{array}{l}\text { Anexo ao Decreto n } \\
\text { Globais - PDG para } 2013 \text { das empresas estatais federais. }\end{array}$ \\
\hline Publicação & Diário Oficial da União, Seção 1, 27/12/2013, págs. p.7-20 \\
\hline Indexação & $\begin{array}{l}\text { Programa de Dispêndios Globais (Empresas Estatais Federais), PGD para 2014 } \\
\text { Telecomunicações Brasileiras S.A., Programa de Dispêndios Globais (Empresas } \\
\text { Estatais Federais), PGD para 2014 }\end{array}$ \\
\hline Temas & $\begin{array}{l}\text { Temas : Atores no Setor de Telecomunicações : Prestadora / Operadora } \\
\text { Temas : Políticas de Telecomunicações : Concorrência no Setor de Telecomunicações }\end{array}$ \\
\hline
\end{tabular}

\section{Portaria Ministerial}

Portaria MC n⿳ 13, de $1^{\circ}$ de fevereiro de 2013 - Institui o processo de habilitação e seleção de propostas para o Projeto das Cidades Digitais para o exercício de 2013.

\begin{tabular}{|l|l|}
\hline Órgão Emissor & Ministério das Comunicações - Gabinete do Ministro. \\
\hline Anexos & Anexo - Tabela de Prazos. \\
\hline Dispositivos & LGT, Art. $2^{\circ}$, inciso I. \\
\hline
\end{tabular}




\begin{tabular}{|l|l|}
\hline Correlata & $\begin{array}{l}\text { Portaria } \mathrm{MC}^{\circ} \text { 376/2011 - Institui o Projeto de Implantação e Manutenção das Cidades } \\
\text { Digitais. }\end{array}$ \\
\hline Publicação & Diário Oficial da União, Seção 1, 04/02/2013, pág. 73 \\
\hline Indexação & $\begin{array}{l}\text { Cidades Digitais, processso de habilitação e seleção de propostas para o Projeto } \\
\text { Projeto Cidades Digitais }\end{array}$ \\
\hline Temas & $\begin{array}{l}\text { Temas : Políticas de Telecomunicações : Pesquisa \& Desenvolvimento } \\
\text { Temas : Políticas de Telecomunicações : Universalização : Acesso à Telecomunicações } \\
\text { : Educação e Pesquisa } \\
\text { Temas : Políticas de Telecomunicações : Universalização : Acesso às Telecomunicações }\end{array}$ \\
\hline
\end{tabular}

Portaria MC no 14, de 6 de fevereiro de 2013 - Estabelece diretrizes para a aceleração do acesso ao Sistema Brasileiro de Televisão Digital Terrestre - SBTVD-T e para a ampliação da disponibilidade de espectro de radiofrequência para atendimento dos objetivos do Programa Nacional de Banda Larga - PNBL.

\begin{tabular}{|l|l|}
\hline Órgão Emissor & Ministério das Comunicações - Gabinete do Ministro. \\
\hline Dispositivos & LGT, Art. $2^{\circ}$, inciso I; LGT, Art. 19, inciso VIII; LGT, Art. 160, caput. \\
\hline Correlata & $\begin{array}{l}\text { Resolução no }{ }^{\circ} \text { 625/2013 - Aprova a Atribuição, a Destinação e o Regulamento sobre } \\
\text { Condições de Uso de Radiofrequências na Faixa de 698 MHz a 806 MHz. }\end{array}$ \\
\hline Publicação & Diário Oficial da União, Seção 1, 07/02/2013, pág. 46 \\
\hline Indexação & $\begin{array}{l}\text { Espectro de Radiofreqüências, Faixa de 698 a 806 MHz, determinação à ANATEL } \\
\text { para que iniciasse os procedimentos administrativos de atribuiçâo, destinação e } \\
\text { distribuição da faixa para atendimento dos objetivos do PNBL } \\
\text { Faixa de 698 a 806 MHz, Programa Nacional de Banda Larga, determinação à } \\
\text { ANATEL para que iniciasse os procedimentos administrativos de atribuição, destinação } \\
\text { e distribuição da faixa para atendimento dos objetivos do PNBL } \\
\text { TV Digital, Faixa de 698 a 806 MHz, determinação à ANATEL para que iniciasse os } \\
\text { procedimentos administrativos de atribuição, destinação e distribuição da faixa para } \\
\text { atendimento dos objetivos do PNBL }\end{array}$ \\
\hline Temas & $\begin{array}{l}\text { Temas : Aplicações de Telecomunicações : Banda Larga } \\
\text { Temas : Infra-estrutura e Recursos do Setor de Telecomunicações : Espectro de } \\
\text { Radiofrequência : Atribuição, Destinação e Distribuição de Radiofrequência } \\
\text { Temas : Serviços no Setor de Telecomunicações : Radiodifusão : Televisão Aberta : } \\
\text { TV Digital } \\
\text { Temas : Serviços no Setor de Telecomunicações : Serviço Móvel Pessoal (SMP) }\end{array}$ \\
\hline
\end{tabular}

Portaria MC n 55, de 12 de março de 2013 - Regulamenta os procedimentos para submissão, análise, aprovação, acompanhamento e fiscalização dos projetos apresentados ao Ministério das Comunicações referentes ao Regime Especial de Tributação do Programa Nacional de Banda Larga para Implantação de Redes de Telecomunicações - REPNBL-Redes, de que trata a Lei $n^{\circ} 12.715$, de 17 de setembro de 2012 e o Decreto $\mathrm{n}^{\circ} 7.921$, de 15 de fevereiro de 2013.

\begin{tabular}{|c|c|c|}
\hline Órgão Emissor & \multicolumn{2}{|c|}{ Ministério das Comunicações - Gabinete do Ministro. } \\
\hline \multirow[t]{2}{*}{ Anexos } & \multicolumn{2}{|c|}{$\begin{array}{l}\text { Anexo } 1 \text { - Descrição dos equipamentos contemplados segundo a Nomenclatura } \\
\text { Comum do Mercosul. }\end{array}$} \\
\hline & \begin{tabular}{|l|}
$\begin{array}{l}\text { Alterado } \\
\text { por }\end{array}$ \\
\end{tabular} & $\begin{array}{l}\text { Portaria } \mathrm{n}^{\circ} 303 / 2013 \text { - Altera a Portaria } \mathrm{n}^{\circ} 55 \text {, de } 12 \text { de março de } 2013 \text {, } \\
\text { do Ministério das Comunicações, que regulamenta os procedimentos } \\
\text { para submissão, análise, aprovação, acompanhamento e fiscalização }\end{array}$ \\
\hline
\end{tabular}




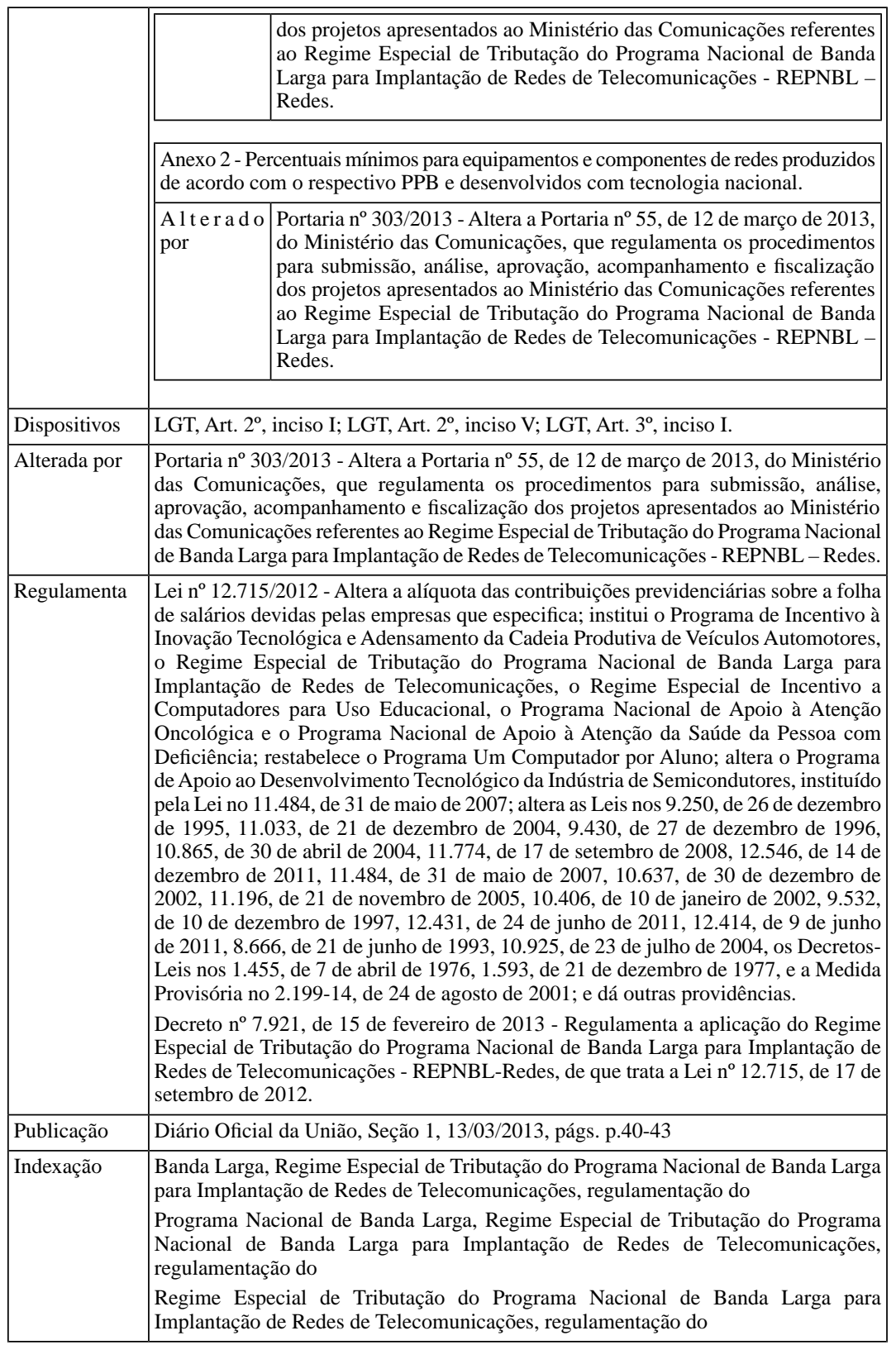




\begin{tabular}{|l|l|}
\hline Temas & $\begin{array}{l}\text { Temas : Aplicações de Telecomunicações : Banda Larga } \\
\text { Temas : Serviços no Setor de Telecomunicações : Internet }\end{array}$ \\
\hline
\end{tabular}

\begin{tabular}{|c|c|}
\hline & $\begin{array}{l}\text { ço de } 2013 \text { - Alte } \\
\text { de } 18 \text { de dezem }\end{array}$ \\
\hline Órgão Emissor & Ministério das Comunicações - Gabinete do Ministro. \\
\hline itivos & II; LGT, A \\
\hline Altera & $\begin{array}{l}\text { Anexo à Portaria n }{ }^{\circ} 489 \text { de } 18 \text { de dezembro de } 2012 \text { - Norma Regulamentar do Canal } \\
\text { da Cidadania. }\end{array}$ \\
\hline Corr & $\begin{array}{l}\text { Lei } \mathrm{n}^{\circ} 11.652 / 2008 \text { - Institui os princípios e objetivos dos serviços de radiodifusão } \\
\text { pública explorados pelo Poder Executivo ou outorgados a entidades de sua } \\
\text { administração indireta; autoriza o Poder Executivo a constituir a Empresa Brasil de } \\
\text { Comunicação - EBC; altera a Lei } \mathrm{n}^{\circ} 5.070 \text {, de } 7 \text { de julho de 1966; e dá outras } \\
\text { providências [Conversão da Medida Provisória no } 398 \text {, de } 10 \text { de outubro de 2007]. }\end{array}$ \\
\hline Regu & $\begin{array}{l}\text { Decreto n }{ }^{\circ} 5.820 / 2006 \text { - Dispõe sobre a implantação do SBTVD-T, estabelece diretrizes } \\
\text { para a transição do sistema de transmissão analógica para o sistema de transmissão } \\
\text { digital do serviço de radiodifusão de sons e imagens e do serviço de retransmissão de } \\
\text { televisão, e dá outras providências. }\end{array}$ \\
\hline Publicação & Diário Oficial da União, Seção 1, 14-03-2013, pág. p.50 \\
\hline Indexação & $\begin{array}{l}\text { Canal da cidadania, Norma Regulamentar do Canal da Cidadania, alteração da } \\
\text { Sistema Brasileiro de Televisão Digital Terrestre, Norma Regulamentar do Canal da } \\
\text { Cidadania, alteração da } \\
\text { TV Digital, Norma Regulamentar do Canal da Cidadania, alteração da }\end{array}$ \\
\hline Ten & $\begin{array}{l}\text { Temas : Aplicações de Telecomunicações : Aplicações Educacionais } \\
\text { Temas : Serviços no Setor de Telecomunicações : Radiodifusão : Televisão Aberta : } \\
\text { TV Digital }\end{array}$ \\
\hline
\end{tabular}

Portaria MC n $\mathbf{~ 8 7}^{0}$, de 10 de abril de 2013 - Estabelece os requisitos técnicos mínimos dos telefones portáteis que possibilitam o acesso à internet em alta velocidade do tipo smartphone, beneficiados pela desoneração fiscal instituída pela Lei $\mathrm{n}^{\circ} 11.196$, de 21 de novembro de 2005 e regulamentada pelo Decreto $\mathrm{n}^{\circ} 5.602$, de 6 de dezembro de 2005.

\begin{tabular}{|c|c|}
\hline Órgão Emissor & Ministério das Comunicações - Gabinete do Ministro. \\
\hline Dispositivos & LGT, Art. $2^{\circ}$, inciso V; LGT, Art. 78, caput; LGT, Art. 79, $\S 1^{\circ}$. \\
\hline Regulamenta & 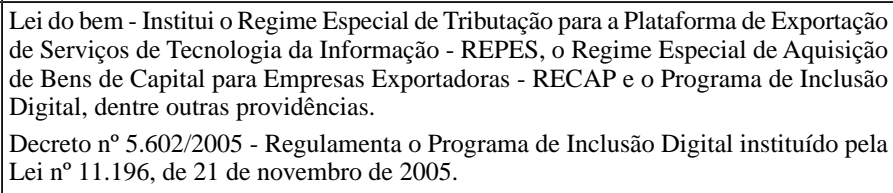 \\
\hline Publicação & Diário Oficial da União, Seção 1, 11/04/2013, pág. p.63 \\
\hline Indexação & $\begin{array}{l}\text { Digitalização, Inclusão Digital, requisitos técnicos mínimos de smartphones para } \\
\text { obtenção de benefício de oneração fiscal } \\
\text { Equipamentos de Telecomunicações } \\
\text { Equipamentos de Telecomunicações, Smartphone, seus requisitos técnicos mínimos } \\
\text { de acesso à internet em alta velocidade para obtenção de benefício de oneração fiscal }\end{array}$ \\
\hline
\end{tabular}




\begin{tabular}{|c|c|}
\hline & $\begin{array}{l}\text { INTERNET, Smartphone, seus requisitos técnicos mínimos de acesso à internet em } \\
\text { alta velocidade para obtenção de benefício de oneração fiscal }\end{array}$ \\
\hline & $\begin{array}{l}\text { Incentivo Fiscal, Inclusão Digital, requisitos técnicos mínimos de smartphones para } \\
\text { obtenção de benefício de oneração fiscal }\end{array}$ \\
\hline & $\begin{array}{l}\text { Inclusão Digital, Incentivo Fiscal, requisitos técnicos mínimos de smartphones para } \\
\text { obtenção de benefício de oneração fiscal }\end{array}$ \\
\hline & $\begin{array}{l}\text { Smartphone, seus requisitos técnicos mínimos de acesso à internet em alta velocidade } \\
\text { para obtenção de benefício de oneração fiscal }\end{array}$ \\
\hline & $\begin{array}{l}\text { Universalização, Inclusão Digital, requisitos técnicos mínimos de smartphones para } \\
\text { obtenção de benefício de oneração fiscal }\end{array}$ \\
\hline \multirow[t]{3}{*}{ Temas } & $\begin{array}{l}\text { Temas : Administração do Setor de Telecomunicações : Tributação no Setor de } \\
\text { Telecomunicações }\end{array}$ \\
\hline & Temas : Políticas de Telecomunicações : Política Industrial \\
\hline & $\begin{array}{l}\text { Temas : Políticas de Telecomunicações : Universalização : Financiamento da } \\
\text { Universalização }\end{array}$ \\
\hline
\end{tabular}

Portaria MC n⿳0 112, de 22 de abril de 2013 - Aprova o Regulamento de Sanções Administrativas aplicáveis a entidades prestadoras dos serviços de radiodifusão, seus ancilares e auxiliares.

\begin{tabular}{|c|c|}
\hline Órgão Emissor & ério das Comunicações - Gabinete do Ministro. \\
\hline Anexos & $\begin{array}{l}\text { Anexo } 1 \text { - Fator Relativo ao Tipo de Serviço/Classe da Emissora (K1). } \\
\text { Anexo } 2 \text { - Fator Relativo ao Porte do Município (K2). } \\
\text { Anexo } 3 \text { - Fator Relativo à Gravidade da Infração (K3). }\end{array}$ \\
\hline Dispositivos & CF, Art. 21, inciso XII, alínea a (em 15/08/1995); LGT, Art. 211, caput. \\
\hline Revoga & Portaria $\mathrm{n}^{\circ} 394$, de 30 de agosto de 2012 \\
\hline Regulamenta & $\begin{array}{l}\text { Lei no } 4.117 / 1962 \text { - Institui o Código Brasileiro de Telecomunicações. } \\
\text { Lei no 9.612/1998 - Institui o Serviço de Radiodifusão Comunitária e dá outras } \\
\text { providências. } \\
\text { Decreto } n^{\circ} 52.795 / 1963 \text { - Aprova o Regulamento dos Serviços de Radiodifusão. } \\
\text { Decreto no } \mathrm{n}^{\circ} \text { 2.615/1998 - Aprova o Regulamento do Serviço de Radiodifusão } \\
\text { Comunitária. } \\
\text { Decreto no } 5.371 / 2005 \text { - Aprova o Regulamento do Serviço de Retransmissão de } \\
\text { Televisão e do Serviço de Repetição de Televisão, ancilares ao Serviço de Radiodifusão } \\
\text { de Sons e Imagens. }\end{array}$ \\
\hline Publicação & Diário Oficial da União, Seção 1, 23/04/2013, págs. p.86-89 \\
\hline Indexação & $\begin{array}{l}\text { Autorização (Radiodifusão), Serviço de Radiodifusão Comunitária, condições de } \\
\text { revogação de autorização do } \\
\text { Cassação, Radiodifusão, aprovação do Regulamento de Sanções Administrativas } \\
\text { aplicáveis a entidades prestadoras dos serviços de radiodifusão, seus ancilares e } \\
\text { auxiliares } \\
\text { Infração, classificação das infrações administrativas } \\
\text { Ministério das Comunicações, Regulamento de Sanções Administrativas, aprovação } \\
\text { do } \\
\text { Multa (Sanção Administrativa), parâmetros para aplicação de } \\
\text { Proporcionalidade, na aplicação de sanções administrativas } \\
\text { Punição } \\
\text { Radiodifusão, Regulamento de Sanções Administrativas, aprovação do }\end{array}$ \\
\hline
\end{tabular}




\begin{tabular}{|l|l|}
\hline Regulamento de Sanções Administrativas \\
Regulamento de Sanções Administrativas, aprovação do \\
Revogação, Radiodifusão, aprovação do Regulamento de Sanções Administrativas \\
aplicáveis a entidades prestadoras dos serviços de radiodifusão, seus ancilares e \\
auxiliares \\
Sanção, Regulamento de Sanções Administrativas, aprovação do \\
Serviço de Radiodifusão Comunitária, Autorização (Radiodifusão), condições de \\
revogação de autorização do \\
Suspensão Temporária (Sanção Administrativa), Radiodifusão, aprovação do \\
Regulamento de Sanções Administrativas aplicáveis a entidades prestadoras dos \\
serviços de radiodifusão, seus ancilares e auxiliares \\
Termo de Ajuste de Conduta, Radiodifusão, previsão de TAC no Regulamento de \\
Sanções Administrativas do Ministério das Comunicações \\
$\begin{array}{l}\text { Temas : Administração do Setor de Telecomunicações : Fiscalização das } \\
\text { Telecomunicações } \\
\text { Temas : Administração do Setor de Telecomunicações : Outorgas : Autorização (regras } \\
\text { aplicáveis) } \\
\text { Temas : Administração do Setor de Telecomunicações : Outorgas : Concessão (regras } \\
\text { aplicáveis) } \\
\text { Temas : Administração do Setor de Telecomunicações : Outorgas : Permissão (regras } \\
\text { aplicáveis) } \\
\text { Temas : Atores no Setor de Telecomunicações : Poder Executivo : Ministério das } \\
\text { Comunicações } \\
\text { Temas : Serviços no Setor de Telecomunicações : Radiodifusão }\end{array}$ \\
\hline
\end{tabular}

Portaria MC n 159, de 11 de junho de 2013 - Autoriza o funcionamento, em caráter provisório, de entidades prestadoras de serviços de radiodifusão e seus ancilares previamente outorgadas via decreto legislativo ou ato de outorga, detenham contrato de concessão ou permissão celebrado com o Ministério das Comunicações e tenham protocolizado requerimento de aprovação dos locais de instalação e uso de equipamentos.

\begin{tabular}{|c|c|}
\hline Órgão Emissor & Ministério das Comunicações - Gabinete do Ministro. \\
\hline Dispositivos & $\begin{array}{l}\text { CF, Art. 21, inciso XII, alínea a (em 15/08/1995); CF, Art. 223, caput; LGT, Art. 211, } \\
\text { caput. }\end{array}$ \\
\hline Altera & $\begin{array}{l}\text { Portaria } \mathrm{MC} \mathrm{n}^{\circ} \text { 366, de } 14 \text { de agosto de } 2012 \text { - Dispõe sobre os procedimentos de } \\
\text { autorização para a execução dos serviços de retransmissão e repetição de televisão. }\end{array}$ \\
\hline Revoga & $\begin{array}{l}\text { Portaria } \mathrm{MC} \mathrm{n}^{\circ} 86 \text {, de } 15 \text { de fevereiro de } 2012 \text { - Disciplina o funcionamento em caráter } \\
\text { provisório de entidades prestadoras de Serviços de Radiodifusão. }\end{array}$ \\
\hline Correlata & $\begin{array}{l}\text { Decreto } \mathrm{n}^{\circ} 7.670 / 2012 \text { - Altera dispositivos do Regulamento dos Serviços de } \\
\text { Radiodifusão aprovado pelo Decreto } \mathrm{n}^{\circ} 52.795 \text {, de } 31 \text { de outubro de } 1963 \text {, e dos } \\
\text { Decretos } \mathrm{n}^{\circ} 88.066 \text {, de } 26 \text { de janeiro de } 1983 \text {, e n } \mathrm{n}^{\circ} 5.820 \text {, de } 29 \text { de junho de } 2006 \text {. } \\
\text { Decreto } \mathrm{n}^{\circ} 7.760 \text {, de } 23 \text { de julho de } 2012 \\
\text { Portaria ANATEL } \mathrm{n}^{\circ} 448 \text {, de } 4 \text { de junho de } 2013 \text { - Atribui a competência decorrente } \\
\text { de Acordo de Cooperação Técnica celebrado entre o Ministério das Comunicações e } \\
\text { a Agência Nacional de Telecomunicações (ANATEL). }\end{array}$ \\
\hline Regulamenta & $\begin{array}{l}\text { Anexo ao Decreto n 52.795, de } 31 \text { de outubro de } 1963 \text { - Regulamento dos Serviços } \\
\text { de Radiodifusão. }\end{array}$ \\
\hline
\end{tabular}




\begin{tabular}{|c|c|}
\hline & $\begin{array}{l}\text { Anexo ao Decreto } \mathrm{n}^{\circ} 5.371 \text {, de } 17 \text { de fevereiro de } 2005 \text { - Regulamento do Serviço de } \\
\text { Retransmissão de Televisão e do Serviço de Repetição de Televisão, ancilares ao } \\
\text { Serviço de Radiodifusão de Sons e Imagens. }\end{array}$ \\
\hline Publicação & Diário Oficial da União, Seção 1, 12/06/2013, pág. p.65 \\
\hline \multirow[t]{11}{*}{ Indexação } & $\begin{array}{l}\text { Competência, Ministério das Comunicações, autorização de funcionamento em caráter } \\
\text { provisório de entidades prestadoras de serviços de radiodifusão e seus ancilares que } \\
\text { ainda não tenham tido o requerimento de aprovação dos locais de instalação e uso de } \\
\text { equipamentos analisado } \\
\text { Competência, Presidência da República, autorização de funcionamento em caráter } \\
\text { provisório de entidades prestadoras de serviços de radiodifusão e seus ancilares que } \\
\text { ainda não tenham tido o requerimento de aprovação dos locais de instalação e uso de } \\
\text { equipamentos analisado }\end{array}$ \\
\hline & $\begin{array}{l}\text { Concessão (Radiodifusão), Competência, autorização de funcionamento em caráter } \\
\text { provisório de entidades prestadoras de serviços de radiodifusão e seus ancilares que } \\
\text { ainda não tenham tido o requerimento de aprovação dos locais de instalação e uso de } \\
\text { equipamentos analisado }\end{array}$ \\
\hline & $\begin{array}{l}\text { Concessão, Radiodifusão, autorização de funcionamento em caráter provisório de } \\
\text { entidades prestadoras de serviços de radiodifusão e seus ancilares que ainda não tenham } \\
\text { tido o requerimento de aprovação dos locais de instalação e uso de equipamentos } \\
\text { analisado }\end{array}$ \\
\hline & $\begin{array}{l}\text { Equipamentos de Telecomunicações, Radiodifusão, autorização de funcionamento } \\
\text { em caráter provisório de entidades prestadoras de serviços de radiodifusão e seus } \\
\text { ancilares que ainda não tenham tido o requerimento de aprovação dos locais de } \\
\text { instalação e uso de equipamentos analisado }\end{array}$ \\
\hline & $\begin{array}{l}\text { Equipamentos de Telecomunicações, Requerimento de Aprovação dos Locais de } \\
\text { Instalação e Uso de Equipamentos, autorização de funcionamento em caráter provisório } \\
\text { de entidades prestadoras de serviços de radiodifusão e seus ancilares que ainda não } \\
\text { tenham tido o requerimento de aprovação dos locais de instalação e uso de } \\
\text { equipamentos analisado }\end{array}$ \\
\hline & $\begin{array}{l}\text { Ministério das Comunicações, Competência, autorização de funcionamento em caráter } \\
\text { provisório de entidades prestadoras de serviços de radiodifusão e seus ancilares que } \\
\text { ainda não tenham tido o requerimento de aprovação dos locais de instalação e uso de } \\
\text { equipamentos analisado }\end{array}$ \\
\hline & $\begin{array}{l}\text { Outorga, Competência, autorização de funcionamento em caráter provisório de } \\
\text { entidades prestadoras de serviços de radiodifusão e seus ancilares que ainda não tenham } \\
\text { tido o requerimento de aprovação dos locais de instalação e uso de equipamentos } \\
\text { analisado }\end{array}$ \\
\hline & $\begin{array}{l}\text { Permissão (Radiodifusão), Competência, autorização de funcionamento em caráter } \\
\text { provisório de entidades prestadoras de serviços de radiodifusão e seus ancilares que } \\
\text { ainda não tenham tido o requerimento de aprovação dos locais de instalação e uso de } \\
\text { equipamentos analisado }\end{array}$ \\
\hline & $\begin{array}{l}\text { Presidência da República, Competência, autorização de funcionamento em caráter } \\
\text { provisório de entidades prestadoras de serviços de radiodifusão e seus ancilares que } \\
\text { ainda não tenham tido o requerimento de aprovação dos locais de instalação e uso de } \\
\text { equipamentos analisado }\end{array}$ \\
\hline & $\begin{array}{l}\text { Radiodifusão, Concessão, autorização de funcionamento em caráter provisório de } \\
\text { entidades prestadoras de serviços de radiodifusão e seus ancilares que ainda não tenham } \\
\text { tido o requerimento de aprovação dos locais de instalação e uso de equipamentos } \\
\text { analisado }\end{array}$ \\
\hline & $\begin{array}{l}\text { Radiodifusão, Outorga, autorização de funcionamento em caráter provisório de } \\
\text { entidades prestadoras de serviços de radiodifusão e seus ancilares que ainda não tenham }\end{array}$ \\
\hline
\end{tabular}




\begin{tabular}{|l|l|}
\hline & $\begin{array}{l}\text { tido o requerimento de aprovação dos locais de instalação e uso de equipamentos } \\
\text { analisado } \\
\text { Radiodifusão, Requerimento de Aprovação dos Locais de Instalação e Uso de } \\
\text { Equipamentos, autorização de funcionamento em caráter provisório de entidades } \\
\text { prestadoras de serviços de radiodifusão e seus ancilares que ainda não tenham tido o } \\
\text { requerimento de aprovação dos locais de instalação e uso de equipamentos analisado } \\
\text { Requerimento de Aprovação dos Locais de Instalação e Uso de Equipamentos, } \\
\text { autorização de funcionamento em caráter provisório de entidades prestadoras de } \\
\text { serviços de radiodifusão e seus ancilares que ainda não tenham tido o requerimento } \\
\text { de aprovação dos locais de instalação e uso de equipamentos analisado } \\
\text { Serviço Ancilar } \\
\text { Serviço Ancilar, Radiodifusão, autorização de funcionamento em caráter provisório } \\
\text { de entidades prestadoras de serviços de radiodifusão e seus ancilares que ainda não } \\
\text { tenham tido o requerimento de aprovação dos locais de instalação e uso de } \\
\text { equipamentos analisado }\end{array}$ \\
\hline Temas & \begin{tabular}{l} 
Temas : Serviços no Setor de Telecomunicações : Radiodifusão \\
\hline
\end{tabular}
\end{tabular}

Portaria MC $\mathbf{n}^{\circ}$ 197, de $1^{\circ}$ julho de 2013 - Estabelece data limite para a apresentação de pedido de renovação de outorga de serviço de radiodifusão comunitária e altera a Norma $n^{\circ} 1 / 2011$, aprovada pela Portaria $n^{\circ} 462$, de 14 de outubro de 2011.

\begin{tabular}{|c|c|}
\hline Órgão Emissor & Ministério das Comunicações - Gabinete do Ministro. \\
\hline Anexos & $\begin{array}{l}\text { Anexo } 1 \text { - Alterações ao Anexo II à Norma } n^{\circ} 01 / 2011 \text {, aprovada pela Portaria } n^{\circ} 462 \text {, } \\
\text { de } 2011 \text {. } \\
\text { Anexo } 2 \text { - Alterações ao Anexo XII à Norma } n^{\circ} 01 / 2011 \text {, aprovada pela Portaria } n^{\circ} \\
462 \text {, de } 2011 \text {. }\end{array}$ \\
\hline Dispositivos & CF, Art. 21, inciso XII, alínea a (em 15/08/1995); LGT, Art. 211, caput. \\
\hline Altera & $\begin{array}{l}\text { Anexo à Portaria } \mathrm{MC} \mathrm{n}^{\circ} 462 \text {, de } 14 \text { de outubro de } 2011 \text { - Norma Complementar } \mathrm{n}^{\circ} \\
1 / 2011 \text { - Serviço de Radiodifusão Comunitária. }\end{array}$ \\
\hline Regulamenta & $\begin{array}{l}\text { Lei n }{ }^{\circ} 4.117 / 1962 \text { - Institui o Código Brasileiro de Telecomunicações. } \\
\text { Lei n }{ }^{\circ} 9.612 / 1998 \text { - Institui o Serviço de Radiodifusão Comunitária e dá outras } \\
\text { providências. } \\
\text { Decreto n }{ }^{\circ} 52.795 / 1963 \text { - Aprova o Regulamento dos Serviços de Radiodifusão. }\end{array}$ \\
\hline Publicação & Diário Oficial da União, Seção 1, 02/07/2013, pág. p.41 \\
\hline Indexação & $\begin{array}{l}\text { Norma Complementar do Serviço de Radiodifusão Comunitária, alteração da } \\
\text { Serviço de Radiodifusão Comunitária, Norma Complementar do Serviço de } \\
\text { Radiodifusão Comunitária, alteração da } \\
\text { Serviço de Radiodifusão Comunitária, disciplina dos pedidos de renovação de outorga } \\
\text { do }\end{array}$ \\
\hline Temas & $\begin{array}{l}\text { Temas : Administração do Setor de Telecomunicações : Fiscalização das } \\
\text { Telecomunicações } \\
\text { Temas : Serviços no Setor de Telecomunicações : Radiodifusão : Radiodifusão } \\
\text { Comunitária }\end{array}$ \\
\hline
\end{tabular}

Portaria MC n⿳ 231, de 7 de agosto de 2013 - Estabelece regras para a autorização de alteração de características técnicas de operação das emissoras de serviços de radiodifusão e seus ancilares que resultem em alteração da classe e grupo de enquadramento.

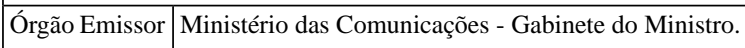




\begin{tabular}{|l|l|}
\hline Anexos & Anexo - Quadros de Grupos e Classes do Serviço de Radiodifusão. \\
\hline Dispositivos & $\begin{array}{l}\text { CF, Art. 21, inciso XII, alínea a (em 15/08/1995); CF, Art. 223, caput; LGT, Art. 211, } \\
\text { caput. }\end{array}$ \\
\hline Revoga & Portaria nº 275/2010 \\
\hline Regulamenta & $\begin{array}{l}\text { Lei no 4.117/1962 - Institui o Código Brasileiro de Telecomunicações. } \\
\text { Decreto nº 52.795/1963 - Aprova o Regulamento dos Serviços de Radiodifusão. }\end{array}$ \\
\hline Publicação & $\begin{array}{l}\text { Diário Oficial da União, Seção 1, 08/08/2013, págs. p.51-52 } \\
\text { Diário Oficial da União, Seção 1, 09/08/2013, pág. p.59 [ Retificação ] }\end{array}$ \\
\hline Indexação & $\begin{array}{l}\text { Alteração de Características Técnicas de Operação de Emissoras de Radiodifusão, } \\
\text { disciplina ministerial da análise de } \\
\text { Promoção de Classe, Alteração de Características Técnicas de Operação de Emissoras } \\
\text { de Radiodifusão, disciplina ministerial da análise de } \\
\text { Radiodifusão Sonora, Alteração de Características Técnicas de Operação de Emissoras } \\
\text { de Radiodifusão, disciplina ministerial da análise de } \\
\text { Radiodifusão Sonora, Promoção de Classe, disciplina ministerial da análise de alteração } \\
\text { de características técnicas de operação de emissoras de radiodifusão } \\
\text { Radiodifusão, Alteração de Características Técnicas de Operação de Emissoras de } \\
\text { Radiodifusão, disciplina ministerial da análise de } \\
\text { Radiodifusão, Promoção de Classe, disciplina ministerial da análise de alteração de } \\
\text { características técnicas de operação de emissoras de radiodifusão }\end{array}$ \\
\hline Temas : Serviços no Setor de Telecomunicações : Radiodifusão \\
\hline Temas
\end{tabular}

Portaria MC n⿳ 252, de 8 de agosto de 2013 - Disciplina a natureza, as condições de prestação, e a competência para outorga, exploração e condições de uso de radiofrequência associadas aos Serviços Auxiliares de Radiodifusão e Correlatos (SARC).

\begin{tabular}{|l|l|}
\hline Órgão Emissor & Ministério das Comunicações - Gabinete do Ministro. \\
\hline Dispositivos & $\begin{array}{l}\text { CF, Art. 21, inciso XI (em 15/08/1995); CF, Art. 21, inciso XII, alínea a (em } \\
15 / 08 / 1995) ; \text { LGT, Art. 62, caput; LGT, Art. 211, caput. }\end{array}$ \\
\hline Correlata & $\begin{array}{l}\text { Portaria MC nº 71, de } 20 \text { de janeiro de } 1978 \\
\text { Portaria MC no 985, de 5 de dezembro de } 1994\end{array}$ \\
\hline Regulamenta & Decreto no 52.795/1963 - Aprova o Regulamento dos Serviços de Radiodifusão. \\
\hline Publicação & $\begin{array}{l}\text { Diário Oficial da União, Seção 1, 09/08/2013, pág. p.58 } \\
\text { Indexação } \\
\text { solicitações de outorga e alterações das condições de outorga dos Serviços Auxiliares } \\
\text { sobre a outorga, exploração e condições de uso de radiofrequência associada ao } \\
\text { Autorização, Serviço Auxiliar de Radiodifusão e Correlatos, aplicação provisória do } \\
\text { valor praticado para execução do Serviço Limitado Privado para as autorizações de } \\
\text { Competência, Agência Nacional de Telecomunicações, competência para processar } \\
\text { solicitações de outorga e alterações das condições de outorga dos Serviços Auxiliares } \\
\text { de Radiodifusão e Correlatos (SARC), bem como para emissão de regulamentação } \\
\text { sobre a outorga, exploração e condições de uso de radiofrequência associada ao } \\
\text { Competência, Serviço Auxiliar de Radiodifusão e Correlatos, competência da ANATEL } \\
\text { para processar solicitações de outorga e alterações das condições de outorga dos } \\
\text { Serviços Auxiliares de Radiodifusão e Correlatos (SARC), bem como para emissão }\end{array}$
\end{tabular}




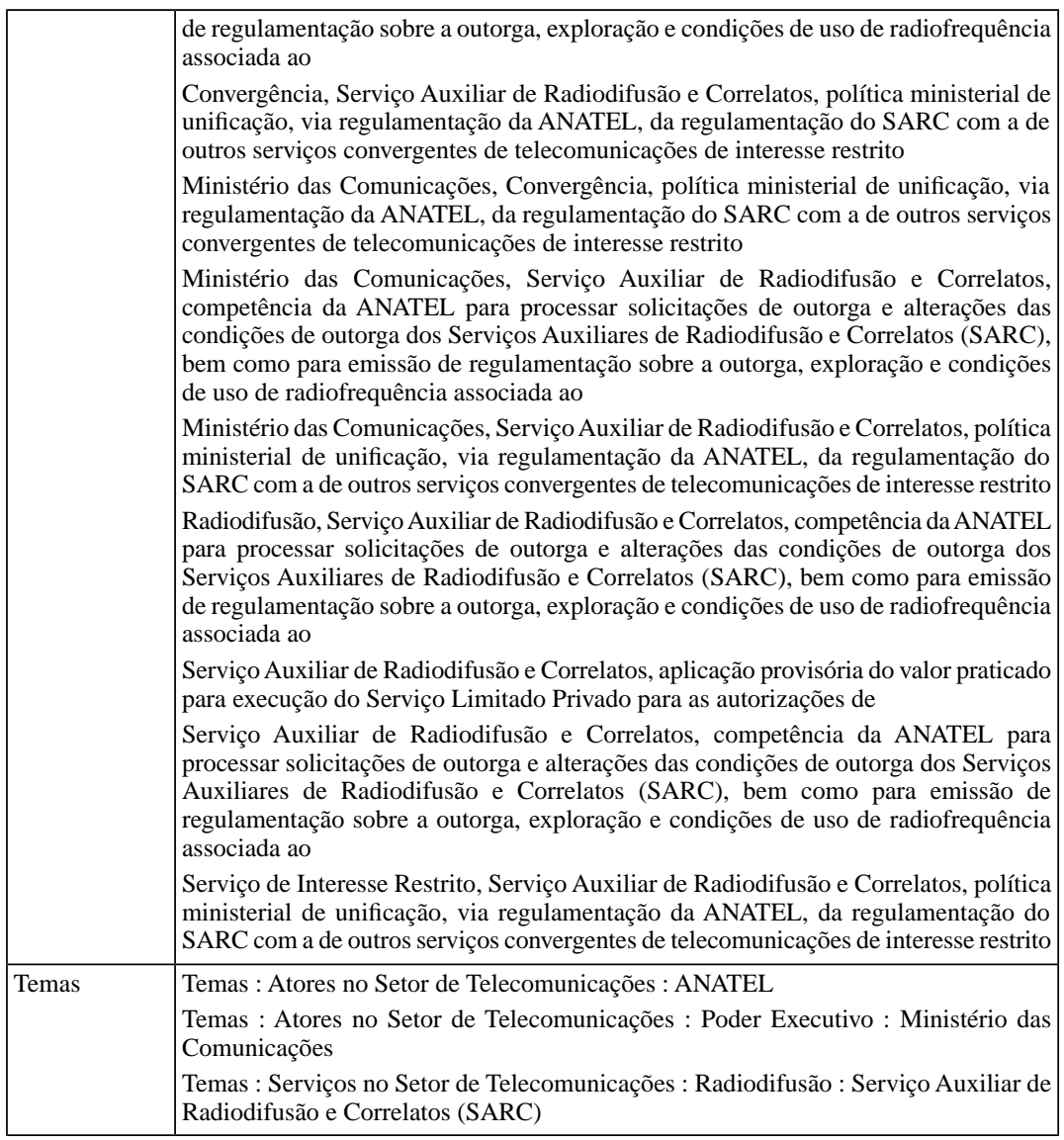

Portaria MC no 275, de 17 de setembro de 2013 - Estabelece política para a disponibilização de faixas de radiofrequência para prestação de acesso à Internet em banda larga por prestadores de serviços de telecomunicações de pequeno porte e por novos competidores.

\begin{tabular}{|l|l|}
\hline Órgão Emissor & Ministério das Comunicações - Gabinete do Ministro. \\
\hline Dispositivos & LGT, Art. $1^{\circ}$, caput; LGT, Art. 157, caput. \\
\hline Correlata & $\begin{array}{l}\text { Decreto } n^{\circ} 4.733 / 2003 \text { - Dispõe sobre políticas públicas de telecomunicações, e dá } \\
\text { outras providências. } \\
\text { Decreto n }{ }^{\circ} 7.175 / 2010 \text { - Institui o Programa Nacional de Banda Larga - PNBL; dispõe } \\
\text { sobre remanejamento de cargos em comissão; altera o Anexo II ao Decreto no } 6.188, \\
\text { de } 17 \text { de agosto de 2007; altera e acresce dispositivos ao Decreto no 6.948, de 25 de } \\
\text { agosto de 2009; e dá outras providências. - Anexo - Quadro demonstrativo dos cargos } \\
\text { em comissão e Quadro resumo dos custos dos cargos em comissão do Gabinete Pessoal } \\
\text { do Presidente da República. }\end{array}$ \\
\hline
\end{tabular}




\begin{tabular}{|c|c|}
\hline Publicação & Diário Oficial da União, Seção 1, 18/09/2013, pág. p.100 \\
\hline \multirow[t]{18}{*}{ Indexação } & $\begin{array}{l}1.785 \mathrm{MHz} \text { a } 1.805 \mathrm{MHz} \text {, Estudos, determinação ministerial para a ANATEL promover } \\
\text { a estudos de viabilidade de disponibilização de faixas de radiofrequência adicionais } \\
\text { para a prestação de acesso à internet em banda larga }\end{array}$ \\
\hline & $\begin{array}{l}1.885 \mathrm{MHz} \text { a } 1.895 \mathrm{MHz} \text {, Estudos, determinação ministerial para a ANATEL promover } \\
\text { a estudos de viabilidade de disponibilização de faixas de radiofrequência adicionais } \\
\text { para a prestação de acesso à internet em banda larga }\end{array}$ \\
\hline & $\begin{array}{l}2.500 \mathrm{MHz} \text { a } 2.690 \mathrm{MHz} \text {, Banda Larga, definição de política para disponibilização } \\
\text { de faixas de radiofrequência para prestação de acesso à internet em banda larga por } \\
\text { prestadores de serviços de telecomunicações de pequeno porte }\end{array}$ \\
\hline & $\begin{array}{l}2.500 \mathrm{MHz} \text { a } 2.690 \mathrm{MHz} \text {, Estudos, determinação ministerial para a ANATEL promover } \\
\text { a estudos de viabilidade de disponibilização de faixas de radiofrequência adicionais } \\
\text { para a prestação de acesso à internet em banda larga }\end{array}$ \\
\hline & $\begin{array}{l}415,85 \mathrm{MHz} \text { a } 421,675 \mathrm{MHz} \text {, Estudos, determinação ministerial para a ANATEL } \\
\text { promover a estudos de viabilidade de disponibilização de faixas de radiofrequência } \\
\text { adicionais para a prestação de acesso à internet em banda larga }\end{array}$ \\
\hline & $\begin{array}{l}\text { 425,85 MHz a } 430 \mathrm{MHz} \text {, Estudos, determinação ministerial para a ANATEL promover } \\
\text { a estudos de viabilidade de disponibilização de faixas de radiofrequência adicionais } \\
\text { para a prestação de acesso à internet em banda larga }\end{array}$ \\
\hline & $\begin{array}{l}\text { Banda Larga, } 2.500 \mathrm{MHz} \text { a } 2.690 \mathrm{MHz} \text {, definição de política para disponibilização } \\
\text { de faixas de radiofrequência para prestação de acesso à internet em banda larga por } \\
\text { prestadores de serviços de telecomunicações de pequeno porte }\end{array}$ \\
\hline & $\begin{array}{l}\text { Banda Larga, definição de política para disponibilização de faixas de radiofrequência } \\
\text { para prestação de acesso à internet em banda larga por prestadores de serviços de } \\
\text { telecomunicações de pequeno porte }\end{array}$ \\
\hline & $\begin{array}{l}\text { Espectro de Radiofreqüências, Uso Licenciado, determinação ministerial para a } \\
\text { ANATEL promover a estudos de viabilidade de disponibilização de faixas de } \\
\text { radiofrequência adicionais para a prestação de acesso à internet em banda larga para }\end{array}$ \\
\hline & $\begin{array}{l}\text { Espectro de Radiofreqüências, Uso Não Licenciado, determinação ministerial para a } \\
\text { ANATEL promover a estudos de viabilidade de disponibilização de faixas de } \\
\text { radiofrequência adicionais para a prestação de acesso à internet em banda larga para }\end{array}$ \\
\hline & $\begin{array}{l}\text { Estudos, determinação ministerial para a ANATEL promover a estudos de viabilidade } \\
\text { de disponibilização de faixas de radiofrequência adicionais para a prestação de acesso } \\
\text { à internet em banda larga }\end{array}$ \\
\hline & $\begin{array}{l}\text { INTERNET, Banda Larga, definição de política para disponibilização de faixas de } \\
\text { radiofrequência para prestação de acesso à internet em banda larga por prestadores } \\
\text { de serviços de telecomunicações de pequeno porte }\end{array}$ \\
\hline & Operadora \\
\hline & $\begin{array}{l}\text { Operadora de Pequeno Porte, Banda Larga, definição de política para disponibilização } \\
\text { de faixas de radiofrequência para prestação de acesso à internet em banda larga por } \\
\text { prestadores de serviços de telecomunicações de pequeno porte }\end{array}$ \\
\hline & Pequeno Porte \\
\hline & Prestadora \\
\hline & $\begin{array}{l}\text { Prestadora de Pequeno Porte, Banda Larga, definição de política para disponibilização } \\
\text { de faixas de radiofrequência para prestação de acesso à internet em banda larga por } \\
\text { prestadores de serviços de telecomunicações de pequeno porte }\end{array}$ \\
\hline & $\begin{array}{l}\text { Uso Não Licenciado, determinação ministerial para a ANATEL promover a estudos } \\
\text { de viabilidade de disponibilização de faixas de radiofrequência adicionais para a } \\
\text { prestação de acesso à internet em banda larga para }\end{array}$ \\
\hline Temas & Larga \\
\hline
\end{tabular}




\begin{tabular}{|l|l|}
\hline Temas : Aplicações de Telecomunicações : Internet \\
& Temas : Atores no Setor de Telecomunicações : Prestadora / Operadora \\
& Temas : Políticas de Telecomunicações : Concorrência no Setor de Telecomunicações \\
& Temas : Políticas de Telecomunicações : Universalização e Massificação \\
\hline
\end{tabular}

\begin{tabular}{|c|c|}
\hline \multicolumn{2}{|c|}{$\begin{array}{l}\text { Portaria MC } \mathbf{n}^{\mathbf{0}} \mathbf{2 8 2} \text {, de } 25 \text { de setembro de } \mathbf{2 0 1 3} \text { - Institui força tarefa e procedimento específico } \\
\text { para outorga do Serviço de Retransmissão de Televisão - RTV, em caráter secundário. }\end{array}$} \\
\hline Órgão Emissor & Ministério das Comunicações - Gabinete do Ministro. \\
\hline Anexos & $\begin{array}{l}\text { Anexo } 1 \text { - Formulário Padronizado para Solicitação de RTV Secundária. } \\
\text { Anexo } 2 \text { - Formulário Padronizado para Projeto Técnico. }\end{array}$ \\
\hline Dispositivos & $\begin{array}{l}\text { CF, Art. 21, inciso XII, alínea a (em 15/08/1995); CF, Art. 223, caput; LGT, Art. 211, } \\
\text { caput. }\end{array}$ \\
\hline Correlata & 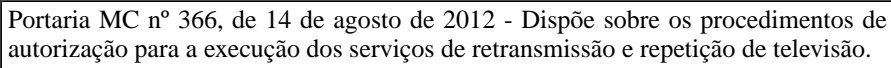 \\
\hline Regulamenta & $\begin{array}{l}\text { Decreto } n^{\circ} 5.371 / 2005 \text { - Aprova o Regulamento do Serviço de Retransmissão de } \\
\text { Televisão e do Serviço de Repetição de Televisão, ancilares ao Serviço de Radiodifusão } \\
\text { de Sons e Imagens. }\end{array}$ \\
\hline Publicação & Diário Oficial da União, Seção 1, 27/09/2013, pág. p.62 \\
\hline Indexação & $\begin{array}{l}\text { Radiodifusão, Serviço de Retransmissão de Televisão, procedimento específico para } \\
\text { outorga do } \\
\text { Regulamento dos Serviços de Retransmissão e de Repetição de Televisão, procedimento } \\
\text { específico para outorga do Serviço de Retransmissão de Televisão } \\
\text { Serviço de Retransmissão de Televisão, procedimento específico para outorga do }\end{array}$ \\
\hline Temas & Temas : Serviços no Setor de Telecomunicações : Radiodifusão \\
\hline
\end{tabular}

\begin{tabular}{|c|c|}
\hline \multicolumn{2}{|c|}{$\begin{array}{l}\text { Portaria MC no 299, de } 7 \text { de outubro de } 2013 \text { - Institui, no âmbito da Secretaria de Serviços de } \\
\text { Comunicação Eletrônica, grupos de trabalho de Radiodifusão Comercial, de Radiodifusão Educativa } \\
\text { e Consignações, de Radiodifusão Ancilar, de TV Digital, e de Documentação e Informação. }\end{array}$} \\
\hline Órgão Emissor & Ministério das Comunicações - Gabinete do Ministro. \\
\hline Dispositivos & CF, Art. 223, caput; LGT, Art. 211, caput. \\
\hline Revoga & Portaria MC n 263, de 6 de junho de 2012 \\
\hline Publicação & Diário Oficial da União, Seção 1, 08/10/2013, pág. p.72 \\
\hline Indexação & $\begin{array}{l}\text { Ministério das Comunicações, Grupo de Trabalho de Documentação e Informação, } \\
\text { instituição do } \\
\text { Ministério das Comunicações, Grupo de Trabalho de Radiodifusão Ancilar, instituição } \\
\text { do } \\
\text { Ministério das Comunicações, Grupo de Trabalho de Radiodifusão Comercial, } \\
\text { instituição do } \\
\text { Ministério das Comunicações, Grupo de Trabalho de Radiodifusão Educativa e } \\
\text { Consignações, instituição do } \\
\text { Ministério das Comunicações, Grupo de Trabalho de TV Digital, instituição do }\end{array}$ \\
\hline Temas & $\begin{array}{l}\text { Temas : Atores no Setor de Telecomunicações : Poder Executivo : Ministério das } \\
\text { Comunicações }\end{array}$ \\
\hline
\end{tabular}


Temas : Serviços no Setor de Telecomunicações : Radiodifusão

Portaria MC no 303, de 16 de outubro de 2013 - Altera a Portaria no 55, de 12 de março de 2013, do Ministério das Comunicações, que regulamenta os procedimentos para submissão, análise, aprovação, acompanhamento e fiscalização dos projetos apresentados ao Ministério das Comunicações referentes ao Regime Especial de Tributação do Programa Nacional de Banda Larga para Implantação de Redes de Telecomunicações - REPNBL - Redes.

\begin{tabular}{|c|c|}
\hline Órgão Emissor & Ministério das Comunicações - Gabinete do Ministro. \\
\hline \multirow[t]{2}{*}{ Anexos } & $\begin{array}{l}\text { Anexo } 1 \text { - Alterações à descrição dos equipamentos contemplados segundo a } \\
\text { Nomenclatura Comum do Mercosul. }\end{array}$ \\
\hline & $\begin{array}{l}\text { Anexo } 2 \text { - Alterações dos percentuais mínimos para equipamentos e componentes de } \\
\text { redes produzidos de acordo com o respectivo PPB e desenvolvidos com tecnologia } \\
\text { nacional. }\end{array}$ \\
\hline Dispositivos & LGT, Art. $2^{\circ}$, inciso I; LGT, Art. $2^{\circ}$, inciso V; LGT, Art. $3^{\circ}$, inciso I. \\
\hline \multirow[t]{3}{*}{ Altera } & $\begin{array}{l}\text { Portaria MC } \mathrm{n}^{\circ} 55 \text {, de } 12 \text { de março de } 2013 \text { - Regulamenta os procedimentos para } \\
\text { submissão, análise, aprovação, acompanhamento e fiscalização dos projetos } \\
\text { apresentados ao Ministério das Comunicações referentes ao Regime Especial de } \\
\text { Tributação do Programa Nacional de Banda Larga para Implantação de Redes de } \\
\text { Telecomunicações - REPNBL-Redes, de que trata a Lei n }{ }^{\circ} 12.715 \text {, de } 17 \text { de setembro } \\
\text { de } 2012 \text { e o Decreto } n^{\circ} 7.921 \text {, de } 15 \text { de fevereiro de } 2013 \text {. }\end{array}$ \\
\hline & $\begin{array}{l}\text { Anexo } 1 \text { - Descrição dos equipamentos contemplados segundo a Nomenclatura Comum } \\
\text { do Mercosul - Descrição dos equipamentos contemplados segundo a Nomenclatura } \\
\text { Comum do Mercosul. }\end{array}$ \\
\hline & $\begin{array}{l}\text { Anexo } 2 \text { - Percentuais mínimos para equipamentos e componentes de redes produzidos } \\
\text { de acordo com o respectivo PPB e desenvolvidos com tecnologia nacional - Percentuais } \\
\text { mínimos para equipamentos e componentes de redes produzidos de acordo com o } \\
\text { respectivo PPB e desenvolvidos com tecnologia nacional. }\end{array}$ \\
\hline \multirow[t]{2}{*}{ Regulamenta } & $\begin{array}{l}\text { Lei n } 12.715 / 2012 \text { - Altera a alíquota das contribuições previdenciárias sobre a folha } \\
\text { de salários devidas pelas empresas que especifica; institui o Programa de Incentivo à } \\
\text { Inovação Tecnológica e Adensamento da Cadeia Produtiva de Veículos Automotores, } \\
\text { o Regime Especial de Tributação do Programa Nacional de Banda Larga para } \\
\text { Implantação de Redes de Telecomunicações, o Regime Especial de Incentivo a } \\
\text { Computadores para Uso Educacional, o Programa Nacional de Apoio à Atenção } \\
\text { Oncológica e o Programa Nacional de Apoio à Atenção da Saúde da Pessoa com } \\
\text { Deficiência; restabelece o Programa Um Computador por Aluno; altera o Programa } \\
\text { de Apoio ao Desenvolvimento Tecnológico da Indústria de Semicondutores, instituído } \\
\text { pela Lei no } 11.484 \text {, de } 31 \text { de maio de } 2007 \text {; altera as Leis nos } 9.250 \text {, de } 26 \text { de dezembro } \\
\text { de } 1995,11.033 \text {, de } 21 \text { de dezembro de } 2004 \text {, } 9.430 \text {, de } 27 \text { de dezembro de } 1996 \text {, } \\
\text { 10.865, de } 30 \text { de abril de } 2004,11.774 \text {, de } 17 \text { de setembro de } 2008 \text {, } 12.546 \text {, de } 14 \text { de } \\
\text { dezembro de } 2011,11.484 \text {, de } 31 \text { de maio de } 2007,10.637 \text {, de } 30 \text { de dezembro de } \\
2002,11.196 \text {, de } 21 \text { de novembro de } 2005,10.406 \text {, de } 10 \text { de janeiro de } 2002,9.532 \text {, } \\
\text { de } 10 \text { de dezembro de } 1997,12.431 \text {, de } 24 \text { de junho de } 2011,12.414 \text {, de } 9 \text { de junho } \\
\text { de } 2011,8.666 \text {, de } 21 \text { de junho de } 1993,10.925 \text {, de } 23 \text { de julho de } 2004 \text {, os Decretos- } \\
\text { Leis nos } 1.455 \text {, de } 7 \text { de abril de } 1976,1.593 \text {, de } 21 \text { de dezembro de } 1977 \text {, e a Medida } \\
\text { Provisória no } 2.199-14 \text {, de } 24 \text { de agosto de } 2001 \text {; e dá outras providências. }\end{array}$ \\
\hline & $\begin{array}{l}\text { Decreto } \mathrm{n}^{\circ} 7.921 \text {, de } 15 \text { de fevereiro de } 2013 \text { - Regulamenta a aplicação do Regime } \\
\text { Especial de Tributação do Programa Nacional de Banda Larga para Implantação de } \\
\text { Redes de Telecomunicações - REPNBL-Redes, de que trata a Lei n }{ }^{\circ} 12.715 \text {, de } 17 \text { de } \\
\text { setembro de } 2012 \text {. }\end{array}$ \\
\hline Publicação & Diário Oficial da União, Seção 1, 17/10/2013, págs. p.37-38 \\
\hline
\end{tabular}




\begin{tabular}{|l|l|}
\hline Indexação & $\begin{array}{l}\text { Banda Larga, Regime Especial de Tributação do Programa Nacional de Banda Larga } \\
\text { para Implantação de Redes de Telecomunicações, regulamentação do } \\
\text { Programa Nacional de Banda Larga, Regime Especial de Tributação do Programa } \\
\text { Nacional de Banda Larga para Implantação de Redes de Telecomunicações, } \\
\text { regulamentação do } \\
\text { Regime Especial de Tributação do Programa Nacional de Banda Larga para } \\
\text { Implantação de Redes de Telecomunicações, regulamentação do }\end{array}$ \\
\hline Temas & $\begin{array}{l}\text { Temas : Aplicações de Telecomunicações : Banda Larga } \\
\text { Temas : Serviços no Setor de Telecomunicações : Internet }\end{array}$ \\
\hline
\end{tabular}

Portaria MC n 305, de 24 de outubro de 2013 - Altera a minuta de Acordo de Cooperação Técnica da Portaria $n^{\circ} 13$, de $1^{\circ}$ de fevereiro de 2013, que instituiu o processo de habilitação e seleção de propostas para o Projeto das Cidades Digitais.

\begin{tabular}{|c|c|}
\hline Órgão Emissor & Ministério das Comunicações - Gabinete do Ministro. \\
\hline Anexos & Anexo - Acordo de Cooperação Técnica. \\
\hline Dispositivos & LGT, Art. $2^{\circ}$, inciso I. \\
\hline Correlata & $\begin{array}{l}\text { Portaria MC n 376/2011 - Institui o Projeto de Implantação e Manutenção das Cidades } \\
\text { Digitais. } \\
\text { Portaria MC nº } 186 \text {, de } 28 \text { de março de } 2012 \text { - Altera a Portaria n }{ }^{\circ} 376 \text {, de } 19 \text { de agosto } \\
\text { de } 2011 \text {, referente à instituição do Projeto de Implantação e Manutenção das Cidades } \\
\text { Digitais. }\end{array}$ \\
\hline Publicação & Diário Oficial da União, Seção 1, 25/10/2013, págs. p.79-80 \\
\hline Indexação & $\begin{array}{l}\text { Acordo de Cooperação Técnica, Cidades Digitais, alteração da minuta de acordo de } \\
\text { cooperação técnica do projeto de implantação e manutenção das } \\
\text { Cidades Digitais, Acordo de Cooperação Técnica, minuta do }\end{array}$ \\
\hline Temas & $\begin{array}{l}\text { Temas : Políticas de Telecomunicações : Pesquisa \& Desenvolvimento } \\
\text { Temas : Políticas de Telecomunicações : Universalização : Acesso à Telecomunicações } \\
\text { : Educação e Pesquisa } \\
\text { Temas : Políticas de Telecomunicações : Universalização : Acesso às Telecomunicações }\end{array}$ \\
\hline
\end{tabular}

\section{Resolução}

Resolução da ANATEL n $^{\circ}$ 606, de 4 de fevereiro de 2013 - Aprova alteração do Anexo I do Regulamento de Tarifação do Serviço Telefônico Fixo Comutado Destinado ao Uso do Público em Geral - STFC Prestado no Regime Público, aprovado pela Resolução n ${ }^{\circ} 424$, de 6 de dezembro de 2005, e do Plano Geral de Códigos Nacionais - PGCN, Anexo II à Resolução nº 263, de 08 de junho de 2001, para mudar o município de Santana do Paraíso, no estado de Minas Gerais, da Área de Tarifação 333 (Caratinga) para a Área de Tarifação 316 (Coronel Fabriciano), e do Código Nacional 33 para o Código Nacional 31.

\begin{tabular}{|l|l|}
\hline Órgão Emissor & ANATEL - Conselho Diretor. \\
\hline Anexos & $\begin{array}{l}\text { Anexo 1 - Áreas de Tarifação do STFC. } \\
\text { Anexo } 2 \text { - Alteração do Plano Geral de Códigos Nacionais. }\end{array}$ \\
\hline Dispositivos & $\begin{array}{l}\text { LGT, Art. 3, inciso IV; LGT, Art. 19, inciso IV; LGT, Art. 19, inciso VII; LGT, Art. } \\
19, \text { inciso XIV; LGT, Art. 64, Parágrafo Único; LGT, Art. 103, caput; LGT, Art. 151, } \\
\text { caput. }\end{array}$ \\
\hline
\end{tabular}




\begin{tabular}{|l|l|}
\hline Altera & $\begin{array}{l}\text { Anexo à Resolução da ANATEL no 263, de } 8 \text { de junho de } 2001 \text { - Plano Geral de } \\
\text { Códigos Nacionais - PGCN. } \\
\text { Anexo à Resolução da ANATEL no 424, de } 6 \text { de dezembro de } 2005 \text { - Regulamento } \\
\text { de Tarifação do Serviço Telefônico Fixo Comutado Destinado ou Uso do Público em } \\
\text { Geral - STFC Prestado no Regime Público. }\end{array}$ \\
\hline Regulamenta & $\begin{array}{l}\text { Lei no 9.472/1997 - Dispõe sobre a organização dos serviços de telecomunicações, a } \\
\text { criação e funcionamento de um órgão regulador e outros aspectos institucionais, nos } \\
\text { termos da Emenda Constitucional no 8, de 1995. }\end{array}$ \\
\hline Publicação & Diário Oficial da União, Seção 1, 28/02/2013, pág. 156 \\
\hline Indexação & $\begin{array}{l}\text { Numeração de Serviços, Serviço Telefônico Fixo Comutado, alteração do Plano Geral } \\
\text { de Códigos Nacionais } \\
\text { Plano Geral de Códigos Nacionais, alteração do } \\
\text { Serviço Telefônico Fixo Comutado, Plano Geral de Códigos Nacionais, alteração do } \\
\text { Serviço Telefônico Fixo Comutado, Área de Tarifação, alteração de área de tarifação } \\
\text { do } \\
\text { Área de Tarifação, Serviço Telefônico Fixo Comutado, alteração de área de tarifação } \\
\text { do }\end{array}$ \\
\hline Temas : Administração do Setor de Telecomunicações : Outorgas : Preço Público e \\
$\begin{array}{l}\text { Treço Privado } \\
\text { Temas : Administração do Setor de Telecomunicações : Planos de Serviços } \\
\text { Temas : Atores no Setor de Telecomunicações : Prestadora / Operadora } \\
\text { Temas : Atores no Setor de Telecomunicações : Usuário / Consumidor } \\
\text { Temas : Políticas de Telecomunicações : Política Tarifária } \\
\text { Temas : Ramos Jurídicos Afins : Direito do Consumidor } \\
\text { Temas : Serviços no Setor de Telecomunicações : Serviço Telefônico Fixo Comutado } \\
\text { (STFC) }\end{array}$ \\
\hline
\end{tabular}

Resolução da ANATEL n 607, de 13 de março de 2013 - Alteração no Regulamento de Numeração do Serviço Telefônico Fixo Comutado, aprovado pela Resolução nº 86, de 30 de dezembro de 1998, e no Regulamento de Administração dos Recursos de Numeração, aprovado pela Resolução $n^{\circ} 84$, de 30 de dezembro de 1998.

\begin{tabular}{|l|l|}
\hline Órgão Emissor & ANATEL - Conselho Diretor. \\
\hline Anexos & $\begin{array}{l}\text { Anexo - Alterações no Regulamento de Numeração do Serviço Telefônico Fixo } \\
\text { Comutado e no Regulamento de Administração dos Recursos de Numeração. }\end{array}$ \\
\hline Dispositivos & LGT, Art. 19, inciso XIX; LGT, Art. 64, Parágrafo Único; LGT, Art. 151, caput. \\
\hline Altera & $\begin{array}{l}\text { Anexo à Resolução da ANATEL n }{ }^{\circ} \text { 84, de } 30 \text { de dezembro de 1998 - Regulamento } \\
\text { de Administração de Recursos de Numeração. } \\
\text { Anexo à Resolução da ANATEL no 86, de 30 de dezembro de 1998 - Regulamento } \\
\text { de Numeração do Serviço Telefônico Fixo Comutado. }\end{array}$ \\
\hline Regulamenta & $\begin{array}{l}\text { Lei no 9.472/1997 - Dispõe sobre a organização dos serviços de telecomunicações, a } \\
\text { criação e funcionamento de um órgão regulador e outros aspectos institucionais, nos } \\
\text { termos da Emenda Constitucional n }{ }^{\circ} \text { 8, de 1995. }\end{array}$ \\
\hline Publicação & $\begin{array}{l}\text { Diário Oficial da União, Seção 1, 20-03-2013, pág. p.34 } \\
\text { Indexação } \\
\text { Administração de Recursos de Numeração, Regulamento de Administração de Recursos } \\
\text { Numeração de Rede, Regulamento de Numeração do STFC, alteração do }\end{array}$
\end{tabular}




\begin{tabular}{|l|l|}
\hline & $\begin{array}{l}\text { Regulamento de Administração de Recursos de Numeração, alteração do } \\
\text { Regulamento de Numeração do STFC, alteração do } \\
\text { Serviço Telefônico Fixo Comutado, Regulamento de Numeração do STFC, alteração } \\
\text { do }\end{array}$ \\
\hline Temas & $\begin{array}{l}\text { Temas : Infraestrutura e Recursos do Setor de Telecomunicações : Redes de } \\
\text { Telecomunicações } \\
\text { Temas : Infraestrutura e Recursos do Setor de Telecomunicações : Redes de } \\
\text { Telecomunicações : Numeração dos Serviços } \\
\text { Temas : Serviços no Setor de Telecomunicações : Serviço Telefônico Fixo Comutado } \\
\text { (STFC) }\end{array}$ \\
\hline
\end{tabular}

Resolução da ANATEL n ${ }^{0}$ 608, de 5 de abril de 2013 - Aprova alteração nos Apêndices C e D do Anexo I do Regulamento de Separação e Alocação Contas - RSAC, aprovado pela Resolução no 396 , de 31 de março de 2005, alterado pela Resolução n 419, de 24 de novembro de 2005, pela Resolução $\mathrm{n}^{\circ} 464$, de 27 de abril de 2007, pela Resolução ${ }^{\circ} 480$, de 14 de agosto de 2007, pela Resolução $\mathrm{n}^{\circ}$ 483, de 24 de outubro de 2007, e pela Resolução ${ }^{\circ} 503$, de 25 de abril de 2008, e define novo prazo para entrega dos dados dos exercícios de 2011 e 2012 e do primeiro trimestre de 2013.

\begin{tabular}{|c|c|}
\hline Órgão Emissor & ANATEL - Conselho Diretor. \\
\hline Anexos & Anexo - Apêndice C (Plano Geral para Separação e Alocação de Contas). \\
\hline Dispositivos & LGT, Art. 93, inciso X; LGT, Art. 127, inciso X. \\
\hline Altera & $\begin{array}{l}\text { Anexo à Resolução da ANATEL n }{ }^{\circ} \text { 396, de } 31 \text { de março de } 2005 \text { - Regulamento de } \\
\text { Separação e Alocação de Contas. }\end{array}$ \\
\hline Correlata & 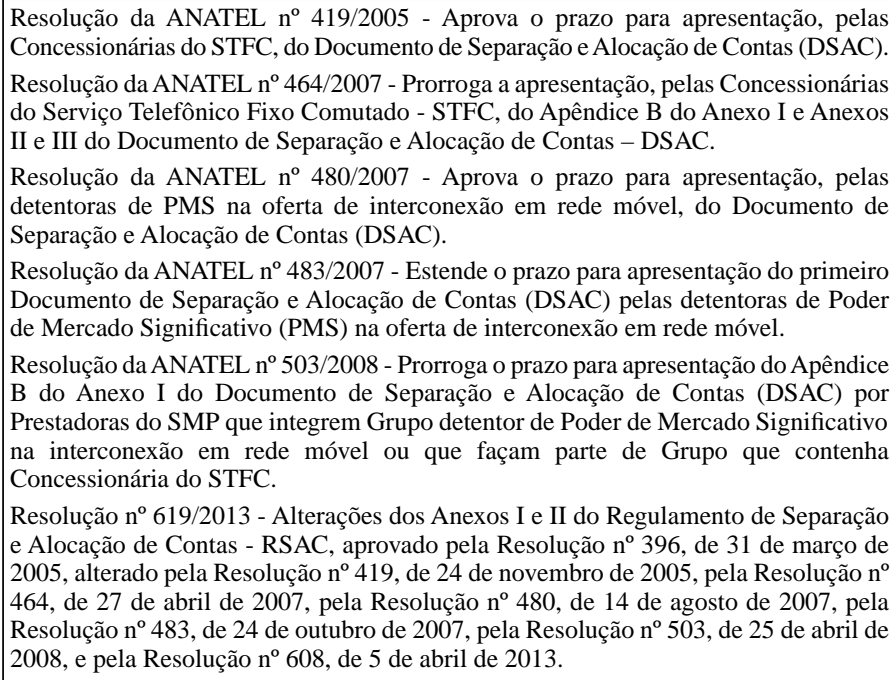 \\
\hline Regulamenta & $\begin{array}{l}\text { Lei no } 9.472 / 1997 \text { - Dispõe sobre a organização dos serviços de telecomunicações, a } \\
\text { criação e funcionamento de um órgão regulador e outros aspectos institucionais, nos } \\
\text { termos da Emenda Constitucional n }{ }^{\circ} 8 \text {, de } 1995 \text {. }\end{array}$ \\
\hline Publicação & Diário Oficial da União, Seção 1, 12-04-2013, págs. p.62-97 \\
\hline
\end{tabular}




\begin{tabular}{|l|l|}
\hline Indexação & Regulamento de Separação e Alocação de Contas, alteração do \\
\hline Temas & Temas : Administração do Setor de Telecomunicações : Fiscalização das \\
& Telecomunicações \\
& Temas : Serviços no Setor de Telecomunicações : Serviço Móvel Pessoal (SMP) \\
& Temas : Serviços no Setor de Telecomunicações : Serviço Telefônico Fixo Comutado \\
& (STFC) \\
& Temas : Serviços no Setor de Telecomunicações : Serviço de Acesso Condicionado \\
& (SeAC) \\
& Temas : Serviços no Setor de Telecomunicações : Serviço de Comunicação Multimídia \\
& $(\mathrm{SCM})$ \\
\hline
\end{tabular}

\begin{tabular}{|c|c|}
\hline Resolução d & $\begin{array}{l}\text { ATEL no } \mathbf{n}^{0} \text {, de } 18 \text { de abril de } 2013 \text { - Norma para Certificação e Homologação } \\
\text { so em Aplicações Ponto-a-Ponto. }\end{array}$ \\
\hline Órgão Emissor & ANATEL - Conselho Diretor. \\
\hline Anexos & $\begin{array}{l}\text { Anexo - Norma para Certificação e Homologação de Antenas para Uso em Aplicações } \\
\text { Ponto-a-Ponto. }\end{array}$ \\
\hline Dispositivos & LGT, Art. 1º, Parágrafo Único; LGT, Art. 19, inciso XIII; LGT, Art. 214, inciso I. \\
\hline Revoga & $\begin{array}{l}\text { Resolução da ANATEL n }{ }^{\circ} \text { 366/2004 - Aprova a Norma para Certificação e } \\
\text { Homologação de Antenas Lineares. - Anexo - Norma para Certificação e Homologação } \\
\text { de Antenas Lineares. } \\
\text { Resolução da ANATEL n }{ }^{\circ} \text { 367/2004 - Aprova a Norma para Certificação e } \\
\text { Homologação de Antenas Direcionais de Abertura. - Anexo - Norma para Certificação } \\
\text { e Homologação de Antenas Direcionais de Abertura. }\end{array}$ \\
\hline Regulamenta & $\begin{array}{l}\text { Lei no } 9.472 / 1997 \text { - Dispõe sobre a organização dos serviços de telecomunicações, a } \\
\text { criação e funcionamento de um órgão regulador e outros aspectos institucionais, nos } \\
\text { termos da Emenda Constitucional } n^{\circ} 8 \text {, de } 1995 \text {. }\end{array}$ \\
\hline Publicação & $\begin{array}{l}\text { Diário Oficial da União, Seção 1, 29/04/2013, págs. p.61-65 } \\
\text { Diário Oficial da União, Seção 1, 02/05/2013, pág. p.68 [ Republicação_Parcial ] }\end{array}$ \\
\hline Indexação & $\begin{array}{l}138 \mathrm{MHz} \text { a } 60 \mathrm{GHz} \text {, Antena para Uso em Aplicações Ponto-a-Ponto, aprovação da } \\
\text { norma para certificação e homologação de } \\
71 \mathrm{GHz} \text { a } 86 \mathrm{GHz} \text {, Antena para Uso em Aplicações Ponto-a-Ponto, aprovação da } \\
\text { norma para certificação e homologação de } \\
\text { Antena Linear, revogação da norma para certificação e homologação de } \\
\text { Aplicação Ponto-a-Ponto, Antena para Uso em Aplicações Ponto-a-Ponto, aprovação } \\
\text { da norma para certificação e homologação de } \\
\text { Aplicação Ponto-a-Ponto, aprovação da norma para certificação e homologação de } \\
\text { Certificação, Antena para Uso em Aplicações Ponto-a-Ponto, aprovação da norma } \\
\text { para certificação e homologação de } \\
\text { Certificação, aprovação da norma para certificação e homologação de antenas para } \\
\text { Discriminação de Polarização Cruzada, Antena para Uso em Aplicações Ponto-a- } \\
\text { Ponto, classes de antenas segundo a desempenho de discriminação de polarização } \\
\text { cruzada } \\
\text { Homologação, Antena para Uso em Aplicaçães Ponto-a-Ponto, aprovação da norma } \\
\text { para certificação e homologação de } \\
\text { Homologação, Aplicação Ponto-a-Ponto, aprovação da norma para certificação e } \\
\text { homologação de antenas para } \\
\text { Ponto a Ponto }\end{array}$ \\
\hline
\end{tabular}




\begin{tabular}{|l|l|}
\hline & Ponto-a-Ponto \\
\hline Temas & Temas : Infraestrutura e Recursos do Setor de Telecomunicações : Equipamentos de \\
& Telecomunicações : Antenas \\
& Temas : Infraestrutura e Recursos do Setor de Telecomunicações : Equipamentos de \\
& Telecomunicações : Certificação / Homologação \\
\hline
\end{tabular}

\begin{tabular}{|c|c|}
\hline $\mathrm{d}$ & $\begin{array}{l}\text { ATEL n 610, de } 18 \text { de abril de } 2013 \text { - Norma para Certificação e Homologação } \\
\text { so em Aplicações Ponto-Área Bidirecionais. }\end{array}$ \\
\hline Órgão Emissor & ANATEL - Conselho Diretor. \\
\hline Anexos & $\begin{array}{l}\text { Anexo - Norma para Certificação e Homologação de Antenas para Uso em Aplicações } \\
\text { Ponto-Área Bidirecionais. }\end{array}$ \\
\hline Dispositivos & LGT, Art. 1º, Parágrafo Único; LGT, Art. 19, inciso XIII; LGT, Art. 214, inciso I. \\
\hline Revoga & $\begin{array}{l}\text { Resolução da ANATEL no } 372 / 2004 \text { - Aprova a Norma para Certificação e } \\
\text { Homologação de Antenas Setoriais e Omnidirecionais. - Anexo - Norma para } \\
\text { Certificação e Homologação de Antenas Setoriais e Omnidirecionais. }\end{array}$ \\
\hline Regulamenta & $\begin{array}{l}\text { Lei } \mathrm{n}^{\circ} 9.472 / 1997 \text { - Dispõe sobre a organização dos serviços de telecomunicações, a } \\
\text { criação e funcionamento de um órgão regulador e outros aspectos institucionais, nos } \\
\text { termos da Emenda Constitucional } \mathrm{n}^{\circ} 8 \text {, de } 1995 \text {. }\end{array}$ \\
\hline Publicação & $\begin{array}{l}\text { Diário Oficial da União, Seção 1, 29/04/2013, págs. p.65-71 } \\
\text { Diário Oficial da União, Seção 1, 02/05/2013, pág. p.84 [ Republicação_Parcial ] }\end{array}$ \\
\hline Indexação & $\begin{array}{l}138 \mathrm{MHz} \text { a } 40,5 \mathrm{GHz} \text {, Antena para Uso em Aplicações Ponto-Área, aprovação da } \\
\text { norma para certificação e homologação de } \\
\text { Antena para Uso em Aplicações Ponto-Área, aprovação da norma para certificação e } \\
\text { homologação de } \\
\text { Aplicação Ponto-Área, Antena para Uso em Aplicações Ponto-Área, aprovação da } \\
\text { norma para certificação e homologação de } \\
\text { Certificação, Antena para Uso em Aplicações Ponto-Área, aprovação da norma para } \\
\text { certificação e homologação de } \\
\text { Certificação, Aplicação Ponto-Área, aprovação da norma para certificação e } \\
\text { homologação de antenas para } \\
\text { Homologação, Antena para Uso em Aplicações Ponto-Área, aprovação da norma para } \\
\text { certificação e homologação de } \\
\text { Homologação, Aplicação Ponto-Área, aprovação da norma para certificação e } \\
\text { homologação de antenas para } \\
\text { Ponto-Área } \\
\text { Serviço Móvel Especializado, Antena para Uso em Aplicações Ponto-Área, aprovação } \\
\text { da norma para certificação e homologação de } \\
\text { Serviço Móvel Pessoal, Antena para Uso em Aplicações Ponto-Área, aprovação da } \\
\text { norma para certificação e homologação de }\end{array}$ \\
\hline Temas & $\begin{array}{l}\text { Temas : Infraestrutura e Recursos do Setor de Telecomunicações : Equipamentos de } \\
\text { Telecomunicações : Antenas } \\
\text { Temas : Infraestrutura e Recursos do Setor de Telecomunicações : Equipamentos de } \\
\text { Telecomunicações : Certificação / Homologação }\end{array}$ \\
\hline
\end{tabular}


Temas : Infraestrutura e Recursos do Setor de Telecomunicações : Equipamentos de Telecomunicações : Estações de Telecomunicações

\begin{tabular}{|c|c|}
\hline 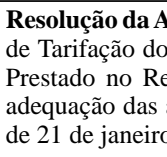 & rviço Telefônico Fixo Comutado Destin \\
\hline Órgã & tor. \\
\hline Anexos & $\begin{array}{l}\text { Anexo - Alteração de áreas de tarifação do Regulamento de Tarifação do Serviço } \\
\text { Telefônico Fixo Comutado Destinado ao Uso do Público em Geral - STFC Prestado } \\
\text { no Regime Público, aprovado pela Resolução no } 424 \text {, de } 6 \text { de dezembro de } 2005 .\end{array}$ \\
\hline Dispo & $\begin{array}{l}\text { LGT, Art. } 3^{\circ} \text {, inciso IV; LGT, Art. } 19 \\
\text { 64, Parágrafo Único; LGT, Art. 103, }\end{array}$ \\
\hline Altera & $\begin{array}{l}\text { Anexo à Resolução da ANATEL no 424, de } 6 \text { de dezembro de } 2005 \text { - Regulamento } \\
\text { de Tarifação do Serviço Telefônico Fixo Comutado Destinado ou Uso do Público em } \\
\text { Geral - STFC Prestado no Regime Público. }\end{array}$ \\
\hline Correlata & $\begin{array}{l}\text { Resolução da ANATEL n }{ }^{\circ} \text { 560/2011 - Aprova o Regulamento sobre Áreas Locais } \\
\text { para o Serviço Telefônico Fixo Comutado Destinado ao Uso do Público em Geral - } \\
\text { STFC. }\end{array}$ \\
\hline Regular & $\begin{array}{l}\text { Lei } \mathrm{n}^{\circ} 9.472 / 1997 \text { - Dispõe sobre a organização dos serviços de telecomunicações, a } \\
\text { criação e funcionamento de um órgão regulador e outros aspectos institucionais, nos } \\
\text { termos da Emenda Constitucional } n^{\circ} 8 \text {, de } 1995 \text {. }\end{array}$ \\
\hline Publicação & Diário Oficial da União, Seção 1, 07/05/2013, p \\
\hline Indexação & $\begin{array}{l}\text { Serviço Telefônico Fixo Comutado, Área de Tarifação, alteração de área de tarifação } \\
\text { do } \\
\text { Tarifa, Área de Tarifação, sua alteração no STFC } \\
\text { Área de Tarifação, Serviço Telefônico Fixo Comutado, alteração de área de tarifação } \\
\text { do }\end{array}$ \\
\hline emas & $\begin{array}{l}\text { Temas : Administração do Setor de Telecomunicações : Outorgas : Concessão (regras } \\
\text { aplicáveis) } \\
\text { Temas : Políticas de Telecomunicações : Política Tarifária } \\
\text { Temas : Serviços no Setor de Telecomunicações : Serviço Telefônico Fixo Comutado } \\
\text { (STFC) }\end{array}$ \\
\hline
\end{tabular}

\begin{tabular}{|l|l|}
\hline \multicolumn{2}{|l|}{ Resolução da ANATEL no $\mathbf{6 1 2}$, de 29 de abril de 2013 - Aprova o Regimento Interno da ANATEL. } \\
\hline Órgão Emissor & ANATEL - Conselho Diretor. \\
\hline Anexos & Anexo - Regimento Interno da Agência Nacional de Telecomunicações - ANATEL. \\
\hline Dispositivos & LGT, Art. 19, inciso XXVII; LGT, Art. 22, inciso X. \\
\hline Revoga & $\begin{array}{l}\text { Resolução da ANATEL } \mathrm{n}^{\circ} \text { 270/2001 - Aprova o Regimento Interno da Agência } \\
\text { Nacional de Telecomunicações - Anatel. }\end{array}$ \\
\hline Correlata & $\begin{array}{l}\text { Anexo ao Decreto } \mathrm{n}^{\circ} 2.338, \text { de } 7 \text { de outubro de 1997 - Regulamento da Agência } \\
\text { Nacional de Telecomunicaçôes. }\end{array}$ \\
\hline Regulamenta & $\begin{array}{l}\text { Lei } \mathrm{n}^{\circ} \text { 9.472/1997 - Dispõe sobre a organização dos serviços de telecomunicações, a } \\
\text { criação e funcionamento de um órgão regulador e outros aspectos institucionais, nos } \\
\text { termos da Emenda Constitucional no }{ }^{\circ} \text {, de 1995. }\end{array}$ \\
\hline
\end{tabular}




\begin{tabular}{|l|l|}
\hline Publicação & $\begin{array}{l}\text { Diário Oficial da União, Seção 1, 02/05/2013, págs. p.68-84 } \\
\text { Diário Oficial da União, Seção 1, 16/05/2013, pág. p.66 [ Retificação ] }\end{array}$ \\
\hline Indexação & $\begin{array}{l}\text { Agência Nacional de Telecomunicações, Regimento Interno da ANATEL } \\
\text { Agência Nacional de Telecomunicações, estrutura organizacional da } \\
\text { Agência Nacional de Telecomunicações, instrumentos deliberativos da } \\
\text { Ata de Reunião, Conselho Diretor - Agencia Nacional de Telecomunicações, requisitos } \\
\text { mínimos da ata de sessão do } \\
\text { Ata de Sessão, Conselho Diretor - Agencia Nacional de Telecomunicações, requisitos } \\
\text { mínimos da ata de sessão do } \\
\text { Circuito Deliberativo, Conselho Diretor, disciplina da votação no } \\
\text { Conselheiro, Voto, exigência de fundamentação do } \\
\text { Conselho Diretor - Agencia Nacional de Telecomunicações, Votação, disciplina da } \\
\text { Cômputo de votos, Conselho Diretor - Agencia Nacional de Telecomunicações, } \\
\text { disciplina da votação no } \\
\text { Distribuição de Matérias, Conselho Diretor - Agencia Nacional de Telecomunicações, } \\
\text { disciplina da distribuição de matérias no } \\
\text { Estrutura Organizacional da ANATEL, Regimento Interno da ANATEL } \\
\text { Expediente Protelatório, Conselho Diretor - Agencia Nacional de Telecomunicações, } \\
\text { consideração da ausência injustificada de conselheiro como expediente protelatório } \\
\text { de decisão } \\
\text { Ilícito, Expediente Protelatório, consideração da ausência injustificada de conselheiro } \\
\text { à sessão ou reunião ou sua não manifestação em circuito deliberativo do Conselho } \\
\text { Diretor da ANATEL como } \\
\text { Instrumentos Deliberativos da ANATEL, Regimento Interno da ANATEL } \\
\text { Regimento Interno da ANATEL } \\
\text { Reunião, Conselho Diretor - Agencia Nacional de Telecomunicações, disciplina da } \\
\text { votação no } \\
\text { Sessão, Conselho Diretor - Agencia Nacional de Telecomunicações, disciplina da } \\
\text { votação no } \\
\text { Sorteio, Distribuição de Matérias, sua disciplina no Conselho Diretor da ANATEL } \\
\text { Vacância, Conselho Diretor - Agencia Nacional de Telecomunicações, efeitos da } \\
\text { vacância de conselheiros no } \\
\text { Votação, Conselho Diretor - Agencia Nacional de Telecomunicações, disciplina da } \\
\text { votação no }\end{array}$ \\
\hline Temas : Atores no Setor de Telecomunicações : ANATEL \\
\hline Temas
\end{tabular}

Resolução da ANATEL no 613, de 9 de maio de 2013 - Altera o art. 48 do Regulamento da Interface Usuário - Rede e de Terminais do Serviço Telefônico Fixo Comutado, aprovado pela Resolução ${ }^{\circ}$ 473, de 27 de julho de 2007.

\begin{tabular}{|l|l|}
\hline Órgão Emissor & ANATEL - Conselho Diretor. \\
\hline Dispositivos & LGT, Art. 19, inciso XIII; LGT, Art. 64, Parágrafo Único; LGT, Art. 156, caput. \\
\hline Regulamenta & $\begin{array}{l}\text { Lei no 9.472/1997 - Dispõe sobre a organização dos serviços de telecomunicações, a } \\
\text { criação e funcionamento de um órgão regulador e outros aspectos institucionais, nos } \\
\text { termos da Emenda Constitucional no 8, de 1995. }\end{array}$ \\
\hline Publicação & Diário Oficial da União, Seção 1, 16/05/2013, pág. p.65 \\
\hline
\end{tabular}




\begin{tabular}{|c|c|}
\hline Indexação & $\begin{array}{l}\text { Deficiência Visual, Terminais de Telecomunicações, dispensa de exigência de } \\
\text { disposição física das teclas de terminais do STFC para identificação por deficiente } \\
\text { visual } \\
\text { Interface Usuário-Rede, Regulamento da Interface Usuário-Rede e de Terminais do } \\
\text { STFC, alteração do } \\
\text { Regulamento da Interface Usuário-Rede e de Terminais do STFC, alteração do }\end{array}$ \\
\hline Temas & $\begin{array}{l}\text { Temas : Infraestrutura e Recursos do Setor de Telecomunicações : Equipamentos de } \\
\text { Telecomunicações : Certificação / Homologação } \\
\text { Temas : Infraestrutura e Recursos do Setor de Telecomunicações : Equipamentos de } \\
\text { Telecomunicações : Terminais } \\
\text { Temas : Políticas de Telecomunicações : Universalização : Acesso à Telecomunicações } \\
: \text { Portador de Deficiência } \\
\text { Temas : Serviços no Setor de Telecomunicações : Serviço Telefônico Fixo Comutado } \\
\text { (STFC) }\end{array}$ \\
\hline
\end{tabular}

Resolução da ANATEL n$^{\circ}$ 614, de 28 de maio de 2013 - Aprova o Regulamento do Serviço de Comunicação Multimídia e altera os Anexos I e III do Regulamento de Cobrança de Preço Público pelo Direito de Exploração de Serviços de Telecomunicações e pelo Direito de Exploração de Satélite.

\begin{tabular}{|c|c|}
\hline Órgão Emissor & ANATEL - Conselho Diretor. \\
\hline Anexos & Anexo - Regulamento do Serviço de Comunicação Multimídia. \\
\hline Dispositivos & CF, Art. $222, \S 3^{\circ}$; LGT, Art. $61, \S 2^{\circ}$; LGT, Art. 127, caput; LGT, Art. 151, caput. \\
\hline Altera & $\begin{array}{l}\text { Anexo à Resolução da ANATEL no } 386 \text {, de } 3 \text { de novembro de } 2004 \text { - Regulamento } \\
\text { de Cobrança de Preço Público pelo Direito de Exploração de Serviços de } \\
\text { Telecomunicações e pelo Direito de Exploração de Satélite. }\end{array}$ \\
\hline Revoga & $\begin{array}{l}\text { Resolução da ANATEL no 190/1999 - Aprova o Regulamento para Uso de Redes de } \\
\text { Serviços de Comunicação de Massa por Assinatura para Provimento de Serviços de } \\
\text { Valor Adicionado. [Ressalva: (12 meses após a publicação da Res. 614/2013)] } \\
\text { Anexo à Resolução da ANATEL no 272, de } 9 \text { de agosto de } 2001 \text { - Regulamento do } \\
\text { Serviço de Comunicação Multimídia. } \\
\text { Anexo } 1 \text { à Resolução da ANATEL no } 328 \text {, de } 29 \text { de janeiro de } 2003 \text { - Modelo de } \\
\text { Termo de Autorização para Exploração do Serviço de Comunicação Multimídia, de } \\
\text { interesse coletivo (Utilizado para autorizaçães autônomas à exploração de Serviço de } \\
\text { Comunicação Multimídia e para adaptaçôes das autorizações de Serviço Limitado } \\
\text { Especializado, nas submodalidades de Rede Especializado e Circuito Especializado). } \\
\text { Anexo } 2 \text { à Resolução da ANATEL no 328, de } 29 \text { de janeiro de } 2003 \text { - Modelo de } \\
\text { Termo de Autorização para Exploração do Serviço de Comunicação Multimídia, de } \\
\text { interesse coletivo (Utilizado para adaptações das autorizações de Serviço de Rede de } \\
\text { Transporte de Telecomunicações, compreendendo o Serviço por Linha Dedicada, o } \\
\text { Serviço de Rede Comutada por Pacote e o Serviço de Rede Comutada por Circuito). }\end{array}$ \\
\hline Correlata & $\begin{array}{l}\text { Lei no 8.078/1990 - Código de Defesa do Consumidor. } \\
\text { Decreto }{ }^{\circ} \text { 6.523/2008 - Regulamenta a Lei no 8.078, de } 11 \text { de setembro de 1990, para } \\
\text { fixar normas gerais sobre o Serviço de Atendimento ao Consumidor - SAC. } \\
\text { Anexo à Resolução da ANATEL no } 73 \text {, de } 25 \text { de novembro de } 1998 \text { - Regulamento } \\
\text { dos Serviços de Telecomunicações. } \\
\text { Resolução da ANATEL no 484/2007 - Aprova a alteração do Regulamento de Cobrança } \\
\text { de Preço Público pelo Direito de Exploração de Serviços de Telecomunicações e pelo } \\
\text { Direito de Exploração de Satélite. }\end{array}$ \\
\hline
\end{tabular}




\begin{tabular}{|c|c|}
\hline & $\begin{array}{l}\text { Resolução } \mathrm{n}^{\circ} \text { 595/2012 - Altera o regulmanento de cobrança de Preço Público pelo } \\
\text { Direito de Exploração de Serviços e Telecomunicações e pelo Direito de Exploração } \\
\text { de Satélite. }\end{array}$ \\
\hline Regulamenta & $\begin{array}{l}\text { Lei n }{ }^{\circ} 9.472 / 1997 \text { - Dispõe sobre a organização dos serviços de telecomunicações, a } \\
\text { criação e funcionamento de um órgão regulador e outros aspectos institucionais, nos } \\
\text { termos da Emenda Constitucional n }{ }^{\circ} 8 \text {, de } 1995 \text {. }\end{array}$ \\
\hline Publicação & Diário Oficial da União, Seção 1, 31/05/2013, págs. p.86-90 \\
\hline Indexação & $\begin{array}{l}\text { Autorização de Uso de Radiofreqüência, Serviço de Comunicação Multimídia, } \\
\text { condições para autorização de uso de radiofreqüência referente ao } \\
\text { Autorização, Serviço de Comunicação Multimídia, condições para autorização do } \\
\text { Serviço Privado de Telecomunicação, Serviço de Comunicação Multimídia, } \\
\text { regulamento do } \\
\text { Serviço de Comunicação Multimídia, Regulamento do Serviço de Comunicação } \\
\text { Multimídia } \\
\text { Serviço de Interesse Coletivo, Serviço de Comunicação Multimídia, regulamento do }\end{array}$ \\
\hline Temas & $\begin{array}{l}\text { Temas : Administração do Setor de Telecomunicações : Outorgas : Autorização (regras } \\
\text { aplicáveis) } \\
\text { Temas : Aplicações de Telecomunicações : Acesso a Serviços de Interesse Público e } \\
\text { Uso de Radiofrequência por tais Serviços : Defesa Civil } \\
\text { Temas : Aplicações de Telecomunicações : Banda Larga } \\
\text { Temas : Atores no Setor de Telecomunicações : Prestadora / Operadora } \\
\text { Temas : Atores no Setor de Telecomunicações : Usuário / Consumidor } \\
\text { Temas : Infraestrutura e Recursos do Setor de Telecomunicações : Redes de } \\
\text { Telecomunicações : Numeração dos Serviços } \\
\text { Temas : Políticas de Telecomunicações : Qualidade do Serviço } \\
\text { Temas : Serviços no Setor de Telecomunicações : Internet } \\
\text { Temas : Serviços no Setor de Telecomunicações : Serviço de Comunicação Multimídia } \\
\text { (SCM) }\end{array}$ \\
\hline
\end{tabular}

Resolução da ANATEL no 615, de 7 de junho de 2013 - Aprova alteração no Regulamento do Serviço Telefônico Fixo Comutado - STFC, aprovado pela Resolução no 426, de 9 de dezembro de 2005, alterado pela Resolução no 432 , de 23 de fevereiro de 2006, e pela Resolução $n^{\circ} 567$, de 24 de maio de 2011.

\begin{tabular}{|c|c|}
\hline Órgão Emissor & ANATEL - Conselho Diretor. \\
\hline Anexos & Anexo - Alterações do Regulamento do Serviço Telefônico Fixo Comutado (STFC). \\
\hline Dispositivos & $\begin{array}{l}\text { CF, Art. } 5^{\circ} \text {, inciso XXXII; CF, Art. 170, inciso V; LGT, Art. 64, Parágrafo Único; } \\
\text { LGT, Art. } 213, \S 2^{\circ} \text {. }\end{array}$ \\
\hline Altera & $\begin{array}{l}\text { Anexo à Resolução da ANATEL no } 426 \text {, de } 9 \text { de dezembro de } 2005 \text { - Regulamento } \\
\text { do Serviço Telefônico Fixo Comutado. } \\
\text { Resolução da ANATEL no } 432 / 2006 \text { - Aprova a alteração dos prazos constantes do } \\
\text { item } 8 \text { da Norma para Alteração da Tarifação do Plano Básico do Serviço Telefônico } \\
\text { Fixo Comutado na Modalidade Local, Prestado em Regime Público. } \\
\text { Anexo à Resolução da ANATEL no } 567 \text {, de } 24 \text { de maio de } 2011 \text { - Alteração do } \\
\text { Regulamento do Serviço Telefônico Fixo Comutado. }\end{array}$ \\
\hline Regulamenta & $\begin{array}{l}\text { Lei n } \text { n }^{\circ} .472 / 1997 \text { - Dispõe sobre a organização dos serviços de telecomunicações, a } \\
\text { criação e funcionamento de um órgão regulador e outros aspectos institucionais, nos } \\
\text { termos da Emenda Constitucional no } 8 \text {, de } 1995 \text {. }\end{array}$ \\
\hline
\end{tabular}




\begin{tabular}{|c|c|}
\hline Publicação & Diário Oficial da União, Seção 1, 11/06/2013, págs. p.30-31 \\
\hline \multirow[t]{13}{*}{ Indexação } & $\begin{array}{l}\text { Atendimento Pessoal, alteração do Regulamento do STFC para disciplinar com maior } \\
\text { detalhamento os direitos dos usuários/consumidores do STFC, em especial, o }\end{array}$ \\
\hline & $\begin{array}{l}\text { Centro de Atendimento (Indicadores de Qualidade do STFC), Regulamento do Serviço } \\
\text { Telefônico Fixo Comutado, sua alteração para disciplina mais detalhada dos direitos } \\
\text { dos usuários/consumidores do STFC }\end{array}$ \\
\hline & $\begin{array}{l}\text { Consumidor, Atendimento Pessoal, alteração do Regulamento do STFC para disciplinar } \\
\text { com maior detalhamento os direitos dos usuários/consumidores do STFC, em especial, } \\
\text { o }\end{array}$ \\
\hline & $\begin{array}{l}\text { Consumidor, Serviço de Atendimento ao Consumidor, alteração do Regulamento do } \\
\text { STFC para disciplinar com maior detalhamento os direitos dos usuários/consumidores } \\
\text { do STFC }\end{array}$ \\
\hline & $\begin{array}{l}\text { Portabilidade de Código de Acesso (STFC), Regulamento do Serviço Telefônico Fixo } \\
\text { Comutado, sua alteração para disciplina mais detalhada dos direitos dos } \\
\text { usuários/consumidores do STFC }\end{array}$ \\
\hline & $\begin{array}{l}\text { Portabilidade, Regulamento do Serviço Telefônico Fixo Comutado, sua alteração para } \\
\text { disciplina mais detalhada dos direitos dos usuários/consumidores do STFC }\end{array}$ \\
\hline & $\begin{array}{l}\text { Regulamento do Serviço Telefônico Fixo Comutado, sua alteração para disciplina } \\
\text { mais detalhada dos direitos dos usuários/consumidores do STFC }\end{array}$ \\
\hline & $\begin{array}{l}\text { Serviço Telefônico Fixo Comutado, Atendimento Pessoal, alteração do Regulamento } \\
\text { do STFC para disciplinar com maior detalhamento os direitos dos } \\
\text { usuários/consumidores do STFC, em especial, o }\end{array}$ \\
\hline & $\begin{array}{l}\text { Serviço Telefônico Fixo Comutado, Terceirização, alteração do Regulamento do STFC } \\
\text { para disciplinar com maior detalhamento os direitos dos usuários/consumidores do } \\
\text { STFC }\end{array}$ \\
\hline & $\begin{array}{l}\text { Serviço de Atendimento ao Consumidor, Regulamento do Serviço Telefônico Fixo } \\
\text { Comutado, sua alteração para disciplina mais detalhada dos direitos dos } \\
\text { usuários/consumidores do STFC }\end{array}$ \\
\hline & $\begin{array}{l}\text { Serviço de Atendimento ao Consumidor, Serviço Telefônico Fixo Comutado, alteração } \\
\text { do Regulamento do STFC para disciplinar com maior detalhamento os direitos dos } \\
\text { usuários/consumidores do }\end{array}$ \\
\hline & $\begin{array}{l}\text { Serviço de Atendimento ao Consumidor, Terceirização, alteração do Regulamento do } \\
\text { STFC para disciplinar com maior detalhamento os direitos dos usuários/consumidores } \\
\text { do STFC }\end{array}$ \\
\hline & $\begin{array}{l}\text { Terceirização, Serviço de Atendimento ao Consumidor, alteração do Regulamento do } \\
\text { STFC para disciplinar com maior detalhamento os direitos dos usuários/consumidores } \\
\text { do STFC }\end{array}$ \\
\hline \multirow[t]{5}{*}{ Temas } & Temas : Atores no Setor de Telecomunicações : Prestadora / Operadora \\
\hline & Temas : Atores no Setor de Telecomunicações : Usuário / Consumidor \\
\hline & Temas : Políticas de Telecomunicações : Qualidade do Serviço \\
\hline & Temas : Ramos Jurídicos Afins : Direito do Consumidor \\
\hline & $\begin{array}{l}\text { Temas : Serviços no Setor de Telecomunicações : Serviço Telefônico Fixo Comutado } \\
\text { (STFC) }\end{array}$ \\
\hline
\end{tabular}

Resolução da ANATEL n⿳ 616, de 18 de junho de 2013 - Aprova a alteração do Regulamento de Cobrança de Preço Público pelo Direito de Exploração de Serviços de Telecomunicações e pelo Direito de Exploração de Satélite, aprovado pela Resolução no 386, de 3 de novembro de 2004, e alterado pela Resolução $n^{\circ} 484$, de 5 de novembro de 2007.

Órgão Emissor ANATEL - Conselho Diretor. 


\begin{tabular}{|c|c|}
\hline Anexos & $\begin{array}{l}\text { Anexo - Alteração do art. } 12 \text { do Regulamento de Cobrança de Preço Público pelo } \\
\text { Direito de Exploração de Serviços de Telecomunicações e pelo Direito de Exploração } \\
\text { de Satélite. }\end{array}$ \\
\hline Dispositivos & $\begin{array}{l}\text { LGT, Art. 19, inciso X; LGT, Art. 19, inciso XXI; LGT, Art. 48, caput; LGT, Art. } \\
\text { 131, caput. }\end{array}$ \\
\hline Altera & $\begin{array}{l}\text { Anexo à Resolução da ANATEL n }{ }^{\circ} 386 \text {, de } 3 \text { de novembro de } 2004 \text { - Regulamento } \\
\text { de Cobrança de Preço Público pelo Direito de Exploração de Serviços de } \\
\text { Telecomunicações e pelo Direito de Exploração de Satélite. } \\
\text { Anexo à Resolução da ANATEL n }{ }^{\circ} 484 \text {, de } 5 \text { de novembro de } 2007 \text { - Alteração do } \\
\text { Regulamento de Cobrança de Preço Público pelo Direito de Exploração de Serviços } \\
\text { de Telecomunicações e pelo Direito de Exploração de Satélite. }\end{array}$ \\
\hline Regulamenta & $\begin{array}{l}\text { Lei n }{ }^{\circ} 9.472 / 1997 \text { - Dispõe sobre a organização dos serviços de telecomunicações, a } \\
\text { criação e funcionamento de um órgão regulador e outros aspectos institucionais, nos } \\
\text { termos da Emenda Constitucional no } 8 \text {, de } 1995 \text {. }\end{array}$ \\
\hline Publicação & Diário Oficial da União, Seção 1, 21.06.2013, págs. p.56-57 \\
\hline Indexação & $\begin{array}{l}\text { Acréscimo de Faixa de Radiofrequência, valor devido por } \\
\text { Espectro de Radiofreqüências, Acréscimo de Faixa de Radiofrequência, valor devido } \\
\text { por } \\
\text { Onerosidade, Acréscimo de Faixa de Radiofrequência, valor devido por } \\
\text { Preço Público, Acréscimo de Faixa de Radiofrequência, valor devido por } \\
\text { Regulamento de Cobrança de Preço Público pelo Direito de Exploração de Serviços } \\
\text { de Telecomunicações e pelo Direito de Exploração de Satélite, alteração do } \\
\text { Serviços de Telecomunicações, Onerosidade, valor devido por acréscimo de faixa de } \\
\text { radiofrequência }\end{array}$ \\
\hline Temas & $\begin{array}{l}\text { Temas : Administração do Setor de Telecomunicações : Outorgas : Autorização (regras } \\
\text { aplicáveis) } \\
\text { Temas : Administração do Setor de Telecomunicações : Outorgas : Concessão (regras } \\
\text { aplicáveis) } \\
\text { Temas : Administração do Setor de Telecomunicações : Outorgas : Preço Público e } \\
\text { Preço Privado } \\
\text { Temas : Atores no Setor de Telecomunicações : Prestadora / Operadora } \\
\text { Temas : Infraestrutura e Recursos do Setor de Telecomunicações : Órbita e Satélite }\end{array}$ \\
\hline
\end{tabular}

\begin{tabular}{|c|c|}
\hline \multicolumn{2}{|c|}{$\begin{array}{l}\text { Resolução da ANATEL nº 617, de } 19 \text { de junho de } 2013 \text { - Aprova o Regulamento do Serviço Limitado } \\
\text { Privado. }\end{array}$} \\
\hline Órgão Emissor & ANATEL - Conselho Diretor. \\
\hline Anexos & Anexo - Regulamento do Serviço Limitado Privado. \\
\hline Dispositivos & $\begin{array}{l}\text { LGT, Art. 19, inciso X; LGT, Art. 19, inciso XI; LGT, Art. 22, inciso VI; LGT, Art. } \\
\text { 127, caput; LGT, Art. 131, caput; LGT, Art. 214, inciso I. }\end{array}$ \\
\hline Altera & $\begin{array}{l}\text { Norma } n^{\circ} 02 / 80 \text { - Serviço Especial de Radioautocine } \\
\text { Norma } n^{\circ} 01 / 82 \text { - Serviço de Rádio-Táxi, aprovada pela Portaria MC no } 44 \text {, de } 3 \text { de } \\
\text { março de } 1982 \\
\text { Norma no } 04 / 86 \text { - Serviço Especial de Supervisão e Controle } \\
\text { Portaria MC n } 193 / 88 \text {, de } 5 \text { de agosto de } 1988 \text { - Serviço Limitado Radioestrada } \\
\text { Portaria } n^{\circ} 892 / 94\end{array}$ \\
\hline
\end{tabular}




\begin{tabular}{|c|c|}
\hline & $\begin{array}{l}\text { Norma } n^{\circ} 17 / 96 \text { - Canalização e Condições de Uso de Frequências pelo Serviço } \\
\text { Especial de Radiochamada e pelo Serviço Limitado Privado de Radiochamada } \\
\text { Anexo à Portaria MC } \text { n }^{\circ} 455 \text {, de } 27 \text { de setembro de } 1997 \text { - Norma no } 13 / 97 \text { - Serviço } \\
\text { Limitado. } \\
\text { Anexo à Portaria MC no } 558 \text {, de } 3 \text { de novembro de } 1997 \text { - Norma no } 15 / 97 \text { - Serviço } \\
\text { Especial de Radiochamada. } \\
\text { Anexo à Resolução da ANATEL no } 386 \text {, de } 3 \text { de novembro de } 2004 \text { - Regulamento } \\
\text { de Cobrança de Preço Público pelo Direito de Exploração de Serviços de } \\
\text { Telecomunicações e pelo Direito de Exploração de Satélite. } \\
\text { Anexo à Resolução da ANATEL no 484, de } 5 \text { de novembro de } 2007 \text { - Alteração do } \\
\text { Regulamento de Cobrança de Preço Público pelo Direito de Exploração de Serviços } \\
\text { de Telecomunicações e pelo Direito de Exploração de Satélite. }\end{array}$ \\
\hline Revoga & $\begin{array}{l}\text { Resolução da ANATEL no 171/1999 - Aprova o Plano de Autorizações do Serviço } \\
\text { Especial de Radiochamada - SER. } \\
\text { Resolução da ANATEL no } 196 / 1999 \text { - Aprova a Norma N. }{ }^{\circ} 8 / 99 \text { - Anatel - "Condições } \\
\text { para Aplicação do Plano de Autorizações do Serviço Especial de Radiochamada". - } \\
\text { Anexo - Norma no 8/99 - "Condições para Aplicação do Plano de Autorizações do } \\
\text { Serviço Especial de Radiochamada". } \\
\text { Resolução da ANATEL no } 211 / 2000 \text { - Aprova Adaptação da Norma no } 15 / 97 \text { - Serviço } \\
\text { Especial de Radiochamada. }\end{array}$ \\
\hline Regulamenta & $\begin{array}{l}\text { Lei no } 9.472 / 1997 \text { - Dispõe sobre a organização dos serviços de telecomunicações, a } \\
\text { criação e funcionamento de um órgão regulador e outros aspectos institucionais, nos } \\
\text { termos da Emenda Constitucional no } 8 \text {, de } 1995 \text {. }\end{array}$ \\
\hline Publicação & $\begin{array}{l}\text { Diário Oficial da União, Seção 1, 21/06/2013, págs. p.57-59 } \\
\text { Diário Oficial da União, Seção 1, 05/07/2013, pág. p.68 [ Retificação ] }\end{array}$ \\
\hline Indexação & $\begin{array}{l}\text { Autorização, Serviço Especial de Radiochamada, Regime Regulatório, substituição } \\
\text { do plano de autorizaços do pelo Regulamento do Serviço Limitado Privado } \\
\text { Condiçães Objetivas, Serviço Limitado Privado, fixação das condições objetivas para } \\
\text { obtenção de autorização do } \\
\text { Condições Subjetivas, Serviço Limitado Privado, fixação das condições objetivas para } \\
\text { obtenção de autorização do } \\
\text { Plano de Autorizações do Serviço Especial de Radiochamada, sua substituição pelo } \\
\text { Regulamento do Serviço Limitado Privado } \\
\text { Regulamento de Cobrança de Preço Público pelo Direito de Exploração de Serviços } \\
\text { de Telecomunicações e pelo Direito de Exploração de Satélite, alteração do } \\
\text { Regulamento do Serviço Limitado Privado, Regulamento de Serviço Limitado, sua } \\
\text { inaplicabilidade ao Serviço Limitado Privado } \\
\text { Regulamento do Serviço Limitado Privado, aprovação do } \\
\text { Regulamento do Serviço Limitado Privado, sua inaplicabilidade ao Serviço Limitado } \\
\text { Privado } \\
\text { Serviço Científico } \\
\text { Serviço Especial de Radiochamada, Regime Regulatório, Plano de Autorizações do } \\
\text { Serviço Especial de Radiochamada, sua substituição pelo Regulamento do Serviço } \\
\text { Limitado Privado } \\
\text { Serviço Especial para Fins Científicos ou Experimentais } \\
\text { Serviço Especial para Fins Científicos ou Experimentais, Regime Regulatório } \\
\text { Serviço Limitado }\end{array}$ \\
\hline
\end{tabular}




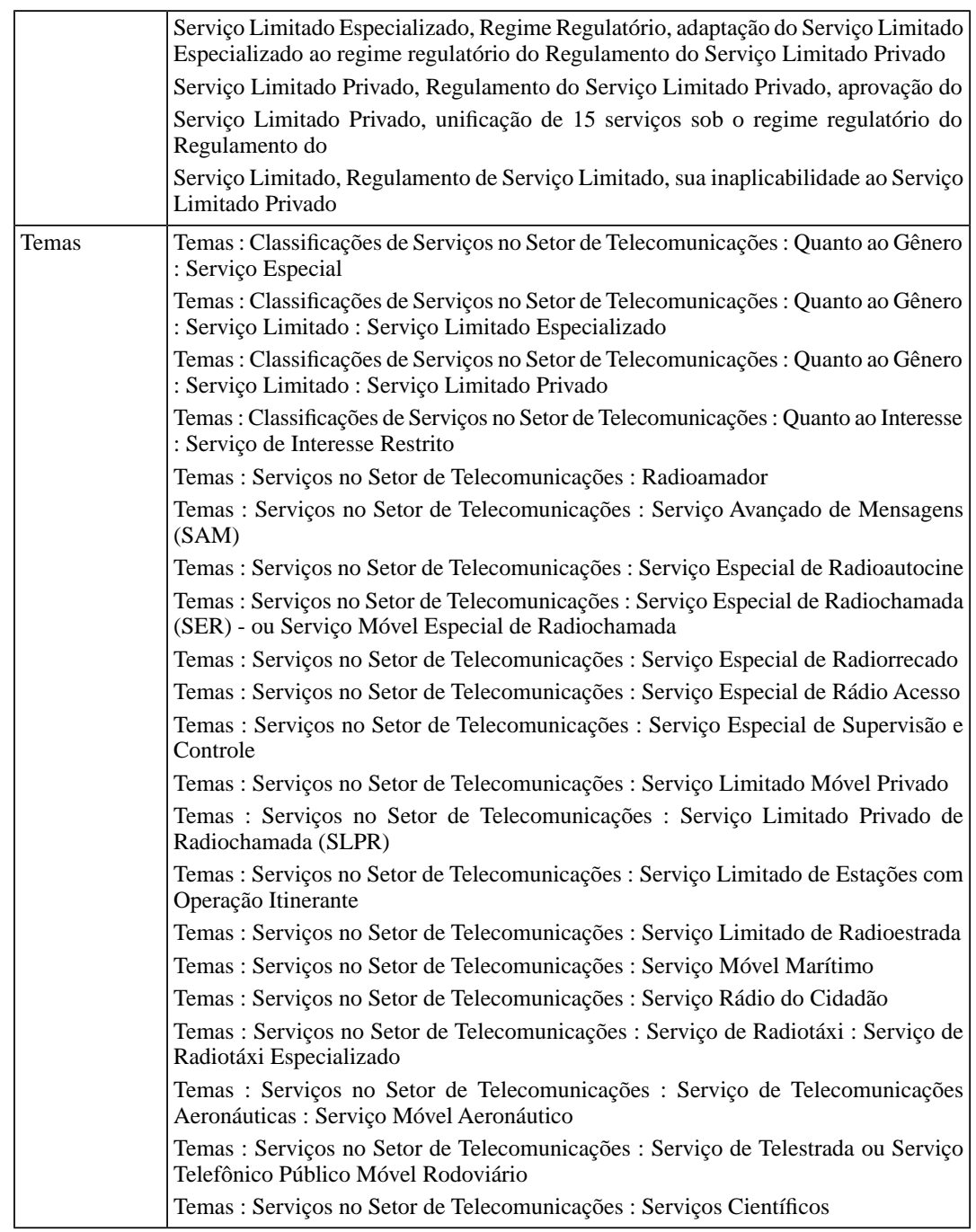

\begin{tabular}{|c|c|}
\hline $\begin{array}{l}\text { Resolução da A } \\
\text { Condicionado ( }\end{array}$ & $\begin{array}{l}\text { NATEL } \mathbf{n}^{\mathbf{6}} \mathbf{6 1 8} \text {, de } 24 \text { de julh } \\
\text { SeAC), aprovado pela Resoluça }\end{array}$ \\
\hline Órgão Emissor & ANATEL - Conselho Diretor. \\
\hline Dispositivos & LGT, Art. 212, caput. \\
\hline
\end{tabular}




\begin{tabular}{|c|c|}
\hline Correlata & $\begin{array}{l}\text { Anexo à Resolução da ANATEL n }{ }^{\circ} 274 \text {, de } 5 \text { de setembro de } 2001 \text { - Regulamento de } \\
\text { Compartilhamento de Infra-estrutura entre as Prestadoras dos Serviços de } \\
\text { Telecomunicações. } \\
\text { Anexo à Resolução Conjunta ANATEL-ANEEL-ANP n }{ }^{\circ} 1 \text {, de } 24 \text { de novembro de } \\
1999 \text { - Regulamento Conjunto para Compartilhamento de Infra-estrutura entre os } \\
\text { Setores de Energia Elétrica, Telecomunicações e Petróleo. }\end{array}$ \\
\hline Regulamenta & $\begin{array}{l}\text { Lei } \mathrm{n}^{\circ} 9.472 / 1997 \text { - Dispõe sobre a organização dos serviços de telecomunicações, a } \\
\text { criação e funcionamento de um órgão regulador e outros aspectos institucionais, nos } \\
\text { termos da Emenda Constitucional } n^{\circ} 8 \text {, de } 1995 \text {. }\end{array}$ \\
\hline Publicação & Diário Oficial da União, Seção 1, 26/07/2013, pág. p.39 \\
\hline Indexação & $\begin{array}{l}\text { Licença para Funcionamento de Estação, Serviço de Acesso Condicionado, alteração } \\
\text { do regulamento do SeAC para permitir a obtenção de licença para funcionamento de } \\
\text { estação independentemente de comprovação de contrato de uso dos postes, dutos, } \\
\text { rede ou seus segmentos, celebrado com empresa proprietária das respectivas } \\
\text { infraestruturas e autorização de Prefeitura para a construção do sistema } \\
\text { Serviço de Acesso Condicionado, alteração do regulamento do SeAC para permitir a } \\
\text { obtenção de licença para funcionamento de estação independentemente de comprovação } \\
\text { de contrato de uso dos postes, dutos, rede ou seus segmentos, celebrado com empresa } \\
\text { proprietária das respectivas infraestruturas e autorização de Prefeitura para a construção } \\
\text { do sistema }\end{array}$ \\
\hline Temas & $\begin{array}{l}\text { Temas : Serviços no Setor de Telecomunicações : Serviço de Acesso Condicionado } \\
(\mathrm{SeAC})\end{array}$ \\
\hline
\end{tabular}

Resolução da ANATEL n ${ }^{0}$ 619, de 8 de agosto de 2013 - Alterações dos Anexos I e II do Regulamento de Separação e Alocação de Contas - RSAC, aprovado pela Resolução n 396, de 31 de março de 2005, alterado pela Resolução n ${ }^{\circ} 419$, de 24 de novembro de 2005, pela Resolução $n^{\circ} 464$, de 27 de abril de 2007, pela Resolução $\mathrm{n}^{\circ} 480$, de 14 de agosto de 2007, pela Resolução $\mathrm{n}^{\circ}$ 483, de 24 de outubro de 2007, pela Resolução n ${ }^{\circ}$ 503, de 25 de abril de 2008, e pela Resolução n n 608 , de 5 de abril de 2013.

\begin{tabular}{|l|l|}
\hline Órgão Emissor & ANATEL - Conselho Diretor. \\
\hline Anexos & $\begin{array}{l}\text { Anexo - Alteraçães dos Anexos I e II do Regulamento de Separação e Alocação de } \\
\text { Contas (RSAC). }\end{array}$ \\
\hline Dispositivos & LGT, Art. 93, inciso X; LGT, Art. 127, inciso X. \\
\hline Altera & Anexo 1 à Resolução da ANATEL n ${ }^{\circ}$ 396, de 31 de março de 2005 \\
\hline Correlata & $\begin{array}{l}\text { Resolução da ANATEL } n^{\circ} \text { 419/2005 - Aprova o prazo para apresentação, pelas } \\
\text { Concessionárias do STFC, do Documento de Separação e Alocação de Contas (DSAC). } \\
\text { Resolução da ANATEL no 464/2007 - Prorroga a apresentação, pelas Concessionárias } \\
\text { do Serviço Telefônico Fixo Comutado - STFC, do Apêndice B do Anexo I e Anexos } \\
\text { II e III do Documento de Separação e Alocação de Contas - DSAC. } \\
\text { Resolução da ANATEL no 480/2007 - Aprova o prazo para apresentação, pelas } \\
\text { detentoras de PMS na oferta de interconexão em rede móvel, do Documento de } \\
\text { Separação e Alocação de Contas (DSAC). } \\
\text { Resolução da ANATEL no 483/2007 - Estende o prazo para apresentação do primeiro } \\
\text { Documento de Separação e Alocação de Contas (DSAC) pelas detentoras de Poder } \\
\text { de Mercado Significativo (PMS) na oferta de interconexão em rede móvel. } \\
\text { Resolução da ANATEL n }{ }^{\circ} \text { 503/2008 - Prorroga o prazo para apresentação do Apêndice } \\
\text { B do Anexo I do Documento de Separação e Alocação de Contas (DSAC) por } \\
\text { Prestadoras do SMP que integrem Grupo detentor de Poder de Mercado Significativo } \\
\text { na interconexão em rede móvel ou que façam parte de Grupo que contenha } \\
\text { Concessionária do STFC. }\end{array}$
\end{tabular}




\begin{tabular}{|c|c|}
\hline & 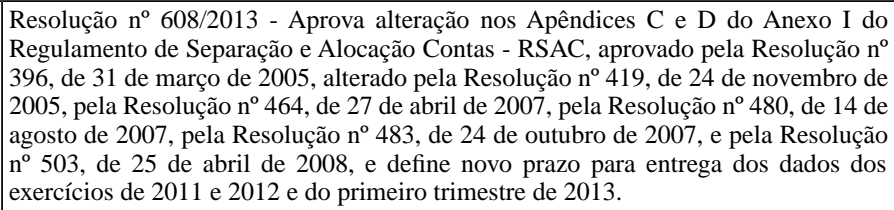 \\
\hline Regulamenta & $\begin{array}{l}\text { Lei } \mathrm{n}^{\circ} 9.472 / 1997 \text { - Dispõe sobre a organização dos serviços de telecomunicações, a } \\
\text { criação e funcionamento de um órgão regulador e outros aspectos institucionais, nos } \\
\text { termos da Emenda Constitucional no } 8 \text {, de } 1995 \text {. }\end{array}$ \\
\hline Publicação & $\begin{array}{l}\text { Diário Oficial da União, Seção 1, 09/08/2013, págs. p.59-96 } \\
\text { Diário Oficial da União, Seção 1, 02/10/2013, pág. p.53 }\end{array}$ \\
\hline Indexação & Regulamento de Separação e Alocação de Contas, alteração do \\
\hline Temas & $\begin{array}{l}\text { Temas : Administração do Setor de Telecomunicações : Fiscalização das } \\
\text { Telecomunicações } \\
\text { Temas : Serviços no Setor de Telecomunicações : Serviço Móvel Pessoal (SMP) } \\
\text { Temas : Serviços no Setor de Telecomunicações : Serviço Telefônico Fixo Comutado } \\
\text { (STFC) } \\
\text { Temas : Serviços no Setor de Telecomunicações : Serviço de Acesso Condicionado } \\
\text { (SeAC) } \\
\text { Temas : Serviços no Setor de Telecomunicações : Serviço de Comunicação Multimídia } \\
\text { (SCM) }\end{array}$ \\
\hline
\end{tabular}

\begin{tabular}{|c|c|}
\hline \multicolumn{2}{|c|}{$\begin{array}{l}\text { Resolução da ANATEL no } \mathbf{6 2 0} \text {, de } 9 \text { de agosto de } \mathbf{2 0 1 3} \text { - Altera os Anexos I e II do Regulamento } \\
\text { sobre Áreas Locais para o Serviço Telefônico Fixo Comutado Destinado ao Uso do Público em Geral } \\
\text { - STFC. }\end{array}$} \\
\hline Órgã & or. \\
\hline Ane & $\begin{array}{l}\text { Anexo } 1 \text { - Alterações ao Anexo I do Regulamento sobre Áreas Locais para o STFC. } \\
\text { Anexo } 2 \text { - Alterações ao Anexo II do Regulamento sobre Áreas Locais para o STFC. } \\
\text { Anexo } 3 \text { - Alterações ao Anexo II do Regulamento sobre Áreas Locais para o STFC. } \\
\text { Anexo } 4 \text { - Alterações ao Anexo II do Regulamento sobre Áreas Locais para o STFC. } \\
\text { Anexo } 5 \text { - Alterações ao Anexo II do Regulamento sobre Áreas Locais para o STFC. }\end{array}$ \\
\hline Dispc & LGT, Art. $2^{\circ}$, il \\
\hline Altera & $\begin{array}{l}\text { Anexo à Resolução da ANATEL no 560, de } 21 \text { de janeiro de } 2011 \text { - Regulamento } \\
\text { sobre Áreas Locais para o Serviço Telefônico Fixo Comutado Destinado ao Uso do } \\
\text { Público em Geral - STFC. }\end{array}$ \\
\hline Regu & $\begin{array}{l}\text { Lei no 9.472/1997 - Dispõe sobre a organização dos serviços de telecomunicações, a } \\
\text { criação e funcionamento de um órgão regulador e outros aspectos institucionais, nos } \\
\text { termos da Emenda Constitucional n }{ }^{\circ} 8 \text {, de } 1995 \text {. }\end{array}$ \\
\hline Publicação & Diário Oficial da União, Seção 1, 13/08/2013, págs. p.78-79 \\
\hline Index & $\begin{array}{l}\text { Regulamento sobre Áreas Locais para o STFC, alteração do } \\
\text { Serviço Telefônico Fixo Comutado, Regulamento sobre Áreas Locais para o STFC, } \\
\text { alteração do } \\
\text { Área Local, Regulamento sobre Áreas Locais para o STFC, alteração do }\end{array}$ \\
\hline
\end{tabular}




\begin{tabular}{|l|l|}
\hline Temas & $\begin{array}{l}\text { Temas : Serviços no Setor de Telecomunicações : Serviço Telefônico Fixo Comutado } \\
\text { (STFC) }\end{array}$ \\
\hline
\end{tabular}

Resolução da ANATEL $n^{\circ}$ 621, de 14 de agosto de 2013 - Aprova alteração do Anexo I do Regulamento de Tarifação do Serviço Telefônico Fixo Comutado Destinado ao Uso do Público em Geral - STFC Prestado no Regime Público, aprovado pela Resolução n ${ }^{\circ} 424$, de 6 de dezembro de 2005, e do Plano Geral de Códigos Nacionais - PGCN, anexo ao Regulamento de Numeração do STFC, aprovado pela Resolução no 86, de 30 de dezembro de 1998, alterado pela Resolução no 263 , de 8 de junho de 2001, para mudar o município de Sabáudia, no estado do Paraná, da Área de Tarifação 442 (Maringá) para a Área de Tarifação 432 (Londrina) e do Código Nacional 44 para o Código Nacional 43.

\begin{tabular}{|c|c|}
\hline Órgão Emissor & selho Diretor. \\
\hline Anexos & $\begin{array}{l}\text { Anexo } 1 \text { - Alterações ao Regulamento de Tarifação do Serviço Telefônico Fixo } \\
\text { Comutado. } \\
\text { Anexo } 2 \text { - Alterações ao Plano Geral de Códigos Nacionais, anexo ao Regulamento } \\
\text { de Numeração do STFC. }\end{array}$ \\
\hline Dispositivos & $\begin{array}{l}\text { LGT, Art. 19, inciso IV; LGT, Art. 19, inciso VII; LGT, Art. 64, Parágrafo Único; } \\
\text { LGT, Art. 103, caput. }\end{array}$ \\
\hline Altera & $\begin{array}{l}\text { Anexo à Resolução da ANATEL no 263, de } 8 \text { de junho de } 2001 \text { - Plano Geral de } \\
\text { Códigos Nacionais - PGCN. } \\
\text { Anexo à Resolução da ANATEL no 424, de } 6 \text { de dezembro de } 2005 \text { - Regulamento } \\
\text { de Tarifação do Serviço Telefônico Fixo Comutado Destinado ou Uso do Público em } \\
\text { Geral - STFC Prestado no Regime Público. }\end{array}$ \\
\hline Regulamenta & $\begin{array}{l}\text { Lei no } 9.472 / 1997 \text { - Dispõe sobre a organização dos serviços de telecomunicações, a } \\
\text { criação e funcionamento de um órgão regulador e outros aspectos institucionais, nos } \\
\text { termos da Emenda Constitucional n }{ }^{\circ} 8 \text {, de } 1995 \text {. }\end{array}$ \\
\hline Publicação & Diário Oficial da União, Seção 1, 15/08/2013, págs. p.54-55 \\
\hline Indexação & $\begin{array}{l}\text { Código Nacional, alteração de } \\
\text { Plano Geral de Códigos Nacionais, alteração do } \\
\text { Serviço Telefônico Fixo Comutado, Plano Geral de Códigos Nacionais, alteração do } \\
\text { Serviço Telefônico Fixo Comutado, Área de Tarifação, alteração de área de tarifação } \\
\text { do } \\
\text { Área de Tarifação, Serviço Telefônico Fixo Comutado, alteração de área de tarifação } \\
\text { do }\end{array}$ \\
\hline Temas & $\begin{array}{l}\text { Temas : Administração do Setor de Telecomunicações : Outorgas : Preço Público e } \\
\text { Preço Privado } \\
\text { Temas : Administração do Setor de Telecomunicações : Planos de Serviços } \\
\text { Temas : Atores no Setor de Telecomunicações : Prestadora / Operadora } \\
\text { Temas : Atores no Setor de Telecomunicações : Usuário / Consumidor } \\
\text { Temas : Políticas de Telecomunicações : Política Tarifária } \\
\text { Temas : Ramos Jurídicos Afins : Direito do Consumidor } \\
\text { Temas : Serviços no Setor de Telecomunicações : Serviço Telefônico Fixo Comutado } \\
\text { (STFC) }\end{array}$ \\
\hline
\end{tabular}

Resolução da ANATEL n ${ }^{\circ}$ 622, de 23 de agosto de 2013 - Aprova o Regulamento sobre a Prestação do Serviço Telefônico Fixo Comutado Destinado ao Público em Geral (STFC) Fora da Área de Tarifa Básica (ATB). 


\begin{tabular}{|c|c|}
\hline Órgão Emissor & ANATEL - Conselho Diretor. \\
\hline Anexos & $\begin{array}{l}\text { Anexo - Regulamento sobre a Prestação do Serviço Telefônico Fixo Comutado } \\
\text { Destinado ao Público em Geral (STFC) Fora da Área de Tarifa Básica (ATB). }\end{array}$ \\
\hline Dispositivos & $\begin{array}{l}\text { LGT, Art. 19, inciso IV; LGT, Art. 19, inciso X; LGT, Art. 64, Parágrafo Único; LGT, } \\
\text { Art. } 79, \S 1^{\circ} \text {. }\end{array}$ \\
\hline Correlata & $\begin{array}{l}\text { Anexo } 1 \text { ao Decreto } \mathrm{n}^{\circ} 7.512 \text {, de } 30 \text { de junho de } 2011 \text { - Anexo } 1 \text { ao Decreto } \mathrm{n}^{\circ} 7.512 \text {, } \\
\text { de } 30 \text { de junho de } 2011 \text { - Plano Geral de Metas para a Universalização do Serviço } \\
\text { Telefônico Fixo Comutado Prestado no Regime Público - PGMU. }\end{array}$ \\
\hline Regulamenta & $\begin{array}{l}\text { Lei n }{ }^{\circ} 9.472 / 1997 \text { - Dispõe sobre a organização dos serviços de telecomunicações, a } \\
\text { criação e funcionamento de um órgão regulador e outros aspectos institucionais, nos } \\
\text { termos da Emenda Constitucional n }{ }^{\circ} 8 \text {, de } 1995 \text {. }\end{array}$ \\
\hline Publicação & Diário Oficial da União, Seção 1, 27/08/2013, págs. p.87-91 \\
\hline Indexação & $\begin{array}{l}\text { Autorização, Contrato de Prestação do STFC fora da Área de Tarifa Básica, modelo } \\
\text { de } \\
\text { Autorização, Serviço Telefônico Fixo Comutado, modelo de contrato de prestação do } \\
\text { STFC fora da Área de Tarifa Básica } \\
\text { Concessão, Contrato de Prestação do STFC fora da Área de Tarifa Básica, modelo de } \\
\text { Concessão, Serviço Telefônico Fixo Comutado, modelo de contrato de prestação do } \\
\text { STFC fora da Área de Tarifa Básica } \\
\text { Contrato de Prestação do STFC fora da Área de Tarifa Básica, modelo de } \\
\text { Plano de Atendimento Rural Complementar (STFC), disciplina do } \\
\text { Plano de Atendimento Rural Facultativo, disciplina do } \\
\text { Plano de Atendimento Rural Suplementar (STFC), disciplina do } \\
\text { Plano de Atendimento Rural, sua exigência para prestação de STFC fora da Área de } \\
\text { Tarifa Básica (ATB) } \\
\text { Rural } \\
\text { Serviço Telefônico Fixo Comutado, Plano de Atendimento Rural, sua exigência para } \\
\text { prestação de STFC fora da Área de Tarifa Básica (ATB) } \\
\text { Serviço Telefônico Fixo Comutado, sua prestação fora da área de tarifa básica (ATB) } \\
\text { Serviço Telefônico Fixo Comutado, Área de Tarifa Básica, disciplina da prestação de } \\
\text { STFC fora da } \\
\text { Zona Rural, Plano de Atendimento Rural, sua exigência para prestação de STFC fora } \\
\text { da Área de Tarifa Básica (ATB) } \\
\text { Zona Rural, Serviço Telefônico Fixo Comutado, sua prestação fora da área de tarifa } \\
\text { básica (ATB) }\end{array}$ \\
\hline Temas & $\begin{array}{l}\text { Temas : Políticas de Telecomunicações : Universalização : Metas de Universalização } \\
\text { Temas : Serviços no Setor de Telecomunicações : Serviço Telefônico Fixo Comutado } \\
\text { (STFC) }\end{array}$ \\
\hline
\end{tabular}

\begin{tabular}{|c|c|}
\hline \multicolumn{2}{|c|}{$\begin{array}{l}\text { Resolução da ANATEL no 623, de } 18 \text { de outubro de } 2013 \text { - Aprova o Regulamento de Conselho de } \\
\text { Usuários. }\end{array}$} \\
\hline Órgão Emissor & ANATEL - Conselho Diretor. \\
\hline Anexos & Conselho \\
\hline Dispositivos & $\begin{array}{l}\text { CF, Art. } 5^{\circ} \text {, inciso XXXII; CF, Art. 170, inciso V; CF, Art. 175, § único, inciso II; } \\
\text { LGT, Art. } 3^{\circ} \text {, caput; LGT, Art. 64, Parágrafo Único; LGT, Art. 127, inciso III; LGT, } \\
\text { Art. } 127 \text {, inciso V. }\end{array}$ \\
\hline
\end{tabular}




\begin{tabular}{|c|c|}
\hline Altera & $\begin{array}{l}\text { Anexo à Resolução da ANATEL nº 426, de } 9 \text { de dezembro de } 2005 \text { - Regulamento } \\
\text { do Serviço Telefônico Fixo Comutado. }\end{array}$ \\
\hline Revoga & $\begin{array}{l}\text { Resolução da ANATEL no 490/2008 - Aprova o Regulamento de Conselho de Usuários } \\
\text { do Serviço Telefônico Fixo Comutado - STFC. - Anexo - Regulamento de Conselho } \\
\text { de Usuários do Serviço Telefônico Fixo Comutado - STFC. }\end{array}$ \\
\hline Regulamenta & $\begin{array}{l}\text { Lei no } 9.472 / 1997 \text { - Dispõe sobre a organização dos serviços de telecomunicações, a } \\
\text { criação e funcionamento de um órgão regulador e outros aspectos institucionais, nos } \\
\text { termos da Emenda Constitucional } n^{\circ} 8 \text {, de } 1995 \text {. }\end{array}$ \\
\hline Publicação & Diário Oficial da União, Seção 1, 21/10/2013, págs. p.51-52 \\
\hline Indexação & $\begin{array}{l}\text { Conselho de Usuários, Plano anual de atividades, não previsto no novo regulamento } \\
\text { de conselho de usuários } \\
\text { Conselho de Usuários, Regulamento de Conselho de Usuários do STFC, aprovação } \\
\text { do } \\
\text { Distribuição de Sinais de Televisão e de Áudio por Assinatura via Satélite (DTH) } \\
\text { Multichannel Multipoint Distribution Service (Serviço de Distribuição de Sinais } \\
\text { Multiponto Multicanal) } \\
\text { Plano anual de atividades, Conselho de Usuários, plano anual não previsto no novo } \\
\text { regulamento de } \\
\text { Regulamento de Conselho de Usuários do STFC, aprovação do } \\
\text { Regulamento de Conselho de Usuários, aprovação do } \\
\text { Serviço Móvel Especializado, Regulamento de Conselho de Usuários, aprovação do } \\
\text { Serviço de Acesso Condicionado } \\
\text { Serviço de Acesso Condicionado, Regulamento de Conselho de Usuários, aprovação } \\
\text { do } \\
\text { Serviço de Distribuição de Sinais Multiponto Multicanal, Regulamento de Conselho } \\
\text { de Usuários, aprovação do } \\
\text { TV a Cabo, Regulamento de Conselho de Usuários, aprovação do } \\
\text { Televisão por Assinatura (Espécie de Serviço Especial), Regulamento de Conselho } \\
\text { de Usuários, aprovação do } \\
\text { Usuário (Serviço Telefônico Fixo Comutado), Conselho de Usuários, aprovação do } \\
\text { Usuário (Serviço Telefônico Fixo Comutado), Regulamento de Conselho de Usuários } \\
\text { do STFC, aprovação do } \\
\text { Usuário, Conselho de Usuários, aprovação do regulamento de }\end{array}$ \\
\hline Temas & $\begin{array}{l}\text { Temas : Administração do Setor de Telecomunicações : Outorgas : Autorização (regras } \\
\text { aplicáveis) } \\
\text { Temas : Administração do Setor de Telecomunicações : Outorgas : Concessão (regras } \\
\text { aplicáveis) } \\
\text { Temas : Atores no Setor de Telecomunicações : Usuário / Consumidor } \\
\text { Temas : Ramos Jurídicos Afins : Direito do Consumidor } \\
\text { Temas : Serviços no Setor de Telecomunicações : Serviço Móvel Especializado ou } \\
\text { Trunking ou Trunk ou Sistema Troncalizado } \\
\text { Temas : Serviços no Setor de Telecomunicações : Serviço Móvel Pessoal (SMP) } \\
\text { Temas : Serviços no Setor de Telecomunicações : Serviço Telefônico Fixo Comutado } \\
\text { (STFC) }\end{array}$ \\
\hline
\end{tabular}


$\begin{aligned} & \text { Temas : Serviços no Setor de Telecomunicações : Serviço de Comunicação Multimídia } \\ & \text { (SCM) }\end{aligned}$
(Sc)

Resolução da ANATEL n$^{0}$ 624, de 30 de outubro de 2013 - Aprova o Regulamento para Uso de Femtocélulas em Redes do Serviço Móvel Pessoal, do Serviço Móvel Especializado e do Serviço de Comunicação Multimídia.

\begin{tabular}{|c|c|}
\hline Órgão Emissor & ANATEL - Conselho Diretor. \\
\hline Anexos & $\begin{array}{l}\text { Anexo - Regulamento para Uso de Femtocélulas em Redes do Serviço Móvel Pessoal, } \\
\text { do Serviço Móvel Especializado e do Serviço de Comunicação Multimídia. }\end{array}$ \\
\hline Dispositivos & LGT, Art. 19, inciso VIII; LGT, Art. 19, inciso X; LGT, Art. 19, inciso XII. \\
\hline Regulamenta & $\begin{array}{l}\text { Lei no } 9.472 / 1997 \text { - Dispõe sobre a organização dos serviços de telecomunicações, a } \\
\text { criação e funcionamento de um órgão regulador e outros aspectos institucionais, nos } \\
\text { termos da Emenda Constitucional n }{ }^{\circ} 8 \text {, de } 1995 \text {. }\end{array}$ \\
\hline Publicação & Diário Oficial da União, Seção 1, 04/11/2013, págs. p.80-81 \\
\hline Indexação & $\begin{array}{l}\text { Alarme, Femtocélula, funcionalidade necessária de restrição de mobilidade para a } \\
\text { Autoconfiguração de Frequências, Femtocélula, funcionalidade necessária de } \\
\text { autoconfiguração de frequências para a } \\
\text { Autoconfiguração de Vizinhanças, Femtocélula, funcionalidade necessária de } \\
\text { autoconfiguração de vizinhanças para a } \\
\text { Consumidor, Femtocélula, direitos e condições contratuais no fornecimento e operação } \\
\text { de } \\
\text { Equipamentos de Telecomunicações, Equipamento de Radiocomunicação de Radiação } \\
\text { Restrita, disciplina das Femtocélulas } \\
\text { Femtocélula, Regulamento para Uso de Femtocélulas em Redes do Serviço Móvel } \\
\text { Pessoal, do Serviço Móvel Especializado e do Serviço de Comunicação Multimídia, } \\
\text { aprovacao do } \\
\text { Fiscalização, Femtocélula, sujeita à fiscalização da ANATEL } \\
\text { Mobilidade Restrita, Femtocélula, funcionalidade necessária de restrição de mobilidade } \\
\text { para a } \\
\text { Rede de Telecomunicações } \\
\text { Rede de Telecomunicações, Femtocélula, sua possibilidade de uso por prestadoras de } \\
\text { SMP, SME e SCM para melhoria do desempenho e cobertura de suas redes } \\
\text { Regulamento para Uso de Femtocélulas em Redes do Serviço Móvel Pessoal, do } \\
\text { Serviço Móvel Especializado e do Serviço de Comunicação Multimídia, aprovação } \\
\text { do } \\
\text { Restrição de Mobilidade, Femtocélula, funcionalidade necessária de restrição de } \\
\text { mobilidade para a } \\
\text { Serviço Móvel Especializado, Femtocélula, disciplina do uso de } \\
\text { Serviço Móvel Especializado, Regulamento para Uso de Femtocélulas em Redes do } \\
\text { Serviço Móvel Pessoal, do Serviço Móvel Especializado e do Serviço de Comunicação } \\
\text { Multimídia, aprovação do } \\
\text { Serviço Móvel Pessoal, Femtocélula, disciplina do uso de } \\
\text { Serviço Móvel Pessoal, Regulamento para Uso de Femtocélulas em Redes do Serviço } \\
\text { Móvel Pessoal, do Serviço Móvel Especializado e do Serviço de Comunicação } \\
\text { Multimídia, aprovação do } \\
\text { Serviço de Comunicação Multimídia, Femtocélula, disciplina do uso de }\end{array}$ \\
\hline
\end{tabular}




\begin{tabular}{|l|l|}
\hline & $\begin{array}{l}\text { Serviço de Comunicação Multimídia, Regulamento para Uso de Femtocélulas em } \\
\text { Redes do Serviço Móvel Pessoal, do Serviço Móvel Especializado e do Serviço de } \\
\text { Comunicação Multimídia, aprovação do } \\
\text { Usuário, Femtocélula, direitos e condições contratuais no fornecimento e operação } \\
\text { de }\end{array}$ \\
\hline Temas & $\begin{array}{l}\text { Temas : Administração do Setor de Telecomunicações : Fiscalização das } \\
\text { Telecomunicações } \\
\text { Temas : Infraestrutura e Recursos do Setor de Telecomunicações : Equipamentos de } \\
\text { Telecomunicações } \\
\text { Temas : Infraestrutura e Recursos do Setor de Telecomunicações : Redes de } \\
\text { Telecomunicações } \\
\text { Temas : Serviços no Setor de Telecomunicações : Serviço Móvel Especializado ou } \\
\text { Trunking ou Trunk ou Sistema Troncalizado } \\
\text { Temas : Serviços no Setor de Telecomunicações : Serviço Móvel Pessoal (SMP) } \\
\text { Temas : Serviços no Setor de Telecomunicações : Serviço de Comunicação Multimídia } \\
\text { (SCM) }\end{array}$ \\
\hline
\end{tabular}

Resolução da ANATEL $\mathbf{n}^{\circ}$ 625, de 11 de novembro de 2013 - Aprova a Atribuição, a Destinação e o Regulamento sobre Condições de Uso de Radiofrequências na Faixa de 698 MHz a 806 MHz.

\begin{tabular}{|c|c|}
\hline Órgão Emissor & ANATEL - Conselho Diretor. \\
\hline Anexos & $\begin{array}{l}\text { Anexo - Regulamento sobre Condições de Uso de Radiofrequências na Faixa de } 698 \\
\text { MHz a } 806 \text { MHz. }\end{array}$ \\
\hline Dispositivos & LGT, Art. 19, inciso VIII; LGT, Art. 159, caput; LGT, Art. 160, caput. \\
\hline \multirow[t]{7}{*}{ Correlata } & $\begin{array}{l}\text { Decreto n }{ }^{\circ} 5.820 / 2006 \text { - Dispõe sobre a implantação do SBTVD-T, estabelece diretrizes } \\
\text { para a transição do sistema de transmissão analógica para o sistema de transmissão } \\
\text { digital do serviço de radiodifusão de sons e imagens e do serviço de retransmissão de } \\
\text { televisão, e dá outras providências. }\end{array}$ \\
\hline & 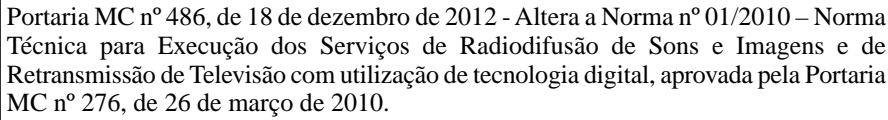 \\
\hline & $\begin{array}{l}\text { Portaria MC n }{ }^{\circ} 489 \text {, de } 18 \text { de dezembro de } 2012 \text { - Aprova a Norma Regulamentar do } \\
\text { Canal da Cidadania. }\end{array}$ \\
\hline & $\begin{array}{l}\text { Portaria MC n }{ }^{\circ} 14 \text {, de } 6 \text { de fevereiro de } 2013 \text { - Estabelece diretrizes para a aceleração } \\
\text { do acesso ao Sistema Brasileiro de Televisão Digital Terrestre - SBTVD-T e para a } \\
\text { ampliação da disponibilidade de espectro de radiofrequência para atendimento dos } \\
\text { objetivos do Programa Nacional de Banda Larga - PNBL. }\end{array}$ \\
\hline & $\begin{array}{l}\text { Anexo à Resolução da ANATEL no } 516 \text {, de } 30 \text { de outubro de } 2008 \text { - Plano Geral de } \\
\text { Atualização da Regulamentação das Telecomunicações no Brasil (PGR). }\end{array}$ \\
\hline & $\begin{array}{l}\text { Resolução no 584/2012 - Alteração do Regulamento sobre Canalização e Condições } \\
\text { de Uso de Radiofrequências para os serviços Auxiliar de Radiodifusão e Correlatos } \\
\text { - SARC, de Repetição de Televisão - RpTV e de Televisão em Circuito Fechado com } \\
\text { Utilização de Radioenlace - CFTV, e dá outras providências. }\end{array}$ \\
\hline & Portaria Anatel no 681, de 6 de agosto de 2012 \\
\hline Regulamenta & $\begin{array}{l}\text { Lei no } 9.472 / 1997 \text { - Dispõe sobre a organização dos serviços de telecomunicações, a } \\
\text { criação e funcionamento de um órgão regulador e outros aspectos institucionais, nos } \\
\text { termos da Emenda Constitucional n }{ }^{\circ} 8 \text {, de } 1995 \text {. }\end{array}$ \\
\hline Publicação & Diário Oficial da União, Seção 1, 13/11/2013, págs. p.129-130 \\
\hline
\end{tabular}




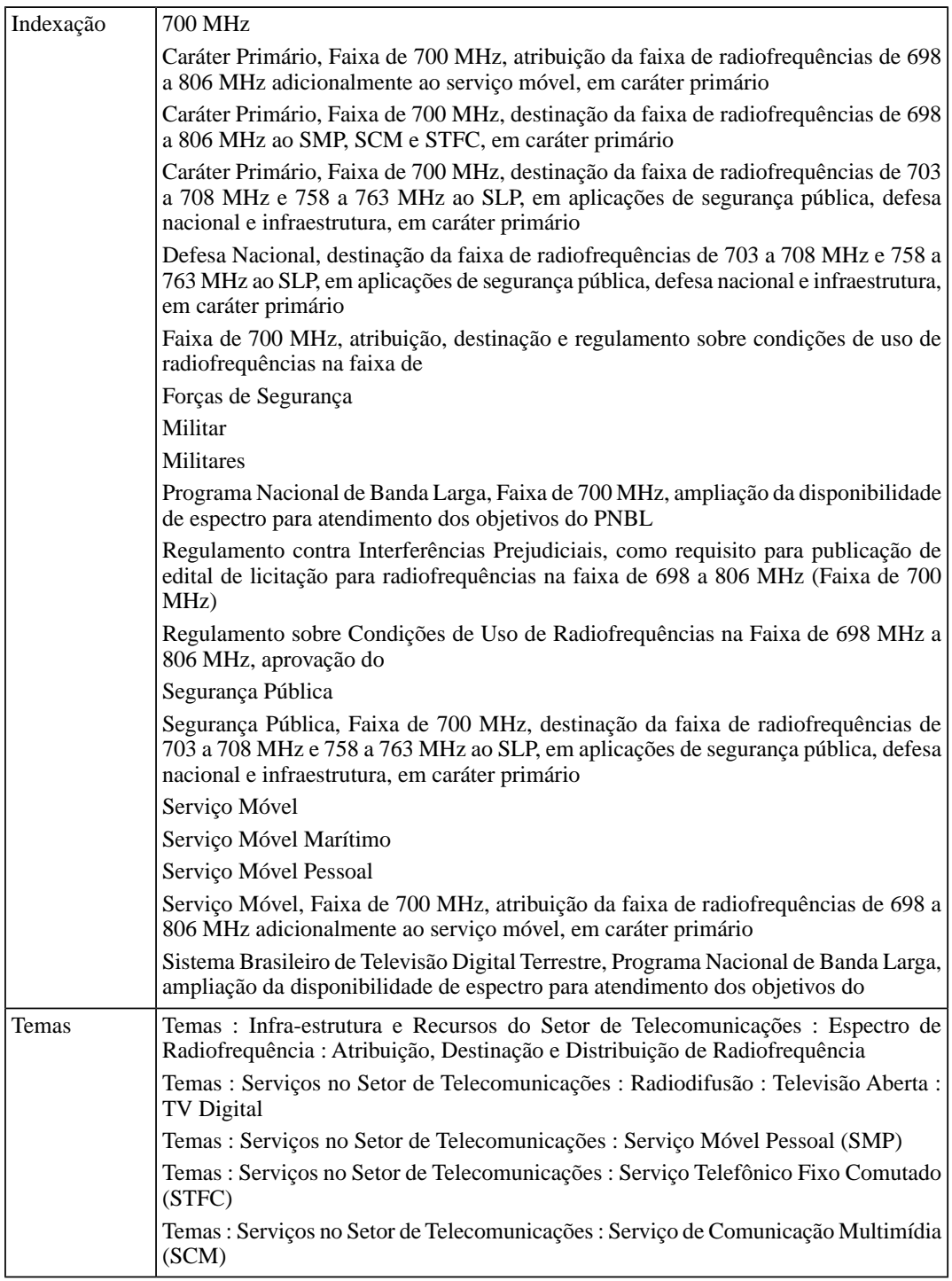

Resolução da ANATEL nº 626, de 20 de novembro de 2013 - Acrescenta o item 8.1 .7 na Norma para Certificação de Produtos para Telecomunicações, aprovada pela Resolução no 323 , de 7 de novembro de 2002 .

\begin{tabular}{|l|l|}
\hline Órgão Emissor & ANATEL - Conselho Diretor.
\end{tabular} 


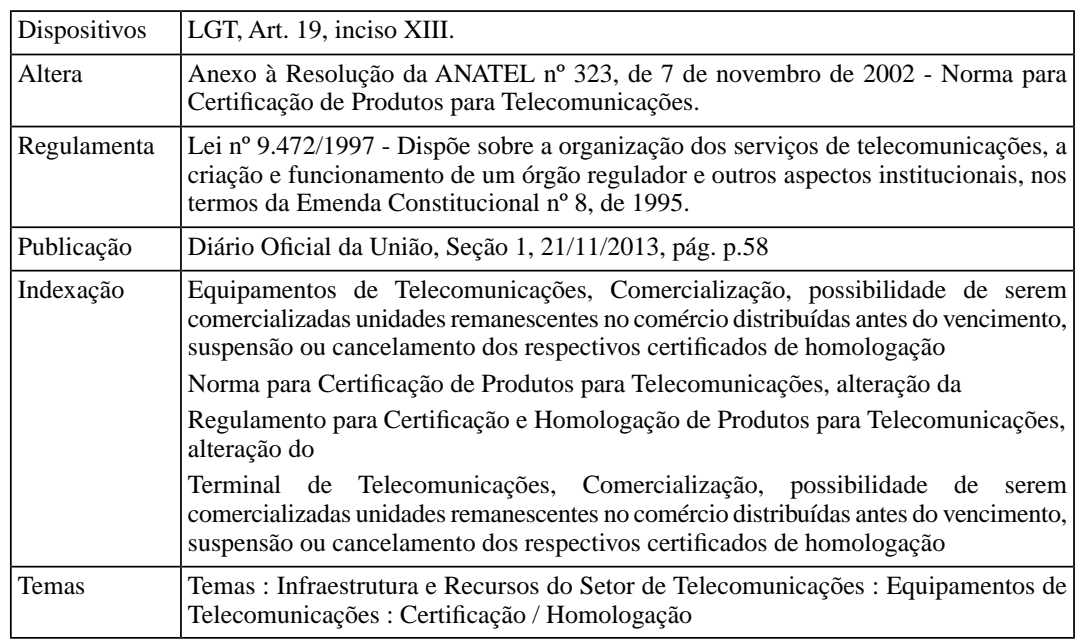

Resolução da ANATEL n⿳ 627, de 28 de novembro de 2013 - Altera o Regulamento do Serviço Móvel Pessoal, aprovado pela Resolução nº 477, de 7 de agosto de 2007.

\begin{tabular}{|l|l|}
\hline Órgão Emissor & ANATEL - Conselho Diretor. \\
\hline Anexos & Anexo - Alterações ao Regulamento do Serviço Móvel Pessoal. \\
\hline Dispositivos & LGT, Art. 109, inciso II. \\
\hline Altera & $\begin{array}{l}\text { Anexo à Resolução da ANATEL no 477, de 7 de agosto de } 2007 \text { - Regulamento do } \\
\text { Serviço Móvel Pessoal - SMP. }\end{array}$ \\
\hline Regulamenta & $\begin{array}{l}\text { Lei no 9.472/1997 - Dispõe sobre a organização dos serviços de telecomunicações, a } \\
\text { criação e funcionamento de um órgão regulador e outros aspectos institucionais, nos } \\
\text { termos da Emenda Constitucional no 8, de 1995. }\end{array}$ \\
\hline Publicação & $\begin{array}{l}\text { Diário Oficial da União, Seção 1, 29/11/2013, pág. p.146 } \\
\text { Diário Oficial da União, Seção 1, 04/12/2013, pág. p.43 [ Retificação ] }\end{array}$ \\
\hline Indexação & $\begin{array}{l}\text { Regulamento do Serviço Móvel Pessoal, alteração do } \\
\text { Serviço Móvel Pessoal, Regulamento do Serviço Móvel Pessoal, alteração do } \\
\text { Serviço de Emergência, Serviço Móvel Pessoal, gratuidade de acesso a serviços } \\
\text { públicos de emergência } \\
\text { Serviço de Utilidade Pública, Serviço Móvel Pessoal, gratuidade de acesso a serviços } \\
\text { públicos de emergência } \\
\text { Serviço de Utilidade Pública, gratuidade de acesso a serviços públicos de emergência }\end{array}$ \\
\hline Temas & $\begin{array}{l}\text { Temas : Aplicações de Telecomunicações : Acesso a Serviços de Interesse Público e } \\
\text { Uso de Radiofrequência por tais Serviços } \\
\text { Temas : Serviços no Setor de Telecomunicações : Serviço Móvel Pessoal (SMP) }\end{array}$ \\
\hline
\end{tabular}

Resolução da ANATEL n 628, de 6 de dezembro de 2013 - Aprova a alteração do Regulamento sobre Condições de Uso de Radiofrequências, na Faixa de $450 \mathrm{MHz}$ a $470 \mathrm{MHz}$, pelo Serviço Limitado Privado no Ẩmbito dos Aeroportos Nacionais. 


\begin{tabular}{|c|c|}
\hline Órgão Emissor & ANATEL - Conselho Diretor. \\
\hline Anexos & $\begin{array}{l}\text { Anexo - Regulamento sobre Condições de Uso de Radiofrequências, na Faixa de } 450 \\
\text { MHz a } 470 \mathrm{MHz} \text {, pelo Serviço Limitado Privado "no Âmbito dos Aeroportos } \\
\text { Nacionais. }\end{array}$ \\
\hline Dispositivos & LGT, Art. 19, inciso VIII; LGT, Art. 159, caput; LGT, Art. 161, caput. \\
\hline Altera & $\begin{array}{l}\text { Resoluçãa da ANATEL n }{ }^{\circ} \text { 558/2010 - Aprova o Regulamento sobre Canalização e } \\
\text { Condições de Uso de Radiofrequências na Faixa de } 450 \text { MHz a } 470 \text { MHz. } \\
\text { Anexo à Resolução da ANATEL no 558, de } 20 \text { de dezembro de } 2010 \text { - Regulamento } \\
\text { sobre Canalização e Condições de Uso de Radiofreqüências na Faixa de } 450 \text { MHz a } \\
470 \text { MHz. }\end{array}$ \\
\hline Revoga & $\begin{array}{l}\text { Resolução da ANATEL no 446/2006 - Aprova o Regulamento sobre Condições de } \\
\text { Uso de Radiofreqüências, na Faixa de } 450 \mathrm{MHz} \text {, pelo Serviço Limitado Privado, no } \\
\text { Âmbito dos Aeroportos Nacionais. - Anexo - Regulamento sobre Condições de Uso } \\
\text { de Radiofrequiências, na Faixa de } 450 \mathrm{MHz} \text {, pelo Serviço Limitado Privado, no Âmbito } \\
\text { dos Aeroportos Nacionais. }\end{array}$ \\
\hline Correlata & $\begin{array}{l}\text { Decreto } \mathrm{n}^{\circ} 7.175 / 2010 \text { - Institui o Programa Nacional de Banda Larga - PNBL; dispõe } \\
\text { sobre remanejamento de cargos em comissão; altera o Anexo II ao Decreto no 6.188, } \\
\text { de } 17 \text { de agosto de } 2007 \text {; altera e acresce dispositivos ao Decreto no 6.948, de } 25 \text { de } \\
\text { agosto de 2009; e dá outras providências. - Anexo - Quadro demonstrativo dos cargos } \\
\text { em comissão e Quadro resumo dos custos dos cargos em comissão do Gabinete Pessoal } \\
\text { do Presidente da República. } \\
\text { Decreto no } 7.512 / 2011 \text { - Aprova o Plano Geral de Metas para a Universalização do } \\
\text { Serviço Telefônico Fixo Comutado Prestado no Regime Público - PGMU, e dá outras } \\
\text { providências. } \\
\text { Resolução } n^{\circ} 115 \text {, de } 6 \text { de outubro de 2009, da Agência Nacional de Aviação Civil } \\
\text { (ANAC) }\end{array}$ \\
\hline Regulamenta & $\begin{array}{l}\text { Lei no } 9.472 / 1997 \text { - Dispõe sobre a organização dos serviços de telecomunicações, a } \\
\text { criação e funcionamento de um órgão regulador e outros aspectos institucionais, nos } \\
\text { termos da Emenda Constitucional n }{ }^{\circ} 8 \text {, de } 1995 \text {. }\end{array}$ \\
\hline Publicação & Diário Oficial da União, Seção 1, 09/12/2013, págs. p.73-74 \\
\hline Indexação & $\begin{array}{l}\text { Aeroporto, Comunicação Aeroportuária, disciplina das condições de uso da faixa de } \\
450 \mathrm{MHz} \text { e contorno de proteção de } 10 \mathrm{~km} \text { de raio dos sistemas de comunicações } \\
\text { operando no âmbito dos aeroportos } \\
\text { Aeroporto, Regulamento sobre Condições de Uso da faixa de } 450 \mathrm{MHz} \\
\text { Aeródromo Público } \\
\text { Aviação Civil, Comunicação Aeroportuária, disciplina das condições de uso da faixa } \\
\text { de } 450 \mathrm{MHz} \text { e contorno de proteção de } 10 \mathrm{~km} \text { de raio dos sistemas de comunicações } \\
\text { operando no âmbito dos aeroportos } \\
\text { Comunicação Aeroportuária, Regulamento sobre Condições de Uso da faixa de } 450 \\
\text { MHz, disciplina das condições de uso da faixa de } 450 \mathrm{MHz} \text { e contorno de proteção } \\
\text { de } 10 \mathrm{~km} \text { de raio dos sistemas de comunicações operando no âmbito dos aeroportos } \\
\text { Copa do Mundo, Comunicação Aeroportuária, disciplina das condições de uso da } \\
\text { faixa de } 450 \mathrm{MHz} \text { e contorno de proteção de } 10 \text { km de raio dos sistemas de } \\
\text { comunicações operando no âmbito dos aeroportos } \\
\text { Distribuição de Canais, Regulamento sobre Condições de Uso da faixa de } 450 \mathrm{MHz} \\
\text { Espectro de Radiofrequiências, Regulamento sobre Condições de Uso da faixa de } 450 \\
\text { MHz }\end{array}$ \\
\hline
\end{tabular}




\begin{tabular}{|l|l|}
\hline \multirow{7}{*}{ Temas } & $\begin{array}{l}\text { Jogos Olímpicos, Comunicação Aeroportuária, disciplina das condições de uso da } \\
\text { faixa de } 450 \mathrm{MHz} \text { e contorno de proteção de } 10 \mathrm{~km} \text { de raio dos sistemas de } \\
\text { comunicações operando no âmbito dos aeroportos } \\
\text { Regulamento sobre Condições de Uso da faixa de } 450 \mathrm{MHz} \\
\text { Serviço Limitado Privado, Regulamento sobre Condições de Uso da faixa de } 450 \\
\mathrm{MHz}\end{array}$ \\
\hline $\begin{array}{l}\text { Temas : Aplicações de Telecomunicações : Tráfego Aéreo } \\
\text { Temas : Classificações de Serviços no Setor de Telecomunicações : Quanto ao Gênero } \\
\text { : Serviço Limitado : Serviço Limitado Privado } \\
\text { Temas : Infraestrutura e Recursos do Setor de Telecomunicações : Espectro de } \\
\text { Radiofrequência : Condições de Uso de Radiofrequência e Canalização (Distribuição } \\
\text { de Canais) } \\
\text { Temas : Ramos Jurídicos Afins : Direito Aeroespacial }\end{array}$ \\
\hline
\end{tabular}

\begin{tabular}{|c|c|}
\hline $\begin{array}{l}\text { Resolução da A } \\
\text { e acompanhame }\end{array}$ & $\begin{array}{l}\text { ANATEL no 629, de } 16 \text { de dezembro de } 2013 \text { - Aprova o Regulamento de celebração } \\
\text { ento de Termo de Compromisso de Ajustamento de Conduta (TAC). }\end{array}$ \\
\hline Órgão Emissor & ANATEL - Conselho Diretor. \\
\hline Anexos & $\begin{array}{l}\text { Anexo - Regulamento de celebração e acompanhamento de Termo de Compromisso } \\
\text { de Ajustamento de Conduta. }\end{array}$ \\
\hline Dispositivos & $\begin{array}{l}\text { CF, Art. } 5^{\circ} \text {, inciso LIV; CF, Art. } 5^{\circ} \text {, inciso LV; LGT, Art. } 1^{\circ} \text {, Parágrafo Único; LGT, } \\
\text { Art. } 2^{\circ} \text {, inciso IV; LGT, Art. 19, inciso VI; LGT, Art. 19, inciso XV; LGT, Art. 137, } \\
\text { caput; LGT, Art. 211, caput. }\end{array}$ \\
\hline Altera & $\begin{array}{l}\text { Lei Complementar 73, de } 10 \text { de fevereiro de } 1993 \\
\text { Lei no 9.469/ } 1997 \\
\text { Lei } n^{\circ} \text { 9.784/1999 - Regula o processo administrativo no âmbito da Administração } \\
\text { Pública Federal. } \\
\text { Resolução no } 589 / 2012 \text { - Aprova o Regulamento de Aplicação de Sanções } \\
\text { Administrativas. }\end{array}$ \\
\hline Regulamenta & $\begin{array}{l}\text { Lei } n^{\circ} 7.347 / 1985 \\
\text { Lei } n^{\circ} 9.472 / 1997 \text { - Dispõe sobre a organização dos serviços de telecomunicações, a } \\
\text { criação e funcionamento de um órgão regulador e outros aspectos institucionais, nos } \\
\text { termos da Emenda Constitucional n }{ }^{\circ} 8 \text {, de } 1995 \text {. }\end{array}$ \\
\hline Publicação & Diário Oficial da União, Seção 1, 18/12/2013, págs. p.59-61 \\
\hline Indexação & $\begin{array}{l}\text { Autorização, Termo de Compromisso de Ajustamento de Conduta, disciplina do } \\
\text { Cláusula, Termo de Compromisso de Ajustamento de Conduta, fixação das cláusulas } \\
\text { obrigatórias no } \\
\text { Concessão } \\
\text { Concessão, Termo de Compromisso de Ajustamento de Conduta, disciplina do } \\
\text { Interesse Público, Termo de Compromisso de Ajustamento de Conduta, interesse } \\
\text { público como requisito para celebração de } \\
\text { Obrigação de fazer, Termo de Compromisso de Ajustamento de Conduta, disciplina } \\
\text { do } \\
\text { Operadora de Telecomunicações, Termo de Compromisso de Ajustamento de Conduta, } \\
\text { disciplina do } \\
\text { Prescrição, Termo de Compromisso de Ajustamento de Conduta, interrupção do prazo } \\
\text { prescricional da pretensão punitiva quando do requerimento de celebração de }\end{array}$ \\
\hline
\end{tabular}




\begin{tabular}{|l|l|}
\hline & $\begin{array}{l}\text { Regulamento de Celebração e Acompanhamento de Termo de Compromisso de } \\
\text { Ajustamento de Conduta, aprovação do } \\
\text { Sanção Administrativa, Termo de Compromisso de Ajustamento de Conduta, disciplina } \\
\text { do } \\
\text { Termo de Compromisso de Ajustamento de Conduta, Regulamento de Celebração e } \\
\text { Acompanhamento de Termo de Compromisso de Ajustamento de Conduta, aprovação } \\
\text { do } \\
\text { Trânsito em julgado administrativo, Termo de Compromisso de Ajustamento de } \\
\text { Conduta, inaplicabilidade do seu regulamento em processos nos quais já tenha havido } \\
\text { decisão transitada em julgado na esfera administrativa } \\
\text { Título Executivo Extrajudicial, Termo de Compromisso de Ajustamento de Conduta, } \\
\text { sua eficácia de título executivo extrajudicial }\end{array}$ \\
$\begin{array}{l}\text { Temas : Administração do Setor de Telecomunicações : Fiscalização das } \\
\text { Telecomunicações } \\
\text { Temas : Atores no Setor de Telecomunicações : ANATEL } \\
\text { Temas : Atores no Setor de Telecomunicações : Prestadora / Operadora } \\
\text { Temas : Políticas de Telecomunicações : Qualidade do Serviço } \\
\text { Temas : Ramos Jurídicos Afins : Direito do Consumidor }\end{array}$ \\
\hline
\end{tabular}

\section{Resolução emitida por outros órgãos}

\begin{tabular}{|c|c|}
\hline \multicolumn{2}{|c|}{$\begin{array}{l}\text { Resolução no } 4 \text { do Senado Federal, de } 2013 \text { - Altera o Regimento Interno do Senado Federal para } \\
\text { dispor sobre o comparecimento de Ministros de Estado e dirigentes das agências reguladoras ao Senado } \\
\text { Federal, em periodicidade anual. }\end{array}$} \\
\hline Órgão Emissor & Senado. \\
\hline Dispositivos & $\begin{array}{l}\text { CF, Art. 49, caput; CF, Art. 70, Parágrafo Único; LGT, Art. 23, caput; LGT, Art. 32, } \\
\text { caput. }\end{array}$ \\
\hline Regulamenta & Constituição da República Federativa do Brasil de 1988 \\
\hline Publicação & Diário Oficial da União, Seção 1, 13/03/2013, pág. p.1 \\
\hline Indexação & $\begin{array}{l}\text { Agência Nacional de Telecomunicações, disciplina de comparecimento anual de } \\
\text { dirigentes de agências reguladoras ao Senado Federal } \\
\text { Congresso Nacional } \\
\text { Prestação de Contas, Agência Nacional de Telecomunicações, disciplina de } \\
\text { comparecimento anual de dirigentes de agências reguladoras ao Senado Federal } \\
\text { Senado Federal, Agência Nacional de Telecomunicações, disciplina de comparecimento } \\
\text { anual de dirigentes de agências reguladoras ao Senado Federal }\end{array}$ \\
\hline Temas & $\begin{array}{l}\text { Temas : Atores no Setor de Telecomunicações : ANATEL } \\
\text { Temas : Atores no Setor de Telecomunicações : Poder Executivo : Ministério das } \\
\text { Comunicações } \\
\text { Temas : Atores no Setor de Telecomunicações : Poder Legislativo : Congresso Nacional } \\
\text { Temas : Políticas de Telecomunicações : Controle Social, Hierárquico e Interorgânico }\end{array}$ \\
\hline
\end{tabular}




\section{Atos Referenciados}

\section{Ato Administrativo}

\section{Ato}

\begin{tabular}{|c|c|}
\hline \multicolumn{2}{|c|}{ Ato do Conselho Diretor da ANATEL no 1.724, de 11 de março de 2013} \\
\hline Ementa & $\begin{array}{l}\text { Aprova a Edição } 2013 \text { do Plano de Atribuição, Destinação e Distribuição de Faixas } \\
\text { de Frequências no Brasil. }\end{array}$ \\
\hline Órgão Emissor & ANATEL - Conselho Diretor. \\
\hline Anexos & $\begin{array}{l}\text { Anexo - Plano de Atribuição, Destinação e Distribuição de Faixas de Frequências no } \\
\text { Brasil. }\end{array}$ \\
\hline Dispositivos & $\begin{array}{l}\text { LGT, Art. 19, inciso VIII; LGT, Art. 22, inciso VIII; LGT, Art. 158, caput; LGT, Art. } \\
\text { 158, } \$ 1^{\circ} \text {, inciso III. }\end{array}$ \\
\hline Regulamenta & $\begin{array}{l}\text { Lei n }{ }^{\circ} 9.472 / 1997 \text { - Dispõe sobre a organização dos serviços de telecomunicações, a } \\
\text { criação e funcionamento de um órgão regulador e outros aspectos institucionais, nos } \\
\text { termos da Emenda Constitucional } n^{\circ} 8 \text {, de } 1995 \text {. }\end{array}$ \\
\hline Publicação & Diário Oficial da União, Seção 1, 09/04/2013, pág. p.47 \\
\hline Indexação & $\begin{array}{l}\text { Espectro de Radiofrequiências, Plano de Atribuição, Destinação e Distribuição de } \\
\text { Faixas de Frequências no Brasil, edição } 2013 \text { do } \\
\text { Plano de Atribuição, Destinação e Distribuição de Faixas de Frequências no Brasil, } \\
\text { edição } 2013 \text { do } \\
\text { Quadro de Atribuição de Faixas de Frequências, aprovação do }\end{array}$ \\
\hline Temas & $\begin{array}{l}\text { Temas : Infra-estrutura e Recursos do Setor de Telecomunicações : Espectro } \\
\text { Radiofrequência : Atribuição, Destinação e Distribuição de Radiofrequência }\end{array}$ \\
\hline
\end{tabular}

\begin{tabular}{|c|c|}
\hline \multicolumn{2}{|c|}{ Ato do Conselho Diretor da ANATEL $n^{\circ} 3.833$, de 20 de junho de 2013} \\
\hline Ementa & $\begin{array}{l}\text { Aprova a classificação dos serviços de telecomunicações quanto aos interesses a que } \\
\text { atendem. }\end{array}$ \\
\hline Órgão Emissor & ANATEL - Conselho Diretor. \\
\hline Anexos & $\begin{array}{l}\text { Anexo - Classificação dos Serviços de Telecomunicações Quanto aos Interesses que } \\
\text { Atendem. }\end{array}$ \\
\hline Dispositivos & CF, Art. 21, inciso XI (em 15/08/1995); LGT, Art. 62, caput. \\
\hline Termos & Confidencialidade. \\
\hline Regulamenta & $\begin{array}{l}\text { Lei n }{ }^{\circ} 9.472 / 1997 \text { - Dispõe sobre a organização dos serviços de telecomunicações, a } \\
\text { criação e funcionamento de um órgão regulador e outros aspectos institucionais, nos } \\
\text { termos da Emenda Constitucional n }{ }^{\circ} 8 \text {, de } 1995 \text {. }\end{array}$ \\
\hline Publicação & Diário Oficial da União, Seção 1, 21/06/2013, pág. p.60 \\
\hline Indexação & $\begin{array}{l}\text { Classificação } \\
\text { Classificação dos Serviços de Telecomunicações quanto ao interesse a que atendem, } \\
\text { ato do Conselho Diretor da ANATEL de classificação dos serviços de telecomunicações } \\
\text { em interesse coletivo ou restrito } \\
\text { Serviço de Interesse Coletivo, Classificação dos Serviços de Telecomunicações quanto } \\
\text { ao interesse a que atendem, ato do Conselho Diretor da ANATEL de classificação } \\
\text { dos serviços de telecomunicações em interesse coletivo ou restrito }\end{array}$ \\
\hline
\end{tabular}




\begin{tabular}{|l|l|}
\hline \multirow{7}{*}{ Temas } & $\begin{array}{l}\text { Serviço de Interesse Restrito, Classificação dos Serviços de Telecomunicações quanto } \\
\text { ao interesse a que atendem, ato do Conselho Diretor da ANATEL de classificação } \\
\text { dos serviços de telecomunicações em interesse coletivo ou restrito } \\
\text { Serviço de Telecomunicações }\end{array}$ \\
\hline $\begin{array}{l}\text { Temas : Classificações de Serviços no Setor de Telecomunicações : Quanto ao Gênero } \\
\text { : Serviço Limitado : Serviço Limitado Especializado } \\
\text { Temas : Serviços no Setor de Telecomunicações : Serviço Especial da } \\
\text { Radiodeterminação por Satélite (SERDS) } \\
\text { Temas : Serviços no Setor de Telecomunicações : Serviço Especial de Boletins } \\
\text { Metereológicos } \\
\text { Temas : Serviços no Setor de Telecomunicações : Serviço Especial de Frequência } \\
\text { Padrão } \\
\text { Temas : Serviços no Setor de Telecomunicações : Serviço Especial de Sinais Horários } \\
\text { Temas : Serviços no Setor de Telecomunicações : Serviço Limitado Especializado } \\
\text { (SLE) : Serviço de Circuito Especializado } \\
\text { Temas : Serviços no Setor de Telecomunicações : Serviço Móvel Global por Satélite } \\
\text { (SMGS) } \\
\text { Temas : Serviços no Setor de Telecomunicações : Serviço Móvel Marítimo } \\
\text { Temas : Serviços no Setor de Telecomunicações : Serviço de Rede : Serviço de Rede } \\
\text { Especializado } \\
\text { Temas : Serviços no Setor de Telecomunicações : Serviço de Rede de Transporte de } \\
\text { Telecomunicações (SRTT) } \\
\text { Temas : Serviços no Setor de Telecomunicações : Serviço de Telecomunicações } \\
\text { Aeronáuticas : Serviço Móvel Aeronáutico } \\
\text { Temas : Serviços no Setor de Telecomunicações : Serviço de Telecomunicações } \\
\text { Aeronáuticas : Serviço de Radiocomunicação Aeronáutico Público Restrito (SRA) } \\
\text { Temas : Serviços no Setor de Telecomunicações : Serviços Científicos }\end{array}$ \\
\hline
\end{tabular}

\section{Enunciado}

\begin{tabular}{|c|c|}
\hline \multicolumn{2}{|c|}{ Enunciado CJF n ${ }^{\circ}$ 531, de abril de 2013} \\
\hline Ementa & $\begin{array}{l}\text { A tutela da dignidade da pessoa humana na sociedade da informação inclui o direito } \\
\text { ao esquecimento (Código Civil, art. 11: “Com exceção dos casos previstos em lei, os } \\
\text { direitos da personalidade são intransmissíveis e irrenunciáveis, não podendo o seu } \\
\text { exercício sofrer limitação voluntária.” Justificativa do Enunciado: Os danos provocados } \\
\text { pelas novas tecnologias de informação vêm-se acumulando nos dias atuais. O direito } \\
\text { ao esquecimento tem sua origem histórica no campo das condenações criminais. Surge } \\
\text { como parcela importante do direito do ex-detento à ressocialização. Não atribui a } \\
\text { ninguém o direito de apagar fatos ou reescrever a própria história, mas apenas assegura } \\
\text { a possibilidade de discutir o uso que é dado aos fatos pretéritos, mais especificamente } \\
\text { o modo e a finalidade com que são lembrados.) }\end{array}$ \\
\hline Dispositivos & $\begin{array}{l}\text { CF, Art. } 5^{\circ} \text {, inciso IV; CF, Art. } 5^{\circ} \text {, inciso V; CF, Art. } 5^{\circ} \text {, inciso IX; CF, Art } 5^{\circ} \text {, inciso } \\
\text { X; CF, Art. } 220, \S 1^{\circ} \text {. }\end{array}$ \\
\hline Termos & Direito ao Esquecimento. \\
\hline Indexação & $\begin{array}{l}\text { Censura, Direito ao Esquecimento, sua não caracterização como censura } \\
\text { Direito } \\
\text { Direito ao Esquecimento, sua caracterização como direito da personalidade } \\
\text { intransmissível e irrenunciável }\end{array}$ \\
\hline
\end{tabular}




\begin{tabular}{|l|l|}
\hline & $\begin{array}{l}\text { Direito à Privacidade } \\
\text { Direitos da Personalidade, Direito ao Esquecimento, sua caracterização como direito } \\
\text { da personalidade intransmissível e irrenunciável }\end{array}$ \\
\hline Temas & $\begin{array}{l}\text { Temas : Aplicações de Telecomunicações : Internet } \\
\text { Temas : Serviços no Setor de Telecomunicações : Internet } \\
\text { Temas : Serviços no Setor de Telecomunicações : Radiodifusão } \\
\text { Temas : Serviços no Setor de Telecomunicações : Serviço de Acesso Condicionado } \\
\text { (SeAC) }\end{array}$ \\
\hline
\end{tabular}

\section{Portaria}

\begin{tabular}{|c|c|}
\hline \multicolumn{2}{|c|}{ Portaria ANATEL n $^{0} 238$, de 9 de abril de 2013} \\
\hline Ementa & $\begin{array}{l}\text { Delega ao Superintendente de Serviços de Comunicação de Massa a competência para } \\
\text { decidir sobre os pedidos de dispensa de que tratam os } \S \S 7^{\circ} \text { e } 8^{\circ} \text { do art. } 32 \text { da Lei } n^{\circ} \\
12.485 \text {, de } 12 \text { de setembro de } 2011 \text {. }\end{array}$ \\
\hline Órgão Emissor & ANATEL - Conselho Diretor. \\
\hline Dispositivos & CF, Art. $220, \S 5^{\circ}$; CF, Art. 221, inciso IV; CF, Art. 222, § $3^{\circ}$; LGT, Art. 22, caput. \\
\hline Regulamenta & $\begin{array}{l}\text { Lei } \mathrm{n}^{\circ} \text { 12.485/2011 - Dispõe sobre a comunicação audiovisual de acesso condicionado; } \\
\text { altera a Medida Provisória no 2.228-1, de } 6 \text { de setembro de } 2001 \text {, e as Leis no } 11.437 \text {, } \\
\text { de } 28 \text { de dezembro de } 2006,5.070 \text {, de } 7 \text { de julho de } 1966,8.977 \text {, de } 6 \text { de janeiro de } \\
1995 \text {, e } 9.472 \text {, de } 16 \text { de julho de } 1997 \text {; e dá outras providências. }\end{array}$ \\
\hline Publicação & Diário Oficial da União, Seção 1, 15/04/2013, pág. p.107 \\
\hline \multirow[t]{4}{*}{ Indexação } & $\begin{array}{l}\text { Canal de Distribuição Obrigatória, exceção ao dever da prestadora do SeAC de tornar } \\
\text { disponível o }\end{array}$ \\
\hline & $\begin{array}{l}\text { Competência, Delegação, delegação de competência do Conselho Diretor da ANATEL } \\
\text { para o Superintendente de Serviços de Comunicação de Massa para decidir sobre os } \\
\text { pedidos de dispensa do dever de distribuição de canais obrigatórios do SeAC }\end{array}$ \\
\hline & $\begin{array}{l}\text { Delegação, Competência, delegação de competência do Conselho Diretor da ANATEL } \\
\text { para o Superintendente de Serviços de Comunicação de Massa para decidir sobre os } \\
\text { pedidos de dispensa do dever de distribuição de canais obrigatórios do SeAC }\end{array}$ \\
\hline & $\begin{array}{l}\text { Serviço de Acesso Condicionado, Canal de Distribuição Obrigatória, exceção ao dever } \\
\text { da prestadora do SeAC de tornar disponível o }\end{array}$ \\
\hline \multirow[t]{2}{*}{ Temas } & Temas : Atores no Setor de Telecomunicações : ANATEL \\
\hline & $\begin{array}{l}\text { Temas : Serviços no Setor de Telecomunicações : Serviço de Acesso Condicionado } \\
\text { (SeAC) }\end{array}$ \\
\hline
\end{tabular}

\begin{tabular}{|l|l|}
\hline \multicolumn{2}{|l|}{ Portaria ANATEL $\mathbf{n}^{\mathbf{0}} \mathbf{4 4 8}$, de 4 de junho de 2013} \\
\hline Ementa & $\begin{array}{l}\text { Atribui a competência decorrente de Acordo de Cooperação Técnica celebrado entre } \\
\text { o Ministério das Comunicações e a Agência Nacional de Telecomunicações } \\
\text { (ANATEL). }\end{array}$ \\
\hline Órgão Emissor & ANATEL - Conselho Diretor. \\
\hline Dispositivos & $\begin{array}{l}\text { CF, Art. 21, inciso XII, alínea a (em 15/08/1995); LGT, Art. } 1^{\circ} \text {, caput; LGT, Art. } 8^{\circ}, \\
\text { caput; LGT, Art. 19, inciso IX; LGT, Art. 211, Parágrafo Único; LGT, Art. 215, inciso } \\
\text { I. }\end{array}$ \\
\hline Correlata & $\begin{array}{l}\text { Portaria MC } \text { n }^{\circ} 159 / 2013 \text { - Autoriza o funcionamento, em caráter provisório, de } \\
\text { entidades prestadoras de serviços de radiodifusão e seus ancilares previamente }\end{array}$ \\
\hline
\end{tabular}




\begin{tabular}{|c|c|}
\hline & $\begin{array}{l}\text { outorgadas via decreto legislativo ou ato de outorga, detenham contrato de concessão } \\
\text { ou permissão celebrado com o Ministério das Comunicações e tenham protocolizado } \\
\text { requerimento de aprovação dos locais de instalação e uso de equipamentos. }\end{array}$ \\
\hline Regulamenta & $\begin{array}{l}\text { Lei no } \text { }^{\circ} .472 / 1997 \text { - Dispõe sobre a organização dos serviços de telecomunicações, a } \\
\text { criação e funcionamento de um órgão regulador e outros aspectos institucionais, nos } \\
\text { termos da Emenda Constitucional n }{ }^{\circ} 8 \text {, de } 1995 \text {. }\end{array}$ \\
\hline Publicação & Diário Oficial da União, Seção 1, 06/06/2013, pág. p.79 \\
\hline Indexação & $\begin{array}{l}\text { Ancilar } \\
\text { Auxiliar } \\
\text { Competência, Delegação, atribuição de competência delegada do Ministério das } \\
\text { Comunicações para a ANATEL para a prática dos atos necessários à análise de } \\
\text { processos técnicos de engenharia nos procedimentos de pós-outorga dos serviços de } \\
\text { radiodifusão, seus ancilares e auxiliares } \\
\text { Delegação, Competência, atribuição de competência delegada do Ministério das } \\
\text { Comunicações para a ANATEL para a prática dos atos necessários à análise de } \\
\text { processos técnicos de engenharia nos procedimentos de pós-outorga dos serviços de } \\
\text { radiodifusão, seus ancilares e auxiliares } \\
\text { Pós-Outorga, atribuição de competência delegada do Ministério das Comunicações } \\
\text { para a ANATEL para a prática dos atos necessários à análise de processos técnicos } \\
\text { de engenharia nos procedimentos de } \\
\text { Radiodifusão } \\
\text { Radiodifusão, Pós-Outorga, atribuição de competência delegada do Ministério das } \\
\text { Comunicações para a ANATEL para a prática dos atos necessários à análise de } \\
\text { processos técnicos de engenharia nos procedimentos de } \\
\text { Serviço Ancilar de Radiodifusão, Pós-Outorga, atribuição de competência delegada } \\
\text { do Ministério das Comunicações para a ANATEL para a prática dos atos necessários } \\
\text { à análise de processos técnicos de engenharia nos procedimentos de } \\
\text { Serviço Auxiliar de Radiodifusão e Correlatos, Pós-Outorga, atribuição de competência } \\
\text { delegada do Ministério das Comunicações para a ANATEL para a prática dos atos } \\
\text { necessários à análise de processos técnicos de engenharia nos procedimentos de } \\
\text { Serviço de Radiodifusão Comunitária, Pós-Outorga, atribuição de competência delegada } \\
\text { do Ministério das Comunicações para a ANATEL para a prática dos atos necessários } \\
\text { à análise de processos técnicos de engenharia nos procedimentos de }\end{array}$ \\
\hline Temas & $\begin{array}{l}\text { Temas : Administração do Setor de Telecomunicações : Fiscalização das } \\
\text { Telecomunicaçôes } \\
\text { Temas : Atores no Setor de Telecomunicações : ANATEL } \\
\text { Temas : Atores no Setor de Telecomunicações : Poder Executivo : Ministério das } \\
\text { Comunicações } \\
\text { Temas : Serviços no Setor de Telecomunicações : Radiodifusão }\end{array}$ \\
\hline
\end{tabular}

\begin{tabular}{|l|l|}
\hline Portaria ANATEL $\mathbf{n}^{\mathbf{0}}$ 559, de 3 de julho de 2013 \\
\hline Ementa & $\begin{array}{l}\text { Aprova a Política de Segurança da Informação e Comunicações da Agência Nacional } \\
\text { de Telecomunicações. }\end{array}$ \\
\hline Órgão Emissor & ANATEL - Conselho Diretor. \\
\hline Anexos & $\begin{array}{l}\text { Anexo - Política de Segurança da Informação e Comunicações da Agência Nacional } \\
\text { de Telecomunicações. }\end{array}$ \\
\hline Termos & $\begin{array}{l}\text { Ativo de informação; Autenticidade; Classificação; Conhecimento; Controle de Acesso; } \\
\text { Dado; Direito de Acesso; Disponibilidade; Documento; Evento de segurança da }\end{array}$
\end{tabular}




\begin{tabular}{|l|l|}
\hline & $\begin{array}{l}\text { informação; Gestor da informação; Incidente de segurança da informação; Informação; } \\
\text { Informação pessoal; Informação Sigilosa; Instrumento de trabalho; Integridade; Política } \\
\text { de Segurança da Informação e Comunicações da ANATEL; Primariedade; } \\
\text { Responsabilidade; Segurança da Informação e Comunicações (ANATEL); Tratamento } \\
\text { da informação; Usuário. }\end{array}$ \\
\hline Regulamenta & Resolução n ${ }^{\circ}$ 612/2013 - Aprova o Regimento Interno da ANATEL. \\
\hline Publicação & Diário Oficial da União, Seção 1, 04/07/2013, págs. p.47-48 \\
\hline Indexação & $\begin{array}{l}\text { Acesso a Informações, Política de Segurança da Informação e Comunicações da } \\
\text { ANATEL, disciplina da } \\
\text { Agência Nacional de Telecomunicações, Política de Segurança da Informação e } \\
\text { Política de Segurança da Informação e Comunicações da ANATEL, disciplina da } \\
\text { Processo Administrativo, Sigilo, disciplina legal do acesso a informações } \\
\text { Sigilo, Processo Administrativo, política de segurança da informação e comunicações } \\
\text { da ANATEL } \\
\text { Transparência, Política de Segurança da Informação e Comunicações da ANATEL, } \\
\text { disciplina da }\end{array}$ \\
\hline Temas & Temas : Atores no Setor de Telecomunicações : ANATEL \\
\hline
\end{tabular}

\begin{tabular}{|c|c|}
\hline \multicolumn{2}{|c|}{ Portaria ANATEL/SOR n ${ }^{\circ}$ 639, de 25 de julho de 2013} \\
\hline Ementa & $\begin{array}{l}\text { Estabelece o Procedimento Simplificado de Outorga - PSO, com a finalidade de } \\
\text { outorga simultânea para explorar o Serviço de Comunicação Multimídia, o Serviço } \\
\text { Telefônico Fixo Comutado Destinado ao Uso do Público em Geral e/ou o Serviço de } \\
\text { Acesso Condicionado. }\end{array}$ \\
\hline Órgão Emissor & ANATEL - Superintendência de Outorga e Recursos à Prestação. \\
\hline Dispositivos & $\begin{array}{l}\text { CF, Art. 21, inciso XI (em 15/08/1995); LGT, Art. 64, Parágrafo Único; LGT, Art. } \\
\text { 131, caput; LGT, Art. } 131, \S 1^{\circ} \text {. }\end{array}$ \\
\hline Regulamenta & $\begin{array}{l}\text { Lei no } 9.472 / 1997 \text { - Dispõe sobre a organização dos serviços de telecomunicações, a } \\
\text { criação e funcionamento de um órgão regulador e outros aspectos institucionais, nos } \\
\text { termos da Emenda Constitucional no } 8 \text {, de } 1995 \text {. }\end{array}$ \\
\hline Publicação & Diário Oficial da União, Seção 1, 08/08/2013, pág. p.56 \\
\hline Temas & $\begin{array}{l}\text { Temas : Administração do Setor de Telecomunicações : Outorgas : Autorização (regras } \\
\text { aplicáveis) } \\
\text { Temas : Atores no Setor de Telecomunicações : ANATEL } \\
\text { Temas : Atores no Setor de Telecomunicações : Prestadora / Operadora } \\
\text { Temas : Serviços no Setor de Telecomunicações : Serviço Telefônico Fixo Comutado } \\
\text { (STFC) } \\
\text { Temas : Serviços no Setor de Telecomunicações : Serviço de Acesso Condicionado } \\
\text { (SeAC) }\end{array}$ \\
\hline
\end{tabular}

\section{Relatório da Ouvidoria da ANATEL}

\begin{tabular}{|l|l|}
\hline \multicolumn{2}{|l|}{ Relatório da Ouvidoria da ANATEL 2013} \\
\hline Órgão Emissor & ANATEL - Ouvidoria. \\
\hline Dispositivos & LGT, Art. 45, Parágrafo Único. \\
\hline Publicação & Diário Oficial da União, Seção 1, 31/12/2013, pág. p.120 \\
\hline
\end{tabular}




\begin{tabular}{|l|l|}
\hline Indexação & Relatório da Ouvidoria, Relatório da Ouvidoria 2013 \\
\hline Temas & Temas : Atores no Setor de Telecomunicações : ANATEL \\
& Temas : Fundamentos : Aspectos Históricos \\
& Temas : Políticas de Telecomunicações : Controle Social, Hierárquico e Interorgânico \\
\hline
\end{tabular}

\section{Súmula}

\begin{tabular}{|c|c|}
\hline \multicolumn{2}{|c|}{ Súmula da ANATEL no 14 , de 28 de junho de 2013} \\
\hline Ementa & $\begin{array}{l}\text { O Pedido de Reconsideração em face de decisão proferida pelo Conselho Diretor da } \\
\text { Anatel, quando da deliberação de Recurso Administrativo, apenas será cabível caso } \\
\text { a referida deliberação tenha ocorrido até o dia } 1^{\circ} \text { de maio de } 2013 \text {. }\end{array}$ \\
\hline Órgão Emissor & ANATEL - Conselho Diretor. \\
\hline Dispositivos & LGT, Art. 19, inciso XVI; LGT, Art. 19, inciso XXV; LGT, Art. 175, Parágrafo Único. \\
\hline Regulamenta & $\begin{array}{l}\text { Lei } n^{\circ} 9.472 / 1997 \text { - Dispõe sobre a organização dos serviços de telecomunicações, a } \\
\text { criação e funcionamento de um órgão regulador e outros aspectos institucionais, nos } \\
\text { termos da Emenda Constitucional } n^{\circ} 8 \text {, de } 1995 \text {. }\end{array}$ \\
\hline Publicação & Diário Oficial da União, Seção 1, 05/07/2013, pág. p.67 \\
\hline Indexação & $\begin{array}{l}\text { Agência Nacional de Telecomunicações } \\
\text { Conselho Diretor, Processo Administrativo, limite temporal ao pedido de } \\
\text { reconsideração em face de decisão proferida pelo Conselho Diretor da ANATEL } \\
\text { quando da deliberação sobre recurso administrativo } \\
\text { Devido Processo Legal, Súmula } n^{\circ} 14 \text {, limite temporal ao pedido de reconsideração } \\
\text { em face de decisão proferida pelo Conselho Diretor da ANATEL quando da deliberação } \\
\text { sobre recurso administrativo } \\
\text { Súmula (Agência Nacional de Telecomunicações), Súmula no } 14 \text {, limite temporal ao } \\
\text { pedido de reconsideração em face de decisão proferida pelo Conselho Diretor da } \\
\text { ANATEL quando da deliberação sobre recurso administrativo }\end{array}$ \\
\hline Temas & $\begin{array}{l}\text { Temas : Administração do Setor de Telecomunicações : Fiscalização das } \\
\text { Telecomunicações } \\
\text { Temas : Atores no Setor de Telecomunicações : ANATEL } \\
\text { Temas : Políticas de Telecomunicações : Controle Social, Hierárquico e Interorgânico }\end{array}$ \\
\hline
\end{tabular}




\section{Índice Alfabético e Remissivo}

\section{Símbolos}

\section{$1.785 \mathrm{MHz}$ a $1.805 \mathrm{MHz}$}

Estudos

determinação ministerial para a ANATEL promover a estudos de viabilidade de disponibilização de faixas de radiofrequência adicionais para a prestação de acesso à internet em banda larga, 331

[Portaria $n^{\circ}$ 275/2013]

\subsection{MHz a $1.895 \mathrm{MHz}$}

\section{Estudos}

determinação ministerial para a ANATEL promover a estudos de viabilidade de disponibilização de faixas de radiofrequência adicionais para a prestação de acesso à internet em banda larga, 331

[Portaria $n^{\circ}$ 275/2013]

\section{$138 \mathrm{MHz}$ a 40,5 GHz}

Antena para Uso em Aplicações Ponto-Área

aprovação da norma para certificação e homologação de, 339

[Resolução nº 610/2013]

\section{$138 \mathrm{MHz}$ a $60 \mathrm{GHz}$}

Antena para Uso em Aplicações Ponto-a-Ponto aprovação da norma para certificação e homologação de, 338

[Resolução nº 609/2013]

\subsection{MHz a 2.690 MHz}

Banda Larga definição de política para disponibilização de faixas de radiofrequência para prestação de acesso à internet em banda larga por prestadores de serviços de telecomunicações de pequeno porte, 331

[Portaria n $\left.{ }^{\circ} 275 / 2013\right]$

Estudos

determinação ministerial para a ANATEL promover a estudos de viabilidade de disponibilização de faixas de radiofrequência adicionais para a prestação de acesso à internet em banda larga, 331 [Portaria $n^{\circ}$ 275/2013]

415,85 MHz a 421,675 MHz

Estudos

determinação ministerial para a ANATEL promover a estudos de viabilidade de disponibilização de faixas de radiofrequência adicionais para a prestação de acesso à internet em banda larga, 331

[Portaria n ${ }^{\circ}$ 275/2013]

\section{5,85 MHz a $430 \mathrm{MHz}$}

Estudos determinação ministerial para a ANATEL promover a estudos de viabilidade de disponibilização de faixas de radiofrequência adicionais para a prestação de acesso à internet em banda larga, 331

[Portaria $\mathrm{n}^{\circ}$ 275/2013]

700 MHz, 354

[Resolução no 625/2013]

$71 \mathrm{GHz}$ a $86 \mathrm{GHz}$

Antena para Uso em Aplicações Ponto-a-Ponto 
aprovação da norma para certificação e homologação de, 338

[Resolução no 609/2013]

\section{A}

\section{Acesso a Informações}

Política de Segurança da Informação

e Comunicações da ANATEL disciplina da, 363

[Portaria n ${ }^{\circ}$ 559/2013]

Acesso a Serviços de Interesse Público e Uso de Radiofrequência por tais Serviços, 307

Acesso às Telecomunicações, 280

Acordo de Cooperação Técnica

Cidades Digitais

alteração da minuta de acordo de cooperação técnica do projeto de implantação e manutenção das, 335

[Portaria $\mathrm{MC} \mathrm{n}^{\circ} 305$, de 24 de outubro de 2013]

Acréscimo de Faixa de Radiofrequência valor devido por, 344

[Resolução n ${ }^{\circ}$ 616/2013]

Administração de Recursos de Numeração

Regulamento de Administração de

Recursos de Numeração alteração do, 336

[Resolução n ${ }^{\circ}$ 607/2013]

Administração do Setor de

Telecomunicações, 272

Administração Pública

(ver Administração Pública (Lei Geral de Licitações))

Administração Pública (Lei Geral de Licitações)

(ver também Administração Pública Federal)

Dados

sua disciplina na administração pública federal direta, autárquica e fundacional, $\mathbf{3 2 1}$
[Decreto $\mathrm{n}^{\circ} 8.135$, de 4 de novembro de 2013]

Administração Pública Federal

(ver também Administração Pública

(Lei Geral de Licitações))

Information and Communication Technology

regulamentação das margens de preferência em licitações de equipamentos de, $\mathbf{3 1 7}$

[Decreto n ${ }^{\circ} 7.903 / 2013$ ]

Aeródromo Público, 356

(ver também Aeroporto)

[Resolução n 628/2013]

\section{Aeroporto}

(ver também Aeródromo Público)

Comunicação Aeroportuária

disciplina das condições de uso da faixa de $450 \mathrm{MHz}$ e contorno de proteção de $10 \mathrm{~km}$ de raio dos sistemas de comunicações operando no âmbito dos aeroportos, 356

[Resolução nº 628/2013]

Regulamento sobre Condições de Uso da faixa de $450 \mathrm{MHz}, 356$

[Resolução n ${ }^{\circ}$ 628/2013]

Agência Nacional de Telecomunicações, 365

[Súmula da ANATEL n ${ }^{\circ}$ 14, de 28 de junho de 2013]

Competência

da ANATEL para processar solicitações de outorga e alterações das condições de outorga dos Serviços Auxiliares de Radiodifusão e Correlatos (SARC), bem como para emissão de regulamentação sobre a outorga, exploração e condições de uso de radiofrequência associada ao, $\mathbf{3 3 0}$

[Portaria MC n 252/2013]

disciplina de comparecimento anual de dirigentes de agências reguladoras ao Senado Federal, 359 
[Resolução $n^{\circ} 4$ do Senado Federal, de 2013]

estrutura organizacional da, $\mathbf{3 4 0}$

[Resolução nº 612/2013]

instrumentos deliberativos da, $\mathbf{3 4 0}$

[Resolução ${ }^{\circ}$ 612/2013]

Política de Segurança da Informação

e Comunicações da ANATEL

disciplina da, 363

[Portaria ${ }^{\circ}$ 559/2013]

Regimento Interno da ANATEL, 340

[Resolução ${ }^{\circ}$ 612/2013]

\section{Alarme}

Femtocélula

funcionalidade necessária de restrição de mobilidade para a, 353

[Resolução nº 624/2013]

Alteração de Características Técnicas de Operação de Emissoras de Radiodifusão

disciplina ministerial da análise de, 329

[Portaria MC nº 231/2013]

ANATEL, 309

(ver Agência Nacional de

Telecomunicações)

Ancilar, 362

[Portaria ANATEL n ${ }^{\circ} 448$, de 4 de junho de 2013]

\section{Antena Linear}

revogação da norma para certificação e homologação de, 338

[Resolução nº 609/2013]

Antena para Uso em Aplicações PontoÁrea

aprovação da norma para certificação e homologação de, 339

[Resolução nº 610/2013]

Antenas, 269

Apagão Analógico (ver Transição Analógico-Digital)

Aplicação Ponto-a-Ponto (ver Ponto a Ponto) (ver Ponto-a-Ponto)

Aplicação Ponto-a-Ponto

Antena para Uso em Aplicações Pontoa-Ponto

aprovação da norma para certificação e homologação de, 338

[Resolução n 609/2013]

aprovação da norma para certificação e homologação de, $\mathbf{3 3 8}$

[Resolução no 609/2013]

Aplicação Ponto-Área

(ver Ponto-Área)

Aplicação Ponto-Área

Antena para Uso em Aplicações PontoÁrea

aprovação da norma para certificação e homologação de, 339

[Resolução nº 610/2013]

Aplicações de Segurança, 306

Aplicações de Telecomunicações, 306

Aplicações Educacionais, 306

Área de Baixa Densidade Populacional (ver Zona Rural)

Área de Tarifação

(ver também Ârea Local)

Serviço Telefônico Fixo Comutado alteração de área de tarifação do, 335, 340, 350

[Resolução n ${ }^{\circ}$ 606/2013] [Resolução ${ }^{\circ}$

Área Local

611/2013] [Resolução $n^{\circ}$ 621/2013]

(ver também Área de Tarifação)

Regulamento sobre Áreas Locais para

o STFC

alteração do, 349

[Resolução nº 620/2013]

Área Rural

(ver Zona Rural)

Aspectos Históricos, 267

Ata de Reunião

Conselho Diretor - Agencia Nacional de Telecomunicações

requisitos mínimos da ata de sessão do, 340

[Resolução n ${ }^{\circ}$ 612/2013] 
Ata de Sessão

Conselho Diretor - Agencia Nacional de Telecomunicações

requisitos mínimos da ata de sessão do, 340

[Resolução no 612/2013]

Atendimento Pessoal

alteração do Regulamento do STFC para disciplinar com maior detalhamento os direitos dos usuários/consumidores do STFC, em especial, o, 343

[Resolução no 615/2013]

Ativo de informação

Definição, 363

[Portaria ${ }^{\circ}$ 559/2013]

Atores no Setor de Telecomunicações, 309

Atribuição, Destinação e Distribuição de Radiofrequência, 271

Autenticidade

Definição, 363

[Portaria ${ }^{\circ}$ 559/2013]

Autenticidade das Informações

como requisito dos programas e equipamentos destinados às comunicações de dados da administração pública federal, 321

[Decreto $\mathrm{n}^{\circ} 8.135$, de 4 de novembro de 2013]

Autoconfiguração de Frequências

Femtocélula

funcionalidade necessária de autoconfiguração de frequências para a, 353

[Resolução no 624/2013]

Autoconfiguração de Vizinhanças

Femtocélula

funcionalidade necessária de autoconfiguração de vizinhanças para a, 353

[Resolução nº 624/2013]

Autorização (Radiodifusão)

Serviço de Radiodifusão Comunitária condições de revogação de autorização do, $\mathbf{3 2 6}$

[Portaria MC no 112/2013]
Autorização (regras aplicáveis), 275

Autorização

(ver também Autorização de Uso de Radiofreqüência)

Contrato de Prestação do STFC fora da Área de Tarifa Básica modelo de, 350

[Resolução no 622/2013]

Procedimento Simplificado de Outorga instituição do, 364

[Portaria n $\left.{ }^{\circ} 639 / 2013\right]$

Serviço Auxiliar de Radiodifusão e Correlatos

aplicação provisória do valor praticado para execução do Serviço Limitado Privado para as autorizações de, 330

[Portaria $\mathrm{MC} \mathrm{n}^{\circ}$ 252/2013]

Serviço de Acesso Condicionado

instituição do Procedimento Simplificado de Outorga de STFC, SCM e SeAC, 364

[Portaria ${ }^{\circ}$ 639/2013]

Serviço de Comunicação Multimídia condições para autorização do, 342 [Resolução n 614/2013]

instituição do Procedimento Simplificado de Outorga de STFC, SCM e SeAC, 364

[Portaria n ${ }^{\circ}$ 639/2013]

Serviço Especial de Radiochamada, Regime Regulatório

substituição do plano de autorizações do pelo Regulamento do Serviço Limitado Privado, 345 [Resolução nº 617/2013]

Serviço Telefônico Fixo Comutado instituição do Procedimento Simplificado de Outorga de STFC, SCM e SeAC, 364

[Portaria n ${ }^{\circ}$ 639/2013]

modelo de contrato de prestação do

STFC fora da Área de Tarifa Básica, 350

[Resolução n 622/2013]

Termo de Compromisso de Ajustamento de Conduta 
disciplina do, 358

[Resolução no 629/2013]

Autorização de Uso de Radiofreqüência (ver também Autorização)

Serviço de Comunicação Multimídia condições para autorização de uso de radiofreqüência referente ao, 342

[Resolução nº 614/2013]

\section{Auxiliar, 362}

[Portaria ANATEL $n^{\circ} 448$, de 4 de junho de 2013]

Avaliação de Conformidade (ver Certificação)

\section{Aviação Civil}

Comunicação Aeroportuária

disciplina das condições de uso da faixa de $450 \mathrm{MHz}$ e contorno de proteção de $10 \mathrm{~km}$ de raio dos sistemas de comunicações operando no âmbito dos aeroportos, $\mathbf{3 5 6}$

[Resolução n 628/2013]

B

\section{Baixa Densidade Populacional} (ver Zona Rural)

Banda Larga, 308

\section{Banda Larga}

(ver também Programa Nacional de Banda Larga)

$2.500 \mathrm{MHz}$ a $2.690 \mathrm{MHz}$

definição de política para disponibilização de faixas de radiofrequência para prestação de acesso à internet em banda larga por prestadores de serviços de telecomunicações de pequeno porte, 331

[Portaria no 275/2013]

definição de política para disponibilização de faixas de radiofrequência para prestação de acesso à internet em banda larga por prestadores de serviços de telecomunicações de pequeno porte, 331

[Portaria n ${ }^{\circ}$ 275/2013]

INTERNET, 319

[Decreto $\mathrm{n}^{\circ} 7.981$, de 8 de abril de 2013]

Regime Especial de Tributação do Programa Nacional de Banda Larga para Implantação de Redes de Telecomunicações regulamentação do, 318, 323, 334 [Decreto $\mathrm{n}^{\circ} 7.921$, de 15 de fevereiro de 2013] [Portaria $\mathrm{MC} \mathrm{n}^{\circ} 55$, de 12 de março de 2013] [Portaria nº 303/2013]

\section{C}

Campo

(ver Zona Rural)

Canal da cidadania

Norma Regulamentar do Canal da Cidadania alteração da, $\mathbf{3 2 5}$

[Portaria MC n ${ }^{\circ}$ 57/2013]

\section{Canal de Distribuição Obrigatória}

exceção ao dever da prestadora do SeAC de tornar disponível o, 362 [Portaria n 238/2013]

\section{Canalização}

(ver Distribuição de Canais)

\section{Caráter Primário}

Faixa de $700 \mathrm{MHz}$

atribuição da faixa de radiofrequências de 698 a 806 $\mathrm{MHz}$ adicionalmente ao serviço móvel, em caráter primário, 354 [Resolução nº 625/2013]

destinação da faixa de radiofrequências de 698 a 806 $\mathrm{MHz}$ ao SMP, SCM e STFC, em caráter primário, 354

[Resolução nº 625/2013]

destinação da faixa de radiofrequências de 703 a 708 $\mathrm{MHz}$ e 758 a $763 \mathrm{MHz}$ ao SLP, em aplicações de segurança 
pública, defesa nacional e infraestrutura, em caráter primário, 354

[Resolução n 625/2013]

\section{Cassação}

Radiodifusão

aprovação do Regulamento de Sanções Administrativas aplicáveis a entidades prestadoras dos serviços de radiodifusão, seus ancilares e auxiliares, 326

[Portaria MC n 112/2013]

\section{Censura}

Direito ao Esquecimento

sua não caracterização como censura, 361

[Enunciado CJF $\mathrm{n}^{\circ}$ 531, de abril de 2013]

Centro de Atendimento

(ver Centro de Atendimento

(Indicadores de Qualidade do

STFC))

Centro de Atendimento (Indicadores

de Qualidade do STFC)

(ver também Serviço de Atendimento

ao Consumidor)

Regulamento do Serviço Telefônico

Fixo Comutado

sua alteração para disciplina mais detalhada dos direitos dos usuários/consumidores do STFC, 343

[Resolução n 615/2013]

\section{Certificação}

\section{(ver também Homologação)}

Antena para Uso em Aplicações Pontoa-Ponto

aprovação da norma para certificação e homologação de, 338

[Resolução n 609/2013]

Antena para Uso em Aplicações PontoÁrea

aprovação da norma para certificação e homologação de, 339

[Resolução nº 610/2013]
Aplicação Ponto-Área

aprovação da norma para certificação e homologação de antenas para, 339

[Resolução n ${ }^{\circ} 610 / 2013$ ]

aprovação da norma para certificação

e homologação de antenas para, 338

[Resolução nº 609/2013]

Certificação / Homologação, 271

Cidades Digitais

(ver Projeto Cidades Digitais)

Cidades Digitais

Acordo de Cooperação Técnica

minuta do, $\mathbf{3 3 5}$

[Portaria $\mathrm{MC} \mathrm{n}^{\circ} 305$, de 24 de outubro de 2013]

processso de habilitação e seleção de propostas para o Projeto, $\mathbf{3 2 2}$

[Portaria $\mathrm{MC} \mathrm{n}^{\circ} 13$, de $1^{\circ}$ de fevereiro de 2013]

Circuito Deliberativo

Conselho Diretor

disciplina da votação no, $\mathbf{3 4 0}$

[Resolução n 612/2013]

Classificação, 360

[Ato do Conselho Diretor da ANATEL ${ }^{\circ}$

3.833, de 20 de junho de 2013]

Definição, 363

[Portaria n $\left.{ }^{\circ} 559 / 2013\right]$

Classificação dos Serviços de Telecomunicações quanto ao interesse a que atendem

(ver também Serviço de Telecomunicações)

ato do Conselho Diretor da ANATEL de classificação dos serviços de telecomunicações em interesse coletivo ou restrito, $\mathbf{3 6 0}$

[Ato do Conselho Diretor da ANATEL $n^{\circ} 3.833$, de 20 de junho de 2013]

Classificações de Serviços no Setor de Telecomunicações, 283

Cláusula

Termo de Compromisso de Ajustamento de Conduta fixação das cláusulas obrigatórias no, 358 
[Resolução nº 629/2013]

\section{CN}

(ver Código Nacional)

Código Nacional

alteração de, $\mathbf{3 5 0}$

\section{Coletivo}

[Resolução nº 621/2013]

(ver Serviço de Interesse Coletivo)

Comércio Eletrônico

Direito do Consumidor

regulamentação da Lei 8.078/1990

para dispor sobre a contratação no comércio eletrônico, 319

[Decreto $\mathrm{n}^{\circ} 7.962$, de 15 de março de 2013]

\section{Competência}

Agência Nacional de

Telecomunicações

competência para processar solicitações de outorga e alterações das condições de outorga dos Serviços Auxiliares de Radiodifusão e Correlatos (SARC), bem como para emissão de regulamentação sobre a outorga, exploração e condições de uso de radiofrequência associada ao, 330

[Portaria $\mathrm{MC} \mathrm{n}^{\circ}$ 252/2013]

Delegação

atribuição de competência delegada do Ministério das Comunicações para a ANATEL para a prática dos atos necessários à análise de processos técnicos de engenharia nos procedimentos de pós-outorga dos serviços de radiodifusão, seus ancilares e auxiliares, 362

[Portaria ANATEL $\mathrm{n}^{\circ} 448$, de 4 de junho de 2013]

delegação de competência do Conselho Diretor da ANATEL para o Superintendente de Serviços de Comunicação de Massa para decidir sobre os pedidos de dispensa do dever de distribuição de canais obrigatórios do SeAC, 362

[Portaria n $\left.{ }^{\circ} 238 / 2013\right]$

Ministério das Comunicações

autorização de funcionamento em caráter provisório de entidades prestadoras de serviços de radiodifusão e seus ancilares que ainda não tenham tido o requerimento de aprovação dos locais de instalação e uso de equipamentos analisado, 327

[Portaria MC n $\left.{ }^{\circ} 159 / 2013\right]$

Presidência da República autorização de funcionamento em caráter provisório de entidades prestadoras de serviços de radiodifusão e seus ancilares que ainda não tenham tido o requerimento de aprovação dos locais de instalação e uso de equipamentos analisado, 327

[Portaria MC no 159/2013]

Serviço Auxiliar de Radiodifusão e Correlatos

competência da ANATEL para processar solicitações de outorga e alterações das condições de outorga dos Serviços Auxiliares de Radiodifusão e Correlatos (SARC), bem como para emissão de regulamentação sobre a outorga, exploração e condições de uso de radiofrequência associada ao, 330

[Portaria $\mathrm{MC} \mathrm{n}^{\circ}$ 252/2013]

\section{Cômputo de votos}

Conselho Diretor - Agencia Nacional de Telecomunicações disciplina da votação no, $\mathbf{3 4 0}$

[Resolução no 612/2013]

\section{Comunicação Aeroportuária}

Regulamento sobre Condições de Uso da faixa de $450 \mathrm{MHz}$

disciplina das condições de uso da faixa de $450 \mathrm{MHz}$ e contorno de proteção de $10 \mathrm{~km}$ de raio dos 


\author{
sistemas de comunicações \\ operando no âmbito dos \\ aeroportos, 356 \\ [Resolução no 628/2013] \\ Concessão \\ (ver Concessão (Radiodifusão)) \\ Concessão (Radiodifusão) \\ (ver também Concessão) \\ Competência \\ autorização de funcionamento em \\ caráter provisório de entidades \\ prestadoras de serviços de \\ radiodifusão e seus ancilares que \\ ainda não tenham tido o \\ requerimento de aprovação dos \\ locais de instalação e uso de \\ equipamentos analisado, $\mathbf{3 2 7}$ \\ [Portaria MC n ${ }^{\circ}$ 159/2013]
}

Concessão (regras aplicáveis), 274

Concessão, 358

(ver também Concessão
(Radiodifusão))
[Resolução ${ }^{\circ}$ 629/2013]
Contrato de Prestação do STFC fora
da Área de Tarifa Básica
modelo de, 350
[Resolução no 622/2013]
Radiodifusão
autorização de funcionamento em
caráter provisório de entidades
prestadoras de serviços de
radiodifusão e seus ancilares que
ainda não tenham tido o
requerimento de aprovação dos
locais de instalação e uso de
equipamentos analisado, 327
[Portaria MC no $\left.{ }^{\circ} 159 / 2013\right]$
Serviço Telefônico Fixo Comutado
modelo de contrato de prestação do
STFC fora da Área de Tarifa
Básica, 350
[Resolução no 622/2013]
Termo de Compromisso de
Ajustamento de Conduta
disciplina do, 358
[Resolução n ${ }^{\circ} 629 / 2013$ ]

Concorrência no Setor de

Telecomunicações, 279

Condições de Uso de Radiofrequência

e Canalização (Distribuição de

Canais), 272

Condições Objetivas

Serviço Limitado Privado

fixação das condições objetivas para obtenção de autorização do, 345

[Resolução n ${ }^{\circ} 617 / 2013$ ]

\section{Condições Subjetivas}

Serviço Limitado Privado

fixação das condições objetivas para obtenção de autorização do, 345

[Resolução n ${ }^{\circ}$ 617/2013]

\section{Confidencialidade}

como requisito dos programas e equipamentos destinados às comunicações de dados da administração pública federal, 321

[Decreto $\mathrm{n}^{\circ} 8.135$, de 4 de novembro de 2013]

Definição, 360

[]

Congresso Nacional, 310

Congresso Nacional, 359

(ver também Senado Federal)

[Resolução $n^{\circ} 4$ do Senado Federal, de 2013]

Conhecimento

Definição, 363

[Portaria $\left.n^{\circ} 559 / 2013\right]$

\section{Conselheiro}

Voto

exigência de fundamentação do, 340

[Resolução nº 612/2013]

Conselho de Defesa Nacional

sua oitiva para edição do Decreto $8.135 / 2013,321$

[Decreto $\mathrm{n}^{\circ} 8.135$, de 4 de novembro de 2013]

Conselho de Usuários

Plano anual de atividades 
não previsto no novo regulamento de conselho de usuários, 351

[Resolução nº 623/2013]

Regulamento de Conselho de Usuários do STFC aprovação do, $\mathbf{3 5 1}$

[Resolução n 623/2013]

\section{Conselho Diretor}

Processo Administrativo

limite temporal ao pedido de reconsideração em face de decisão proferida pelo Conselho Diretor da ANATEL quando da deliberação sobre recurso administrativo, 365

[Súmula da ANATEL n ${ }^{\circ} 14$, de 28 de junho de 2013]

Votação

disciplina da, 340

[Resolução no 612/2013]

Conselho Diretor - Agencia Nacional de Telecomunicações

Votação

disciplina da, 340

[Resolução nº 612/2013]

\section{Consumidor, 319}

(ver também Usuário)

[Decreto $n^{\circ} 7.962$, de 15 de março de 2013]

Atendimento Pessoal

alteração do Regulamento do STFC para disciplinar com maior detalhamento os direitos dos usuários/consumidores do STFC, em especial, o, 343

[Resolução ${ }^{\circ}$ 615/2013]

Comércio Eletrônico

regulamentação da Lei 8.078/1990 para dispor sobre a contratação no comércio eletrônico, 319

[Decreto $\mathrm{n}^{\circ} 7.962$, de 15 de março de 2013]

Direito de Arrependimento

sua previsão na contratação via comércio eletrônico, 319

[Decreto $\mathrm{n}^{\circ} 7.962$, de 15 de março de 2013]

Femtocélula direitos e condições contratuais no fornecimento e operação de, $\mathbf{3 5 3}$

[Resolução no 624/2013]

Serviço de Atendimento ao

Consumidor

alteração do Regulamento do STFC para disciplinar com maior detalhamento os direitos dos usuários/consumidores do STFC, 343

[Resolução no 615/2013]

\section{Contrato de Prestação do STFC fora} da Área de Tarifa Básica

modelo de, 350

[Resolução nº 622/2013]

Controle de Ácesso

Definição, 363

[Portaria ${ }^{\circ}$ 559/2013]

Controle Social, Hierárquico e

Interorgânico, 283

Convalidação do Ato Administrativo

convalidação dos atos praticados pela antiga Superintendência de Serviços de Comunicação de Massa sobre análise de processos técnicos de engenharia nos procedimentos de pós-outorga dos serviços de radiodifusão, seus ancilares e auxiliares, $\mathbf{3 6 2}$

[Portaria ANATEL $\mathrm{n}^{\circ} 448$, de 4 de junho de 2013]

\section{Convergência}

Serviço Auxiliar de Radiodifusão e Correlatos

política ministerial de unificação, via regulamentação da ANATEL, da regulamentação do SARC com a de outros serviços convergentes de telecomunicações de interesse restrito, 330

[Portaria MC n ${ }^{\circ}$ 252/2013]

\section{Copa do Mundo}

Comunicação Aeroportuária disciplina das condições de uso da faixa de $450 \mathrm{MHz}$ e contorno de proteção de $10 \mathrm{~km}$ de raio dos sistemas de comunicações 
operando no âmbito dos aeroportos, 356

[Resolução no 628/2013]

\section{Cronograma de Desligamento da TV} analógica

sua alteração para ocorrência no período de $1^{\circ}$ de janeiro de 2015 a 31 de dezembro de 2018, 320

[Decreto $\mathrm{n}^{\circ} 8.061$, de 29 de julho de 2013]

D

Dado

Definição, 363

[Portaria $n^{\circ}$ 559/2013]

\section{Dados}

(ver também Forma de

\section{Telecomunicação)}

exigência de que as comunicações de dados da administração pública federal sejam realizadas por redes de telecomunicações e serviços de tecnologia da informação fornecidos por órgãos ou entidades da administração pública federal, incluindo empresas públicas e sociedades de economia mista da União e suas subsidiárias, 321

[Decreto $\mathrm{n}^{\circ} 8.135$, de 4 de novembro de 2013]

sua disciplina na administração pública federal direta, autárquica e fundacional, 321

[Decreto $\mathrm{n}^{\circ} 8.135$, de 4 de novembro de 2013]

Defesa Civil, 307

Defesa do consumidor (ver Consumidor)

Defesa do Usuário (ver Usuário)

\section{Defesa Nacional}

(ver também Forças de Segurança) (ver também Militar) (ver também Militares) destinação da faixa de radiofrequências de 703 a $708 \mathrm{MHz}$ e 758 a $763 \mathrm{MHz}$ ao SLP, em aplicações de segurança pública, defesa nacional e infraestrutura, em caráter primário, 354

[Resolução n ${ }^{\circ}$ 625/2013]

\section{Deficiência Visual}

Terminais de Telecomunicações

dispensa de exigência de disposição física das teclas de terminais do STFC para identificação por deficiente visual, 341

[Resolução nº 613/2013]

\section{Delegação}

Competência

atribuição de competência delegada do Ministério das Comunicações para a ANATEL para a prática dos atos necessários à análise de processos técnicos de engenharia nos procedimentos de pós-outorga dos serviços de radiodifusão, seus ancilares e auxiliares, 362

[Portaria ANATEL n ${ }^{\circ} 448$, de 4 de junho de 2013]

delegação de competência do Conselho Diretor da ANATEL para o Superintendente de Serviços de Comunicação de Massa para decidir sobre os pedidos de dispensa do dever de distribuição de canais obrigatórios do SeAC, 362

[Portaria n ${ }^{\circ}$ 238/2013]

\section{Devido Processo Legal}

Súmula n ${ }^{\circ} 14$

limite temporal ao pedido de reconsideração em face de decisão proferida pelo Conselho Diretor da ANATEL quando da deliberação sobre recurso administrativo, $\mathbf{3 6 5}$

[Súmula da ANATEL n ${ }^{\circ}$ 14, de 28 de junho de 2013]

\section{Digitalização}

Inclusão Digital, 319

[Decreto $\mathrm{n}^{\circ} 7.981$, de 8 de abril de 2013] 
requisitos técnicos mínimos de smartphones para obtenção de benefício de oneração fiscal, 325 [Portaria $\mathrm{MC} \mathrm{n}^{\circ} 87$, de 10 de abril de 2013]

Radiodifusão

sua alteração para ocorrência no período de $1^{\mathrm{o}}$ de janeiro de 2015 a 31 de dezembro de 2018, 320

[Decreto $\mathrm{n}^{\circ} 8.061$, de 29 de julho de 2013]

Direito, 361

(ver também Direito à Privacidade) (ver também Sigilo)

[Enunciado CJF n ${ }^{\circ}$ 531, de abril de 2013]

Direito à Privacidade, 267

Direito à Privacidade, 361

(ver também Direito)

[Enunciado CJF n ${ }^{\circ}$ 531, de abril de 2013]

Direito Aeroespacial, 305

Direito ao Esquecimento

Definição, 361

[]

sua caracterização como direito da personalidade intransmissível e irrenunciável, 361

[Enunciado CJF $\mathrm{n}^{\circ}$ 531, de abril de 2013]

Direito de Acesso

Definição, 363

[Portaria ${ }^{\circ}$ 559/2013]

Direito de Arrependimento

sua previsão na contratação via comércio eletrônico, 319

[Decreto $\mathrm{n}^{\circ}$ 7.962, de 15 de março de 2013]

Direito do Consumidor, 304

(ver Consumidor)

Direitos da Personalidade

Direito ao Esquecimento

sua caracterização como direito da personalidade intransmissível e irrenunciável, 361

[Enunciado CJF $\mathrm{n}^{\circ}$ 531, de abril de 2013]
Discriminação de Polarização Cruzada

Antena para Uso em Aplicações Pontoa-Ponto classes de antenas segundo a desempenho de discriminação de polarização cruzada, 338

[Resolução no 609/2013]

Disponibilidade

Definição, 363

[Portaria n ${ }^{\circ}$ 559/2013]

Distribuição de Canais

(ver também Espectro de

Radiofreqüências)

Regulamento sobre Condições de Uso da faixa de $450 \mathrm{MHz}, 356$

[Resolução nº 628/2013]

Distribuição de Matérias

Conselho Diretor - Agencia Nacional de Telecomunicações

disciplina da distribuição de matérias no, 340

[Resolução nº 612/2013]

Distribuição de Sinais de Televisão e de Áudio por Assinatura via Satélite (DTH), 351

[Resolução no 623/2013]

Distribuição de Sinais Multiponto

Multicanal

(ver Serviço de Distribuição de Sinais

Multiponto Multicanal)

Documento

Definição, 363

[Portaria n ${ }^{\circ}$ 559/2013]

\section{E}

EBC

(ver Empresa Brasil de Comunicação)

Educação e Pesquisa, 280

Emergência

(ver Serviço de Emergência)

Empresa Brasil de Comunicação

estatuto social da, 319

[Decreto $n^{\circ} 7.932$, de 19 de fevereiro de 2013]

Empresa Brasileira de Comunicação

S.A. 


\section{(ver RADIOBRÁS)}

\section{Engenharia}

Pós-Outorga

atribuição de competência delegada do Ministério das Comunicações para a ANATEL para a prática dos atos necessários à análise de processos técnicos de engenharia nos procedimentos de, $\mathbf{3 6 2}$

[Portaria ANATEL $\mathrm{n}^{\circ} 448$, de 4 de junho de 2013]

Equipamentos de Telecomunicações, 268

Equipamentos de Telecomunicações, 325

\section{(ver também Rede de}

Telecomunicações)

[Portaria $\mathrm{MC} \mathrm{n}^{\circ} 87$, de 10 de abril de 2013]

Comercialização

possibilidade de serem comercializadas unidades remanescentes no comércio distribuídas antes do vencimento, suspensão ou cancelamento dos respectivos certificados de homologação, 355

[Resolução n ${ }^{\circ}$ 626/2013]

Equipamento de Radiocomunicação de Radiação Restrita disciplina das Femtocélulas, 353

[Resolução no 624/2013]

Radiodifusão

autorização de funcionamento em caráter provisório de entidades prestadoras de serviços de radiodifusão e seus ancilares que ainda não tenham tido o requerimento de aprovação dos locais de instalação e uso de equipamentos analisado, $\mathbf{3 2 7}$

[Portaria $\mathrm{MC} \mathrm{n}^{\circ}$ 159/2013]

Requerimento de Aprovação dos Locais de Instalação e Uso de Equipamentos

autorização de funcionamento em caráter provisório de entidades prestadoras de serviços de radiodifusão e seus ancilares que ainda não tenham tido o requerimento de aprovação dos locais de instalação e uso de equipamentos analisado, 327

[Portaria MC n $\left.{ }^{\circ} 159 / 2013\right]$

Smartphone

seus requisitos técnicos mínimos de acesso à internet em alta velocidade para obtenção de benefício de oneração fiscal, $\mathbf{3 2 5}$ [Portaria MC $\mathrm{n}^{\mathrm{o}}$ 87, de 10 de abril de 2013]

Espécies de Outorga, 274

Espectro de Radiofrequência, 271

Espectro de Radiofreqüências

(ver também Distribuição de Canais)

$2.500 \mathrm{MHz}$ a $2.690 \mathrm{MHz}$

determinação ministerial para a ANATEL promover a estudos de viabilidade de disponibilização de faixas de radiofrequência adicionais para a prestação de acesso à internet em banda larga, 331

[Portaria n ${ }^{\circ}$ 275/2013]

Acréscimo de Faixa de

Radiofrequência

valor devido por, 344

[Resolução n 616/2013]

Faixa de 698 a $806 \mathrm{MHz}$

determinação à ANATEL para que iniciasse os procedimentos administrativos de atribuição, destinação e distribuição da faixa para atendimento dos objetivos do PNBL, 323

[Portaria MC $\mathrm{n}^{\circ} 14$, de 6 de fevereiro de 2013]

Plano de Atribuição, Destinação e Distribuição de Faixas de

Frequências no Brasil edição 2013 do, 360

[Ato do Conselho Diretor da ANATEL $\mathrm{n}^{\circ} 1.724$, de 11 de março de 2013]

Regulamento sobre Condições de Uso da faixa de $450 \mathrm{MHz}, 356$ 
[Resolução n 628/2013]

Uso Licenciado

determinação ministerial para a ANATEL promover a estudos de viabilidade de disponibilização de faixas de radiofrequência adicionais para a prestação de acesso à internet em banda larga para, 331

[Portaria n ${ }^{\circ}$ 275/2013]

Uso Não Licenciado

determinação ministerial para a ANATEL promover a estudos de viabilidade de disponibilização de faixas de radiofrequência adicionais para a prestação de acesso à internet em banda larga para, 331

[Portaria n ${ }^{\circ}$ 275/2013]

Estações de Telecomunicações, 269

Estrutura Organizacional da ANATEL Regimento Interno da ANATEL, 340

\section{Estudos}

[Resolução nº 612/2013]

determinação ministerial para a ANATEL promover a estudos de viabilidade de disponibilização de faixas de radiofrequência adicionais para a prestação de acesso à internet em banda larga, 331

[Portaria $n^{\circ}$ 275/2013]

Evento de segurança da informação

Definição, 364

[Portaria ${ }^{\circ}$ 559/2013]

Expediente Protelatório

Conselho Diretor - Agencia Nacional de Telecomunicações

consideração da ausência injustificada de conselheiro como expediente protelatório de decisão, 340

[Resolução nº 612/2013]

Experimento em Telecomunicação (ver Serviço Especial para Fins Científicos ou Experimentais)

$F$

\section{Faixa de 698 a $806 \mathrm{MHz}$}

Programa Nacional de Banda Larga determinação à ANATEL para que iniciasse os procedimentos administrativos de atribuição, destinação e distribuição da faixa para atendimento dos objetivos do PNBL, 323

[Portaria MC n ${ }^{\circ} 14$, de 6 de fevereiro de 2013]

Faixa de $700 \mathrm{MHz}$

(ver $700 \mathrm{MHz})$

Faixa de $700 \mathrm{MHz}$

(ver também TV Digital)

atribuição, destinação e regulamento sobre condições de uso de radiofrequências na faixa de, $\mathbf{3 5 4}$

[Resolução nº 625/2013]

Faixa de Radiofreqüência

(ver Espectro de Radiofreqüiências)

Femtocélula

Regulamento para Uso de Femtocélulas em Redes do Serviço Móvel Pessoal, do Serviço Móvel Especializado e do Serviço de Comunicação Multimídia aprovacao do, $\mathbf{3 5 3}$

[Resolução no 624/2013]

Financiamento da Universalização, 281 Fiscalização

Femtocélula sujeita à fiscalização da ANATEL, 353

[Resolução n ${ }^{\circ}$ 624/2013]

Fiscalização das Telecomunicações, 272

FM

(ver Frequência Modulada)

Forças de Segurança, 354

(ver também Defesa Nacional)

[Resolução no 625/2013]

Forma de Telecomunicação, 321 


\section{(ver também Dados)}

[Decreto $\mathrm{n}^{\circ} 8.135$, de 4 de novembro de 2013]

\section{Frequência Modulada}

Rádio FM

disciplina da extinção do serviço de radiodifusão sonora em ondas médias e sua possível adaptação de instrumentos de outorgas para os de execução do serviço de radiodifusão sonoram em frequência modulada, $\mathbf{3 2 2}$

[Decreto $n^{\circ} 8139 / 2013$ ]

Fundamentos, 267

\section{G}

Garantia de Inviolabilidade das Comunicações de Dados

dispensa de licitação nas contratações de comunicação de dados que possam comprometer a, $\mathbf{3 2 1}$

[Decreto $\mathrm{n}^{\mathrm{o}} 8.135$, de 4 de novembro de 2013]

\section{Gestor da informação}

Definição, 364

[Portaria n ${ }^{\circ}$ 559/2013]

\section{H}

\section{Homologação}

\section{(ver também Certificação)}

Antena para Uso em Aplicações Pontoa-Ponto aprovação da norma para certificação e homologação de, 338

[Resolução no 609/2013]

Antena para Uso em Aplicações PontoÁrea aprovação da norma para certificação e homologação de, 339

[Resolução no 610/2013]

Aplicação Ponto-a-Ponto aprovação da norma para certificação e homologação de antenas para, 338

[Resolução n 609/2013]

Aplicação Ponto-Área

aprovação da norma para certificação e homologação de antenas para, 339

[Resolução n 610/2013]

\section{Ilícito}

Expediente Protelatório

consideração da ausência injustificada de conselheiro à sessão ou reunião ou sua não manifestação em circuito deliberativo do Conselho Diretor da ANATEL como, 340

[Resolução nº 612/2013]

\section{Incentivo Fiscal}

Inclusão Digital, 319

[Decreto $\mathrm{n}^{\circ} 7.981$, de 8 de abril de 2013]

requisitos técnicos mínimos de smartphones para obtenção de benefício de oneração fiscal, $\mathbf{3 2 5}$ [Portaria MC n ${ }^{\circ} 87$, de 10 de abril de 2013]

Incidente de segurança da informação Definição, 364

[Portaria n $\left.{ }^{\circ} 559 / 2013\right]$

\section{Inclusão Digital}

\section{(ver também Universalização)}

Incentivo Fiscal, 319

[Decreto $\mathrm{n}^{\circ} 7.981$, de 8 de abril de 2013]

requisitos técnicos mínimos de smartphones para obtenção de benefício de oneração fiscal, $\mathbf{3 2 5}$ [Portaria MC $\mathrm{n}^{\circ} 87$, de 10 de abril de 2013]

\section{Inclusão Financeira}

sua disciplina como integrante do Sistema de Pagamentos Brasileiro (SPB), 316 
[Lei no $12.865 / 2013$ ]

\section{Informação}

Definição, 364

[Portaria ${ }^{\circ}$ 559/2013]

Informação pessoal

Definição, 364

[Portaria $\mathrm{n}^{\circ}$ 559/2013]

Informação Sigilosa

Definição, 364

[Portaria ${ }^{\circ}$ 559/2013]

\section{Information and Communication \\ Technology}

regulamentação das margens de preferência em licitações de equipamentos de, $\mathbf{3 1 7}$

[Decreto ${ }^{\circ} 7.903 / 2013$ ]

\section{Infração}

(ver também Sanção)

classificação das infrações

administrativas, 326

[Portaria $\mathrm{MC} \mathrm{n}^{\circ}$ 112/2013]

Infraestrutura de Telecomunicações, 267

Infraestrutura e Recursos do Setor de

Telecomunicações, 267

Instrumento de trabalho

Definição, 364

[Portaria ${ }^{\circ}$ 559/2013]

Instrumentos Deliberativos da

ANATEL

Regimento Interno da ANATEL, 340

[Resolução n 612/2013]

\section{Integridade}

como requisito dos programas $\mathrm{e}$ equipamentos destinados às comunicações de dados da administração pública federal, 321

[Decreto $\mathrm{n}^{\circ} 8.135$, de 4 de novembro de 2013]

Definição, 364

[Portaria ${ }^{\circ}$ 559/2013]

Interesse Coletivo

(ver Serviço de Interesse Coletivo)

Interesse Público

Termo de Compromisso de Ajustamento de Conduta interesse público como requisito para celebração de, $\mathbf{3 5 8}$

[Resolução nº 629/2013]

Interesse Restrito

(ver Serviço de Interesse Restrito)

Interface Usuário-Rede

Regulamento da Interface Usuário-

Rede e de Terminais do STFC

alteração do, 341

[Resolução nº 613/2013]

Internet, 286, 306

INTERNET, 318

(ver também Serviço de Valor Adicionado)

[Decreto $\mathrm{n}^{\circ} 7.921$, de 15 de fevereiro de 2013]

Banda Larga

definição de política para disponibilização de faixas de radiofrequência para prestação de acesso à internet em banda larga por prestadores de serviços de telecomunicações de pequeno porte, 331

[Portaria n ${ }^{\circ}$ 275/2013]

Smartphone

seus requisitos técnicos mínimos de acesso à internet em alta velocidade para obtenção de benefício de oneração fiscal, 325 [Portaria $\mathrm{MC} \mathrm{n}^{\circ} 87$, de 10 de abril de 2013]

Inviolabilidade das comunicações de dados

na administração pública federal direta e indireta, 321

[Decreto $\mathrm{n}^{\circ} 8.135$, de 4 de novembro de 2013]

ISDB-TB

(ver Sistema Brasileiro de Televisão Digital Terrestre)

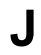

Jogos Olímpicos

Comunicação Aeroportuária 
disciplina das condições de uso da faixa de $450 \mathrm{MHz}$ e contorno de proteção de $10 \mathrm{~km}$ de raio dos sistemas de comunicações operando no âmbito dos aeroportos, 356

[Resolução nº 628/2013]

\section{Lei Geral de Telecomunicações} alteração da, $\mathbf{3 1 6}$

[Lei $\mathrm{n}^{\circ}$ 12.841, de 9 de julho de 2013]

Lei $n^{\circ}$ 9472/97

(ver Lei Geral de Telecomunicações)

\section{LGT}

(ver Lei Geral de Telecomunicações)

\section{Licença para Funcionamento de Estação}

Serviço de Acesso Condicionado alteração do regulamento do $\mathrm{SeAC}$ para permitir a obtenção de licença para funcionamento de estação independentemente de comprovação de contrato de uso dos postes, dutos, rede ou seus segmentos, celebrado com empresa proprietária das respectivas infraestruturas $\mathrm{e}$ autorização de Prefeitura para a construção do sistema, 347

[Resolução n 618/2013]

\section{Licitação, 274}

\section{Licitação}

dispensa de licitação nas contratações de comunicação de dados que possam comprometer a, $\mathbf{3 2 1}$

[Decreto $\mathrm{n}^{\circ} 8.135$, de 4 de novembro de 2013]

\section{M}

Metas de Universalização, 281

Militar, 354

(ver também Defesa Nacional)

[Resolução n ${ }^{\circ}$ 625/2013]

\section{Militares, 354}

(ver também Defesa Nacional)

[Resolução $n^{\circ}$ 625/2013]

Ministério das Comunicações, 311

Ministério das Comunicações

Competência

autorização de funcionamento em caráter provisório de entidades prestadoras de serviços de radiodifusão e seus ancilares que ainda não tenham tido o requerimento de aprovação dos locais de instalação e uso de equipamentos analisado, $\mathbf{3 2 7}$

[Portaria MC n ${ }^{\circ}$ 159/2013]

Convergência

política ministerial de unificação, via regulamentação da ANATEL, da regulamentação do SARC com a de outros serviços convergentes de telecomunicações de interesse restrito, 330

[Portaria $\mathrm{MC} \mathrm{n}^{\circ}$ 252/2013]

Grupo de Trabalho de Documentação

e Informação

instituição do, 333

[Portaria MC n 299, de 7 de outubro de 2013]

Grupo de Trabalho de Radiodifusão

Ancilar

instituição do, 333

[Portaria MC n ${ }^{\circ} 299$, de 7 de outubro de 2013]

Grupo de Trabalho de Radiodifusão

Comercial

instituição do, 333

[Portaria MC n 299, de 7 de outubro de 2013]

Grupo de Trabalho de Radiodifusão

Educativa e Consignações

instituição do, $\mathbf{3 3 3}$

[Portaria MC n ${ }^{\circ} 299$, de 7 de outubro de 2013]

Grupo de Trabalho de TV Digital instituição do, $\mathbf{3 3 3}$

[Portaria MC n ${ }^{\circ} 299$, de 7 de outubro de 2013] 
instauração de procedimento para apuração de infrações referentes a serviços de radiodifusão e seus ancilares, 362

[Portaria ANATEL no 448, de 4 de junho de 2013]

Regulamento de Sanções

Administrativas

aprovação do, $\mathbf{3 2 6}$

[Portaria MC nº 112/2013]

Serviço Auxiliar de Radiodifusão e Correlatos

competência da ANATEL para processar solicitações de outorga e alterações das condições de outorga dos Serviços Auxiliares de Radiodifusão e Correlatos (SARC), bem como para emissão de regulamentação sobre a outorga, exploração e condições de uso de radiofrequência associada ao, 330

[Portaria MC n ${ }^{\circ}$ 252/2013]

política ministerial de unificação, via regulamentação da ANATEL, da regulamentação do SARC com a de outros serviços convergentes de telecomunicações de interesse restrito, 330

[Portaria MC n ${ }^{\circ}$ 252/2013]

Ministro das Comunicações

(ver Ministério das Comunicações)

Mobile Payment, 316

[Lei $n^{\circ} 12.865 / 2013$ ]

Mobilidade Restrita

Femtocélula

funcionalidade necessária de restrição de mobilidade para a, 353

Multa

[Resolução n 624/2013]

(ver Multa (Sanção Administrativa))

Multa (Sanção Administrativa)

parâmetros para aplicação de, $\mathbf{3 2 6}$

[Portaria MC n $\left.{ }^{\circ} 112 / 2013\right]$
Multichannel Multipoint Distribution Service (Serviço de Distribuição de Sinais Multiponto Multicanal), 351 (ver também Serviço de Distribuição de Sinais Multiponto Multicanal)

[Resolução n 623/2013]

\section{$\mathbf{N}$}

Norma Complementar do Serviço de Radiodifusão Comunitária alteração da, $\mathbf{3 2 9}$

[Portaria MC $\mathrm{n}^{\circ} 197$, de $1^{\circ}$ julho de 2013]

Norma para Certificação de Produtos para Telecomunicações

(ver também Regulamento para Certificação e Homologação de Produtos para Telecomunicações)

alteração da, $\mathbf{3 5 5}$

[Resolução n 626/2013]

Numeração de Rede

Regulamento de Numeração do STFC alteração do, 336 [Resolução nº 607/2013]

Numeração de Serviços

Serviço Telefônico Fixo Comutado alteração do Plano Geral de Códigos Nacionais, 335

[Resolução n ${ }^{\circ}$ 606/2013]

Numeração dos Serviços, 268

0

Obrigação de fazer (ver também Sanção Administrativa)

Termo de Compromisso de Ajustamento de Conduta disciplina do, 358 [Resolução n 629/2013]

Obrigações de Universalização (ver Universalização)

Olimpíadas

(ver Jogos Olímpicos)

Ondas Médias

Rádio AM 
disciplina da extinção do serviço de radiodifusão sonora em ondas médias e sua possível adaptação de instrumentos de outorgas para os de execução do serviço de radiodifusão sonoram em frequência modulada, 322

[Decreto $n^{\circ} 8139 / 2013$ ]

\section{Onerosidade}

Acréscimo de Faixa de
Radiofrequência
valor devido por, 344
[Resolução n ${ }^{\circ}$ 616/2013]
Procedimento Simplificado de Outorga
instituição do, 364
[Portaria $n^{\circ}$ 639/2013]

Operadora, 331

(ver também Operadora de Pequeno Porte)

[Portaria no 275/2013]

Operadora de Pequeno Porte

(ver também Operadora)

Banda Larga

definição de política para disponibilização de faixas de radiofrequência para prestação de acesso à internet em banda larga por prestadores de serviços de telecomunicações de pequeno porte, 331

[Portaria n ${ }^{\circ}$ 275/2013]

Operadora de Telecomunicações

(ver também Prestadora)

Termo de Compromisso de

Ajustamento de Conduta

disciplina do, $\mathbf{3 5 8}$

[Resolução no 629/2013]

Órbita e Satélite, 272

Outorga

Competência

autorização de funcionamento em caráter provisório de entidades prestadoras de serviços de radiodifusão e seus ancilares que ainda não tenham tido o requerimento de aprovação dos locais de instalação e uso de equipamentos analisado, 327

[Portaria MC no 159/2013]

P

PADIS

(ver Programa de Apoio ao Desenvolvimento Tecnológico da Indústria de Semicondutores (PADIS))

PAR-C (ver Plano de Atendimento Rural Complementar (STFC))

PAR-S

(ver Plano de Atendimento Rural Suplementar (STFC))

Penalidade Administrativa

(ver Sanção Administrativa)

Pequeno Porte, 331

[Portaria n ${ }^{\circ}$ 275/2013]

Permissão

(ver Permissão (Radiodifusão))

Permissão (Radiodifusão)

Competência

autorização de funcionamento em caráter provisório de entidades prestadoras de serviços de radiodifusão e seus ancilares que ainda não tenham tido o requerimento de aprovação dos locais de instalação e uso de equipamentos analisado, 327

[Portaria MC no 159/2013]

Permissão (regras aplicáveis), 275

Pesquisa \& Desenvolvimento, 281

PGCN

(ver Plano Geral de Códigos Nacionais)

Plano anual de atividades

Conselho de Usuários

plano anual não previsto no novo regulamento de, 351

[Resolução n 623/2013] 
Plano de Atendimento Rural

sua exigência para prestação de STFC fora da Área de Tarifa Básica (ATB), 350

[Resolução n ${ }^{\circ}$ 622/2013]

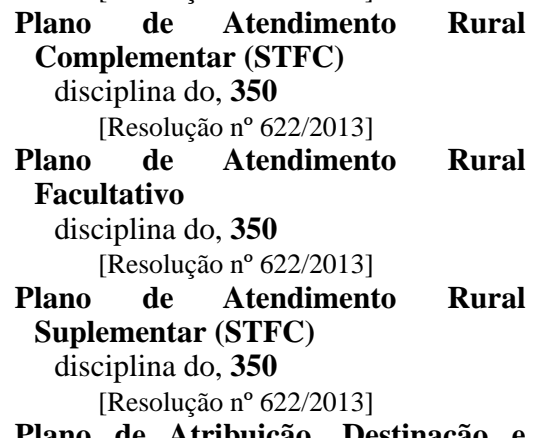

Plano de Atribuição, Destinação e Distribuição de Faixas de Frequências no Brasil edição 2013 do, $\mathbf{3 6 0}$

[Ato do Conselho Diretor da ANATEL $\mathrm{n}^{\circ} 1.724$, de 11 de março de 2013]

Plano de Autorizações do Serviço Especial de Radiochamada sua substituição pelo Regulamento do Serviço Limitado Privado, 345

[Resolução nº 617/2013]

Plano Geral de Códigos Nacionais alteração do, 335, 350

[Resolução $n^{\circ}$ 606/2013] [Resolução n ${ }^{\circ}$ 621/2013]

Planos de Serviços, 277

PNBL

(ver Programa Nacional de Banda Larga)

Poder Executivo, 311

Poder Legislativo, 310

Política de Segurança da Informação e Comunicações da ANATEL

Definição, 364

[Portaria ${ }^{\circ}$ 559/2013]

disciplina da Processo Administrativo, Sigilo, disciplina legal do acesso a informações, 363

[Portaria ${ }^{\circ}$ 559/2013]
Política Industrial, 279

Política Industrial

alteração do anexo III do Decreto 6.233/2007, 317

[Decreto $\mathrm{n}^{\circ} 7.913$, de 7 de fevereiro de 2013]

Information and Communication Technology

regulamentação das margens de preferência em licitações de equipamentos de, $\mathbf{3 1 7}$

[Decreto n ${ }^{\circ}$ 7.903/2013]

Margem de Preferência

regulamentação das margens de preferência em licitações de equipamentos de tecnologias da informação e comunicação, $\mathbf{3 1 7}$

[Decreto ${ }^{\circ}$ 7.903/2013]

Política Tarifária, 278

Políticas de Telecomunicações, 278

Ponto a Ponto, 338

[Resolução n 609/2013]

Ponto-a-Ponto, 338

[Resolução ${ }^{\circ}$ 609/2013]

Ponto-Área, 339

[Resolução nº 610/2013]

Portabilidade

Regulamento do Serviço Telefônico

Fixo Comutado

sua alteração para disciplina mais detalhada dos direitos dos usuários/consumidores do STFC, 343

[Resolução n 615/2013]

Portabilidade de Código de Acesso

(ver Portabilidade de Código de Acesso (STFC))

Portabilidade de Código de Acesso (STFC)

Regulamento do Serviço Telefônico

Fixo Comutado

sua alteração para disciplina mais detalhada dos direitos dos usuários/consumidores do STFC, 343

[Resolução nº 615/2013] 
Portador de Deficiência, 280

Pós-Outorga

atribuição de competência delegada do Ministério das Comunicações para a ANATEL para a prática dos atos necessários à análise de processos técnicos de engenharia nos procedimentos de, $\mathbf{3 6 2}$

[Portaria ANATEL $\mathrm{n}^{\circ}$ 448, de 4 de junho de 2013]

POSIC/Anatel

(ver Política de Segurança da Informação e Comunicações da ANATEL)

Preço Público

(ver também Tarifa)

Acréscimo de Faixa de

Radiofrequência valor devido por, 344

[Resolução no 616/2013]

Preço Público e Preço Privado, 276

Prescrição

Termo de Compromisso de

Ajustamento de Conduta

interrupção do prazo prescricional da pretensão punitiva quando do requerimento de celebração de, 358

[Resolução n 629/2013]

Presidência da República

Competência

autorização de funcionamento em caráter provisório de entidades prestadoras de serviços de radiodifusão e seus ancilares que ainda não tenham tido o requerimento de aprovação dos locais de instalação e uso de equipamentos analisado, 327

[Portaria MC no 159/2013]

Prestação de Contas

Agência Nacional de

Telecomunicações

disciplina de comparecimento anual de dirigentes de agências reguladoras ao Senado Federal, 359
[Resolução $n^{\circ} 4$ do Senado Federal, de 2013]

Prestação de Serviços, 274

Prestador de Serviço de

Telecomunicações

(ver Operadora de Telecomunicações)

Prestadora, 331

(ver também Operadora de Telecomunicações)

[Portaria ${ }^{\circ}$ 275/2013]

Prestadora / Operadora, 312

Prestadora de Pequeno Porte

Banda Larga

definição de política para disponibilização de faixas de radiofrequência para prestação de acesso à internet em banda larga por prestadores de serviços de telecomunicações de pequeno porte, $\mathbf{3 3 1}$

[Portaria n ${ }^{\circ}$ 275/2013]

Primariedade

Definição, 364

[Portaria ${ }^{\circ}$ 559/2013]

Princípio da Generalidade

(ver Universalização)

Privacidade

(ver Direito à Privacidade)

Procedimento Simplificado de Outorga instituição do, $\mathbf{3 6 4}$

[Portaria ${ }^{\circ}$ 639/2013]

Produto de Telecomunicação

(ver Equipamentos de Telecomunicações)

Programa de Apoio ao

Desenvolvimento Tecnológico da

Indústria de Semicondutores (PADIS), 317

[Decreto $\mathrm{n}^{\circ} 7.913$, de 7 de fevereiro de 2013]

Programa de Dispêndios Globais

(Empresas Estatais Federais)

PGD para 2014, 322

[Decreto $n^{\circ} 8174 / 2013$ ]

Programa Nacional de Banda Larga

(ver também Banda Larga)

Faixa de $700 \mathrm{MHz}$ 
ampliação da disponibilidade de espectro para atendimento dos objetivos do PNBL, 354

[Resolução n ${ }^{\circ}$ 625/2013]

Regime Especial de Tributação do Programa Nacional de Banda Larga para Implantação de Redes de Telecomunicações regulamentação do, 318, 323, 334 [Decreto $\mathrm{n}^{\circ} 7.921$, de 15 de fevereiro de 2013] [Portaria $\mathrm{MC} \mathrm{n}^{\circ} 55$, de 12 de março de 2013] [Portaria n ${ }^{\circ} 303 / 2013$ ]

Projeto Cidades Digitais, 322

[Portaria MC $\mathrm{n}^{\mathrm{o}} 13$, de $1^{\circ}$ de fevereiro de 2013]

Promoção de Classe

Alteração de Características Técnicas de Operação de Emissoras de Radiodifusão

disciplina ministerial da análise de, 329

[Portaria MC n 231/2013]

\section{Proporcionalidade}

na aplicação de sanções administrativas, 326

[Portaria MC no 112/2013]

\section{Prorrogação da Transição Digital}

Cronograma de Desligamento da TV analógica

sua alteração para ocorrência no período de $1^{\circ}$ de janeiro de 2015 a 31 de dezembro de 2018, 320

[Decreto $\mathrm{n}^{\circ} 8.061$, de 29 de julho de 2013]

Proteção do Consumidor (ver Consumidor)

Proteção do Usuário (ver Usuário)

PSO

(ver Procedimento Simplificado de Outorga)

Punição, 326

[Portaria MC n 112/2013]

\section{Q}

Quadro de Atribuição de Faixas de Frequências aprovação do, $\mathbf{3 6 0}$

[Ato do Conselho Diretor da ANATEL $\mathrm{n}^{\circ} 1.724$, de 11 de março de 2013]

Qualidade do Serviço, 282

Quanto ao Gênero, 284

Quanto ao Interesse, 283

\section{$\mathbf{R}$}

\section{RadCom}

(ver Serviço de Radiodifusão Comunitária)

Radioamador, 287

\section{RADIOBRÁS, 319}

[Decreto $\mathrm{n}^{\circ} 7.932$, de 19 de fevereiro de 2013]

Radiodifusão, 288

Radiodifusão, 362

(ver também Radiodifusão Sonora) (ver também Sistema Brasileiro de Televisão Digital Terrestre)

[Portaria ANATEL n ${ }^{\circ} 448$, de 4 de junho de 2013]

Alteração de Características Técnicas de Operação de Emissoras de Radiodifusão

disciplina ministerial da análise de, 329

[Portaria MC no 231/2013]

\section{Concessão}

autorização de funcionamento em caráter provisório de entidades prestadoras de serviços de radiodifusão e seus ancilares que ainda não tenham tido o requerimento de aprovação dos locais de instalação e uso de equipamentos analisado, 327

[Portaria $\mathrm{MC} \mathrm{n}^{\circ}$ 159/2013]

Cronograma de Desligamento da TV analógica 
sua alteração para ocorrência no período de $1^{\circ}$ de janeiro de 2015 a 31 de dezembro de 2018, 320

[Decreto $\mathrm{n}^{\mathrm{o}} 8.061$, de 29 de julho de 2013]

Outorga

autorização de funcionamento em caráter provisório de entidades prestadoras de serviços de radiodifusão e seus ancilares que ainda não tenham tido o requerimento de aprovação dos locais de instalação e uso de equipamentos analisado, $\mathbf{3 2 7}$

[Portaria MC no 159/2013]

Pós-Outorga

atribuição de competência delegada do Ministério das Comunicações para a ANATEL para a prática dos atos necessários à análise de processos técnicos de engenharia nos procedimentos de, $\mathbf{3 6 2}$

[Portaria ANATEL n ${ }^{\circ} 448$, de 4 de junho de 2013]

Promoção de Classe

disciplina ministerial da análise de alteração de características técnicas de operação de emissoras de radiodifusão, 329

[Portaria $\mathrm{MC} \mathrm{n}^{\circ}$ 231/2013]

Regulamento de Sanções

Administrativas

aprovação do, 326

[Portaria MC n ${ }^{\circ}$ 112/2013]

Requerimento de Aprovação dos

Locais de Instalação e Uso de

Equipamentos

autorização de funcionamento em caráter provisório de entidades prestadoras de serviços de radiodifusão e seus ancilares que ainda não tenham tido o requerimento de aprovação dos locais de instalação e uso de equipamentos analisado, 327

[Portaria MC n 159/2013]
Serviço Auxiliar de Radiodifusão e Correlatos competência da ANATEL para processar solicitações de outorga e alterações das condições de outorga dos Serviços Auxiliares de Radiodifusão e Correlatos (SARC), bem como para emissão de regulamentação sobre a outorga, exploração e condições de uso de radiofrequência associada ao, 330

[Portaria MC n ${ }^{\circ}$ 252/2013]

Serviço de Retransmissão de Televisão procedimento específico para outorga do, 333

[Portaria n ${ }^{\circ}$ 282/2013]

\section{Radiodifusão Comunitária, 289}

\section{(ver Serviço de Radiodifusão Comunitária) \\ Radiodifusão Sonora \\ (ver também Radiodifusão)}

Alteração de Características Técnicas de Operação de Emissoras de Radiodifusão

disciplina ministerial da análise de, 329

[Portaria MC n 231/2013]

Ondas Médias

disciplina da extinção do serviço de radiodifusão sonora em ondas médias e sua possível adaptação de instrumentos de outorgas para os de execução do serviço de radiodifusão sonoram em frequência modulada, $\mathbf{3 2 2}$

[Decreto n' 8139/2013]

Promoção de Classe

disciplina ministerial da análise de alteração de características técnicas de operação de emissoras de radiodifusão, $\mathbf{3 2 9}$

[Portaria MC n 231/2013]

Rádio AM

disciplina da extinção do serviço de radiodifusão sonora em ondas médias e sua possível adaptação 
de instrumentos de outorgas para os de execução do serviço de radiodifusão sonoram em frequência modulada, 322

[Decreto $n^{\circ}$ 8139/2013]

\section{Radiofreqüência}

(ver Espectro de Radiofreqüências)

Radiolocalização, 307

Ramos Jurídicos Afins, 304

Rede de Telecomunicações, 353

(ver também Equipamentos de

Telecomunicações)

[Resolução n ${ }^{\circ}$ 624/2013]

Femtocélula

sua possibilidade de uso por prestadoras de SMP, SME e SCM para melhoria do desempenho e cobertura de suas redes, $\mathbf{3 5 3}$

[Resolução nº 624/2013]

Redes de Telecomunicações, 267

Regime de Prestação de Serviços de Telecomunicações

(ver Serviços de Telecomunicações)

Regime Especial de Tributação do Programa Nacional de Banda Larga para Implantação de Redes de Telecomunicações

extensão da data-limite para adesão ao, 315

[Lei $\mathrm{n}^{\circ} 12.837 / 2013$ ]

regulamentação do, 318, 323, 334

[Decreto $\mathrm{n}^{\circ} 7.921$, de 15 de fevereiro de 2013] [Portaria $\mathrm{MC} \mathrm{n}^{\circ}$ 55, de 12 de março de 2013] [Portaria no 303/2013]

Regimento Interno da ANATEL, 340

[Resolução nº 612/2013]

Regulamento contra Interferências Prejudiciais

como requisito para publicação de edital de licitação para radiofrequências na faixa de 698 a $806 \mathrm{MHz}$ (Faixa de $700 \mathrm{MHz}$ ), 354

[Resolução n ${ }^{\circ}$ 625/2013]

Regulamento da Interface Usuário-

Rede e de Terminais do STFC alteração do, 341

[Resolução n 613/2013]
Regulamento de Administração de Recursos de Numeração alteração do, 336

[Resolução nº 607/2013]

Regulamento de Celebração e Acompanhamento de Termo de Compromisso de Ajustamento de Conduta aprovação do, 358

[Resolução nº 629/2013]

Regulamento de Cobrança de Preço Público pelo Direito de Exploração de Serviços de Telecomunicações e pelo Direito de Exploração de Satélite alteração do, 344-345

[Resolução nº 616/2013] [Resolução n ${ }^{\circ}$ 617/2013]

Regulamento de Conselho de Usuários aprovação do, 351

[Resolução no 623/2013]

Regulamento de Conselho de Usuários do STFC

aprovação do, 351

[Resolução no 623/2013]

Regulamento de Numeração do STFC alteração do, 336

[Resolução nº 607/2013]

Regulamento de Sanções

Administrativas, 326

[Portaria MC no 112/2013]

aprovação do, 326

[Portaria MC n ${ }^{\circ}$ 112/2013]

Regulamento de Separação e Alocação de Contas

alteração do, 337, 348

[Resolução n ${ }^{\circ}$ 608/2013] [Resolução n ${ }^{\circ}$ 619/2013]

Regulamento do Serviço Limitado Privado

aprovação do, 345

[Resolução n ${ }^{\circ}$ 617/2013]

Regulamento de Serviço Limitado sua inaplicabilidade ao Serviço

Limitado Privado, 345

[Resolução nº 617/2013]

sua inaplicabilidade ao Serviço Limitado Privado, 345 
[Resolução no 617/2013]

Regulamento do Serviço Móvel Pessoal alteração do, 356

[Resolução no 627/2013]

Regulamento do Serviço Telefônico Fixo Comutado

sua alteração para disciplina mais detalhada dos direitos dos usuários/consumidores do STFC, 343 [Resolução no 615/2013]

Regulamento dos Serviços de Retransmissão e de Repetição de Televisão

procedimento específico para outorga do Serviço de Retransmissão de Televisão, 333

[Portaria ${ }^{\circ}$ 282/2013]

Regulamento para Certificação e Homologação de Produtos para Telecomunicações

(ver também Norma para Certificação de Produtos para Telecomunicações) alteração do, 355

[Resolução no 626/2013]

Regulamento para Uso de Femtocélulas em Redes do Serviço Móvel Pessoal, do Serviço Móvel Especializado e do Serviço de Comunicação Multimídia aprovação do, 353

[Resolução no 624/2013]

Regulamento sobre Áreas Locais para o STFC

alteração do, 349

[Resolução no 620/2013]

Regulamento sobre Condições de Uso da faixa de $450 \mathrm{MHz}, 356$

[Resolução n ${ }^{\circ}$ 628/2013]

Regulamento sobre Condições de Uso de Radiofrequências na Faixa de 698 MHz a 806 MHz aprovação do, 354

[Resolução n ${ }^{\circ}$ 625/2013]

Relatório da Ouvidoria

Relatório da Ouvidoria 2013, 364

[Relatório da Ouvidoria da ANATEL 2013]

REPNBL-Redes (ver Regime Especial de Tributação do Programa Nacional de Banda Larga para Implantação de Redes de Telecomunicações)

Requerimento de Aprovação dos Locais de Instalação e Uso de Equipamentos autorização de funcionamento em caráter provisório de entidades prestadoras de serviços de radiodifusão e seus ancilares que ainda não tenham tido o requerimento de aprovação dos locais de instalação e uso de equipamentos analisado, 327

[Portaria MC no 159/2013]

Responsabilidade

Definição, 364

[Portaria ${ }^{\circ}$ 559/2013]

Restrição de Mobilidade

Femtocélula

funcionalidade necessária de restrição de mobilidade para a, 353

Restrito

[Resolução nº 624/2013]

(ver Serviço de Interesse Restrito)

Retransmissão de TV

(ver Serviço de Retransmissão de Televisão)

Reunião

Conselho Diretor - Agencia Nacional de Telecomunicações

disciplina da votação no, $\mathbf{3 4 0}$

[Resolução no 612/2013]

Revogação

Radiodifusão

aprovação do Regulamento de Sanções Administrativas aplicáveis a entidades prestadoras dos serviços de radiodifusão, seus ancilares e auxiliares, 326

[Portaria MC n ${ }^{\circ}$ 112/2013]

RSAC

(ver Regulamento de Separação e RTV
Alocação de Contas) 
(ver Serviço de Retransmissão de Televisão)

Rural, 350

(ver também Zona Rural)

[Resolução no 622/2013]

\section{S}

SAC

(ver Serviço de Atendimento ao Consumidor)

Sanção

(ver Punição)

Sanção

(ver também Infração)

(ver também Sanção Administrativa)

Regulamento de Sanções

Administrativas

aprovação do, 326

[Portaria MC n 112/2013]

Sanção Administrativa

(ver também Obrigação de fazer)

(ver também Sanção)

(ver também Usuário)

Termo de Compromisso de

Ajustamento de Conduta

disciplina do, 358

[Resolução n 629/2013]

\section{SARC}

(ver Serviço Auxiliar de Radiodifusão e Correlatos)

SBTVD-T

(ver Sistema Brasileiro de Televisão Digital Terrestre)

\section{SCM}

(ver Serviço de Comunicação Multimídia)

Segurança da Informação e

Comunicações (ANATEL)

Definição, 364

[Portaria ${ }^{\circ}$ 559/2013]

Segurança Pública, 354

[Resolução n ${ }^{\circ}$ 625/2013]

Faixa de $700 \mathrm{MHz}$

destinação da faixa de radiofrequências de 703 a 708 $\mathrm{MHz}$ e 758 a $763 \mathrm{MHz}$ ao SLP, em aplicações de segurança pública, defesa nacional e infraestrutura, em caráter primário, 354

[Resolução n ${ }^{\circ} 625 / 2013$ ]

\section{Senado Federal}

\section{(ver também Congresso Nacional)}

Agência Nacional de

Telecomunicações

disciplina de comparecimento anual de dirigentes de agências reguladoras ao Senado Federal, 359

[Resolução no 4 do Senado Federal, de 2013]

SER

(ver Serviço Especial de Radiochamada, Regime Regulatório)

Serviço Ancilar, 327

[Portaria MC n ${ }^{\circ}$ 159/2013]

Radiodifusão autorização de funcionamento em caráter provisório de entidades prestadoras de serviços de radiodifusão e seus ancilares que ainda não tenham tido o requerimento de aprovação dos locais de instalação e uso de equipamentos analisado, 327 [Portaria MC n ${ }^{\circ}$ 159/2013]

Serviço Ancilar de Radiodifusão (ver Ancilar)

Serviço Ancilar de Radiodifusão

Pós-Outorga

atribuição de competência delegada do Ministério das Comunicações para a ANATEL para a prática dos atos necessários à análise de processos técnicos de engenharia nos procedimentos de, $\mathbf{3 6 2}$

[Portaria ANATEL $\mathrm{n}^{\circ} 448$, de 4 de junho de 2013]

Serviço Auxiliar de Radiodifusão

(ver Auxiliar)

Serviço Auxiliar de Radiodifusão e Correlatos 
(ver Auxiliar)

Serviço Auxiliar de Radiodifusão e Correlatos (SARC), 289

Serviço Auxiliar de Radiodifusão e Correlatos

aplicação provisória do valor praticado para execução do Serviço Limitado Privado para as autorizações de, 330

[Portaria $\mathrm{MC} \mathrm{n}^{\circ}$ 252/2013]

competência da ANATEL para processar solicitações de outorga e alterações das condições de outorga dos Serviços Auxiliares de Radiodifusão e Correlatos (SARC), bem como para emissão de regulamentação sobre a outorga, exploração e condições de uso de radiofrequência associada ao, $\mathbf{3 3 0}$

[Portaria MC n 252/2013]

Pós-Outorga

atribuição de competência delegada do Ministério das Comunicações para a ANATEL para a prática dos atos necessários à análise de processos técnicos de engenharia nos procedimentos de, $\mathbf{3 6 2}$

[Portaria ANATEL $\mathrm{n}^{\circ} 448$, de 4 de junho de 2013]

Serviço Avançado de Mensagens

(SAM), 290

Serviço Científico

(ver Serviço Especial para Fins Científicos ou Experimentais)

Serviço Científico, 345

[Resolução n 617/2013]

Serviço de Acesso Condicionado (SeAC), 300

Serviço de Acesso Condicionado, 351

(ver também Serviço de Distribuição de Sinais Multiponto Multicanal)

[Resolução n 623/2013]

alteração do regulamento do SeAC para permitir a obtenção de licença para funcionamento de estação independentemente de comprovação de contrato de uso dos postes, dutos, rede ou seus segmentos, celebrado com empresa proprietária das respectivas infraestruturas e autorização de Prefeitura para a construção do sistema, 347

[Resolução nº 618/2013]

Autorização

instituição do Procedimento Simplificado de Outorga de STFC, SCM e SeAC, 364

[Portaria n ${ }^{\circ}$ 639/2013]

Canal de Distribuição Obrigatória exceção ao dever da prestadora do SeAC de tornar disponível o, $\mathbf{3 6 2}$ [Portaria n ${ }^{\circ}$ 238/2013]

Regulamento de Conselho de Usuários aprovação do, 351

[Resolução no 623/2013]

Serviço de Atendimento ao Consumidor (ver também Centro de Atendimento (Indicadores de Qualidade do STFC))

Regulamento do Serviço Telefônico Fixo Comutado

sua alteração para disciplina mais detalhada dos direitos dos usuários/consumidores do STFC, 343

[Resolução n 615/2013]

Serviço Telefônico Fixo Comutado alteração do Regulamento do STFC para disciplinar com maior detalhamento os direitos dos usuários/consumidores do, $\mathbf{3 4 3}$

[Resolução nº 615/2013]

Terceirização

alteração do Regulamento do STFC para disciplinar com maior detalhamento os direitos dos usuários/consumidores do STFC, 343

[Resolução nº 615/2013]

Serviço de Circuito Especializado, 293 Serviço de Comunicação Multimída (SCM), 301

Serviço de Comunicação Multimídia 
(ver também Serviço Privado de Telecomunicação)

Autorização

instituição do Procedimento Simplificado de Outorga de STFC, SCM e SeAC, 364

[Portaria ${ }^{\circ}$ 639/2013]

Femtocélula disciplina do uso de, $\mathbf{3 5 3}$

[Resolução n 624/2013]

Regulamento do Serviço de Comunicação Multimídia, 342

[Resolução no 614/2013]

Regulamento para Uso de Femtocélulas em Redes do Serviço Móvel Pessoal, do Serviço Móvel Especializado e do Serviço de Comunicação Multimídia aprovação do, $\mathbf{3 5 3}$

[Resolução nº 624/2013]

Serviço de Distribuição de Sinais de Televisão e de Áudio por Assinatura via Satélite

(ver Distribuição de Sinais de Televisão e de Áudio por Assinatura via Satélite (DTH))

Serviço de Distribuição de Sinais Multiponto Multicanal

(ver também Multichannel Multipoint

Distribution Service (Serviço de

Distribuição de Sinais Multiponto Multicanal))

(ver também Serviço de Acesso Condicionado)

Regulamento de Conselho de Usuários aprovação do, 351

[Resolução n ${ }^{\circ}$ 623/2013]

Serviço de Emergência

(ver também Serviço de Utilidade Pública)

Serviço Móvel Pessoal

gratuidade de acesso a serviços públicos de emergência, 356

[Resolução nº 627/2013]
Serviço de Interesse Coletivo

Classificação dos Serviços de Telecomunicações quanto ao interesse a que atendem ato do Conselho Diretor da ANATEL de classificação dos serviços de telecomunicações em interesse coletivo ou restrito, $\mathbf{3 6 0}$ [Ato do Conselho Diretor da ANATEL $\mathrm{n}^{\circ} 3.833$, de 20 de junho de 2013]

Serviço de Comunicação Multimídia regulamento do, $\mathbf{3 4 2}$

[Resolução n 614/2013]

Serviço de Interesse Restrito, 283

Serviço de Interesse Restrito

Classificação dos Serviços de Telecomunicações quanto ao interesse a que atendem

ato do Conselho Diretor da ANATEL de classificação dos serviços de telecomunicações em interesse coletivo ou restrito, $\mathbf{3 6 0}$ [Ato do Conselho Diretor da ANATEL $\mathrm{n}^{\circ} 3.833$, de 20 de junho de 2013]

Serviço Auxiliar de Radiodifusão e Correlatos

política ministerial de unificação, via regulamentação da ANATEL, da regulamentação do SARC com a de outros serviços convergentes de telecomunicações de interesse restrito, 330

[Portaria $\mathrm{MC} \mathrm{n}^{\circ}$ 252/2013]

Serviço de Radiocomunicação Aeronáutico Público Restrito (SRA), 303

Serviço de Radiodifusão, 285

Serviço de Radiodifusão Comunitária

Autorização (Radiodifusão)

condições de revogação de autorização do, 326

[Portaria MC n ${ }^{\circ}$ 112/2013]

disciplina dos pedidos de renovação de outorga do, 329

[Portaria MC n ${ }^{\circ} 197$, de $1^{\circ}$ julho de 2013] 
Norma Complementar do Serviço de

Radiodifusão Comunitária alteração da, 329

[Portaria MC $\mathrm{n}^{\circ}$ 197, de $1^{\circ}$ julho de 2013]

Pós-Outorga

atribuição de competência delegada do Ministério das Comunicações para a ANATEL para a prática dos atos necessários à análise de processos técnicos de engenharia nos procedimentos de, $\mathbf{3 6 2}$

[Portaria ANATEL $n^{\circ} 448$, de 4 de junho de 2013]

Serviço de Radiodifusão de Sons e Imagens (ver Radiodifusão)

Serviço de Radiodifusão Sonora (ver Radiodifusão)

Serviço de Radiotáxi, 302

Serviço de Radiotáxi Especializado, 302

Serviço de Rede, 302

Serviço de Rede de Transporte de

Telecomunicações (SRTT), 302

Serviço de Rede Especializado, 302

Serviço de Retransmissão de Televisão procedimento específico para outorga do, 333

[Portaria $\mathrm{n}^{\circ}$ 282/2013]

Serviço de Telecomunicações, 360

(ver também Classificação dos Serviços de Telecomunicações quanto ao interesse a que atendem) [Ato do Conselho Diretor da ANATEL n ${ }^{\circ}$ 3.833 , de 20 de junho de 2013]

Serviço de Telecomunicações Aeronáuticas, 303

Serviço de Telestrada ou Serviço Telefônico Público Móvel Rodoviário, 303

Serviço de Utilidade Pública

(ver também Serviço de Emergência) gratuidade de acesso a serviços públicos de emergência, 356

[Resolução n 627/2013]

Serviço Móvel Pessoal gratuidade de acesso a serviços públicos de emergência, 356

[Resolução no 627/2013]

Serviço de Valor Acrescentado

(ver Serviço de Valor Adicionado)

Serviço de Valor Acrescido

(ver Serviço de Valor Adicionado)

Serviço de Valor Adicionado, 285

Serviço de Valor Adicionado

(ver também INTERNET)

sua disciplina como integrante do

Sistema de Pagamentos Brasileiro

(SPB), 316

[Lei ${ }^{\circ} 12.865 / 2013$ ]

Serviço Especial, 285

Serviço Especial de Boletim

Metereológico, 291

Serviço Especial de Frequência Padrão, 291

Serviço Especial de Rádio Acesso, 292

Serviço Especial de Radioautocine, 291

Serviço Especial de Radiochamada

(SER) - ou Serviço Móvel Especial de

Radiochamada, 292

Serviço Especial de Radiochamada,

Regime Regulatório

(ver também Serviço Móvel)

(ver também Serviço Privado de

Telecomunicação)

Plano de Autorizações do Serviço

Especial de Radiochamada

sua substituição pelo Regulamento do Serviço Limitado Privado, 345 [Resolução no 617/2013]

Serviço Especial de Radiodeterminação por Satélite (SERDS), 291

Serviço Especial de Radiorrecado, 292

Serviço Especial de Sinais Horários, 292

Serviço Especial de Supervisão e Controle, 293

Serviço Especial de TV por Assinatura (ver Televisão por Assinatura (Espécie de Serviço Especial))

Serviço Especial para Fins Científicos ou Experimentais, 345

[Resolução n 617/2013] 
Regime Regulatório, 345

[Resolução n ${ }^{\circ} 617 / 2013$ ]

Serviço Limitado, 284

Serviço Limitado, 345

(ver também Serviço Limitado

Privado)

[Resolução no 617/2013]

Regulamento de Serviço Limitado sua inaplicabilidade ao Serviço Limitado Privado, 345

[Resolução nº 617/2013]

Serviço Limitado de Estações com Operação Itinerante, 294

Serviço Limitado de Radioestrada, 294

Serviço Limitado Especializado, 284

Serviço Limitado Especializado (SLE), 293

Serviço Limitado Especializado (ver também Serviço Privado de Telecomunicação)

Regime Regulatório

$$
\begin{aligned}
& \text { adaptação do Serviço Limitado } \\
& \text { Especializado ao regime } \\
& \text { regulatório do Regulamento do } \\
& \text { Serviço Limitado Privado, } 345 \\
& \text { [Resolução }{ }^{\circ} \text { 617/2013] }
\end{aligned}
$$

Serviço Limitado Móvel Privado, 293

Serviço Limitado Privado, 284

Serviço Limitado Privado

(ver também Serviço Limitado)

Regulamento do Serviço Limitado

Privado

aprovação do, 345

[Resolução nº 617/2013]

Regulamento sobre Condições de Uso da faixa de $450 \mathrm{MHz}, 356$

[Resolução n ${ }^{\circ}$ 628/2013]

unificação de 15 serviços sob o regime

regulatório do Regulamento do, 345

[Resolução nº 617/2013]

Serviço Limitado Privado de

Radiochamada (SLPR), 293

Serviço Móvel, 354

(ver também Serviço Especial de

Radiochamada,

Regime

Regulatório)

(ver também Serviço Móvel Marítimo) (ver também Serviço Móvel Pessoal)

[Resolução n ${ }^{\circ}$ 625/2013]

Faixa de $700 \mathrm{MHz}$ atribuição da faixa de radiofrequências de 698 a 806 $\mathrm{MHz}$ adicionalmente ao serviço móvel, em caráter primário, 354

[Resolução nº 625/2013]

Serviço Móvel Aeronáutico, 303

Serviço Móvel Especial de

Radiochamada

(ver Serviço Especial de

Radiochamada, Regime

Regulatório)

Serviço Móvel Especializado

(ver também Serviço Privado de Telecomunicação)

Antena para Uso em Aplicações PontoÁrea

aprovação da norma para certificação e homologação de, 339

[Resolução n 610/2013]

Femtocélula disciplina do uso de, $\mathbf{3 5 3}$

[Resolução n 624/2013]

Regulamento de Conselho de Usuários aprovação do, 351

[Resolução n 623/2013]

Regulamento para Uso de Femtocélulas em Redes do Serviço Móvel Pessoal, do Serviço Móvel Especializado e do Serviço de Comunicação Multimídia

aprovação do, $\mathbf{3 5 3}$

[Resolução no 624/2013]

Serviço Móvel Especializado ou

Trunking ou Trunk ou Sistema Troncalizado, 294

Serviço Móvel Global por Satélite (SMGS), 294

Serviço Móvel Marítimo, 295

Serviço Móvel Marítimo, 354

(ver também Serviço Móvel)

[Resolução n ${ }^{\circ}$ 625/2013]

Serviço Móvel Pessoal (SMP), 295

Serviço Móvel Pessoal, 354 
(ver também Serviço Móvel)

[Resolução n 625/2013]

Antena para Uso em Aplicações PontoÁrea aprovação da norma para certificação e homologação de, 339

[Resolução no 610/2013]

Femtocélula

disciplina do uso de, $\mathbf{3 5 3}$

[Resolução n 624/2013]

Regulamento do Serviço Móvel

Pessoal

alteração do, 356

[Resolução no 627/2013]

Regulamento para Uso de

Femtocélulas em Redes do Serviço

Móvel Pessoal, do Serviço Móvel

Especializado e do Serviço de

Comunicação Multimídia aprovação do, 353

[Resolução no 624/2013]

sua disciplina como integrante do

Sistema de Pagamentos Brasileiro (SPB), 316

[Lei ${ }^{\circ}$ 12.865/2013]

Serviço Privado de Telecomunicação

(ver também Serviço de Comunicação

Multimídia)

(ver também Serviço Especial de Radiochamada, Regime

Regulatório)

(ver também Serviço Limitado

Especializado)

(ver também Serviço Móvel

Especializado)

(ver também Serviços de

Telecomunicações)

Serviço de Comunicação Multimídia

regulamento do, $\mathbf{3 4 2}$

[Resolução no 614/2013]

Serviço Rádio do Cidadão, 297

Serviço Telefônico Fixo Comutado

(STFC), 297

Serviço Telefônico Fixo Comutado, 297

Área de Tarifa Básica disciplina da prestação de STFC fora da, 350

[Resolução n 622/2013]

Área de Tarifação

alteração de área de tarifação do, 335, 340, 350

[Resolução n ${ }^{\circ}$ 606/2013] [Resolução n ${ }^{\circ}$ 611/2013] [Resolução nº 621/2013]

Atendimento Pessoal

alteração do Regulamento do STFC para disciplinar com maior detalhamento os direitos dos usuários/consumidores do STFC, em especial, o, 343

[Resolução no 615/2013]

Autorização

instituição do Procedimento Simplificado de Outorga de STFC, SCM e SeAC, 364

[Portaria n ${ }^{\circ}$ 639/2013]

Plano de Atendimento Rural

sua exigência para prestação de STFC fora da Área de Tarifa Básica (ATB), 350

[Resolução nº 622/2013]

Plano Geral de Códigos Nacionais alteração do, 335, 350

[Resolução n ${ }^{\circ}$ 606/2013] [Resolução n ${ }^{\circ}$ 621/2013]

Regulamento de Numeração do STFC alteração do, 336

[Resolução n 607/2013]

Regulamento sobre Áreas Locais para o STFC

alteração do, 349

[Resolução n 620/2013]

sua prestação fora da área de tarifa básica (ATB), 350

[Resolução n 622/2013]

Terceirização

alteração do Regulamento do STFC para disciplinar com maior detalhamento os direitos dos usuários/consumidores do STFC, 343

[Resolução nº 615/2013] 
Serviços Científicos, 304

Serviços de Telecomunicações (ver também Serviço Privado de Telecomunicação)

Onerosidade

valor devido por acréscimo de faixa de radiofrequência, 344

[Resolução nº 616/2013]

Serviços no Setor de Telecomunicações, 286

Sessão

Conselho Diretor - Agencia Nacional de Telecomunicações disciplina da votação no, 340

[Resolução n 612/2013]

Sigilo

(ver também Direito)

Processo Administrativo política de segurança da informação e comunicações da ANATEL, 363 [Portaria $\mathrm{n}^{\circ}$ 559/2013]

Sigilo em Telecomunicações, 283

Sistema Brasileiro de Televisão Digital

Terrestre

(ver também Radiodifusão)

(ver também TV Digital)

Cronograma de Desligamento da TV analógica

sua alteração para ocorrência no período de $1^{\circ}$ de janeiro de 2015 a 31 de dezembro de 2018, 320

[Decreto $\mathrm{n}^{\mathrm{o}} 8.061$, de 29 de julho de 2013]

Norma Regulamentar do Canal da Cidadania alteração da, 325

[Portaria MC n ${ }^{\circ}$ 57/2013]

Programa Nacional de Banda Larga ampliação da disponibilidade de espectro para atendimento dos objetivos do, 354

[Resolução nº 625/2013]

Sistema de Pagamentos e Transferência de Valores Monetários por meio de Dispositivos Móveis (STDM) (ver Mobile Payment)

Sistema de Pagamentos e Transferência de Valores Monetários por meio de Dispositivos Móveis (STDM), 316

[Lei $n^{\circ}$ 12.865/2013]

Sistema de Pagamentos e Transferência de Valores Monetários por meio de Dispositivos Móveis (STDM), 316 [Lei $n^{\circ}$ 12.865/2013]

Sistema TELEBRAS

(ver Telecomunicações Brasileiras S.A.)

SLE

(ver Serviço Limitado Especializado)

SLP

(ver Serviço Limitado Privado)

Smartphone

seus requisitos técnicos mínimos de acesso à internet em alta velocidade para obtenção de benefício de oneração fiscal, 325

[Portaria MC n ${ }^{\circ} 87$, de 10 de abril de 2013]

SME

(ver Serviço Móvel Especializado)

SMM

(ver Serviço Móvel Marítimo)

SMP

(ver Serviço Móvel Pessoal)

Sorteio

Distribuição de Matérias

sua disciplina no Conselho Diretor da ANATEL, 340

[Resolução n 612/2013]

STFC

(ver Serviço Telefônico Fixo Comutado)

Súmula

(ver Súmula (Agência Nacional de Telecomunicações))

Súmula (Agência Nacional de

Telecomunicações)

Súmula ${ }^{\circ} 14$

limite temporal ao pedido de reconsideração em face de decisão proferida pelo Conselho Diretor da ANATEL quando da 
deliberação sobre recurso administrativo, 365

[Súmula da ANATEL nº 14, de 28 de junho de 2013]

Superintendência de Competição atributos da, 340

[Resolução no 612/2013]

Superintendência de Controle de Obrigações

atributos da, 340

[Resolução no 612/2013]

Superintendência de Fiscalização atributos da, 340

[Resolução no 612/2013]

Superintendência de Planejamento e

Regulamentação

atributos da, 340

[Resolução nº 612/2013]

Suspensão Temporária

(ver Suspensão Temporária (Sanção Administrativa))

Suspensão Temporária (Sanção

Administrativa)

Radiodifusão

aprovação do Regulamento de Sanções Administrativas aplicáveis a entidades prestadoras dos serviços de radiodifusão, seus ancilares e auxiliares, 326

[Portaria MC n 112/2013]

SVA

(ver Serviço de Valor Adicionado)

T

TAC

(ver Termo de Compromisso de Ajustamento de Conduta)

Tarifa

(ver também Preço Público)

Área de Tarifação sua alteração no STFC, 340

[Resolução no 611/2013]

\section{TELEBRAS}

(ver Telecomunicações Brasileiras S.A.)

Telecomunicações Brasileiras S.A.

Dados

exigência de que tais comunicações sejam realizadas por redes de telecomunicações e serviços de tecnologia da informação fornecidos por órgãos ou entidades da administração pública federal, incluindo empresas públicas e sociedades de economia mista da União e suas subsidiárias, $\mathbf{3 2 1}$

[Decreto ${ }^{\circ} 8.135$, de 4 de novembro de 2013]

Programa de Dispêndios Globais (Empresas Estatais Federais)

PGD para 2014, 322

[Decreto $\mathrm{n}^{\circ} 8174 / 2013$ ]

Televisão Aberta, 290

Televisão Digital

(ver TV Digital)

Televisão por Assinatura (Espécie de Serviço Especial)

Regulamento de Conselho de Usuários aprovação do, 351

[Resolução nº 623/2013]

Terceirização

Serviço de Atendimento ao Consumidor

alteração do Regulamento do STFC para disciplinar com maior detalhamento os direitos dos usuários/consumidores do STFC, 343

[Resolução nº 615/2013]

Terminais, 269

Terminal de Telecomunicações

Comercialização

possibilidade de serem comercializadas unidades remanescentes no comércio distribuídas antes do vencimento, suspensão ou cancelamento dos respectivos certificados de homologação, 355 
[Resolução nº 626/2013]

Termo de Ajuste de Conduta

Radiodifusão

previsão de TAC no Regulamento de Sanções Administrativas do Ministério das Comunicações, 326

[Portaria MC n $\left.{ }^{\circ} 112 / 2013\right]$

Termo de Compromisso de Ajustamento de Conduta

Regulamento de Celebração e Acompanhamento de Termo de Compromisso de Ajustamento de Conduta aprovação do, 358

TIC [Resolução nº 629/2013]

(ver Information and Communication Technology)

\section{Título Executivo Extrajudicial}

Termo de Compromisso de Ajustamento de Conduta sua eficácia de título executivo extrajudicial, 358

[Resolução nº 629/2013]

Título Oneroso (ver Onerosidade)

Tráfego Aéreo, 307

Transição Analógico-Digital

Radiodifusão

alteração para ocorrência no período de $1^{\circ}$ de janeiro de 2015 a 31 de dezembro de 2018, 320

[Decreto $\mathrm{n}^{\circ} 8.061$, de 29 de julho de 2013]

Trânsito em julgado administrativo

Termo de Compromisso de Ajustamento de Conduta

inaplicabilidade do seu regulamento em processos nos quais já tenha havido decisão transitada em julgado na esfera administrativa, 358

[Resolução nº 629/2013]

\section{Transparência}

Política de Segurança da Informação e Comunicações da ANATEL disciplina da, 363

[Portaria $\mathrm{n}^{\circ}$ 559/2013]

Tratamento da informação

Definição, 364

[Portaria ${ }^{\circ}$ 559/2013]

Tributação no Setor de

Telecomunicações, 274

Trunking

(ver Serviço Móvel Especializado)

TV a Cabo

Regulamento de Conselho de Usuários aprovação do, 351

[Resolução n 623/2013]

TV Digital, 290

TV Digital

(ver também Faixa de $700 \mathrm{MHz}$ )

(ver também Sistema Brasileiro de Televisão Digital Terrestre)

Cronograma de Desligamento da TV analógica

sua alteração para ocorrência no período de $1^{\circ}$ de janeiro de 2015 a 31 de dezembro de 2018, 320

[Decreto $\mathrm{n}^{\circ} 8.061$, de 29 de julho de 2013]

Faixa de 698 a $806 \mathrm{MHz}$

determinação à ANATEL para que iniciasse os procedimentos administrativos de atribuição, destinação e distribuição da faixa para atendimento dos objetivos do PNBL, 323

[Portaria MC n ${ }^{\circ} 14$, de 6 de fevereiro de 2013]

Norma Regulamentar do Canal da Cidadania alteração da, $\mathbf{3 2 5}$

[Portaria MC n ${ }^{\circ}$ 57/2013]

TVA

(ver Televisão por Assinatura (Espécie de Serviço Especial))

TVC

(ver TV a Cabo)

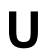

Universalização 


\section{(ver também Inclusão Digital)}

Inclusão Digital, 319

[Decreto $\mathrm{n}^{\circ} 7.981$, de 8 de abril de 2013]

requisitos técnicos mínimos de smartphones para obtenção de benefício de oneração fiscal, $\mathbf{3 2 5}$ [Portaria MC $\mathrm{n}^{\mathrm{o}} 87$, de 10 de abril de 2013]

Universalização e Massificação, 280

Uso Não Licenciado

determinação ministerial para a

ANATEL promover a estudos de viabilidade de disponibilização de faixas de radiofrequência adicionais para a prestação de acesso à internet em banda larga para, 331

[Portaria ${ }^{\circ}$ 275/2013]

Usuário (Serviço Telefônico Fixo Comutado)

Conselho de Usuários aprovação do, 351

[Resolução no 623/2013]

Regulamento de Conselho de Usuários do STFC

aprovação do, $\mathbf{3 5 1}$

[Resolução n 623/2013]

\section{Usuário}

(ver também Consumidor)

(ver também Sanção Administrativa)

Conselho de Usuários

aprovação do regulamento de, $\mathbf{3 5 1}$

[Resolução n 623/2013]

Definição, 364

[Portaria $n^{\circ}$ 559/2013]

Femtocélula

direitos e condições contratuais no fornecimento e operação de, $\mathbf{3 5 3}$

[Resolução no 624/2013]

Usuário / Consumidor, 314

\section{Vacância}

Conselho Diretor - Agencia Nacional de Telecomunicações efeitos da vacância de conselheiros no, 340

[Resolução n ${ }^{\circ}$ 612/2013]

Valor Adicionado

(ver Serviço de Valor Adicionado)

Vias Integradas

(ver Rede de Telecomunicações)

Votação

Conselho Diretor disciplina da votação no, 340

[Resolução n 612/2013]

Conselho Diretor - Agencia Nacional de Telecomunicações disciplina da votação no, 340

[Resolução nº 612/2013]

\section{$X$}

XPD

(ver Discriminação de Polarização Cruzada)

Z

zona rural

(ver Rural)

Zona Rural

(ver também Rural)

Plano de Atendimento Rural

sua exigência para prestação de STFC fora da Área de Tarifa Básica (ATB), 350

[Resolução nº 622/2013]

Serviço Telefônico Fixo Comutado sua prestação fora da área de tarifa básica (ATB), 350

[Resolução nº 622/2013] 